\title{
FUNKTIONEN DER PARTIKULÄREN GUANYLATZYKLASE NPR2 IN DER SCHMERZVERARBEITUNG
}

\author{
Dissertation \\ zur Erlangung des Doktorgrades \\ der Naturwissenschaften
}

vorgelegt beim Fachbereich Biochemie, Chemie und Pharmazie (FB 14)

der Goethe-Universität

in Frankfurt am Main

\author{
von \\ Lea Kennel \\ aus Wuppertal
}

Frankfurt am Main 2021

(D 30) 
vom Fachbereich Biochemie, Chemie und Pharmazie (FB 14) der Goethe-Universität als Dissertation angenommen.

Dekan: Prof. Dr. Clemens Glaubitz

Gutachter: $\quad$ Prof. Dr. Dr. Achim Schmidtko

Prof. Dr. Eugen Proschak

Datum der Disputation: $\quad 24.09 .2021$ 
$\sim$ Deine wirkliche Stärke erkennst du dann, wenn Aufgeben keine Option ist.

Für Martina Westhoff, ohne die ich nicht die wäre, die ich heute bin. 


\section{INHALTSVERZEICHNIS}

1 EINLEITUNG

1.1 DAS NOZIZEPTIVE SYSTEM

1.1.1 SUBPOPULATIONEN PRIMÄR AFFERENTER NEURONE

1.1.2 TRP-KANÄLE ALS WICHTIGE THERMOSENSOREN

1.2 AKUTER SCHMERZ

1.3 Chronischer SCHMERZ

1.4 Periphere und zentrale Sensibilisierung

1.5 GUANYLATZYKLASEN

1.5.1 LÖSLICHE GUANYLATZYKLASEN

1.5.2 PARTIKULÄRE GUANYLATZYKLASEN

1.6 DOWNSTREAM-TARGETS VON NPR2

1.6.1 PHOSPHODIESTERASEN

1.6.2 IONENKANÄLE

1.6.3 CGMP-ABHÄNGIGE PROTEINKINASE

1.6.4 CYSTEIN-REICHES PROTEIN 4 (CRP4)

2 ZIELSETZUNG

3 MATERIAL UND METHODEN 26

3.1 Materialien 26

3.1.1 GERÄTE 26

3.1.2 VERBRAUCHSMATERIALIEN UND KITS 28

3.1.3 ANTIKÖRPER UND SONDEN 29

3.1.4 CHEMIKALIEN UND REAGENZIEN 30

3.1.5 PUFFER UND LÖSUNGEN 32

3.1.6 GRÖßENSTANDARDS UND POLYMERASEN 33

$\begin{array}{lll}3.1 .7 & \text { SUBSTANZEN IM TIERMODELL } & 34\end{array}$

$\begin{array}{lll}3.1 .8 & \text { ANALYSESOFTWARES } & 34\end{array}$

3.2 MethodeN $\quad 35$

3.2.1 TIEREXPERIMENTELLE METHODEN

3.2.2 Molekularbiologische Methoden 44

\subsection{EXPRESSIONSANALYSEN VON CNP UND NPR2}

4.1.1 VERTEILUNG VON CNP IN SPINALGANGLIEN UND RÜCKENMARK

4.1.2 VERTEILUNG VON NPR1 UND NPR2 IN SPINALGANGLIEN UND RÜCKENMARK

4.1.3 COLOKALISATION MIT MÖGLICHEN DOWNSTREAM-TARGETS 62 
4.2 GenerIeRUNG UND VeRIFIZIERUNG EINES KONDITIONELLEN NPR2-KNOCKOUTS 65

4.2.1 ZUCHT UND GRUNDCHARAKTERISIERUNG DER ADV-NPR2-LINIE 65

4.2.2 ZUCHT UND GRUNDCHARAKTERISIERUNG DER SNS-NPR2-LINE 65

4.2.3 VERIFIZIERUNG DES KNOCKOUTS UND MÖGLICHE KOMPENSATORISCHE REGULATION VON NPR1 UND NPR3 68

4.2.4 ÜBERPRÜFUNG DER MOTORISCHEN KOORDINATION

4.2.5 NOZIZEPTIVES VERHALTEN DER SNS-NPR2-LINIE

4.3 GENERIERUNG UND VERIFIZIERUNG EINES KONDITIONELLEN CNP-KNOCKOUTS

4.3.1 ZUCHT UND GRUNDCHARAKTERISIERUNG DER LBX1-NPPC-LINIE

4.3.2 ÜBERPRÜFUNG DER MOTORISCHEN KOORDINATION

4.3.3 MODELLE DES AKUTEN NOZIZEPTIVEN SCHMERZES $\quad 86$

$\begin{array}{lll}4.4 & \text { VerhaltenStest AN CRP4-MÄUSEN } & 88\end{array}$

4.4.1 DeR HOt-PLATE TeST ALS AKUTES NOZIZEPTIVES SCHMERZMODELL 88

$\underline{5}$ DISKUSSION $\quad 89$

5.1 EXPRESSIONSANALYSEN VON CNP UND NPR2 UND MÖGLICHEN DOWNSTREAM-TARGETS 89

5.2 GRUNDCHARAKTERISIERUNG UND ZUCHTPROBLEME DER VERSCHIEDENEN MAUSLINIEN 91

5.3 AUSWERTUNG DeR VerhaltenSTESTS MIT MÄUSEN DER LINIEN SNS-NPR2 UND LBX1-NPPC 94

$\begin{array}{lll}\text { 5.3.1 } & \text { TAIL-FLICK UND PLANTAR TEST } & 95\end{array}$

5.3.2 UNTERSUCHUNG MÖGLICHER INTERAKTIONSPARTNER 95

5.3.3 MÖGLICHE SIGNALWEGE FÜR NPR2 UND TRPA1 97

5.3.4 ENDOGENE AKTIVIERUNG UND MODULIERUNG VON TRPA1 98

$\begin{array}{lll}5.4 & \text { EINFLUSS VON NPR2 AUF NEUROPATHISCHE SCHMERZEN } & 105\end{array}$

6 $\quad$ AUSBLICK $\quad 107$

$\underline{7}$ ZUSAMMENFASSUNG $\quad 109$

$\underline{8}$ ABKÜRZUNGSVERZEICHNIS $\quad 110$

$\underline{9}$ LITERATUR 118

10 KOOPERATIONSPARTNER 131

11 ANHANG 132

11.1 VeRÖFFENTLICHUNGEN UND TAGUNGSBEITRÄGE 132

11.1.1 VERÖFFENTLICHUNGEN 132

$\begin{array}{ll}\text { 11.1.2 TAGUNGSBEITRÄGE } & 133\end{array}$ 


\section{EINLEITUNG}

\section{$1.1 \quad$ Das nozizeptive System}

Die Sinneswahrnehmung Schmerz wird unter physiologischen Bedingungen durch intensive, noxische Reize ausgelöst, die chemischer, thermischer oder mechanischer Natur sein können. Erfasst werden sie von spezialisierten primär afferenten Neuronen, sogenannten nozizeptiven Fasern, deren freien Endigungen in der Haut oder im tieferen Gewebe sitzen. Hier fungieren sie als Rezeptoren und werden daher auch Nozizeptoren genannt. Ihre Zellkörper liegen in Ganglien, die je nach Lage in Spinalganglien (DRG; dorsal eines jeden Wirbelsegmentes) oder in das Ganglion trigeminale (innerhalb der Schädelhöhle liegend und dem Trigeminalnerv zugehörig) untergliedert werden. ${ }^{1}$

Nozizeptive Fasern gehören zur Gruppe der pseudounipolaren Neurone. Der periphere Zweig umfasst die Endigung des Rezeptors und ist für die Detektion schmerzhafter Stimuli zuständig. Der zentrale axonale Zweig hingegen zieht in das Dorsalhorn des Rückenmarks, oder im Falle des Ganglion trigeminale, in den Hirnstamm. ${ }^{2-4}$

Das Dorsalhorn des Rückenmarks wird anatomisch in sechs verschiedene Laminae gegliedert (Lamina I-VI). ${ }^{5}$ Innerhalb dieser Schichten findet eine Verschaltung auf Inter- und Projektionsneurone statt, die das Signal zur weiteren Verarbeitung an verschiedene Hirnregionen senden und so die Schmerzbotschaft vermitteln. ${ }^{6}$ Durch das Ausschütten unterschiedlicher exzitatorisch und inhibitorisch wirkender Neurotransmitter, wie Glutamat und $\gamma$-Aminobuttersäure (GABA), kann so die Information weiter prozessiert werden. Zudem werden Neuropeptide, unter anderem Substanz P (SubP) und das Calcitonin Gene-related-Peptide (CGRP), freigesetzt. Dadurch wird das Signal an die Formatio reticularis, die Amygdala, den Thalamus und den cerebralen Cortex weitergeleitert. ${ }^{1,3,4,6-9}$

\subsubsection{Subpopulationen primär afferenter Neurone}

Primär afferente Neurone lassen sich abhängig von ihrer Funktion in drei verschiedene Gruppen untergliedern. ${ }^{10} \mathrm{Zu}$ ihnen gehören die $A \beta-, A \delta$ - und C-Fasern. Je nach Fasertyp projizieren sie in unterschiedliche Schichten des Dorsalhorns. A $\beta$-Fasern enden in Laminae III, IV und V und sind unter physiologischen Bedingungen für das Erfassen nicht noxischer, mechanischer Reize 
verantwortlich. A $\delta$-Fasern ziehen in Laminae I und $V$, sind dünn myelinisiert und für den ersten oder schnellen Schmerz zuständig. ${ }^{4}$ Durch ihre Erregungsleitung von 5-30 m/s sorgen sie für eine schnelle bis mittlere Reizweiterleitung. ${ }^{11}$ Diese gewährleistet, dass der Organismus auf Gefahrensituationen, die mit potentiellen Gewebeschädigungen einhergehen, reflexartig reagieren kann. C-Fasern projizieren in Laminae I-II (s. Abbildung 1). Im Gegensatz zu A $\delta$-Fasern sind sie nicht-myelinsiert und haben einen geringen Durchmesser. Aus diesem Grund vermitteln sie eine langsamere Reizantwort mit einer Geschwindigkeit von 0,5-2 m/s. ${ }^{11}$

Elektrophysiologische Untersuchungen ergaben eine Aufteilung der Aठ-Fasern in zwei Klassen. Die sogenannten HTM-Fasern (high-threshold mechanical nociceptors) gehören zum Typ-I und reagieren sowohl auf mechanische als auch chemische Stimuli. Sie sind allerdings weniger sensitiv für thermische Reize und benötigen einen starken Impuls von $>50{ }^{\circ} \mathrm{C} .{ }^{4}$ Wenn jedoch der Hitzereiz über eine längere Zeit aufrechterhalten wird, kommt es zu einer Sensibilisierung dieser primären Afferenzen, sodass sie auch bei niedrigeren Temperaturen Aktionspotentiale senden. Gleiches tritt im Falle einer Gewebeverletzung ein, wobei auch die mechanische Schwelle sinkt. Typ-II Aठ-Fasern hingegen reagieren primär auf Hitzestimuli, sind aber weniger empfindlich für mechanische Reize. ${ }^{4}$

Auch Neurone der C-Fasern lassen sich elektrophysiologisch in unterschiedliche Gruppen

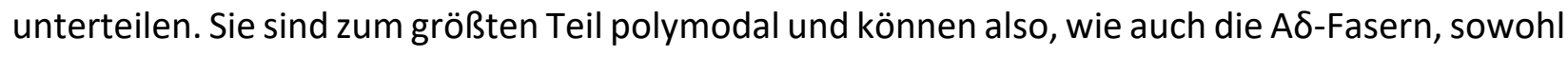
auf mechanische als auch auf thermische Reize reagieren. Aufgrund dieser Eigenschaft werden sie unter dem Begriff CMH (C-Fasern mit Mechano- und Hitzesensibilität) zusammengefasst. ${ }^{4,12}$ Eine besondere Untergruppe nehmen die sogenannten stillen Nozizeptoren ein. Sie reagieren vor allem auf Hitzeschmerz, können aber mechanisch aktiviert werden, wenn eine Gewebsverletzung vorliegt. Im Vergleich zu Neuronen der $\mathrm{CMH}$-Gruppe reagieren sie verstärkt auf chemische Reizstoffe wie Capsaicin und Histamin und spielen daher vermehrt eine Rolle in inflammatorischen Prozessen oder beim Juckreiz. ${ }^{13}$ Allerdings gehören nicht alle Neurone der C-Fasern dem nozizeptiven System an. So ist ein Teil dieser Neurone für das Erfassen von Kälte sowie leichter Berührung zuständig. ${ }^{14}$ Neurone die das Erkennen nicht noxischer Reize 
ermöglichen, werden unter dem Begriff low-threshold-Mechanorezeptoren (LTMRs) zusammengefasst. Ihnen gehören auch die $A \beta$-Fasern an.

LTMRs können in verschiedene Subtypen unterteilt werden, die sich in ihrer Sensibilität, Leitungsgeschwindigkeiten und Adaption an anhaltende mechanische Stimuli unterscheiden. So sind die langsam adaptierende SA(slowly adapting)-Mechanorezeptoren für die Druckempfindung verantwortlich, während sogenannte schnell adaptierende RA(rapidly adapting)-Mechanorezeptoren die Geschwindigkeit erfassen, mit der der Reiz ausgeübt wird. Durch ein Zusammenspiel unterschiedlicher LTMRs können so Sinneswahrnehmungen wie Druck (über SA1-LTMRs), Hautdehnung (über SA2-LTMRs), -bewegungen (über RA1-LTMRs) und -vibrationen (über RA2-LTMRs) erfasst werden. ${ }^{15}$

Zusätzlich zu der beschriebenen elektrophysiologischen Einteilung, ermöglichen neue Studien eine weitere Untergliederung der primären Afferenzen. ${ }^{16,17}$ Hier erfolgt die Klassifizierung nach Genexpressionsprofilen in 17 verschiedene Subtypen. ${ }^{16}$ Mithilfe einer Transkriptomanalyse von 2015 konnten vier Cluster identifiziert werden, die eine Zuordnung der Zellen nach neuronaler Funktion erlauben. ${ }^{17}$ Hierzu zählt unter anderem das Neurofilament(NF)-Cluster, welches alle myelinisierten DRG-Neurone zusammenfasst. ${ }^{16,17}$ Unter diese Gruppe fallen beispielsweise die low-threshold-Mechanorezeptoren der A $\beta$-Fasern, sowie Neurone, die als Propriozeptoren Informationen über die Tiefensesibilität senden. ${ }^{17}$ Neurone der C-Fasern können in weitere Subpopulationen unterteilt werden. Molekularbiologisch wird zwischen peptidergen und nicht-peptidergen Neuronen unterschieden. Peptiderge Neurone, die zum sogenannten PEP-Cluster gehören, exprimieren neben den Neuropeptiden Substanz P und CGRP auch den Tropomyosin Rezeptor Kinase A (TrkA) Neurotrophin Rezeptor. Neurone dieser Gruppe werden vor allem mit dem Erfassen von Hitzereizen assoziiert und gehören somit zur CMH-Gruppe. ${ }^{17}$ Nicht-peptiderge Neurone scheinen vermehrt eine Rolle beim (inflammatorischen) Juckreiz zu spielen. ${ }^{17}$ Sie exprimieren den Mas-related G-Protein gekoppelten Rezeptor D (MrgprD), den ATP-sensitiven P2X3-Rezeptor sowie den c-Ret Neurotrophin Rezeptor und werden unter dem NP-Cluster zusammengefasst. Zudem binden viele der nicht-peptidergen Neurone das Isolectin B4. ${ }^{4}$ Eine weitere Population nicht-myelinisierter C-Fasern exprimieren die Tyrosinhydroxylase (TH) und werden daher im TH-Cluster gebündelt. Bei diesen Neuronen handelt es sich um 
sogenannte low-threshold-Mechanorezeptoren (C-Typ LTMRs). 2018 wurde zusätzlich ein Cluster peptiderger Neurone erkannt, welche TRPM8 exprimieren. ${ }^{16}$ Da TRPM8 in der Literatur als wichtiger Kälterezeptor beschrieben wird, wird vermutet, dass Neurone dieser Gruppe für die Detektion von Kälte zuständig sind.

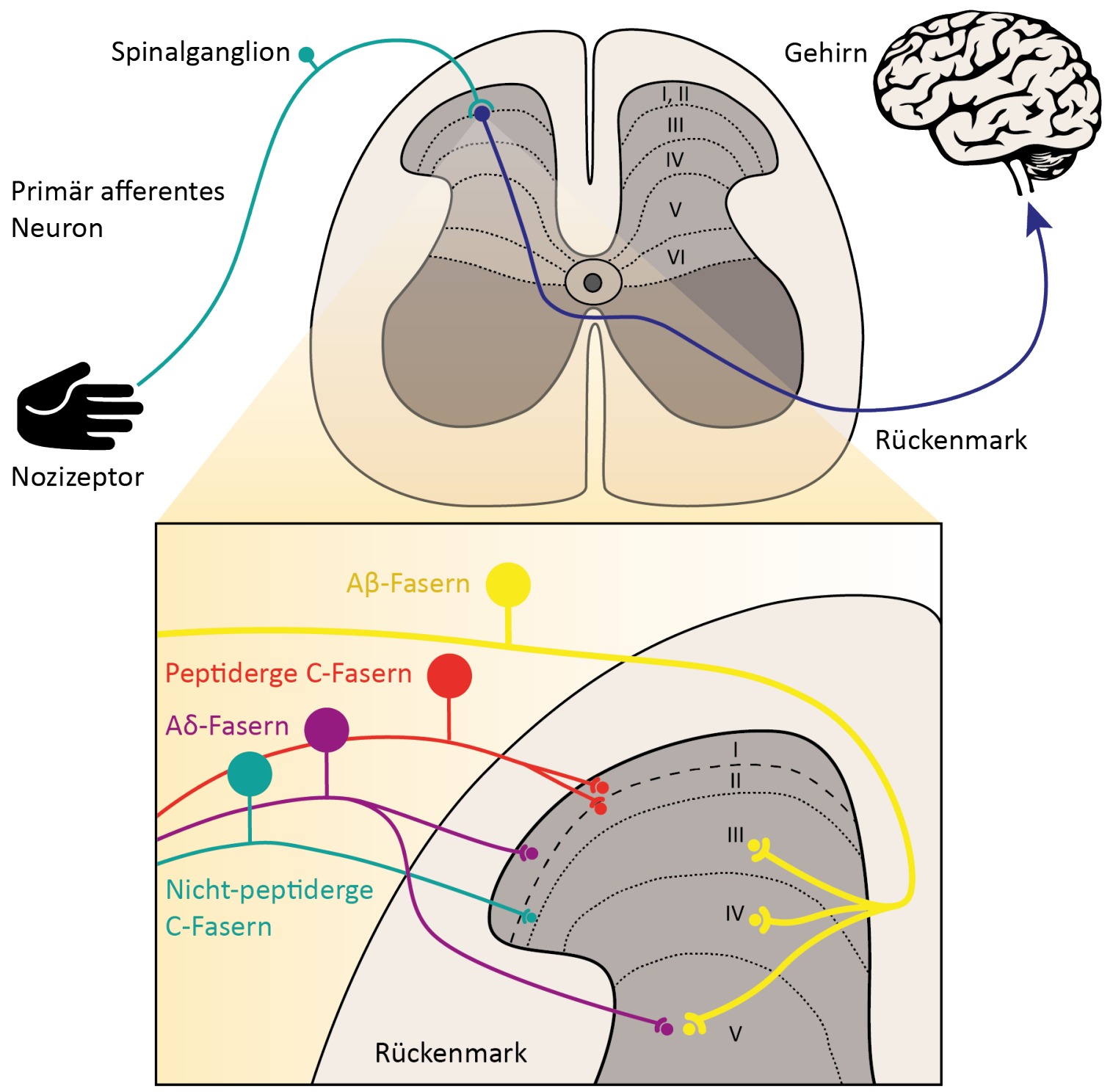

Abbildung 1: (Oberes Bild) schematische Darstellung des nozizeptiven Systems. Primär afferente Neurone ziehen von der Peripherie in das Dorsalhorn des Rückenmarks (hellgrau), welches sich in sechs Laminae untergliedert (Lamina I-VI). Hier findet die Verschaltung auf Projektionsneurone statt, die das Signal an Gehirnareale weiterleiten. (Unteres Bild) Ort der Verschaltung im Dorsalhorn des Rückenmarks. Peptiderge (rot) und nicht-peptiderge (grün) C-Fasern projizieren in Laminae I-II. A $\delta$-Fasern (violett) werden in Lamina I + V verschaltet. A $\beta$-Fasern (gelb) projizieren in Lamina III, IV + V. Verändert nach Schmidtko et. al 2009. ${ }^{7}$ 


\subsubsection{TRP-Kanäle als wichtige Thermosensoren}

Eine wichtige Rolle für die Wahrnehmung potenziell gewebeschädigender Reize spielen die transient receptor potential (TRP) Kanäle. Sie bestehen aus sechs Unterfamilien, die circa 30 unterschiedliche Subtypen zusammenfassen. Zu ihnen gehören die kanonischen (TRPC), die Vanilloid-Rezeptor- (TRPV), die Ankyrin- (TRPA), die Melastatin- (TRPM), die Polycystin- (TRPP) und die Mucolipin (TRPML) Unterfamilien. ${ }^{18}$ Hierbei handelt es sich um nicht-selektive, Liganden gebundene Kanäle, die als Homotetramere vorliegen. Durch ihre Aktivierung erfolgt ein verstärkter Kationen-Influx, welcher eine Depolarisation der Zellmembran auslöst. Durch die so herbeigeführte intrazelluläre Änderung der lonenkonzentration kommt es zur Ausbildung eines Aktionspotentials und somit zur Reizweiterleitung an das Gehirn. ${ }^{4}$ Daher fungieren TRP-Kanäle als molekulare Sensoren, die durch das Erfassen chemischer, thermischer und mechanischer Reize eine Schmerz- oder Juckreizempfindung sowie weitere Empfindungen auslösen können. ${ }^{18}$ Für die Detektion thermischer Reize sind in erster Linie der TRPA1-Kanal, Mitglieder der Vanilloid-Rezeptor-Unterfamilie (TRPV1, TRPV2, TRPV3 und TRPV4) und Mitglieder der Melastatin-Gruppe (TRPM2, TRPM3 und TRPM8) von Bedeutung. Sie sind verstärkt in somatosensorischen Neuronen exprimiert und können den gesamten thermischen Bereich von schmerzhafter Kälte bis hin zu extremer Hitze erfassen. ${ }^{4,18-25}$ Mehrere Studien zeigten, dass TRPM8 und TRPA1 durch tiefe Temperaturen aktiviert werden. Daher wird vermutet, dass sie den Körper vor Unterkühlung und Kälteverbrennung schützen, wenngleich die Rolle von TRPA1 in der Literatur kontrovers diskutiert wird. ${ }^{26-29}$

Für die Registrierung nicht-schmerzhafter Wärme wurden die Kanäle TRPV3 und TRPV4 detektiert, welche bei Temperaturen zwischen $25-35{ }^{\circ} \mathrm{C}$ aktiviert werden. ${ }^{4,19}$ Dabei sind sowohl TRPV3 als auch TRPV4 in Keratinozyten und Epithelzellen wesentlich stärker exprimiert als in sensorischen Neuronen. So können harmlose Wärmereize durch eine Wechselwirkung zwischen Kutis und den darunterliegenden primär afferenten Fasern erkannt werden. ${ }^{4,30,31}$ Es konnte nachgewiesen werden, dass der Organismus die Wahrnehmung Hitze von harmloser Wärme unterscheiden kann. Der Schwellenwert für Temperaturen, die Gewebeschäden verursachen können, liegt bei Menschen bei ungefähr $43{ }^{\circ} \mathrm{C} .{ }^{4}$ Bei dieser Temperatur $\left(\geq 43{ }^{\circ} \mathrm{C}\right)$ wird TRPV1 
aktiviert und ist somit primär an der Wahrnehmung noxischer Hitze beteiligt. ${ }^{21}$ Allerdings führt ein Fehlen von TRPV1 nicht zu einem vollständigen Verlust des Hitzeschmerzes. ${ }^{4,32}$ Dies lässt darauf schließen, dass neben TRPV1 weitere molekulare Wärmesensoren exprimiert werden, die zu einer Hitzeschmerzempfindung beitragen. Eine Reihe von Hinweisen lassen vermuten, dass andere TRP-Kanäle, darunter TRPV2, der bei Temperaturen von ungefähr $52{ }^{\circ} \mathrm{C}$ aktiviert wird, beteiligt sind. ${ }^{21,33}$ Zudem konnten TRPM3 sowie der $\mathrm{Ca}^{2+}$-abhängige $\mathrm{Cl}^{-}-\mathrm{Kanal}$ Anoctamin-1 (ANO1) als wichtige Thermosensoren charakterisiert werden, welche mit TRPV1 coexprimiert sind. ${ }^{23,32,34,35}$ Neben diesen Kanälen ist auch TRPA1 in einigen DRG-Neuronen des PEP-Clusters stark mit TRPV1 sowie mit TRPM3 colokalisiert.16,17,32,36 Auch zeigten jüngste Forschungsergebnisse von Vandewauw et al., dass ein Tripleknockout von TRPV1, TRPM3 und TRPA1 in Mäusen zu einer starken Abnahme des Hitzeempfindens führt. ${ }^{32}$ Dieser Befund könnte erklären, warum die pharmakologische oder genetische Blockade des TRPA1-Kanals allein in den meisten der früheren Säugetierstudien keine Veränderungen der Hitzestimulation bewirkt hat. ${ }^{37}$

Somit scheint TRPA1 in Säugetieren als intrinsischer bidirektionaler Thermosensor zu fungieren, der sowohl durch Kälte als auch Hitze aktiviert werden kann. ${ }^{38}$

Zudem kann die Funktion von TRPA1 durch mehrere Faktoren moduliert werden. Hierzu zählen unter anderem eine erhöhte $\mathrm{Ca}^{2+}$-Konzentration, Spurenmetalle, ein erhöhter $\mathrm{pH}$-Wert sowie reaktive Sauerstoff-, Stickstoff- und Carbonyl-Spezies. ${ }^{39}$ Auch verschiedene exogene Substanzen wie Senföl oder Formalin können TRPA1 anregen.

\section{$1.2 \quad$ Akuter Schmerz}

Schmerz wird nach der Begriffserklärung der International Association for the Study of Pain (IASP) als „unangenehmes Sinnes- und Gefühlserlebnis [beschrieben], das mit einer tatsächlichen oder drohenden Gewebeschädigung verknüpft ist [...]“. Er ist lebensnotwendig, um den Körper vor Verletzungen zu schützen und benötigt im Normalfall einen hohen Stimulus. Ein bekanntes Beispiel ist das versehentliche Berühren eines heißen Gegenstandes. Hier reagiert der Betroffene innerhalb des Bruchteiles einer Sekunde, indem er die entsprechende Körperstelle von der Gefahrenquelle entfernt. In diesem Fall spricht man von einem akuten, physiologischen oder 
nozizeptiven Schmerz. Er ist auf den Ort der Gewebeverletzung begrenzt und dient als wichtige Warnfunktion. Ist diese nicht vorhanden, können schwerwiegende Gewebeschäden auftreten und die Lebenserwartung kann reduziert sein. ${ }^{4,40}$

\subsection{Chronischer Schmerz}

Im Gegensatz zu dem zuvor beschriebenen akuten Schmerz steht der klinische oder chronische Schmerz. Er lässt sich in zwei Hauptkategorien untergliedern, die auf unterschiedlichen molekularen Mechanismen beruhen. Der inflammatorische Schmerz tritt ein, wenn eine Gewebeschädigung auftritt. Aufgrund dieser Schmerzen werden der Kontakt und die Bewegung der verletzten Stelle eingeschränkt und der Heilungsprozess unterstützt. Entzündliche Schmerzen nehmen typischerweise ab, wenn die Verletzung und die Entzündungsreaktion abklingen. ${ }^{40}$

Die zweite Kategorie umfasst den sogenannten neuropathischen Schmerz. Er zeichnet sich dadurch aus, dass schon harmlose Reize als schmerzhaft empfunden werden können (Allodynie), dass ein üblicherweise schmerzhafter Stimulus mit einer übermäßigen Schmerzempfindung einhergeht (Hyperalgesie) oder, dass Spontanschmerzen ohne Stimulation auftreten. In diesem Fall liegt eine Entkopplung der eigentlichen Schutzfunktion vor, da die sensorische Verarbeitung anhaltend oder wiederkehrend ist. Ursache hierfür sind meist Nervenschädigungen, die aufgrund von Verletzungen aber auch durch Erkrankungen auftreten. Da neuropathische Schmerzen auch lange nach der ersten Verletzung anhalten können, verursachen sie große gesundheitliche Probleme. Der Schmerz wird zur Krankheit und benötigt Therapiebedarf. Meist werden laut der deutschen Schmerzgesellschaft e. V. Antikonvulsiva (wie Gabapentin und Pregabalin), tri- und tetrazyklische Antidepressiva, selektive Serotonin-/Noradrenalin-Wiederaufnahmehemmer sowie Tramadol und hochpotente Opioide eingesetzt. Allerdings klagen viele Betroffene über unzureichende Behandlungserfolge, die meist mit starken Nebenwirkungen assoziiert sind. ${ }^{41}$ Daher ist es notwendig, die molekularen Mechanismen, die an der Schmerzentstehung beteiligt sind, genauer zu untersuchen, um weitere Therapieansätze entwickeln zu können.

Neben den zuvor beschriebenen inflammatorischen und neuropathischen Schmerzen wird seit 2017 auch der noziplastische Schmerz von der IASP aufgeführt. Dieser zeichnet sich durch eine 
veränderte Nozizeption aus, ohne, dass eine bestehende oder potenzielle Gewebeschädigung oder Erkrankung des somatosensorischen Systems als Ursache besteht. ${ }^{42}$ Ein bekanntes Beispiel hierfür ist die Fibromyalgie, die sich durch tiefe Muskelschmerzen ohne organische Ursache auszeichnet. $^{43}$

Auch können Kombinationen der oben aufgeführten Schmerzen auftreten. Ist dies der Fall spricht man von einem sogenannten Mischschmerz oder Mixed Pain, der häufig von Tumorpatienten beschrieben wird. ${ }^{44}$ Die Schmerzkomponenten treten dabei gemeinsam auf, unterscheiden sich jedoch in ihrer Intensität. ${ }^{43}$

\subsection{Periphere und zentrale Sensibilisierung}

Persistierende Schmerzen gehen oft mit funktionalen, chemischen oder strukturellen Änderungen des nozizeptiven Systems einher. Sie können sowohl am Ort der Gewebsschädigung (peripher), oder im Rückenmark beziehungsweise Gehirn (zentral) auftreten. ${ }^{40}$ Durch einen verstärkten nozizeptiven Stimulus oder ein Herabsetzen des Schwellenpotentials wird die Erregbarkeit primär afferenter Neurone erhöht. Dies führt zu einer vermehrten Generierung von Aktionspotentialen und einer Freisetzung von Neurotransmittern. ${ }^{4}$ Oft resultiert eine solche periphere Sensibilisierung aus Inflammationsbedingten Änderungen der chemischen Nervenfaserumgebung. ${ }^{45}$ Durch Infiltrierung von Immunzellen und Freisetzung zahlreicher Mediatoren, wie Eicosanoiden, Lipiden, Neutrophinen, Cytokinen, Chemokinen, extrazellulären Proteasen und Protonen, wird eine Sensibilisierung der Nozizeptoren im umliegenden Gewebe ausgelöst. ${ }^{4}$ Diese Botenstoffe bewirken unter anderem eine verstärkte Expression und Aktivierung verschiedener lonenkanäle. Gleichzeitig löst eine Dauerstimulation der Nozizeptoren verschiedene intrazelluläre Signalwege aus. Es kommt zu einer Aktivierung der Proteinkinase-A (PKA), d Proteinkinase-C (PKC), der Phosphoinositid-3-Kinase (PI3K), der extracellular-signal regulated Kinase (ERK) sowie der C-Jun N-terminale Kinase (JNK). Sie bewirken eine Phosphorylierung der TRP-Kanäle TRPA1 und TRPV1 sowie der spannungsabhängigen $\mathrm{Na}^{+}-K a n a ̈ l e$ Nav1.7, Nav1.8 und Nav1.9 und führen zu einer Reduktion der Aktivierungsschwelle. ${ }^{4}$ Zudem erhöht sich die Expression entsprechender Kanäle, welche vermehrt in die Zellmembran 
nozizeptiver Endigungen eingelagert werden. Als Folge wird die Sensitivität gegenüber peripheren Stimuli verstärkt (s. Abbildung 2 A). ${ }^{40,46,47}$

Zusätzlich verusacht eine Aktivierung entsprechender Kinasen eine Induktion verschiedener Transkriptionsfaktoren. ${ }^{48,49}$ Diese gehören gemeinsam mit weiteren Genen zu den sogenannten Regenerations-assoziierten Genen (RAGs) und sind wahrscheinlich an zellulären Reprogrammierungsprozessen beteiligt, die das axonale Wachstum einleiten. Hierzu zählen vor allem die Axonführung, die Axonogenese und die Zellmigration. Transkriptionsfaktoren, die innerhalb weniger Stunden nach Verletzung von den meisten neuronalen Subtypen gebildet werden, sind unter anderem der aktivierende Trankskriptionsfaktor 3 (Atf3), das Jun ProtoOnkogen (C-Jun) und der Krueppel-like Factor 6 (KIf6). $.50,51$ Durch epigenetische Modifikationen werden so verschiedene RAGs aktiviert, die das Neuritenwachstum fördern. Zudem werden weitere Gene exprimiert, die molekularen Mechanismen auslösen, welche für die Wiederherstellung der Reizweiterleitung zuständig sind und eine Reinnervation der Zielzelle ermöglichen. Gleichzeitig leiten sie die Apoptose geschädigter Zellen ein. ${ }^{51}$ Finden diese Prozesse unvollständig statt, kann ein Empfindungsverlust sowie das Auftreten chronischer Neuropathien die Folge sein. Beispiele hierfür sind der Phantomschmerz oder diabetischen Neuropathien. ${ }^{51}$

Neben der peripheren Sensibilisierung werden zudem Mechanismen im zentralen Nervensystem (ZNS) angesteuert. $\mathrm{Zu}$ diesen gehören unter anderem eine veränderte Glutamat-/NMDA-Rezeptor-Signaltransduktion, die sich in einer NMDA-Rezeptor vermittelten Hypersensitivität äußert. Im Falle des akuten Schmerzes setzen Nozizeptoren vermehrt die Neurotransmitter Glutamat und Substanz $P$ frei. Dadurch werden über eine Aktivierung von Glutamat- und $\alpha$-Amino-3-hydroxy-5-methyl-4-isoxazol-Propionsäure (AMPA)-Rezeptoren exzitatorische postsynaptische Potentiale (EPSPs) an Projektions- und Interneuronen des Dorsalhorns ausgelöst. Unter normalen Bedingungen ist der NMDA-Rezeptor über ein $\mathrm{Mg}^{2+}-$ Ion, das die Kanalpore blockiert, inaktiv. ${ }^{6}$ Setzen jeodch primär afferente Neurone verstärkt Transmitter frei, wird die Blockade gelöst und es strömt vermehrt $\mathrm{Ca}^{2+}$ in die Zelle ein. Dieser Einstrom führt zur Aktivierung verschiedener Proteinkinasen (MAPK, PKA, PKC, PI3K und Src) und bewirkt so eine Phosphorylierung von AMPA- und NMDA-Rezeptoren. ${ }^{2,4}$ Als Folge werden sie 
vermehrt aus intrazellulären Speichern ausgeschüttet und an der Zelloberfläche präsentiert. Somit wird die Empfindlichkeit gegenüber Glutamat erhöht und eine Aktivierung von AMPA- und NMDA-Rezeptoren außerhalb des Schwellenwertes erreicht. ${ }^{2,52}$ Neben der verstärkten NMDA-Rezeptor-Sensibilisierung wird durch die Aktivierung der genannten Proteinkinasen die Genexpression von zum Beispiel c-Fos, Cyclooxygenase 2 (Cox-2), Neurokinin-1-Rezeptor (NK-1) oder Tropomyosin-Rezeptor-Kinase-B (TrkB) verändert, was langfristig ebenfalls die Schmerzverarbeitung moduliert. ${ }^{2}$

Ein weiterer wichtiger Mechanismus, der zu einer erhöhten Schmerzantwort führt, ist die sogenannte Disinhibition. GABAerge und glycinerge inhibitorische Interneurone liegen in hoher Dichte in den äußeren Laminae des Dorsalhorns vor und kontrollieren durch Bildung inhibitorischer postsynaptischer Potentiale (IPSP) die Schmerzintensität. Durch periphere Nervenverletzungen können diese Ströme reduziert sein. Unter anderem scheint hier der $\mathrm{K}^{+} / \mathrm{Cl}^{-}$-Cotransporter $\mathrm{KCC} 2$ eine zentrale Rolle einzunehmen. $\mathrm{KCC} 2$ ist für die Ausbildung eines stabilen $\mathrm{K}^{+} / \mathrm{Cl}^{-}$-Plasmamembrangradienten essentiell. Durch eine verringerte Genexpression des Transporters kommt es zu einer Veränderung der $\mathrm{Cl}^{-}$-Konzentration. Die Aktivierung der GABA-Rezeptoren löst in diesem Fall keine Hyperpolarisation mehr aus und wirkt somit der IPSP-Entstehung entgegen. Zudem wird durch eine vermehrte Freisetzung von Prostaglandin E2 $\left(\mathrm{PGE}_{2}\right)$ ein CAMP-PKA Signalweg aktiviert, der die Phosphorylierung des Glycinrezeptors $\alpha 3$ (GlyRa3) bewirkt. Als Folge kann dieser nicht mehr von Glycin aktiviert werden, um seine inhibitorische Wirkung zu erzielen (s. Abbildung 2 C). 4,40,53,54

Zudem wird über eine Glia-Neuron-Interaktion eine Schmerzsensibilisierung begünstigt. Nach peripherer Nervenverletzung werden Mikroglia in den oberen Laminae des Dorsal- sowie im Ventralhorn aktiviert. Sie führen über eine Induktion verschiedener Mitogen-induzierter Kinasen (MAPK) zur Ausschüttung von Cytokinen und weiteren Botenstoffen wie beispielsweise Stickstoffmonoxid (NO). Diese sorgen für eine verstärkte neuronale zentrale Sensibilisierung und tragen somit ebenfalls zu Ausbildung persistierender Schmerzen bei (s. Abbildung 2 B). ${ }^{4,55-58}$ 
A) Nozizeptor

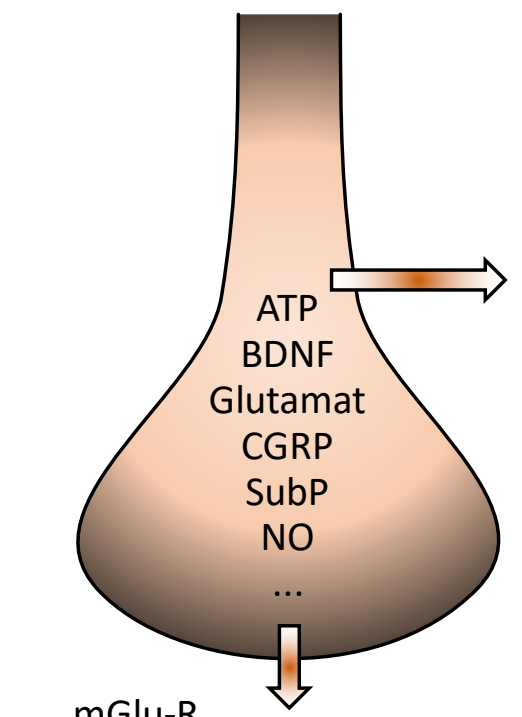

B) Aktivierte Mikrogliazelle

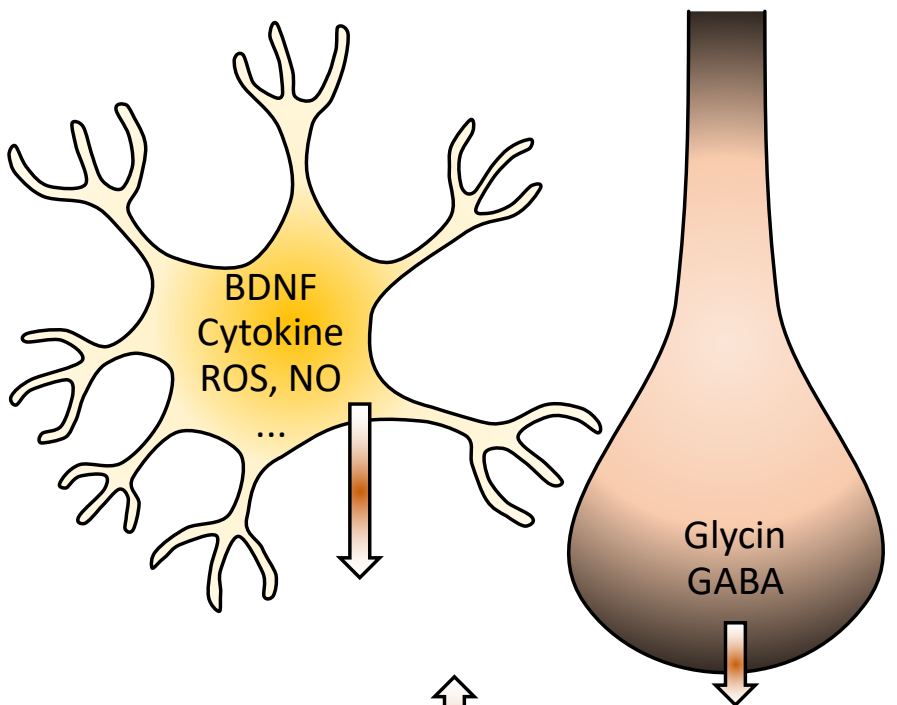

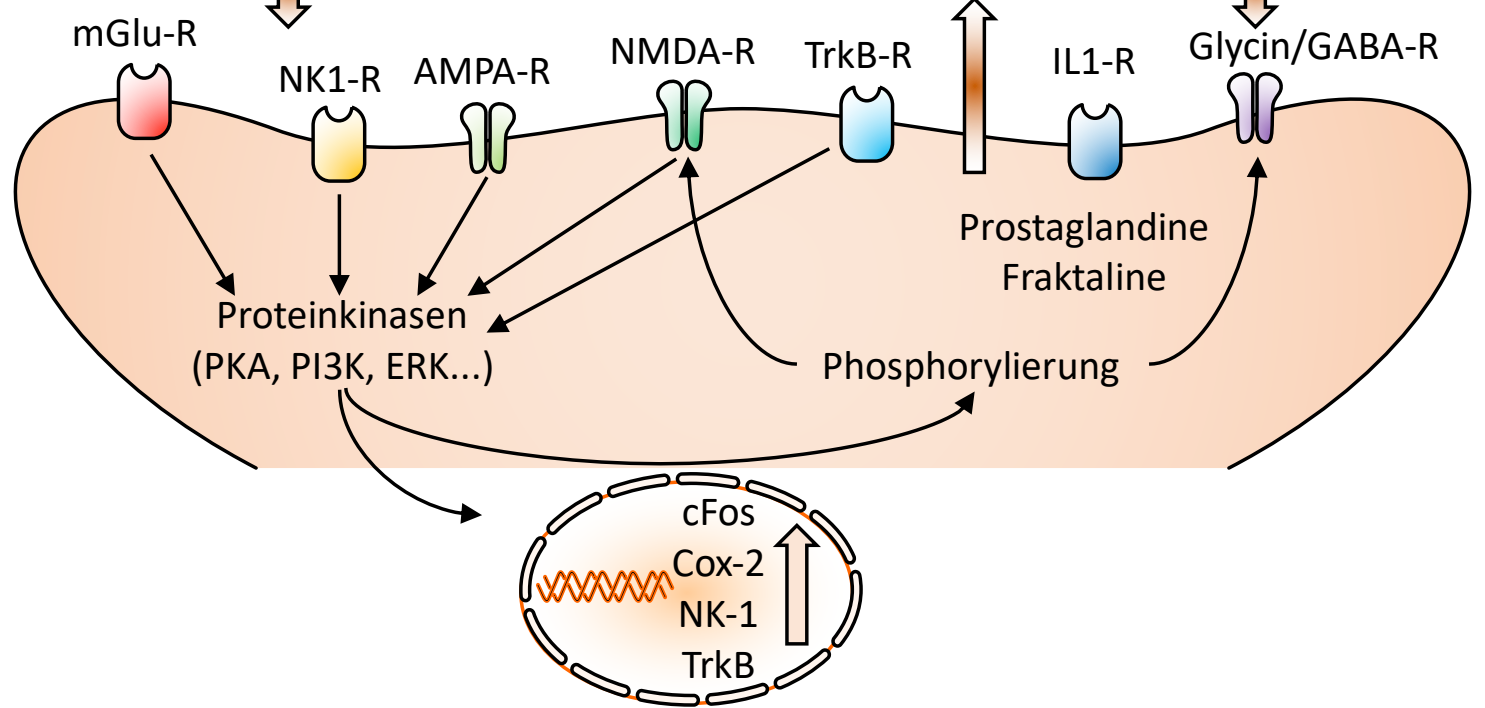

Abbildung 2: Molekulare Prozesse der zentralen Schmerzsensibilisierung im Dorsalhorn des Rückenmarks. A) Darstellung der Sensibilisierung nach Aktivierung der Nozizeptoren. Die Freisetzung von Neurotransmittern und Botenstoffen bewirkt postsynaptisch eine Aktivierung verschiedener Proteinkinasen. Diese führen zu einer verstärkten Transkription schmerzrelevanter Proteine und gleichzeitig zu einer Phosphorylierung und Sensitivitätssteigerung von Neurotransmitter-Rezeptoren. B) Eine Glia-Neuron Interaktion löst eine Aktivierung der Gliazellen aus. Es kommt zur Freisetzung unterschiedlicher Botenstoffe, die verschiedene Signalkaskaden ansteuern können und so die nozizeptive Antwort verstärken. C) Schematische Darstellung der Disinhibition. Durch Hemmung der Rezeptoren inhibitorisch wirkender Interneurone wird ihre abschwächende Wirkung auf die Schmerzreizweiterleitung vermindert.

Abkürzungen: AMPA: $\alpha$-Amino-3-hydroxy-5-methyl-4-isoxazol-Propionsäure, ATP: Adenosintriphosphat, BDNF: Brain-derived neurotrophic factor, GABA-R: $\gamma$-Aminobuttersäure-Rezeptor, CGRP: Calcitonin Gene-Related Peptide, Cox-2: Cyclooxygenase 2, IL1-R: Interleukin-1-Rezeptor, mGlu-R: Metabotrope Glutamatrezeptoren, NK1-R: Neurokinin-1-Rezeptor, NMDA-R: N-Methyl-D-Aspartat-Rezeptor, NO: Stickstoffmonoxid, ROS: Reaktive Sauerstoffspezies, SubP: Substanz P, TrkB-R: Tropomyosin-Rezeptor-Kinase-B. 
Zusätzlich zu den beschriebenen Mechanismen können nach peripheren Nervenverletzungen strukturelle Veränderungen der $A \beta$-Fasern auftreten. Unter normalen Bedingungen sind diese für die Reizweiterleitung leichter, nicht schmerzhafter Berührungen verantwortlich, indem sie den Reiz in die tieferen Laminae des Dorsalhorns übermitteln. Im Falle einer Nervenläsion können sie jedoch auch heterosynaptische Verschaltungen in den oberen Laminae eingehen und somit eine sogenannte sekundäre Hyperalgesie auslösen. ${ }^{3,4,59}$

\section{$1.5 \quad$ Guanylatzyklasen}

In verschiedenen Studien konnte gezeigt werden, dass die Produktion des Second Messenger-Moleküls „zyklisches Guanosinmonophosphat“ (cGMP) mit der Empfindung von Schmerz assoziiert ist, indem es verschiedene Effektormoleküle aktiviert. ${ }^{60,61}$ So wurden bereits mehrere cGMP-Signalwege im Dorsalhorn des Rückenmarks detektiert, die einer Schmerzsensibilisierung zugrunde liegen. ${ }^{7,62,63}$

Gebildet wird cGMP ausgehend von Guanosintriphosphat (GTP) über die Enzymklasse der Guanylatzyklasen (GCs). Ihre Untergliederung erfolgt in zwei Gruppen. Diese unterscheiden sich sowohl von ihrer Lokalisation als auch von ihrer Rezeptoraktivierung. Während die löslichen Guanylatzyklasen (sGCs) überwiegend im Zytoplasma der Zelle vorliegen und durch NO aktiviert werden, sind die partikulären Guanylatzyklasen (pGCs) membranständiger Natur und binden Peptidliganden.

\subsubsection{Lösliche Guanylatzyklasen}

Lösliche Guanylatzyklasen (sGCs) sind Häm-Proteine und werden durch Bindung ihres Liganden NO, aber auch durch CO, aktiviert. Daher werden sie auch unter dem Namen Stickstoffmonoxidsensitive Guanylatzyklasen (NO-GC) geführt. Sie treten als Heterodimere auf, welche aus einer homologen $\alpha$ - und $\beta$-Untereinheit bestehen. ${ }^{64}$ In Säugetieren wurden zwei Gene identifiziert, die für die Expression der beiden Untereinheiten verantwortlich sind. Aufgrund alternativer Spleiß-Prozesse lassen sich diese in $\alpha 1$ und $\alpha 2$ sowie $\beta 1$ separieren. Je nach Zusammensetzung können verschiedene Isoformen des Enzyms gebildet werden. Die am häufigsten exprimierte Form ist ein Heterodimer aus $\alpha 1 \beta 1$ und wird NO-GC1 genannt (s. Abbildung 3). Sie findet sich in 
einem Großteil aller Gewebearten wieder. ${ }^{65}$ Eine weitere Variante ist die Isoform NO-GC2, welche aus einem $\alpha 2 \beta 1$-Heterodimer besteht. ${ }^{66}$

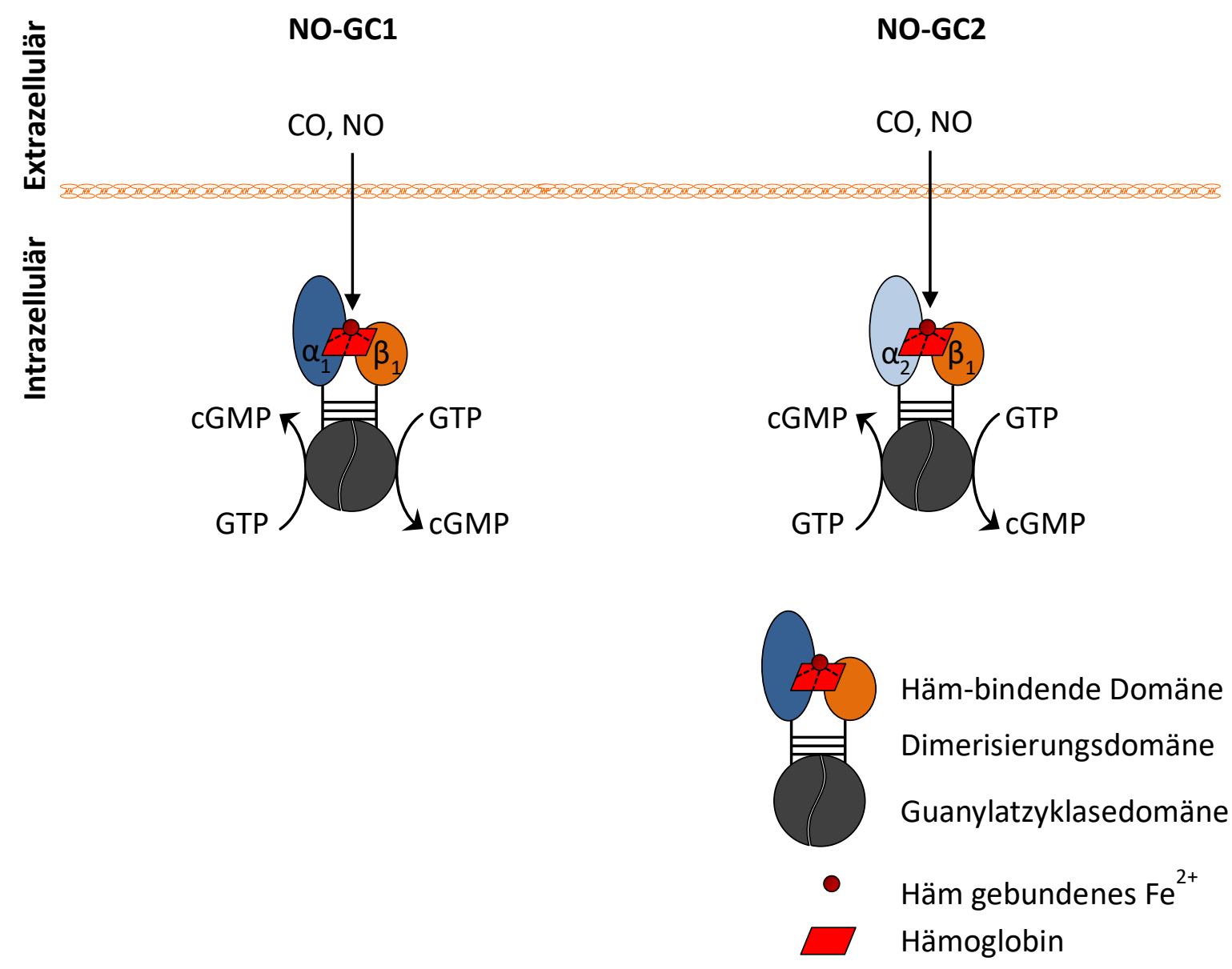

Abbildung 3: Übersicht der löslichen Guanylatzyklasen NO-GC1 und NO-GC2. Beide Isoformen setzen sich aus der GCB1- und einer GC $\alpha$-Untereinheit zusammen. Dabei bildet die GCa1-Untereinheit die NO-GC1 und GC 2 2-Untereinheit die NO-GC2 Isoform. Beide Isoformen bestehen aus einer katalytischen Domäne, einer Dimerisierungsdomäne sowie einer Häm-bindenden Domäne. Durch Bindung von NO wird eine sterische Konformationsänderung herbeigeführt, die eine Umsetzung von GTP zu cGMP ermöglicht.

Abkürzungen: cGMP, zyklisches Guanosinmonophopshat; CO, Kohlenstoffmonoxid; NO, Stickstoffmonoxid; GTP, Guanosintriphosphat.

Beide Isoformen sind im schmerzrelevanten Gewebe zu finden. Während NO-GC1 vor allem in inhibitorischen Neuronen der Laminae II-III des Dorsalhorns nachweisbar ist, zeigt NO-GC2 eine breite Expression in inhibitorischen sowie exzitatorischen Neuronen der Laminae II-IV auf. ${ }^{67}$ Zudem wird letztere in Spinalganglien von Satellitenzellen gebildet. Bei persistierenden Schmerzen wird über das Enzym neuronale NO-Synthase (nNOS) vermehrt NO freigesetzt, 
welches die Aktivierung beider Isoformen bewirkt. ${ }^{68-72}$ Es konnte jüngst bewiesen werden, dass NO-GC1 bei der Prozessierung neuropathischer Schmerzen beteiligt ist, während eine Aktivierung von NO-GC2 vor allem einen hemmenden Effekt auf die Verarbeitung inflammatorischer Schmerzen hat. $^{67}$

\subsubsection{Partikuläre Guanylatzyklasen}

Die Gruppe der humanen partikulären Guanylatzyklasen umfasst fünf verschiedene Enzyme. Hierzu zählen die GC-A, GC-B, GC-C, GC-E und GC-F, welche auch unter den Bezeichnungen NPR1, NPR2, StaR, Ret1-GC und Ret2-GC geführt werden (s. Abbildung 4). Allen gemein ist ihr ähnlicher struktureller Aufbau. Er wird durch einen einzelnen Polypeptidstrang aus circa 1.050 Aminosäuren (AS) geformt und bildet ein Monomer. Jedes Monomer umfasst eine membranumspannende Region, die aus 21 bis 25 hydrophoben AS besteht und das Enzym in der Zellmembran verankert. Eine intrazelluläre Kinase Homologie Domäne (KHD) weist Analogien zu Proteinkinasen auf. Sie umfasst ungefähr 250 AS und vermittelt nach extrazellulärer Ligandenbindung die Signalübertragung an die katalytische Domäne des Enzyms. Des Weiteren besitzt sie verschiedene Phosphorylierungsstellen, welche über Serin- und Threonin-Seitenketten gebildet werden. Die darauf anschließende Dimerisierungs- oder Hinge-Region-Domäne trennt die KHD von der katalytischen Untereinheit. Zudem ermöglicht sie über eine amphipatische $\alpha$-Helixstruktur die Ausbildung zum katalytisch aktiven Homodimer und unterdrückt bei Abwesenheit des Liganden die Zyklaseaktivität durch Konformationsänderungen. ${ }^{73}$ Die Guanylatzyklasedomäne stellt die katalytische Untereinheit des Enzyms dar. Sie liegt hoch konserviert vor und hat Ähnlichkeiten zur Adenylatzyklase. Um enzymatisch aktiv zu sein, muss sie mindestens als Dimer vorliegen. Nur dann findet die Umwandlung von GTP zu cGMP statt. 

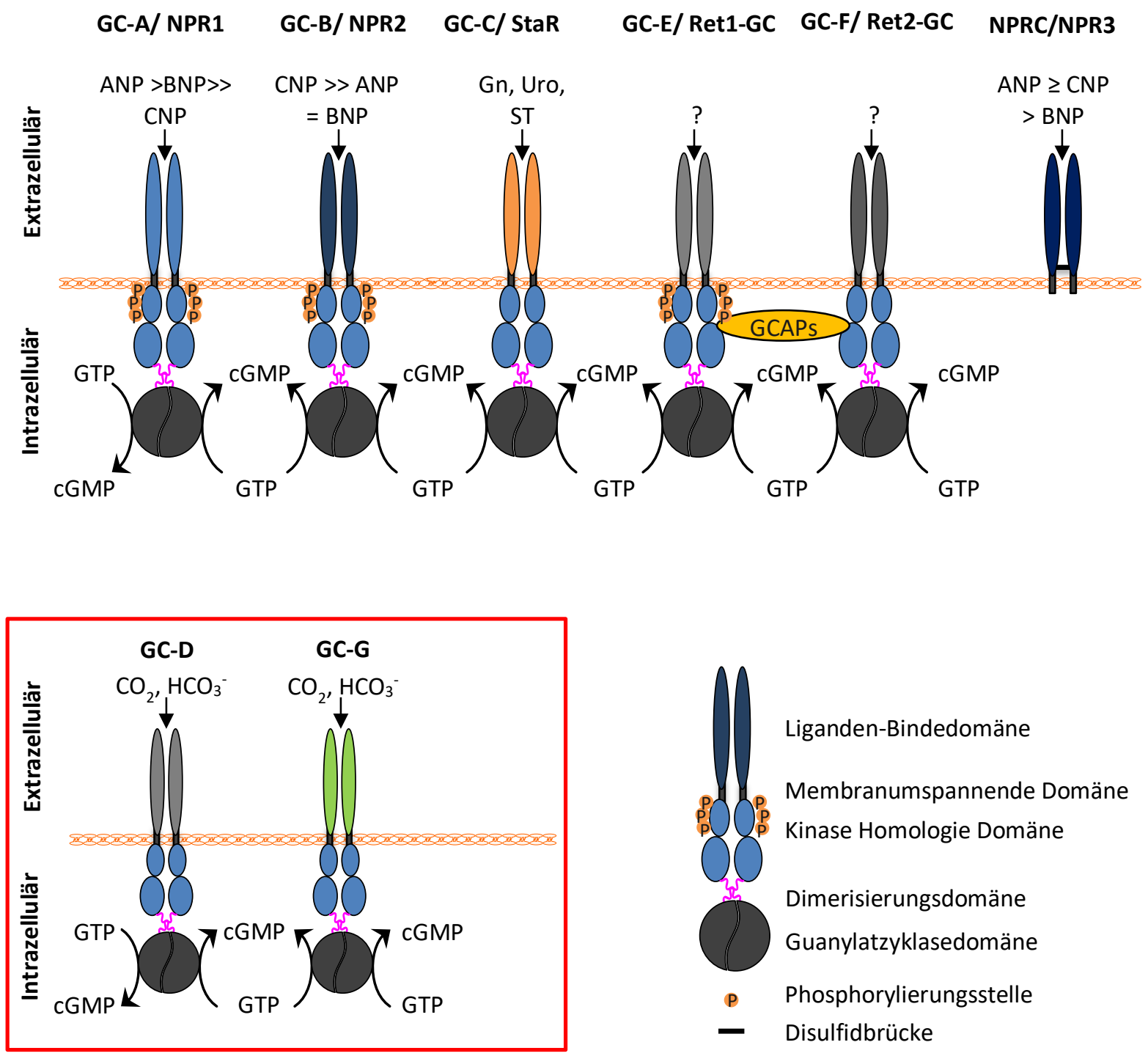

Abbildung 4: Übersicht der partikulären Guanylatzyklasen (Säuger) und deren Liganden. Insgesamt sind sieben dieser Enzyme bekannt, wobei GC-D und GC-G nur in Nagern exprimiert werden. Ähnliche Farben in der Liganden-Binde-Domäne deuten auf vergleichbare primäre AS-Sequenzen der Rezeptoren hin.

Abkürzungen: ANP, Atriales natriuretisches Peptid; BNP, B-Typ natriuretisches Peptid; CNP, C-Typ natriuretisches Peptid; $\mathrm{CO}_{2}$, Kohlenstoffdioxid; $\mathrm{HCO}_{3}{ }^{-}$, Bicarbonat; GCAPs, zytosolische Calcium-bindende Guanylatzyklase-aktivierende Proteine; GC, Guanylatzyklase; Gn, Guanylin; NPRC, Natriuretischer Peptidrezeptor Typ-C; Sta, hitzestabile Enterotoxine; Uro, Uroguanylin.

\subsubsection{Guanylatzyklase C}

Die Guanylatzyklase C (staR) findet sich in hoher Konzentration an der apikalen Membran des Darmepithels wieder. Ihre Aktivierung erfolgt über hitzestabile Enterotoxine (ST) durch E. coli, 
Guanylin oder Uroguanylin. Durch eine Erhöhung des intrazellulären cGMP-Spiegels löst sie einer verstärkten $\mathrm{Cl}^{-}$-Sekretion aus, die eine Dehydrierung und Obstruktion des Darms verhindert. ${ }^{74}$

\subsubsection{Guanylatzyklase E und F}

Bei den Guanylatzyklasen E (Ret1-GC) und F (Ret2-GC) handelt es sich um retinale Enzyme, welche im Falle von geringen $\mathrm{Ca}^{2+}$-Konzentrationen über sogenannte zytosolische Calcium-bindende Guanylatzyklase-aktivierende Proteine (GCAPs) 1 und 2 stimuliert werden. ${ }^{75}$ Sie sind in Photorezeptoren lokalisiert, bewirken die Regulierung der normalen Lichtadaption und sind für die Wiederherstellung des Dunkelheitzustandes von zentraler Bedeutung. ${ }^{76,77}$

\subsubsection{Guanylatzyklase D und G}

Zusätzlich zu den bisher beschriebenen Formen wurden in Nagern zwei weitere Guanylatzyklasen, GC-D und GC-G, entdeckt. Diese kommen im olfaktorischen System vor und können über geringe $\mathrm{CO}_{2-}$ oder $\mathrm{HCO}_{3}^{-}$-Konzentrationen sowie durch peptiderge als auch nicht-peptiderge Geruchsstoffe und Kühle aktiviert werden. ${ }^{77}$ In Menschen werden sie allerdings als Pseudogene exprimiert und sind daher funktionslos. ${ }^{74,77-79}$

\subsubsection{Guanylatzyklase A (NPR1) und B (NPR2) und ihre Liganden}

Die Aktivierung der partikulären Guanylatzyklasen A (NPR1) und B (NPR2) erfolgt über die Bindung von natriuretischen Peptiden. Hierzu gehören das atriale natriuretische Peptid (ANP), das B-Typ natriuretische Peptid (BNP) und das C-Typ natriuretische Peptid (CNP). Sie gehören zu einer Peptidfamilie, die strukturell verwandt ist, sich aber genetisch und in ihrer Funktion unterscheidet. ${ }^{74}$ Alle drei Peptide werden als Präprohormone synthetisiert, welche anschließend unter Abspaltung eines $\mathrm{N}$-terminalen Signalpeptids in kleinere funktionell wirksame Propeptide umgewandelt werden. Ihr Grundgerüst ist ein C-terminaler Disulfidring, welcher aus 17 Aminosäureresten besteht (s. Abbildung 5). Dieser ist entscheidend für die Rezeptorbindung und liegt in allen hoch konserviert vor. ${ }^{80}$ 


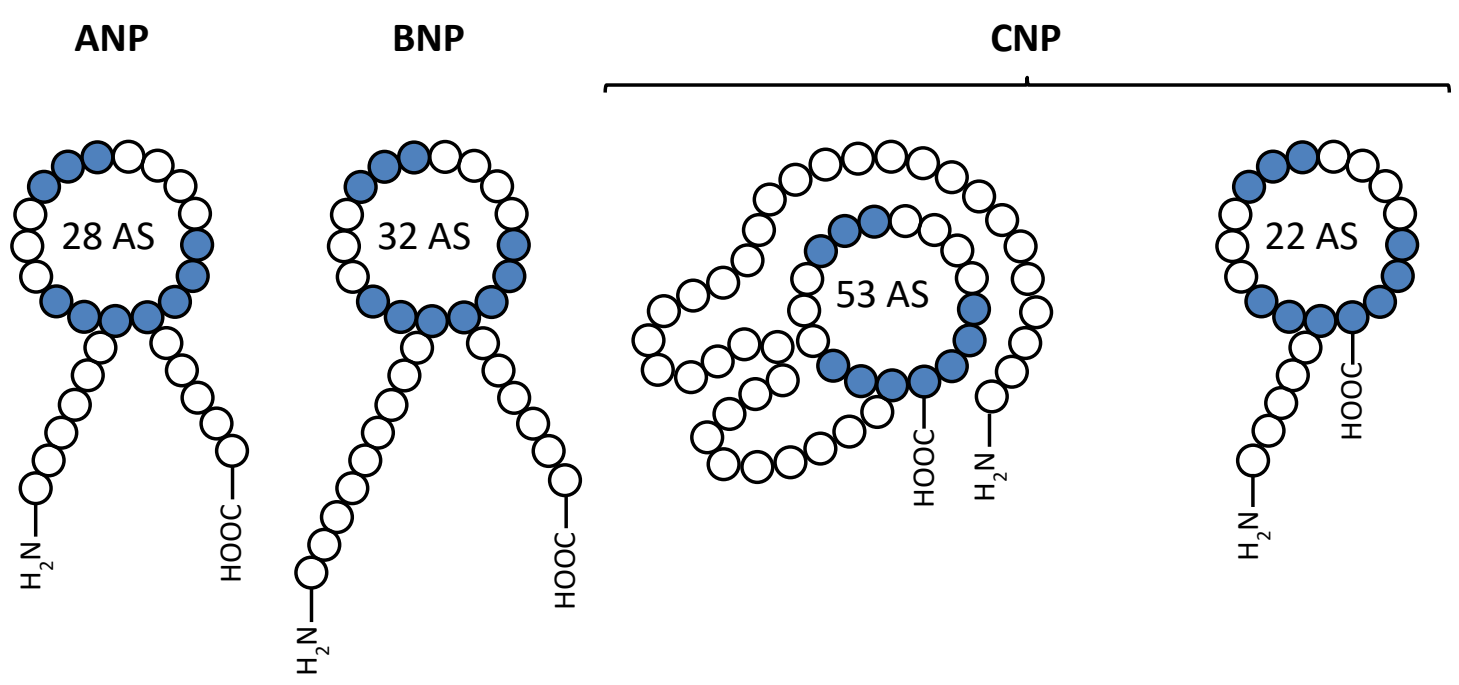

Abbildung 5: Struktureller Aufbau der natriuretischen Peptide ANP, BNP und der beiden Formen von CNP. Blau dargestellt sind Aminosäuresequenzen, die in allen hochkonserviert vorliegen und für die Rezeptorbindung entscheidend sind.

Abkürzungen: AS, Aminosäuren.

Die natriuretischen Peptide ANP und BNP binden vor allem an die Guanylatzyklase A (NPR1). Diese ist an zahlreichen physiologischen Prozessen beteiligt und wird daher in vielen Geweben gebildet. Hierzu gehören die Niere, die Nebenniere, die Lunge, die Gefäße, das Hirn und Rückenmark, das Endothel sowie das Fettgewebe. ${ }^{81,82}$ Zudem wird sie in geringen Mengen im Herzen exprimiert, wo sie eine wichtige Rolle in der Blutdruckregulation einnimmt. Durch die Freisetzung von ANP und BNP können diese NPR1 aktivieren und so diuretisch und natriuretisch wirken. Im Falle eines zu hohen Blutdrucks stimuliert NPR1 die Vasorelaxation, fördert die Natriurese und Diurese, erhöht die Endothelpermeabilität und inhibiert das Renin-Angiotensin-System.

Im Rückenmark scheint NPR1 vor allem in den Laminae I-II exprimiert zu werden und eine wichtige Funktion in der Entstehung und Weiterleitung von Juckreiz zu spielen. ${ }^{83} \mathrm{Im}$ Falle eines prurizeptiven Stimulus wird BNP von primär afferenten Nervenfasern freigesetzt und führt im Anschluss zu einer NPR1-Aktivierung. So kann das Signal an entsprechende Gehirnareale übermittelt werden.

Die Guanylatzyklase B (NPR2) weist eine ähnliche Topologie zu NPR1 auf. Während NPR1 primär über ANP und BNP aktiviert wird, zeigt NPR2 eine höhere Affinität zu CNP. Das C-Typ 
natriuretische Peptid wird in einer kurzen (22 AS) und einer langen (53 AS) Form freigesetzt. Beide werden als ein 126 AS umfassendes Präprotein gebildet. Dieses wird über die intrazelluläre Konvertase Furin in die lange Form (CNP-53) gespalten, welches im Anschluss in den Extrazellularraum abgesondert wird. Hier kann es im weiteren Verlauf durch ein noch unbekanntes Enzym in das kurze CNP-22 gespalten werden. ${ }^{84}$ Beide Formen können mit ähnlicher Affinität an NPR2 binden. Während CNP-53 primär in Geweben synthetisiert wird, findet man CNP-22 vor allem in Flüssigkeiten vor. ${ }^{82}$ Gemeinsam mit NPR2 wird CNP in vielen Geweben coexprimiert. Hierzu gehören das Hirn, die Knochen, das Herz, die Lunge, die Blutgefäße, die Niere, die Gebärmutter, die Eierstöcke und Hoden, wo dieses System lokale auto- und parakrine Funktionen haben kann. ${ }^{85-87}$ Trotz seiner Expression in den Nieren und im Herzen, zeigt eine CNP vermittelten NPR2-Aktivierung nur eine geringe natriuretische Wirkung. ${ }^{88-90}$ Allerdings scheint sie entscheidend für die chondrale Ossifikation zu sein. So führt eine Inaktivierung von NPR2 sowie ein Fehlen von CNP zu einer Verkürzung des Knochenwachstums, ${ }^{91}$ welches sich bei den Betroffenen in einer akromesomelen Dysplasie äußert. ${ }^{77,92}$ Zusätzlich scheint NPR2 einen Einfluss bei der Fortpflanzung zu haben, indem es nach Aktivierung in den Kumulus-Zellen die Oozyten in einem meiotischen Stillzustand hält. ${ }^{93}$ Zudem konnte in verschiedenen Mausstudien gezeigt werden, dass eine CNP-vermittelte NPR2-Aktivierung während der Embryonalentwicklung entscheidend für die Ausprägung der axonalen Bifurkation ist. ${ }^{94}$ Diese Studien zeigten, dass NPR2 embryonal sowohl im Dorsalhorn des Rückenmarks als auch in DRG-Neuronen gebildet und somit im schmerzrelevanten Gewebe exprimiert wird. Auch konnte gezeigt werden, dass $\mathrm{Npr}^{-/-}$- und $\mathrm{Nppc}^{-/-}$-Mauslinien ein verändertes Schmerzverhalten in verschiedenen nozizeptiven Modellen aufweisen. ${ }^{95,96}$ Dabei ist jedoch unklar, ob diese phänotypische Ausprägung auf Bifurkationsprobleme oder einen NPR2-vermittelten Signalweg zurückzuführen ist.

\subsubsection{Der Clearance Receptor NPRC (NPR3)}

Neben NPR1 und NPR2 binden die natriuretischen Peptide auch mit einer hohen Affinität (ANP > CNP > BNP) an den natriuretischen Peptidrezeptor C (NPRC/NPR3). Er gehört jedoch nicht zu den Guanylatzyklasen, da er keine GC-Domäne besitzt. Gebildet wird er als Homodimer, welches über extrazelluläre, Juxtamembran-intramolekulare Disulfidbrücken stabilisiert wird. ${ }^{97}$ Die 
intrazelluläre Region jeder Untereinheit bildet eine sich überlappende $\mathrm{G}_{\mathrm{i}} / \mathrm{G}_{0}-\mathrm{Sequenz}$, die laut in vitro Studien eine Hemmung der Adenylatzyklase-Aktivität und des Phospholipase C Umsatzes bewirken. ${ }^{98}$ Hauptsächlich fungiert NPR3 jedoch als sogenannter Clearance Receptor, der zirkulierende natriuretische Peptide bindet und diese abbaut. Somit dient NPR3 als wichtiger Regulator für NPR1 und NPR2 und wirkt einer übermäßigen cGMP-Produktion entgegen. NPR3 wird vor allem in der Niere, der Lunge, in den glatten Muskel- sowie Endothelzellen der Gefäße und auch in geringer Konzentration in allen anderen Organen exprimiert. ${ }^{99}$

\subsection{Downstream-Targets von NPR2}

Durch Aktivierung von löslichen sowie partikulären Guanylatzyklasen wird cGMP gebildet, welches anschließend verschiedene Signalkaskaden in der Zelle auslösen kann. Abhängig von der Lokalisierung der Guanylatzyklase sowie des nachgeschalteten Downstream-Mechanismus kann cGMP sowohl pro- als auch antinozizeptive Wirkungen aufzeigen. ${ }^{7,100,101}$

\subsubsection{Phosphodiesterasen}

Aufgrund seiner Rolle als Second-Messenger muss die Konzentration von cGMP streng kontrolliert werden. Dies geschieht über sogenannte Phosphodiesterasen (PDEs), welche unabhängig von der Guanylatzyklase-Aktivität cGMP hydrolysieren und eliminieren. ${ }^{100}$ Inwieweit PDEs einen Einfluss auf die Schmerzverarbeitung durch cGMP-Signalkaskaden haben, ist bisher wenig bekannt. Es wurde jedoch eine Expression der PDE2, 4, 5 und 9 im Rückenmark ${ }^{100,102-104}$ und der PDE3 und PDE5 in DRGs ${ }^{105}$ beschrieben.

\subsubsection{Ionenkanäle}

Zu den Zielmolekülen, die über eine cGMP-Produktion aktiviert werden, gehören verschiedene Ionenkanäle. Hierzu zählen unter anderem die zyklischen Nukleotid-aktivierten-Ionenkanäle (CNGs). ${ }^{105,106}$ Eine bedeutsame Rolle in der inflammatorischen Nozizeption scheint die Untereinheit CNGA3 zu spielen, welche hier inhibitorische Effekte aufweist. ${ }^{101}$ 


\subsection{3 cGMP-abhängige Proteinkinase}

Ein weiteres entscheidendes Schlüsselenzym in der Reizweiterleitung von Schmerzen ist die cGMP-abhängige Proteinkinase (cGK). Bei diesem Enzym handelt es sich um eine Serin/Threonin-Kinase, welche aus zwei Untereinheiten mit einer katalytischen und regulatorischen cGMP-bindenden Domäne besteht. Sie existiert in zwei Isoformen (cGKI und cGKII), die durch zwei Gene codiert werden. Während cGKII nur in einer Form gebildet wird, liegt die cGKI in den beiden Spleiß-Varianten cGKI $\alpha$ und cGKIß vor. ${ }^{107}$

\subsubsection{Rolle von cGMP und cGKI im schmerverarbeitenden System}

Während cGKIß und cGKII im schmerzverarbeitenden System offenbar nur eine untergeordnete Rolle spielen, scheint cGKI $\alpha$ als wichtiger Modulator für die Nozizeption zu fungieren. Sie wird in A $\delta$ - und C-Fasern der DRG-Neurone sowie in den obersten Laminae des Dorsalhorns exprimiert und nach nozizeptiven Stimuli verstärkt gebildet. ${ }^{108-111}$ Liegt eine periphere Nervenverletzung oder Entzündung vor, wird cGKI $\alpha$ in Nozizeptoren über eine verstärkte cGMP-Freisetzung aktiviert und kann zudem retrograd in das neuronale Soma transportiert werden. Gleichzeitig wird die Expression im Rückenmark gesteigert. ${ }^{7,108,112-115}$ Dies deutet darauf hin, dass eine Aktivierung von cGKl $\alpha$ ausgehend von cGMP eine wichtige Funktion in der nozizeptiven Reizweiterleitung hat. Diese Hypothese wird durch verschiedene Mausmodelle bestätigt. So weisen $\mathrm{CGKI}^{-1-}$-Mäuse in Entzündungsmodellen eine deutlich reduzierte Hyperalgesie auf. ${ }^{109}$ Gleiches stützen tierexperimentelle Untersuchungen mit cGKI-Inhibitoren, welche antinozizeptive Wirkungen zeigen. ${ }^{108,116}$ Allerdings belegen unterschiedliche Studien, dass cGKI $\alpha$ nicht, wie lange Zeit angenommen, durch NO-GC gebildetes cGMP aktiviert wird. Während cGKla stark in DRG-Neuronen exprimiert wird, kommt die NO-GC in DRG-Neuronen nicht vor. Expressionsanalysen für das Rückenmark weisen nur eine geringe Colokalisation für cGKI und NO-GC auf. ${ }^{7,67}$ Es wurde berichtet, dass cGKIa in DRGs mit den partikulären Guanylatzyklasen NPR1 und NPR2 colokalisiert und nach Stimulation mit natriuretischen Peptiden aktiviert wird. ${ }^{94,116-118}$ Darüber hinaus verursacht die intrathekale Injektion von CNP eine Allodynie, welche durch einen cGKI-Inhibitor antagonisiert werden kann. Im Gegensatz dazu wird der pronozizeptive Effekt eines NO-Donors nicht durch den cGKI-Inhibitor gehemmt. ${ }^{116}$ 
Diese Daten liefern Hinweise, dass eine Aktivierung von cGKla über partikuläre Guanylatzyklasen an der Ausbildung von Schmerzen beteiligt ist. Indem sie weitere Downstream-Targets phosphoryliert leitet sie den Reiz zur Verarbeitung an das Gehirn weiter. ${ }^{116}$ Hierzu gehören unter anderem das Vasodilatator-stimulierte Phosphoprotein (VASP), die Myosin-leichte-Ketten-Kinase (MLC) und der Inositol 1,4,5-Triphosphat Rezeptor $1\left(\mathrm{IP}_{3} \mathrm{R} 1\right)$, welche einen Einfluss auf die Entwicklung von LTPs (Synaptische Langzeitpotenzierung) zu haben scheinen ${ }^{119}$. Möglicherweise werden auch Calcium-aktivierte Kaliumkanäle mit großer Leitfähigkeit $\left(\mathrm{BK}_{\mathrm{Ca}}\right)$ indirekt über eine cGKI/cGMP-Produktion aktiviert, denen eine inhibitorische Funktion auf inflammatorische Schmerzen nachgewiesen wurde. ${ }^{117,118,120}$

\subsubsection{Cystein-reiches Protein 4 (CRP4)}

Ein weiteres potenzielles Downstream-Target der cGKI $\alpha$ ist das Cystein-reiche Protein 4 (CRP4, früher CRP2), welches in einem Hefe-zwei-Hybrid-System detektiert wurde. ${ }^{110}$ Das Lim-Domänen-Protein CRP4 ist hauptsächlich für seine Funktion in der Zellproliferation und -differenzierung, in Entwicklungsprozessen und seiner Beteiligung an der zytoskelettalen Organisation bekannt und tritt vor allem in Arterien, Fibroblasten und Kardiomyozyten auf. ${ }^{121,122}$

Es konnte jedoch gezeigt werden, dass CRP4 auch in primär afferenten Neuronen sowie deren axoterminalen Endigungen in Laminae I-II des Dorsalhorns gebildet, nach nozizeptiven Stimuli hochreguliert wird und mit cGKI $\alpha$ colokalisiert ist. ${ }^{110}$ Tierexperimentelle Verhaltenstests lassen ebenfalls Rückschlüsse auf die Bedeutung dieses Proteins im nozizeptiven System zu. So weisen CRP4 $\%$-Mäuse eine erhöhte entzündliche Hyperalgesie auf, was auf eine hemmende Funktion des Proteins bei inflammatorischen Schmerzen hindeutet. ${ }^{110}$ 


\section{$2 \quad$ ZIELSETZUNG}

In früheren Studien wurde gezeigt, dass die Bildung von cGMP zur Schmerzsensibilisierung beiträgt. Diese konzentrierten sich hauptsächlich auf die NO-abhängige cGMP-Produktion. Über den Mechanismus der partikulären Guanylatzyklasen im nozizeptiven System ist jedoch wenig bekannt. Im Rahmen dieser Arbeit sollte der Einfluss der partikulären Guanylatzyklase NPR2, ihre Aktivierung sowie mögliche Downstream-Targets genauer charakterisiert werden. Hierzu gehört neben der cGMP-abhängigen Proteinkinase Typ l $\alpha$ (cGKl $\alpha$ ) auch das Cystein-reiche Protein 4 (CRP4), welches in vorherigen Studien als Zielprotein von cGKI detektiert wurde. ${ }^{110}$

Mithilfe von Immunfluoreszenzanalysen und In-situ-Hybridisierungen in Spinalganglien und dem Rückenmark wurde die Lokalisierung von NPR2, ihrem Liganden CNP und möglichen Interaktionspartnern untersucht. Zudem wurden neben den klassischen molekularbiologischen Analysen, Verhaltensexperimente an Knockout-Mäusen durchgeführt. Es wurden Tiere generiert, die eine Runterregulierung von NPR2 in den Spinalganglien aufweisen. Außerdem wurden Mäuse mit einem CNP-Knockdown im Dorsalhorn des Rückenmarks gezüchtet. Zusätzlich wurden globale CRP4-Knockout-Mäuse verwendet, um so dessen Rolle in der Schmerzsensibilisierung genauer zu bestimmen. Übergeordnetes Ziel dieser Arbeit war es ein tieferes Grundlagenverständnis für die Entwicklung neuer, innovativer Arzneistoffe für die Schmerztherapie zu erlangen. 
3 Material und Methoden

3.1 Materialien

3.1.1 Geräte

Tabelle 3-1: Geräte und Hersteller

\begin{tabular}{|c|c|c|}
\hline Geräte /Anwendung & Bezeichnung & Hersteller \\
\hline $\begin{array}{l}\text { Chemilumineszenz und } \\
\text { Fluoreszenz Detektion }\end{array}$ & Odyssey ${ }^{\circledR} 9120$ Imaging System & $\begin{array}{l}\text { Li-COR Bioscience, Bad Homburg } \\
\text { ChemiDoc XRS, Bio-Rad, } \\
\text { Kalifornien }\end{array}$ \\
\hline $\begin{array}{l}\text { Dynamic Plantar } \\
\text { Aesthesiometer }\end{array}$ & 37450 & Ugo Basile, Gemonio (Italien) \\
\hline Elektrophorese-Kammer & $\begin{array}{l}\text { OwlScientific, B1 } \\
\text { Electrophoresis Systems }\end{array}$ & $\begin{array}{l}\text { Thermo Fisher Scientific, } \\
\text { Waltham (USA) }\end{array}$ \\
\hline Fluoreszenzkamera & Nikon DS-Qi2 (Monochrom) & Nikon GmbH, Düsseldorf \\
\hline Fluoreszenzlampe & Intensilight C-HGFI & Nikon GmbH, Düsseldorf \\
\hline Fluoreszenzmikroskop & Nikon Eclipse Ni-U & Nikon GmbH, Düsseldorf \\
\hline Fluoreszenzmikroskopfilter & $\begin{array}{l}\text { Orange H Bandpass Filterset } \\
\text { DAPI ET-Set } \\
\text { mCherry HC-Filterset } \\
\text { FITC-3540C-000 Brightline } \\
\text { Filterset } \\
\text { Cy5-4040C-000 Brightline } \\
\text { Filterset }\end{array}$ & $\begin{array}{l}\text { AHF, Tübingen } \\
\text { AHF, Tübingen } \\
\text { AHF, Tübingen } \\
\text { Semrock, New York (USA) } \\
\text { Semrock, New York (USA) }\end{array}$ \\
\hline Fluoreszenzmikroskopobjektive & $\begin{array}{l}\text { 4x Plan Fluor, } \\
\text { 10x Plan Fluor, } \\
\text { 20x Plan Apo } \lambda \text {, } \\
\text { 40x Plan Fluor, } \\
\text { 60x Öl, Plan Apo } \lambda\end{array}$ & Nikon, Düsseldorf \\
\hline Gelkammer & $\begin{array}{l}\text { X Cell Surelock Electrophoresis } \\
\text { Cell }\end{array}$ & $\begin{array}{l}\text { Life Technologies GmbH } \\
\text { (Darmstadt) }\end{array}$ \\
\hline Hargreaves Apparatur & 37370 & Ugo Basile, Gemonio (Italien) \\
\hline Hot-/ Cold-Plate & 35100 & Ugo Basile, Gemonio (Italien) \\
\hline Hybridisierungsofen & ThermoBrite ${ }^{\circledR}$ & $\begin{array}{l}\text { Leica Mikrosysteme Vertrieb } \\
\text { GmbH, Wetzlar }\end{array}$ \\
\hline Kryotom & Cryostar ${ }^{\circledR}$ NX50 Cryostat & $\begin{array}{l}\text { Thermo Fisher Scientific, } \\
\text { Waltham (USA) }\end{array}$ \\
\hline
\end{tabular}




\begin{tabular}{|c|c|c|}
\hline \multicolumn{2}{|l|}{ Laborbesteck } & $\begin{array}{l}\text { Fine Scientific Tools } \mathrm{GmbH} \text {, } \\
\text { Heidelberg }\end{array}$ \\
\hline Magnetplatte & $\begin{array}{l}\text { Variomag Electonicrührer } \\
\text { Mono }\end{array}$ & $\begin{array}{l}\text { Thermo Fisher Sientific, Waltham } \\
\text { (USA) }\end{array}$ \\
\hline Mikrozentrifuge & Modell SD & Carl Roth, Karlsruhe \\
\hline Mouse Rota-Rod & 47600 & Ugo Basile, Gemonio (Italien) \\
\hline Narkosegerät & UniVet Porta & Groppler, Deggendorf \\
\hline PCR-Cycler & $\begin{array}{l}\text { T100 Thermal Cycler, } \\
\text { Primus } 25 \text { advanced }^{\circledR} \text {, } \\
\text { CFX96 Touch }{ }^{\text {TM }} \text { Real-Time } \\
\text { System }\end{array}$ & $\begin{array}{l}\text { BioRad, Kalifornien } \\
\text { PeqLab, Erlangen } \\
\text { BioRad, Kalifornien }\end{array}$ \\
\hline pH-Meter & & Mettler Toledo, Gießen \\
\hline Plethysmometer & 37140 & Ugo Basile, Gemonio (Italien) \\
\hline Spannungsgeber & $\begin{array}{l}\text { PowerPac'M Basic Power Supply } \\
\text { Power Supply EPS } 301\end{array}$ & $\begin{array}{l}\text { BioRad, Kalifornien } \\
\text { GE Healthcare Europe } \mathrm{GmbH} \text {, } \\
\text { Freiburg }\end{array}$ \\
\hline Stereo-Mikroskop & $\begin{array}{l}\text { GUS2 Stand und C-FMBN } \\
\text { Fokus-Einheit, } \\
\text { Kaltlichtquelle KL } 200 \text { LED }\end{array}$ & $\begin{array}{l}\text { Nikon, Tokio (Japan) } \\
\text { Schott, Mainz }\end{array}$ \\
\hline UV-VIS-Spektralphotometer & NanoDrop ${ }^{\mathrm{TM}} 2000$ & $\begin{array}{l}\text { Thermo Fisher Scientific, } \\
\text { Waltham (USA) }\end{array}$ \\
\hline Zentrifugen & $\begin{array}{l}\text { Centrifuge } 5810 \mathrm{R} \\
\text { GS-15 Zentrifuge } \\
\text { Sigma } 1-16 \mathrm{~K} \\
\text { S-R }\end{array}$ & $\begin{array}{l}\text { Eppendorf, Wesseling } \\
\text { Beckmann, Krefeld } \\
\text { Sigma-Aldrich, Missouri (USA) } \\
\text { Thermo Fisher Scientific, } \\
\text { Walthram (USA) }\end{array}$ \\
\hline & uge primo & Heraeus, Hanau \\
\hline
\end{tabular}




\subsubsection{Verbrauchsmaterialien und Kits}

Tabelle 3-2: Verbrauchsmaterialien und Hersteller

\begin{tabular}{|c|c|}
\hline Verbrauchsmaterial & Hersteller \\
\hline Cryomold Einbettschalen Sakura biopsy & Sakura Finetek Germany GmbH, Staufen \\
\hline Deckgläser 24x60mm & $\begin{array}{l}\text { Waldemar Knittel Glasbearbeitungs GmbH, } \\
\text { Braunschweig }\end{array}$ \\
\hline Kanülen (Sterican ${ }^{\oplus}$; G 30 1⁄2; G 27 1⁄2/2) & B. Braun Melsungen AG, Melsungen \\
\hline Kanülen (Sterican ${ }^{\circledR} ;$ G 33) & TSK Laboratory (Japan) \\
\hline Mikroplatte 96-well, PS, U-Boden & greiner bio-one $\mathrm{GmbH}$, Frickenhausen \\
\hline $\begin{array}{l}\text { Objektträger (Thermo } \\
\text { Scientific }{ }^{\text {TM }} \text { SuperFrost Plus }{ }^{\mathrm{TM}} \text { Adhesion slides) }\end{array}$ & Thermo Fisher Scientific, Waltham (USA) \\
\hline PCR-Platte (Hard-Shell ${ }^{\circledR}$ 96-Well PCR Plate) & Bio-Rad, Kalifornien \\
\hline Pipettenspitzen $(10 \mu \mathrm{l}, 100 \mu \mathrm{l}, 200 \mu \mathrm{l}, 1000 \mu \mathrm{l})$ & Starlab GmbH, Hamburg \\
\hline Reaktionsgefäß $2 \mathrm{ml}$ & Sarstedt AG \& Co. KG, Nümbrecht \\
\hline Reaktionsgefäß 0,5 ml & Sarstedt AG \& Co. KG, Nümbrecht \\
\hline SafeSeal Gefäß 1,5 ml & Sarstedt AG \& Co. KG, Nümbrecht \\
\hline Schraubröhre $15 \mathrm{ml}$ & Sarstedt AG \& Co. KG, Nümbrecht \\
\hline Schraubröhre $50 \mathrm{ml}$ & Sarstedt AG \& Co. KG, Nümbrecht \\
\hline Spritzen (Injekt-F) & B Braun, Kronberg \\
\hline
\end{tabular}

Tabelle 3-3: Kitsysteme und Hersteller

\begin{tabular}{ll}
\hline Bezeichnung & Hersteller \\
\hline First Strand cDNA Synthesis Kit & Thermo Fisher Scientific, Waltham (USA) \\
innuPREP Micro RNA Kit & Analytik Jena AG, Jena \\
RNEAsy Midi Kit & Qiagen GmbH, Hilden \\
RNAse-Free DNAse I Set & Qiagen GmbH, Hilden \\
& Thermo Scientific ${ }^{\text {TM }}$ by Thermo Fisher Scientifc \\
ViewRNA & Inc., MA (USA) \\
\hline
\end{tabular}




\subsubsection{Antikörper und Sonden}

Tabelle 3-4: Primäre Antikörper

\begin{tabular}{lll}
\hline Bezeichnung & Katalognummer & Hersteller \\
\hline CGRP & C 9487 & Sigma-Aldrich, Missouri (USA) \\
IB4- Alexa Fluor gelabelt (AF488) & $\# 121411$ & Invitrogen/Molecular Probes (USA) \\
NeuN & MAB377 & Millipore/Chemicon, Darmstadt \\
NF200 (Neurofilament) & N4142 & Sigma-Aldrich, Missouri (USA) \\
Peripherin & MAB1527 & Chemicon, Nürnberg \\
PKG I & & Enzo Life Sciences AG, Lausen \\
B-Gal & ab9361 & abcam, Cambridge (UK) \\
STMN2 & NBP1-43461 & Novus Biologicals, Wiesbaden \\
Substance P & 556312 & BD (USA) \\
\hline
\end{tabular}

Tabelle 3-5: sekundäre Antikörper

\begin{tabular}{lll}
\hline Bezeichnung & Katalognummer & Hersteller \\
\hline Anti-Rat AF488 & A11006 & Invitrogen, Carlsbad (USA) \\
Anti-Rabbit AF488 & A11008 & Invitrogen, Carlsbad (USA) \\
Anti-Mouse AF 488 & A11029 & Invitrogen, Carlsbad (USA) \\
Anti-Chicken AF488 & A11039 & Invitrogen, Carlsbad (USA) \\
Anti-Mouse AF 488 & A11076 & Invitrogen, Carlsbad (USA) \\
Anti-Mouse AF 680 & A21048 & Invitrogen, Carlsbad (USA) \\
Anti-Mouse AF 350 & A21130 & Invitrogen, Carlsbad (USA) \\
Anti-Mouse AF 555 & A21127 & Invitrogen, Carlsbad (USA) \\
Anti-Mouse AF 555 & A21147 & Life technolog., Carlsbad (USA) \\
Anti-Mouse AF 555 & A21137 & Invitrogen, Carlsbad (USA) \\
Anti-Rabbit AF488 & A21206 & Invitrogen/Molecular Probes (USA) \\
Anti-Mouse AF 555 & A31570 & Invitrogen, Carlsbad (USA) \\
Anti-Rabbit AF555 & A31572 & Invitrogen, Carlsbad (USA) \\
Anti-Rabbit Cy5 & ab6564 & abcam, Cambridge (UK) \\
\hline
\end{tabular}


Tabelle 3-6: In-situ-Hybridisierungssonden

\begin{tabular}{|c|c|c|c|}
\hline Bezeichnung & Markierung & Katalognummer & Hersteller \\
\hline CRIP2 & Typ6 & VB6-3206172-01 & $\begin{array}{l}\text { Thermo Scientific }{ }^{\mathrm{TM}} \text { by } \\
\text { Thermo Fisher Scientifc } \\
\text { Inc., MA (USA) }\end{array}$ \\
\hline Nppc & Typ1 & VB1-3030998-01 & $\begin{array}{l}\text { Thermo Scientific }{ }^{\mathrm{TM}} \text { by } \\
\text { Thermo Fisher Scientifc } \\
\text { Inc., MA (USA) }\end{array}$ \\
\hline Nppc & Typ6 & VB6-20409 & $\begin{array}{l}\text { Thermo Scientific }{ }^{\mathrm{TM}} \text { by } \\
\text { Thermo Fisher Scientifc } \\
\text { Inc., MA (USA) } \\
\text { Thermo Scientific }{ }^{\mathrm{TM}} \text { by }\end{array}$ \\
\hline NPR1 & Typ6 & VB6-20424 & $\begin{array}{l}\text { Thermo Fisher Scientifc } \\
\text { Inc., MA (USA) } \\
\text { Thermo Scientific }{ }^{\mathrm{TM}} \text { by }\end{array}$ \\
\hline NPR2 & Typ1 & VB1-20407 & $\begin{array}{l}\text { Thermo Fisher Scientifc } \\
\text { Inc., MA (USA) } \\
\text { Thermo Scientific }{ }^{\text {TM }} \text { by }\end{array}$ \\
\hline NPR2 & Typ6 & VB6-3198145 & $\begin{array}{l}\text { Thermo Fisher Scientifc } \\
\text { Inc., MA (USA) }\end{array}$ \\
\hline Prkg1 & Typ1 & VB1-19757 & $\begin{array}{l}\text { Thermo Fisher Scientifc } \\
\text { Inc., MA (USA) } \\
\text { Thermo Scientific }{ }^{\mathrm{TM}} \text { by }\end{array}$ \\
\hline Other scramble & Typ1 & VF1-17155 & $\begin{array}{l}\text { Thermo Fisher Scientifc } \\
\text { Inc., MA (USA) } \\
\text { Thermo Scientific }{ }^{\mathrm{TM}} \text { by }\end{array}$ \\
\hline Unknown scramble & Typ6 & VB6-18580 & $\begin{array}{l}\text { Thermo Fisher Scientifc } \\
\text { Inc., MA (USA) }\end{array}$ \\
\hline
\end{tabular}

\subsubsection{Chemikalien und Reagenzien}

Tabelle 3-7: Chemikalien und Hersteller

\begin{tabular}{ll}
\hline Bezeichnung & Hersteller \\
\hline Agarose & Genaxxon bioscience GmbH, Ulm \\
ANP 4-23 & Sigma Aldrich Laborchemikalien GmbH, Steinheim \\
Borsäure & Sigma-Aldrich Laborchemikalien GmbH, Steinheim \\
Bovine Serum Albumin & Carl Roth GmbH \& Co, Karlsruhe \\
Bradford-Reagenz (Roti ${ }^{\circledR}$-Quant) & Carl Roth GmbH \& Co, Karlsruhe \\
Calciumchlorid & Merck KGaA, Darmstadt \\
Calciumchlorid & Merck KGaA, Darmstadt \\
Calciumhydroxid & Merck KGaA, Darmstadt \\
Capsaicin & Sigma-Aldrich Laborchemikalien GmbH, Steinheim \\
\hline
\end{tabular}




\begin{tabular}{|c|c|}
\hline Carprofen (Rimadyl ${ }^{\oplus}$ ) & Zeotis Deutschland GmbH, Berlin \\
\hline Chloroform & Merck KGaA, Darmstadt \\
\hline Chloroquindiphosphat & Sigma-Aldrich Laborchemikalien GmbH, Steinheim \\
\hline CNP-22 & PhoenixPharmaceuticals Inc., Manneim \\
\hline DAPI & $\begin{array}{l}\text { Invitrogen by Thermo Fisher Scientific; Life Technologies } \\
\text { Corporation, Eugene (USA) }\end{array}$ \\
\hline Diethyldicarbonat (DEPC) & Carl Roth GmbH \& Co, Karlsruhe \\
\hline Dimethylsulfoxid (DMSO) & Carl Roth GmbH \& Co, Karlsruhe \\
\hline Dinatriumhydrogenphosphat & Sigma-Aldrich Laborchemikalien GmbH, Steinheim \\
\hline dNTPs & Qiagen GmbH, Hilden \\
\hline EDTA & Sigma-Aldrich ${ }^{\circledR}$, St. Louis, MO (USA) \\
\hline Ethanol (absolut) & Carl Roth GmbH \& Co. KG, Karlsruhe \\
\hline Fluoromount-G & Invitrogen ${ }^{\mathrm{TM}}$ by Thermo Fisher Scientifc Inc., MA (USA) \\
\hline Formaldehyd-Lösung (37\%) & AppliChem GmbH, Darmstadt \\
\hline Gasgemisch $95 \% \mathrm{CO}_{2}+5 \% \mathrm{O}_{2}$ & Praxair, Biebesheim am Rhein \\
\hline $\begin{array}{l}\text { Gefriermedium (Tissue-Tek }{ }^{\circledR} \\
\text { O.C.T.TM) }\end{array}$ & Sakura Finetek Germany GmbH, Staufen \\
\hline GeneRuler 100 bp DNA Ladder & Thermo Scientific ${ }^{\mathrm{TM}}$ by Thermo Fisher Scientifc Inc., MA (USA) \\
\hline Histamin & Sigma-Aldrich Laborchemikalien GmbH, Steinheim \\
\hline Isofluran (Forene ${ }^{\circledR}$ ) & AbbVie Inc., IL (USA) \\
\hline Isopropanol & Merck KGaA, Darmstadt \\
\hline Kaliumdihydrogenphosphat & Carl Roth GmbH \& Co, Karlsruhe \\
\hline Kaliumferricyanid & Sigma-Aldrich Laborchemikalien GmbH, Steinheim \\
\hline Kaliumferrocyanid & Sigma-Aldrich Laborchemikalien GmbH, Steinheim \\
\hline Kohlenstoffdioxid $\left(\mathrm{CO}_{2}\right)$ & Praxair, Biebesheim am Rhein \\
\hline Magnesiumchlorid & AppliChem GmbH, Darmstadt \\
\hline Natriumchlorid & Gibco $^{\mathrm{TM}}$ by Thermo Fisher Scientifc Inc., MA (USA) \\
\hline Natriumchlorid-Lösung & B. Braun Melsungen AG, Melsungen \\
\hline Natriumdihydrogenphosphat & Sigma-Aldrich Laborchemikalien GmbH, Steinheim \\
\hline Natriumhydroxid-Plätzchen & Sigma-Aldrich Laborchemikalien GmbH, Steinheim \\
\hline Normal goat Serum & Sigma-Aldrich Laborchemikalien GmbH, Steinheim \\
\hline Oligonukleotide & Biomers.net $\mathrm{GmbH}$, Ulm \\
\hline Paraformaldehyd & Sigma-Aldrich Laborchemikalien GmbH, Steinheim \\
\hline Proteinase $\mathrm{K}$ & Carl Roth GmbH \& Co. KG, Karlsruhe \\
\hline QIAZOL Lysis-Reagent & Qiagen GmbH, Hilden \\
\hline RedMastermix & Genaxxon bioscience $\mathrm{GmbH}$, Ulm \\
\hline RNase freies Wasser & Qiagen GmbH, Hilden \\
\hline
\end{tabular}




\begin{tabular}{ll}
\hline RNaseZap $^{\text {TM }}$ & $\begin{array}{l}\text { Invitrogen by Thermo Fisher Scientific; Life Technologies } \\
\text { Corporation, Eugene (USA) }\end{array}$ \\
Roti $^{\circledR}$-GelStain & Carl Roth GmbH \& Co. KG, Karlsruhe \\
Roti $^{\circledR}$-Load (4x) & Carl Roth GmbH \& Co, Karlsruhe \\
Roti $^{\circledR}$-Safe & Carl Roth GmbH \& Co, Karlsruhe \\
Sacubitril & MedChemExpress, Monmouth Junction (USA) \\
Salzsäure (rauchend (37\%)) & Carl Roth GmbH \& Co, Karlsruhe \\
Sucrose & Carl Roth GmbH \& Co, Karlsruhe \\
Sudanschwarz B & Sigma-Aldrich Laborchemikalien GmbH, Steinheim \\
Taq DNA Polymerase 2x Master Mix & Ampliqon, Odense (Dänemark) \\
RED, 1,5 mM MgCl & \\
Tissue-Tek & Sakura Finetek U.S.A. Inc. \\
Tris & Merck KGaA, Darmstadt \\
Triton X-100 & Sigma-Aldrich Laborchemikalien GmbH, Steinheim \\
Tween ${ }^{\circledR} 20$ & Sigma-Aldrich Laborchemikalien GmbH, Steinheim \\
Tween ${ }^{\circledR} 80$ & Sigma-Aldrich Laborchemikalien GmbH, Steinheim \\
x-Gal & Sigma-Aldrich Laborchemikalien GmbH, Steinheim \\
Zymosan A & Sigma-Aldrich Laborchemikalien GmbH, Steinheim \\
\hline
\end{tabular}

\subsubsection{Puffer und Lösungen}

Tabelle 3-8: Puffer und Lösungen

\begin{tabular}{|c|c|}
\hline Bezeichnung & Zusammensetzung \\
\hline Blockierungspuffer & $\begin{array}{l}3 \%(v / v) \text { Bovine serum albumin } \\
10 \%(v / v) \text { Normal goat Serum } \\
1 x \text { PBS }\end{array}$ \\
\hline Färbepuffer (x-Gal) & $\begin{array}{l}0,2 \mathrm{M} \mathrm{MgCl}_{2} \\
\text { Ad 0,5 I PBS-Triton X-100 }\end{array}$ \\
\hline NaCl-Lösung (Perfusion) & $\begin{array}{l}0,9 \% \mathrm{NaCl} \\
\text { Ad } 1 \text { I } \mathrm{H}_{2} \mathrm{O}\end{array}$ \\
\hline PBS (10x) & $\begin{array}{l}1,7 \mathrm{M} \mathrm{NaCl} \\
109,3 \mathrm{mM} \mathrm{Na}_{2} \mathrm{HPO}_{4} \\
33,5 \mathrm{mM} \mathrm{KCl} \\
18,4 \mathrm{mM} \mathrm{KH}_{2} \mathrm{PO}_{4}\end{array}$ \\
\hline PBS-Triton X-100 & 99,9 \%(v/v) $10 \%$ 10xPBS(v/v) 0,1 \% Triton X-100 \\
\hline
\end{tabular}




\begin{tabular}{|c|c|}
\hline Proteinase K-Puffer & $\begin{array}{l}10 \mathrm{mg} / \mathrm{ml} \text { Proteinase } \mathrm{K} \\
5 \mathrm{ml} 1 \mathrm{M} \mathrm{TRIS}-\mathrm{HCl}(\mathrm{pH} 8) \\
0,15 \mathrm{~g} \mathrm{CaCl}_{2} \\
25 \mathrm{ml} \mathrm{Glycerol}\end{array}$ \\
\hline 4\% PFA-Lösung & $\begin{array}{l}4 \%(w / v) \text { PFA } 10 \%(v / v) \text { 10xPBS } \\
\mathrm{NaOH}, \mathrm{HCl}, \mathrm{pH} 7,3-7,4\end{array}$ \\
\hline Schwanzlyse-Puffer & $\begin{array}{l}100 \mathrm{mM} \text { Tris- } \mathrm{HCl}(\mathrm{pH} 8,5) \\
5 \mathrm{mM} \text { EDTA } \\
0,2 \% \mathrm{SDS} \\
200 \mathrm{mM} \mathrm{NaCl}\end{array}$ \\
\hline Sucroselösung & $\begin{array}{l}20 \% \text { Sucrose } \\
10 \% 10 x P B S\end{array}$ \\
\hline TBE-Puffer (10x) & $\begin{array}{l}108 \text { g TRIS-Base } \\
55 \text { g Borsäure } \\
40 \mathrm{ml} \text { EDTA }(0,5 \mathrm{M}, \mathrm{pH} 8,0) \\
\text { Ad } 1 \text { I } \mathrm{H}_{2} \mathrm{O}\end{array}$ \\
\hline Waschpuffer (In-situ-Hybridisierung) & $\begin{array}{l}27 \mathrm{ml} \text { Waschkomponente } 1 \\
\text { 7,5 } \mathrm{ml} \text { Waschkomponente } 2 \\
\text { Ad } 3 \text { I autoklaviertes } 0,1 \% \text { iges DEPC-Millipore Wasser }\end{array}$ \\
\hline
\end{tabular}

\subsubsection{Größenstandards und Polymerasen}

Tabelle 3-9: Größenstandards (DNA-Marker)

\begin{tabular}{ll}
\hline Bezeichnung & Hersteller \\
\hline 100 bp GeneRuler & Thermo Fisher Scientific, Waltham (USA) \\
$1 \mathrm{~kb}$ GeneRuler & Thermo Fisher Scientific, Waltham (USA) \\
\hline
\end{tabular}

Tabelle 3-10: Polymerasen

\begin{tabular}{ll}
\hline Bezeichnung & Hersteller \\
\hline iTaq Universal SYBR Green SuperMix & BioRad, Kalifornien (USA) \\
Taq DNA Polymerase 2x Master Mix & Ampliqon, Odense (Dänemark) \\
RED, $1,5 \mathrm{mM} \mathrm{MgCl}_{2}$ & \\
\hline
\end{tabular}




\subsubsection{Substanzen im Tiermodell}

Tabelle 3-11: Substanzen zur Anästhesie und Analgesie

\begin{tabular}{lll}
\hline Bezeichnung & Konzentration und Applikation & Hersteller \\
\hline Carprofen (RIMADYL $\left.{ }^{\circledR}\right)$ & $5 \mathrm{mg} / \mathrm{kg}$ Subkutan & Zoetis, New Jersey (USA) \\
& & CP-Pharma \\
Isofluran $\mathrm{CP}^{\circledR}$ & Inhalations-Narkotikum & $\begin{array}{l}\text { Handelsgesellschaft } \mathrm{mbH}, \\
\text { Burgdorf }\end{array}$ \\
\hline
\end{tabular}

Tabelle 3-12: Substanzen für Schmerz- und Entzündungsmodelle

\begin{tabular}{llll}
\hline Bezeichnung & Konzentration & Injiziertes Volumen & Applikationsart \\
\hline Capsaicin & $5 \mu \mathrm{g}$ in 2\% DMSO in & $20 \mu \mathrm{l}$ & intraplantar \\
& PBS & & \\
Formalin & $0,5 \%$ in PBS & $15 \mu \mathrm{l}$ & intraplantar \\
Zymosan & $0,1 \mathrm{mg}$ in PBS & $20 \mu \mathrm{l}$ & intraplantar \\
\hline
\end{tabular}

\subsubsection{Analysesoftwares}

Tabelle 3-13: Software

\begin{tabular}{|c|c|}
\hline Verwendung & Software \\
\hline Fotobearbeitungsprogramme & $\begin{array}{l}\text { Adobe Photoshop CS6 } \\
\text { Image J }\end{array}$ \\
\hline Statistikprogramme & $\begin{array}{l}\text { Graph Pad Prism } 8 \\
\text { MS Excel } 2016 \\
\text { SPSS Statistik } 26\end{array}$ \\
\hline Gelektrophorese Analysesoftware & Image Lab (BioRad ${ }^{\circledR}$ ) \\
\hline Real-Time PCR Analysesoftware & CFX-Manager ${ }^{\mathrm{TM}}$ \\
\hline
\end{tabular}




\section{$3.2 \quad$ Methoden}

\subsubsection{Tierexperimentelle Methoden}

\subsubsection{Versuchstiere}

Zur Untersuchung der CNP/NPR2/cGMP/cGKIa/CRP4-Signalkaskade wurden unterschiedliche Knockout-Mauslinien verwendet. Die Zucht konditioneller Adv-Npr2 ${ }^{--_{-}}$, SNS-Npr2 ${ }^{-\sigma_{-}}$sowie Lbx1-Nppc ${ }^{-1}$-Mäuse erfolgte über das Cre/loxP-System. Hierfür wurden Mäuse mit einer zellspezifischen Cre-Rekombinase-Expression (Adv-Cre, SNS-Cre, Lbx1-Cre) mit Tieren verpaart, bei denen bestimmte Genabschnitte der zu untersuchenden Proteine durch loxP-Sequenzen flankiert waren. Durch zwei genetische Kreuzungen konnten so gewebsspezifische Knockouttiere und deren wildtypische Wurfgeschwister gezüchtet werden. In der ersten Kreuzung wurden Mäuse, die heterozygot das Gen der entsprechenden Cre-Rekombinase (Cre $\left.{ }^{+/ w t}\right)$ trugen, mit Mäusen verpaart, die hetero- oder homozygot für das gefloxte Allel des Gens Npr2 (Npr2 ${ }^{\text {fl/wt; }}$ $\left.N p r 2^{f l / f l}\right)$ beziehungsweise Nppc $\left(\mathrm{Nppc}^{\mathrm{fl} / \mathrm{wt}}, \mathrm{Nppc}^{\mathrm{fl} / f l}\right)$ waren. So wurden Nachkommen generiert, die heterozygot für das gefloxte Allel und Träger der Cre-Rekombinase waren. Durch eine zweite Kreuzung konnten anschließend die gewebsspezifischen Knockout- und entsprechende Kontrolltiere erzeugt werden.

Für die Zucht konditioneller Npr2-Knockouttiere wurden Npr2-flox(Npr2 $\left.2^{f / f l}\right)$-Mäuse von Herrn PD Dr. Hannes Schmidt (Interfakultäres Institut für Biochemie, Universität Tübingen) zur Verfügung gestellt, bei denen jeweils zwei loxP-Stellen in die flankierenden intronischen Sequenzen der Exons 17 und 18 des murinen Npr2-Gens eingefügt waren. ${ }^{123}$

Zunächst wurden Adv-Npr2\%-Mäuse gezüchtet. Hierbei wurde eine Mauslinie (Adv-Cre) verwendet, deren Cre-Rekombinase unter Kontrolle des Gens Advillin stand. Diese Linie wurde ausgesucht, da Advillin in nahezu allen sensorischen Neuronen exprimiert wird ${ }^{124}$ und somit ein vollständiger konditioneller Npr2-Knockout in DRG-Neuronen herbeigeführt werden sollte.

Zudem wurden mithilfe der SNS-Cre-Linie weitere konditionelle Knockout-Tiere (SNS-Npr2 ${ }^{-/-}$) generiert. Bei SNS-Cre (transgene insertion 1) handelt es sich um eine Cre-Rekombinase, die unter Kontrolle des Natrium-Kanals Nav1.8 steht. Dieser wird in den meisten nozizeptiven und 
thermorezeptiven Neuronen der Trigeminus- und Spinalganglien exprimiert und weist nur eine sehr geringe propriozeptive Expression auf. ${ }^{125}$

Des Weiteren wurden gewebespezifische Knockoutmäuse generiert, die einen Knockout von Nppc im Dorsalhorn des Rückenmarks aufwiesen. Hierfür wurde eine Lbx1-Cre-Reporter-Linie verwendet. Ladybird Homeobox 1 (Lbx1) ist ein Gen, welches nur in Neuronen des Dorsalhorns und des Hinterhirns exprimiert wird. ${ }^{126}$ Zur Verpaarung wurden heterozygote Nppcflox(Nppc $\left.{ }^{\mathrm{fl} / \mathrm{wt}}\right)$-Tiere von Herrn PD Dr. Hannes Schmidt (Interfakultäres Institut für Biochemie, Universität Tübingen) verwendet. Diese Tiere enthielten loxP-Sequenzen, die Exon 1 und 2 des murinen Nppc-Gens flankierten.

Neben den zuvor beschriebenen Linien wurden globale CRP4-Knockout-Mäuse untersucht, welche von Herrn Prof. Dr. Peter Ruth und Herrn Prof. Dr. Robert Lukowski (Institut für Pharmazie, Universität Tübingen) zur Verfügung gestellt wurden. Hierbei handelte es sich um einen Inzuchtstamm mit einem 129/sv Hintergrund, dessen Exons 2 bis 7 durch eine loxP-Sequenz und eine floxierte Neomycin Phosphotransferase-Thymidin Kinase-(Neo/tk-)Kassette gekennzeichnet waren, sodass eine gezielte Rekombination von CRP4 erfolgen konnte. ${ }^{110}$

Die Verhaltensversuche wurden an Knockout-Tieren sowie entsprechenden Kontrolltieren durchgeführt. Dabei wurden Tiere beiderlei Geschlechts im Alter von zehn Wochen bis elf Monaten untersucht.

Um die RNA- und/oder Proteinexpression in wildtypischen Geweben zu analysieren, wurden vier bis acht Wochen alte C57BL/6 Mäuse beider Geschlechter verwendet. Diese Tiere wurden im Institut für Pharmakologie und Klinische Pharmazie (Goethe-Universität Frankfurt) gezüchtet oder von Charles River (Freiburg) bezogen. Zudem wurden gewebsspezifische Expressionsanalysen an $\mathrm{CNP}^{+/ L a c z}$ und $\mathrm{Npr}^{+/ L a c Z}-$ Mäusen durchgeführt, welche ebenfalls von Herrn PD Dr. Hannes Schmidt (Interfakultäres Institut für Biochemie, Universität Tübingen) zur Verfügung gestellt wurden. Der CNP ${ }^{+/ L a c z}$-Mausstamm wurde erzeugt, indem von einem Allel das Exon 1 des Nppc-Gens durch eine LacZ-Expressionskassette ersetzt wurde. ${ }^{127}$ Deckungsgleich 
hierzu wurde bei Mäusen der Npr2 ${ }^{+/ L a c z}$-Linie auf einem Allel das Exon 1 des Npr2-Gens durch eine LacZ-Expressionskassette, einem Poly-A-Strang und einer selbstexzidierenden Cre-RekombinaseKassette ausgetauscht. ${ }^{128}$

Die Haltung und Versorgung der Versuchstiere erfolgte unter konstanten Bedingungen (Raumtemperatur $22 \pm 2^{\circ} \mathrm{C}$; Luftfeuchtigkeit 45-65\%; Hell-/Dunkelzyklus 7/19 Uhr) mit Trockenfutter und Wasser ad libitum. Während der Durchführung der nozizeptiven Verhaltensversuche war der Beobachter bezüglich des Genotyps der Tiere verblindet. Alle Tierversuche wurden von der zuständigen Behörde (Regierungspräsidium Darmstadt) genehmigt.

\subsubsection{Genotypisierung}

Für die Genotypisierung der einzelnen Knockout-Tiere wurden Ohrlochbiopsien verwendet, die bis zur Weiterverarbeitung bei $4{ }^{\circ} \mathrm{C}$ oder $-20^{\circ} \mathrm{C}$ gelagert wurden. Die Extraktion der DNA erfolgte über eine alkalische Lyse. Hierfür wurden die Biopsien in $500 \mu$ l Lysepuffer mit $1 \%$ Proteinase-K aufgenommen und über Nacht bei $55^{\circ} \mathrm{C}$ und $550 \mathrm{rpm}$ inkubiert. Am darauffolgenden Tag wurden die Ansätze für fünf Minuten bei $13.000 \mathrm{~g}$ zentrifugiert und der Überstand in $500 \mu$ l 100\%igem Isopropanol gefällt. Nach erneuter zehnminütiger Zentrifugation wurde der Überstand verworfen, die DNA in $500 \mu \mathrm{l}$ Ethanol gewaschen und anschließend getrocknet. Danach wurde sie in $50 \mu \mathrm{l}$ RNAse/DNase-freiem Wasser über 15 Minuten bei $55^{\circ} \mathrm{C}$ gelöst. Die aufgereinigte DNA wurde bis zur weiteren Verwendung bei $-20^{\circ} \mathrm{C}$ gelagert.

Die Genotypisierung wurde mithilfe einer Polymerase-Kettenreaktion durchgeführt. Durch Einsatz spezifischer Primer wurde der nachzuweisende DNA-Abschnitt flankiert. Über anschließende zyklische Denaturierung des Doppelstranges, Hybridisierung der Primer und Verlängerung der DNA-Oligonukleotide mit Desoxy-Nukleotidtriphosphaten (dNTPs) erfolgte die exponentielle Amplifikation des DNA-Abschnitts. Für die Genotypisierung wurde der FastREDExtract-N-Amp Reaction Mix des REDExtract-N-Amp ${ }^{T M}$ Tissue PCR Kit (Sigma-Aldrich) verwendet, welcher bereits eine thermostabile DNA-Polymerase sowie dNTPs enthielt. 
Genotypisierungsansatz:

$10 \mu \mathrm{l}$

FastREDExtract-N-Amp-Reaction Mix

je $1,5 \mu \mathrm{l} \quad$ Primer $(10 \mu \mathrm{M})$

$4 \mu \mathrm{l} \quad$ DNA-Extraktionsansatz

ad $20 \mu \mathrm{l} \quad \mathrm{H}_{2} \mathrm{O}$

Die für die Genotypisierung eingesetzten Primer sind Tabelle 3-14 zu entnehmen. Die Hybridisierungstemperatur wurde durch Schmelztemperaturen der jeweiligen Primer bestimmt und die Polymerisationszeit durch die Länge der erwarteten PCR-Produkte ermittelt. Die Programme für die jeweiligen Genotypisierungen sind im Anschluss gelistet. Zur Detektion Cre-exprimierender Zellen wurde ein Kontrollgen (CB1) amplifiziert, um sicherzustellen das ein Template in der Probe vorlag.

Für die Analyse der Polymerase-Kettenreaktion wurden die Ansätze auf ein 1,5-2\%iges Agarosegel aufgetragen und nach Bandengröße separiert. Zur Visualisierung der DNA wurde Roti-Safe ${ }^{\circledR}$ eingesetzt. Die Detektion erfolgte mit dem Fluoreszenz-Detektionsgerät ChemiDoc XRS (BioRad).

Tabelle 3-14: verwendete Primer zur Genotypisierung

\begin{tabular}{lll}
\hline Nachgewiesenes Gen & Primersequenz & Fragmentgröße \\
\hline CB1 & Fwd 5'-gct gtc tct ggt cct ctt aaa-3' & CB1 400 bp \\
& Rew 5'-ggt gtc acc tct gaa aac aga-3' & \\
Nppc & Fwd 5'-cgt ggc agc att tgt gaa ga -3' & WT 266 bp \\
& Fwd 5'-aaa ccc acc act gac cac tg -3' & Flox 300 bp \\
& Rew 5'-agt tga gtt gag agc agg gc -3' & $\Delta 33$ bp \\
Cre & Fwd 5'-gaa agc cat gtc caa ttt act gac cgt a-3' & Cre 250 bp \\
& Rew 5'-gcg cgc ctg aag ata tag aag -3' & WT keine Bande \\
Npr2 & Fwd 5'-cct gct ttg atg cca tta tcg -3' & WT 506 bp \\
& Rew 5'-ctg caa caa cca aag ctc ag -3' & Flox 648 bp \\
\hline
\end{tabular}


PCR-Programm für Nppc-flox

(zwei Primer):

$\left.\begin{array}{ll}5 \mathrm{~min} & 95^{\circ} \mathrm{C} \\ 30 \mathrm{~s} & 95^{\circ} \mathrm{C} \\ 30 \mathrm{~s} & 62{ }^{\circ} \mathrm{C} \\ 30 \mathrm{~s} & 72{ }^{\circ} \mathrm{C}\end{array}\right\} 35 \mathrm{x}$

$10 \min 72{ }^{\circ} \mathrm{C}$

$\infty 4{ }^{\circ} \mathrm{C}$

PCR-Programm für Cre:

$5 \min 94^{\circ} \mathrm{C}$

$\left.\begin{array}{l}1 \min 94^{\circ} \mathrm{C} \\ 1 \min 55^{\circ} \mathrm{C} \\ 2 \min 72{ }^{\circ} \mathrm{C}\end{array}\right\} 40 \mathrm{x}$

$10 \min 72{ }^{\circ} \mathrm{C}$

$\infty 4{ }^{\circ} \mathrm{C}$
PCR-Programm für Nppc-flox

(drei Primer zur Bestimmung der $\Delta$-Bande):

$5 \min 95^{\circ} \mathrm{C}$

$1 \min 95^{\circ} \mathrm{C}$

30 s $\left.59,4{ }^{\circ} \mathrm{C}\right\} 35 \mathrm{x}$

$30 \mathrm{~s} \quad 72{ }^{\circ} \mathrm{C}$

$10 \min 72{ }^{\circ} \mathrm{C}$

$\infty 8^{\circ} \mathrm{C}$

PCR-Programm für Npr2-flox:

$3 \min 95^{\circ} \mathrm{C}$

$30 \mathrm{~s} \quad 94^{\circ} \mathrm{C}$

$\left.30 \mathrm{~s} \quad 59^{\circ} \mathrm{C}\right\} 35 \mathrm{x}$

$45 \mathrm{~s} \quad 72^{\circ} \mathrm{C}$

$5 \min 72{ }^{\circ} \mathrm{C}$

$\infty 4{ }^{\circ} \mathrm{C}$

\subsubsection{Rotarod-Test}

Die motorische Koordinationsfähigkeit der Knockout-Linien wurde mit dem Rotarod-Test überprüft. Hierfür wurden Versuchstiere auf eine mit konstanter Geschwindigkeit (15 rpm) rotierenden Stange (Rotarod Treadmill für Mäuse; Ugo Basile) gesetzt. Anschließend wurde die Zeit, die sich die Mäuse auf der Stange halten konnten, gemessen. Nach einer Cut-off-Zeit von 120 Sekunden wurde die Messung spätestens abgebrochen. Vor dem eigentlichen Versuchsstart wurden die Tiere über mehrere Trainingsläufe (zwei Trainingseinheiten) mit der Apparatur vertraut gemacht. 


\subsubsection{Dynamic Plantar Aesthesiometer-Test}

Für die Bestimmung der Reizantwort nach mechanischer Stimulation wurde ein Dynamic Plantar Aesthesiometer (Ugo Basile) verwendet. Während des Versuchs wurden die Mäuse in einen Käfig gesetzt, dessen Boden aus einem engmaschigen Gitter bestand. Nach einer ausreichenden Eingewöhnungszeit wurde die Plantarseite der zu messenden Pfote mit einem feinen Metallstab (0,5 mm Durchmesser) angesteuert. Dieser baute über die ersten zehn Sekunden einen konstant ansteigenden Druck auf (0-5 g mit 0,5 g/s) und hielt diesen für weitere zehn Sekunden. ${ }^{116,120,129}$ Die Latenzzeit, die das Tier bis zum Wegziehen der Pfote brauchte, wurde erfasst und der Durchschnitt von vier bis sechs aufeinanderfolgenden Expositionen mit Messabständen von mindestens $20 \mathrm{~s}$ berechnet.

\subsubsection{Hargreaves Test}

Um die Reizantwort nach thermischer Stimulation zu erfassen, wurde der Hargreaves Test (Hargreaves Apparatur, Ugo Basile) durchgeführt. Während des Versuchs befanden sich die Mäuse in einem Käfig mit einem Boden aus einer Plexiglasplatte. In diesem Versuch wurde die Plantarseite der zu messenden Pfote mit einer Hitzequelle angezielt (Infrarot (IR) Intensität 30) und die Latenzzeit bis zur ersten Reaktion ermittelt. ${ }^{130}$ Als Reaktion wurde ein Wegziehen oder Anheben der Pfote gedeutet. Die maximale Zeit, die das Tier der Hitzequelle ausgesetzt war, betrug $20 \mathrm{~s}$. Dabei wurde jedes Tier mindestens drei bis fünf Mal gemessen und die Werte im Anschluss gemittelt. Der Abstand zwischen jeder Messung betrug $\geq$ fünf Minuten. Auch hier fand vor dem Versuchsstart eine mindestens halbstündige Gewöhnungsphase statt. Die Auswertung erfolgte analog zum Dynamic Plantar Test.

\subsubsection{Tail-Flick Test}

Der Tail-Flick Test wurde als weiterer Versuch verwendet, um die Schmerzantwort nach thermischer Reizung zu erfassen. Hierfür wurden die Tiere in eine Hargreaves Apparatur gesetzt (Hargreaves Apparatur, Ugo Basile) und die Hitzequelle (IR-Intensität 30) auf den Schwanz zwei Zentimeter unterhalb der Schwanzwurzel gerichtet. Zieht die Maus den Schwanz weg, wird die Hitzequelle abgeschaltet. Die Latenzzeit bis zum Wegziehen des Schwanzes dient als Maß für die 
akute thermische Schmerzschwelle. Die Latenzzeit bis zur ersten Reaktion wurde insgesamt drei bis fünf Mal mit einem Abstand von $\geq$ fünf Minuten zwischen jeder Messung erfasst und ihr Mittelwert für die Auswertung berechnet. Die Eingewöhnungsphase vor Versuchsbeginn betrug mindestens 30 Minuten.

\subsubsection{Hot-Plate Test}

Mithilfe des Hot-Plate Tests wurde das akute Schmerzverhalten nach thermischer Stimulation untersucht. ${ }^{131}$ In diesem Versuch wurden Tiere auf eine $50{ }^{\circ} \mathrm{C}, 52^{\circ} \mathrm{C}$ und $54{ }^{\circ} \mathrm{C}$ heiße Platte (Ugo Basile) gesetzt und die Latenzzeit bis zur ersten nozizeptiven Reaktion ermittelt. Diese wurde als Lecken beziehungsweise Schütteln einer Hinterpfote oder dem Hochspringen des Tieres gewertet. Um Gewebeschäden zu verhindern, wurde im Falle einer ausbleibenden Reaktion das Experiment nach 60 Sekunden (für $50^{\circ} \mathrm{C}$ ), nach 40 Sekunden (für $52^{\circ} \mathrm{C}$ ) und nach 20 Sekunden (für $54{ }^{\circ} \mathrm{C}$ ) beendet. Die Messungen der verschiedenen Temperaturen erfolgten an unterschiedlichen Tagen. Um einen Gewöhnungseffekt auszuschließen wurde jedes Tier nur einmal pro Temperatur gemessen. ${ }^{132}$

\subsubsection{Capsaicin-Test}

Der Capsaicin-Test dient der gezielten Stimulation der TRPV1-Kanäle in sensorischen Neuronen. ${ }^{133,134}$ Hierfür wurde dem Versuchstier $20 \mu$ l einer Capsaicin-Lösung (s. Tabelle 3-12) dorsal in die Hinterpfote appliziert. Als Antwort wurde ein Leckverhalten der betroffenen Pfote ausgelöst. Dieses wurde mithilfe einer Stoppuhr über 20 Minuten gemessen. ${ }^{135}$ Vor Beginn des Versuchs wurden die Tiere mindestens eine halbe Stunde an den Versuchsraum und die Umgebung gewöhnt.

\subsubsection{Formalin-Test}

Als tonisches Schmerzmodell wurde der Formalin-Test durchgeführt. ${ }^{136,137}$ Vor Versuchsstart fand auch hier eine mindestens halbstündige Gewöhnungsphase statt. Anschließend wurden $15 \mu l$ einer 0,5\%igen Formaldehyd-Lösung (s. Tabelle 3-12) subkutan in die Dorsalseite der Hinterpfote appliziert und das ausgelöste Leckverhalten über 60 Minuten mit einer Stoppuhr ermittelt. Dieses 
beruht auf der Aktivierung von TRPA1-Kanälen in sensorischen Neuronen und kann in zwei Phasen untergliedert werden. Die erste Phase wird unmittelbar nach der Injektion ausgelöst und dauert etwa zehn bis 15 Minuten an. Ursache ist die direkte Stimulation der Nozizeptoren, insbesondere der A $\delta$-Fasern. Nach einer Ruhepause von fünf bis zehn Minuten wird die zweite Phase eingeleitet, die sich durch ein intensives Lecken kennzeichnet. Sie ist auf einsetzende Entzündungsprozesse in der Peripherie und zentralen Veränderungen im Rückenmark zurückzuführen und wird durch eine anhaltendende Aktivierung der C-Fasern bestimmt. ${ }^{138,139}$

\subsubsection{Zymosan-Test}

Für die Charakterisierung des inflammatorischen Schmerzverhaltens wurde das Modell der Zymosan-induzierten mechanischen Hyperalgesie untersucht. ${ }^{140}$ In diesem Modell wurden $20 \mu l$ einer 5 mg/ml Zymosan-Suspension (s. Tabelle 3-12) in die Plantarseite der Hinterpfote injiziert. Die dadurch ausgelöste Pfotenentzündung führte zu einer Hyperalgesie, welche mithilfe des Dynamic Plantar Aesthesiometers (s. Kapitel 3.2.1.2) quantifiziert wurde. Hierbei wurde die Latenzzeit der Mäuse stündlich über acht Stunden sowie nach 24, 48, 72 und 96 Stunden gemessen. Zusätzlich wurde die Größe des Pfotenödems nach acht Stunden sowie den weiteren Messzeitpunkten durch Einsatz eines Plethysmometers (Ugo Basile, Comerico, Italien) bestimmt. Die Arbeitsweise des Plethysmometers beruht auf das Eintauchen der Pfote in eine Wasserzelle. Das verdängte Wasservolumen wird erfasst und ermöglicht so die Quantifizierung des Pfotenvolumens beziehungsweise des Pfotenödems.

\subsubsection{Die Crush Injury als neuropathisches Modell}

Als neuropathisches Schmerzmodell wurde die Crush Injury durchgeführt. Dabei erfolgte eine stumpfe Quetschung des Ischiasnervs, ohne die Nervenscheiden zu beschädigen. Als Analgetikum wurde den Mäusen vor der Operation subkutan $5 \mathrm{mg} / \mathrm{kg}$ Carprofen (in $\mathrm{NaCl}$ ) verabreicht (s Tabelle 3-11). Anschließend wurden sie unter Isofluran/Carbogen-Gabe anästhesiert. Über einen Hautschnitt und das stumpfe Auseinanderschieben des Muskels wurde der Ischiasnerv freigelegt und über 30 Sekunden mithilfe eines Nadelhalters und unter Kontrolle einer Stoppuhr gequetscht. Schließlich wurden Muskel- und Hautverletzung mit chirurgischen Wundnadeln 
(Sutranox Kalt Nadel) und Wundnahtfaden (Größe 6-0) vernäht. Nach der Operation wurden die Mäuse über einen Zeitraum von 35 Tagen in verschiedenen Schmerzmodellen getestet (Hargreaves und Dynamic Plantar Test). Um den Allgemeinzustand der Tiere zu überprüfen wurden sie in den ersten drei Tagen täglich und anschließend zweimal pro Woche kontrolliert und gewogen. Auffälligkeiten wurden auf einem Beurteilungsbogen vermerkt.

\subsubsection{Gewebeentnahme}

Die Expressionsanalyse der einzelnen Zielproteine erfolgte an Gewebeschnitten. Für die Gewebepräparation wurden die Versuchstiere in $\mathrm{CO}_{2}$ getötet und mittels kardialer Punktion entblutet. Diese erfolgte über eine Perfusion mit isotonischer $\mathrm{NaCl}$-Lösung. Für die Freilegung des Rückenmarks wurde die Wirbelsäule frei präpariert, in Höhe des Zervikalmarks durchtrennt und die kaudalen Wirbelbögen seitlich geteilt. Der lumbale Bereich des Rückenmarks sowie die dazugehörigen Spinalganglien (DRGs L4 bis L6) wurden entnommen und in flüssigem Stickstoff schockgefroren. Für die Entnahme des Gehirns wurde der Schädel seitlich aufgetrennt, das Gehirn im Ganzen entnommen und in flüssigen Stickstoff überführt. Anschließend wurde das Gewebe bis zur weiteren Verwendung bei $-80^{\circ} \mathrm{C}$ gelagert.

Für die Herstellung von Gefrierschnitten wurden die Tiere in $\mathrm{CO}_{2}$ getötet und nach Entbluten zusätzlich in einer 1 bis 4\%igen Paraformaldehyd-(PFA-)Lösung fixiert (s. Tabelle 3-8). Die Gewebepräparation wurde wie oben beschrieben durchgeführt. Anschließend folgte eine 15-minütige Nachfixierung in der gleichen PFA-Konzentration wie sie auch für die Entnahme eingesetzt wurde. Das Gewebe wurde über Nacht bei $4{ }^{\circ} \mathrm{C}$ in einer $30 \%$ igen D-Sucrose-Lösung entwässert (s. Tabelle 3-8). Am darauffolgenden Tag konnte es in Gefriermedium (Tissue-Tek Sakura Finetek U.S.A. Inc.) auf Trockeneis eingebettet und bis zur weiteren Verwendung bei $-80^{\circ} \mathrm{C}$ gelagert werden.

Mithilfe eines Kryostats (Cryostar ${ }^{T M}$, Thermo Fisher Scientific ${ }^{T M}$ ) wurden Gewebeschnitte in 14-16 $\mu \mathrm{m}$ Dicke angefertigt (Objekttemperatur: $-19{ }^{\circ} \mathrm{C}$, Kammertemperatur: $-20{ }^{\circ} \mathrm{C}$ ) und bei RT für zwei Stunden getrocknet. Danach wurden die Schnitte bis zur weiteren Verwendung bei $-80^{\circ} \mathrm{C}$ weggefroren. 


\subsubsection{Molekularbiologische Methoden}

\subsubsection{Quantitative Echtzeit-PCR zur Analyse der RNA-Expression}

\subsection{RNA-Isolierung aus Rückenmark und Cerebellum}

Die Bestätigung des konditionellen Knockouts erfolgte mithilfe der quantitativen Echtzeit-PCR (qPCR). Diese ermöglicht die quantitative Analyse der RNA-Expression der Gene Npr2 und Nppc.

Die RNA-Isolierung aus Rückenmarks- und Cerebellum-Proben erfolgte über eine Phenol-Chloroform-Fällung. ${ }^{141}$ Die Proben wurden in $100 \mu$ l phenolhaltigem Qizaol-Reagenz (QLR, Qiagen oder TRIzol Reagenz, Thermo Fisher) aufgenommen und mit einer Mikropistille auf Eis homogenisiert. Im Anschluss wurde die Suspension mit Lyse-Reagenz auf $200 \mu \mathrm{l}$ aufgefüllt, nochmals homogenisiert und bis zur weiteren Verarbeitung auf Eis gelagert. Die Proben wurden durch Zugabe von QLR (oder TRIzol) auf ein Volumen von $800 \mu \mathrm{l}$ gebracht, in einem Vortexer gemischt und für fünf Minuten bei RT inkubiert. Jede Probe wurde mit $160 \mu \mathrm{l}$ Chloroform versetzt und durch Invertierung gemischt. Nach einer weiteren fünfminütigen Inkubation bei RT wurden die Proben bei $12.000 \mathrm{~g}$ und $4{ }^{\circ} \mathrm{C}$ für 15 Minuten zentrifugiert. Die wässrige Phase, welche die gefällte RNA enthielt, wurde abgenommen und in ein neues Reaktionsgefäß überführt. Danach wurde jede Probe mit $600 \mu l$ 70\%igem Ethanol versetzt und in einem Vortexer gemischt. Für die Isolation wurden die Proben auf eine RNEasy Mini Säule gegeben, für 15 Sekunden bei $8.000 \mathrm{~g}$ zentrifugiert und der Durchfluss verworfen.

Um einer Kontamination durch genomische DNA entgegenzuwirken, wurde ein DNase-Verdau mithilfe des DNASE-I Kit (Qiagen) durchgeführt. Hierfür wurden die Säulen mit $350 \mu$ I RW1 Puffer versetzt und bei $8.000 \mathrm{~g}$ über 15 Sekunden zentrifugiert. Der Durchfluss wurde verworfen und die Säulen für den DNase-Verdau mit einem Ansatz von $10 \mathrm{ml}$ DNase-I-Stammlösung und $70 \mathrm{ml}$ RDDPuffer versetzt. Nach einer Inkubationszeit von 15 Minuten bei RT wurden die Säulen mit $350 \mu l$ RW1 Puffer gewaschen und für 15 Sekunden bei 8.000 g zentrifugiert. Der Durchfluss wurde verworfen und jede Säule mit $500 \mu \mathrm{l}$ RPE-Puffer gewaschen. Anschließend wurden die Säulen erneut für 15 Sekunden bei $8.000 \mathrm{~g}$ zentrifugiert und nochmals mit RPE-Puffer versetzt. Die Zentrifugation erfolgte über zwei Minuten bei 13.000 g. Für das vollständige Entfernen des RPE- 
Puffes wurden die Säulen in ein neues Reaktionsgefäß überführt und für eine Minute bei $20.000 \mathrm{~g}$ zentrifugiert.

Die RNA-Elution erfolgte in einem neuen Reaktionsgefäß. Hierfür wurden $30 \mu \mathrm{l}$ steriles, RNase und DNase freies Wasser auf die Säulen pipettiert und diese bei $8.000 \mathrm{~g}$ zentrifugiert. Um eine höhere RNA-Konzentration zu gewinnen, wurde dieser Schritt mit dem Eluat wiederholt. Anschließend wurden die Proben bei $-20^{\circ} \mathrm{C}$ bis zur weiteren Verwendung weggefroren.

\subsection{RNA-Isolierung aus DRG-Neuronen}

Für die RNA-Isolierung aus DRG-Neuronen wurde das InnuPREP Micro RNA Kit (Analytik Jena AG) verwendet. Hierfür wurden in einem Reaktionsgefäß maximal 20 mg des Gewebes mit $100 \mu \mathrm{l}$ Lysepuffer RL versetzt und auf Eis mit einem Potter zerkleinert. Im Anschluss wurde die Suspension mit Lysepuffer RL auf $450 \mu$ l aufgefüllt und bei $20.627 \mathrm{~g}$ für eine Minute zentrifugiert. Währenddessen wurde pro Probe ein Spin Filter D auf ein neues Reaktionsgefäß gesetzt, auf den der Überstand überführt wurde. Die Proben wurden bei $10.000 \mathrm{~g}$ erneut zentrifugiert und der Filter verworfen. Das Eluat wurde in einem 1:1-Verhältnis (ca. $400 \mu \mathrm{l}$ ) mit SRB-Lösung versetzt. Ein Spin Filter R wurde auf ein frisches Reaktionsgefäß gesetzt und das Filtrat hinzugegeben. Nach zweiminütigem Zentrifugieren bei $10.000 \mathrm{~g}$ wurde der Durchfluss verworfen und $500 \mu \mathrm{HS}$ Lösung auf den Spin Filter R pipettiert. Die Proben wurden wiederholt für eine Minute bei $10.000 \mathrm{~g}$ zentrifugiert. Der Durchfluss wurde verworfen, $750 \mu \mathrm{l}$ einer LS-Lösung auf den Spin Filter R gegeben und für eine Minute bei $10.000 \mathrm{~g}$ zentrifugiert. Der Durchfluss wurde erneut verworfen und die Proben zur vollständigen Entfernung der Lösung bei $20.627 \mathrm{~g}$ für drei Minuten zentrifugiert. Für die Elution wurde der Spin Filter R auf ein neues Reaktionsgefäß gesetzt und mit $30 \mu \mathrm{l}$ destilliertem, RNase- und DNase-freiem Wasser versetzt. Nach einer Inkubationszeit von einer Minute bei RT wurden die Proben bei $6.000 \mathrm{~g}$ zentrifugiert, der Spin Filter R verworfen und das Eluat bis zur weiteren Verwendung bei $-20^{\circ} \mathrm{C}$ weggefroren. 


\subsection{Bestimmung der RNA-Konzentration}

Die RNA-Konzentration wurde mithilfe eines UV-Vis-Spektralphotometers (NanoDrop ${ }^{\mathrm{TM}}$ 2000, Thermo Fisher Scientific) ermittelt. Hierfür wurde $1 \mu$ l des RNA-Konzentrats auf den Messplatz pipettiert und photometrisch bei einer Wellenlänge von I = $260 \mathrm{~nm}$ gemessen. Durch die Bestimmung der Verhältnisse $A_{260 / 280}$ und $A_{260 / 230}$ wurde die Reinheit der Proben ermittelt. Hierbei sollten die Werte für $A_{260 / 280}$ für RNA bei ca. 2,0 liegen (für DNA bei ca. 1,8).

\subsubsection{4 cDNA-Synthese}

Die komplementäre DNA-(cDNA-)Synthese erfolgte durch Verwendung des First Strand cDNA Synthesis Kits (Thermo Fisher). Hierfür wurden 200 ng RNA auf eine Microtiterplatte vorgelegt und anschließend ein Mastermix, der mit entsprechenden Primern, dNTPs sowie einer reversen Transkriptase angesetzt wurde, hinzugefügt. Mit Nuklease-freiem Wasser wurde der Ansatz auf ein Endvolumen von $20 \mu \mathrm{l}$ aufgefüllt.

$\begin{array}{lll}\text { Mastermix zur Herstellung der cDNA: } & 1 \mu \mathrm{l} & \text { Random Hexamer Primer } \\ 4 \mu \mathrm{l} & 5 x \text { Reacton Buffer } \\ 1 \mu \mathrm{l} & \text { RiboLock RNase Inhibitor } \\ 2 \mu \mathrm{l} & 10 \mathrm{nM} \text { dNTP Mix } \\ 2 \mu \mathrm{l} & \text { M-MulV-Reverse Transkriptase }\end{array}$

Anschließend wurden die Proben in einem PCR-Cycler über fünf Minuten bei $25^{\circ} \mathrm{C}$ inkubiert und für 60 min auf $37^{\circ} \mathrm{C}$ erwärmt. Im letzten Schritt wurde die Platte zur Inaktivierung der reversen Transkriptase über fünf Minuten auf $70^{\circ} \mathrm{C}$ erhitzt.

\subsubsection{2 qPCR und quantitative Auswertung}

Für die qPCR wurden Primer entworfen, die innerhalb des nachzuweisenden Genabschnitts binden konnten. Die entsprechende mRNA-Sequenz wurde über die Plattform NCBI ermittelt und anschließend mithilfe des Online-Tools Prime3Plus moduliert. Als endogene Kontrolle wurde zusätzlich die Expression von GAPDH bestimmt. Die verwendeten Primerpaare sind Tabelle 3-15 zu entnehmen. 
Tabelle 3-15: Verwendete Primer für die qPCR

\begin{tabular}{ll}
\hline Nachgewiesene RNA & Primersequenz \\
\hline \multirow{2}{*}{ Npr1 } & Fwd 5'-gca ctc gag gct gac cta ct-3' \\
& Rev 5'-gtg tca ttg ctg gca cag g-3' \\
Npr2 & Fwd 5'-ctg tct ctt cct tcc gca tc-3' \\
& Rev 5'-ctt tag agc ttg gcc att cg-3' \\
Nprc & Fwd 5'-tccttgcaaatcatcaggtg-3' \\
& Rev 5'-tggaatcttctcgcagctct-3' \\
Gapdh & Fwd 5'-caa tgt gtc cgt cgt gga tct -3' \\
& Rev 5'-gtc ctc agt gta gcc caa gat g-3' \\
\hline
\end{tabular}

Unter Verwendung des iTaq Universal SYBR Green Supermix wurde anschließend die qPCR durchgeführt. Dabei wurden alle Proben in einer Doppelbestimmung gemessen. Um zu gewährleisten, dass keine Verunreinigungen durch genomische DNA die Ergebnisse beeinflussten, wurde in jedem qPCR-Ansatz eine Kontrolle ohne reverse Transkriptase sowie eine Kontrolle ohne Template mitgeführt und das fehlende Volumen mit Wasser aufgefüllt.

Mastermix zur Durchführung der qPCR: $1 \mu \mathrm{l}$ cDNA ( $\triangleq 10 \mathrm{ng}$ der Ausgangs-RNA)

$5 \mu$ iTAq-Master Mix (x2)

$2 \mu \mathrm{l}$ Primer forward $(5 \mu \mathrm{M})$

$2 \mu$ Primer reverse $(5 \mu \mathrm{M})$

Die PCR wurde in einem CFX-Cycler (Biorad) unter Verwendung des folgenden Programms durchgeführt.

PCR-Programm für die qPCR: $\quad 2 \mathrm{~min} \quad 50^{\circ} \mathrm{C}$

$10 \min \quad 95^{\circ} \mathrm{C}$

$\left.\begin{array}{ll}25 \mathrm{~s} & 95^{\circ} \mathrm{C} \\ 1 \mathrm{~min} & 60^{\circ} \mathrm{C}\end{array}\right\}^{40 \mathrm{x}}$

Durch die Bindung des Cyanin-Farbstoffs SYBR-Green an doppelsträngige DNA wurde ein DNA-Fluoreszenzfarbstoff-Komplex erzeugt, welcher photometrisch erfasst werden konnte. ${ }^{142}$ 


\subsubsection{Quantifizierung der relativen mRNA-Expression}

Die Quantifizierung der relativen mRNA-Expression erfolgte mithilfe der $2^{-\Delta \Delta C T}$-Methode. Hierfür wurden die cycle threshold-( $\left.\mathrm{C}_{\mathrm{T}^{-}}\right)$Werte, bei denen sich die DNA-Amplifikation in der exponentiellen Phase befand, verwendet. Die $\mathrm{C}_{\mathrm{T}}$-Werte spiegeln den Zeitpunkt der PCR wider, an dem das Fluoreszenzsignal signifikant über dem Hintergrundsignal ansteigt und den sogenannten Schwellenwert definiert. Dieser wurde für jedes Experiment festgelegt (s. Abbildung 6). Anschließend konnten die ermittelten $\mathrm{C}_{\mathrm{T}}$-Werte quantifiziert werden.

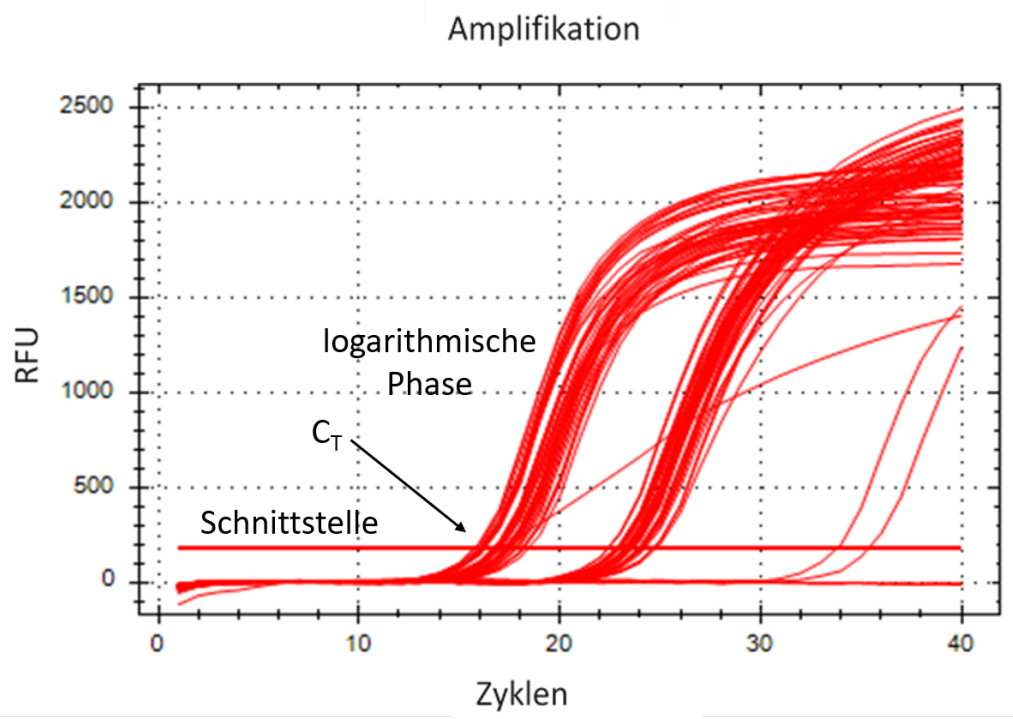

Abbildung 6: Quantifizierung der qPCR am Beispiel der Werte für Npr2. Die Schnittpunkte der Fluoreszenzsignale an der horizontalen Schnittlinie stellen den $\mathrm{C}_{\mathrm{T}}$-Wert dar, der zur Berechnung der relativen RNA-Menge eingesetzt wird.

Die Berechnung der RNA-Expression erfolgte durch Bildung des $\mathrm{C}_{\mathrm{T}}$-Mittelwertes der Doppelbestimmung, welcher auf den $\mathrm{C}_{\mathrm{T}}$-Wert der endogenen Kontrolle normalisiert wurde:

$$
C_{T}(\text { Zielgen })-C_{T}(\text { endogene Kontrolle })=\Delta C_{T}
$$

Aus den daraus resultierenden Werten für $\Delta \mathrm{C}_{\mathrm{T}}$ wurde die Differenz der Proben der genetisch veränderten Tiere sowie der Proben der zugehörigen Kontrolltiere gebildet, die als Kalibrator dienten:

$$
\Delta \mathrm{C}_{\mathrm{T}} \text { Probe }-\Delta \mathrm{C}_{\mathrm{T}} \text { Kalibrator }=\Delta \Delta \mathrm{C}_{\mathrm{T}}
$$


Die relative Expressionsstärke konnte näherungsweise über die mathematische Formel für $2^{-\triangle \Delta C T}$ berechnet werden. Hierbei wird allgemein angenommen, dass während der logarithmischen Phase der PCR Folgendes gilt:

$$
X_{n}=X_{0} * E^{n}
$$

(mit: $\mathrm{X}_{\mathrm{n}}=$ DNA-Gehalt in Zyklus $\mathrm{n} ; \mathrm{X}_{0}=$ DNA-Ausgangsmenge; $\mathrm{E}=$ Effizienz der PCR; $\mathrm{n}=$ Zykluszahl)

An den Schnittpunkten zweier Fluoreszenzsignale mit horizontaler Linie gilt:

$$
X_{n(1)}=X_{n(2)}
$$

Für den Vergleich der Signale einer Probe (Gewebe eines behandelten Tieres bzw. genetisch veränderten Tieres) und einer Kontrollprobe (Gewebe eines unbehandelten Tieres bzw. entsprechendens Kontrolltieres) gilt demnach für die Schnittpunkte:

$$
\begin{gathered}
X_{n(\text { Probe })}=X_{n(\text { Kontrolle })} \\
X_{0 \text { (Probe) }} * E^{n(\text { Probe })}=X_{0(\text { Kontrolle })} * E^{n(\text { Kontrolle })} \\
\rightarrow X_{n \text { (Probe) }} / X_{n(\text { Kontrolle })}=E^{n(\text { Kontrolle })} / E^{n(\text { Probe })}=E^{n(\text { Kontrolle })-n(\text { Probe })}
\end{gathered}
$$

Die relative DNA-Ausgangsmenge des Zielgens Z (zum Beispiel Npr2) im Vergleich zu einem Referenzgen R (GAPDH) kann mittels der Zykluszahl $n$ am Schnittpunkt mit der horizontalen Linie wie folgt berechnet werden:

$$
\begin{aligned}
& \mathrm{Z} / \mathrm{R}=\left(\mathrm{X}_{\mathrm{OZ}(\text { Probe) }} / \mathrm{X}_{\mathrm{OZ}(\text { Kontrolle })}\right) /\left(\mathrm{X}_{\mathrm{OR}(\text { Probe) }} / \mathrm{X}_{\mathrm{OR} \text { (Kontrolle })}\right) \\
& \rightarrow Z / R=E_{Z}^{n(\text { Kontrolle }) Z-n(\text { Probe }) Z} / E_{R}{ }^{n(\text { Kontrolle }) R-n(\text { Probe }) R}
\end{aligned}
$$

Setzt man die Effizienz E = 2 (für eine maximale Effizienz), gilt:

$$
Z / R=2^{\text {(n(Kontrolle)Z-n(Probe)Z) }-(n(\text { Kontrolle)R-n(Probe) R) }}
$$

Durch das Einsetzen der $\mathrm{C}_{\mathrm{T}}$-Werte in die hergeleitete Formel, erhält man:

$$
Z / R=2^{-\Delta \Delta C T} .
$$


Diese kann somit zur Berechnung der $\mathrm{n}$-fachen Expression des Zielgens bezogen auf das Referenzgen verwendet werden.

\subsubsection{In-situ-Hybridisierung}

Um die RNA-Expression verschiedener Zielproteine auf fixiertem Gewebe nachzuweisen, wurde die In-situ-Hybridisierung mit Hilfe des ViewRNA ${ }^{T M}$ Tissue Assay Kits (2-plex) (Thermo Fisher) durchgeführt. Der Versuch erfolgte nach Anleitung des Herstellers, wobei die Mengenangaben leicht angepasst wurden. Zur Verminderung einer endogenen Alkalischen Phosphatase-Reaktion, die in fast allen Geweben exprimiert wird und zu einer Ergebnisverfälschung führen könnte, wurden alle verwendeten Lösungen mit autoklaviertem 0,1\%igem DEPC-Millipore-Wasser angesetzt. Für die In-situ-Hybridisierung wurde Gewebe verwendet, welches zuvor in 2-4\%igem PFA postfixiert wurde (siehe Kapitel 3.2.1.12).

Zunächst wurden die Gefrierschnitte über Nacht bei $4{ }^{\circ} \mathrm{C}$ in $4 \%$ igem PFA nachfixiert. Anschließend wurden die Schnitte zweimal in PBS gewaschen und mit einer aufsteigenden Ethanol-Reihe (50\%, $70 \%$ und $100 \%$ ) für jeweils zehn Minuten und darauffolgend unter 30-minütigem Erhitzen bei $60{ }^{\circ} \mathrm{C}$ in einem Hybridisierungsofen (ThermoBrite ${ }^{\circledR}$ ) dehydriert. Zur Permeabilisierung wurde jeder Schnitt mit $100 \mu \mathrm{l}$ einer Protease-Lösung behandelt und über 25 Minuten bei $40{ }^{\circ} \mathrm{C}$ inkubiert. Danach wurden die Schnitte zweimal vorsichtig in 1xPBS gewaschen und erneut für fünf Minuten in 4\%igem PFA fixiert. Nachdem sie zweimal in 1xPBS gewaschen wurden, konnten sie über Nacht mit den entsprechenden Primär-Sonden bei $40{ }^{\circ} \mathrm{C}$ inkubiert werden. Diese enthielten entsprechende Oligonukleotide, die an die nachzuweisende mRNA-Sequenz binden konnten. Hierfür wurde ein Mix aus $5 \mu$ l Sonde und $195 \mu$ l Probe Set Diluent QT (vorgewärmt auf $40^{\circ} \mathrm{C}$ ) hergestellt. Um die Colokalisierung verschiedener mRNAs zu ermöglichen, wurden Typ1- und Typ6 -markierte Sonden eingesetzt, die zwei kompatible Signale erzeugten. Um nichtgebundene Sonden zu entfernen, wurden die Schnitte am nächsten Tag dreimal stark in Waschpuffer gewaschen und für eine Signalverstärkung mit $200 \mu$ l eines Pre-Amplifiers über 25 Minuten bei $40{ }^{\circ} \mathrm{C}$ inkubiert. Nachdem die Proben dreimal durch starkes Schütteln in Waschpuffer gewaschen worden waren, wurden sie über 15 Minuten mit $200 \mu$ l eines Amplifiers inkubiert. Dabei wurden verzweigte DNA-Stränge (bDNA) an die hybridisierten Sonden gebunden und das Signal erhöht. 
Überschüssige Lösungen wurden durch dreimaliges Waschen in Waschpuffer entfernt. Anschließend erfolgte die Hybridisierung mit Typ1- beziehungsweise Typ6-spezifischen Oligonukleotiden, die mit einer Alkalische Phosphatase konjugiert waren. Diese konnten an komplementäre Sequenzen des Amplifiers binden. Die Signalentwicklung erfolgte über den Einsatz eines Fast-red-Substrates, für Typ1 markierte Sonden, und eines Blue-Substrates, für Typ6 markierte Sonden, welche von der Alkalischen Phosphatase erkannt und in ein chromogenes und fluoreszierendes Signal umgewandelt wurden. Gestoppt wurden die Reaktionen durch die Gabe von $100 \mu \mathrm{l}$ AP-Stop-QT (Typ6) sowie $100 \mu \mathrm{l}$ Enhancer-Solution (Typ1). Überschüssige Lösung wurde durch zweimaliges starkes Waschen in 1xPBS entfernt.

Um die Signale einer Zelle oder einem bestimmten Zelltyp zuordnen zu können, wurden anschließend teilweise eine DAPI (4',6-Diamidin-2-phenylindol)-Kernfärbung sowie eine Immunfluoreszenzfärbung mit spezifischen Antikörpern durchgeführt (s. Kapitel 3.2.2.5).

Für das Eindeckeln der gefärbten Schnitte wurde Fluoromount-G eingesetzt.

Im Anschluss wurde die typspezifische Farbreaktion licht- sowie fluoreszenzmikroskopisch erfasst. So konnte das mRNA-Signal über eine Farbkamera als rot (Typ1 markierte Sonden) oder blau (Typ6 markierte Sonden) beziehungsweise über das Fluoreszenzmikroskop im Cy3 (Typ1) oder Cy5 (Typ6) detektiert werden. Die eingesetzten Sonden (Thermo Fisher) sind Tabelle 3-6 (Materialien und Methodenteil) zu entnehmen.

\subsubsection{Immunfluoreszenzfärbung an Gewebeschnitten}

Für die Analyse und Lokalisierung der Proteine in den zu untersuchenden Geweben wurden Immunfluoreszenfärbungen an Gefrierschnitten durchgeführt. Hierfür wurden Gefrierschnitte mit Roti ${ }^{\circledR}$-Liquid Barrier Marker (Roth) umrandet. Anschließend wurde das überschüssige Gefriermedium durch dreimaliges Waschen mit 1xPBS entfernt. Um das Gewebe für die Immunreaktion zugänglich zu machen, wurde die Zellmembran mit einer PBS-Triton-X-100-Lösung (0,1\%ig) permeabilisiert. Das Absättigen unspezifischer Proteinbindungen erfolgte über eine Stunde mithilfe eines Blockierungspuffers (3\% BSA, $10 \%$ 
NGS in 1xPBS). Die Primärantikörper wurden entsprechend ihres Einsatzes in einer 3\%igen BSA-Lösung (in PBS) verdünnt (s. Tabelle 3-16) und das Gewebe über Nacht bei $4{ }^{\circ} \mathrm{C}$ inkubiert.

Am darauffolgenden Tag wurden die Schnitte dreimal in 1xPBS gewaschen, um überschüssige Primärantikörperlösung zu entfernen. Anschließend wurden die jeweiligen Sekundärantikörper in einer 1:2000 Verdünnung (in 1xPBS) über zwei Stunden bei RT inkubiert. Die nicht gebundene Sekundärantikörperlösung wurde durch dreimaliges Waschen (in 1xPBS) entfernt. Die Kernfärbung wurde mit DAPI durchgeführt. Hierfür wurden die Schnitte mit einer $300 \mathrm{nM}$ DAPI-Lösung (in 1xPBS) für drei Minuten inkubiert. Nach dreimaligem Waschen mit 1xPBS wurden die Schnitte über fünf Minuten mit einer 0,06\%igen Sudanschwarzlösung (in 70\%igem Ethanol) inkubiert. Ziel dieser Behandlung war es die Lipofuszin-Eigenfluoreszenz des Gewebeszu reduzieren. ${ }^{143}$ Einige der Schnitte wurden mit dem AF488-gekoppelten Griffonia simplicifolia Isolectin B4 (IB4) gefärbt. Die Inkubation von IB4 erfolgte nach Einsatz der Sekundärantikörper für zwei Stunden bei RT. Nachdem die Schnitte erneut dreimal in 1xPBS gewaschen wurden, konnten sie eingedeckelt und mithilfe von Fluoromount-G haltbar gemacht werden. Die Scnitte wurden bei $4{ }^{\circ} \mathrm{C}$ gelagert.

Tabelle 3-16: Antikörpernachweis und Einsatz

\begin{tabular}{|c|c|c|c|c|}
\hline Antikörper & Wirt & Nachweis & Verdünnung & Firma \\
\hline $\begin{array}{l}\text { NF200 } \\
\text { (Neurofilament) }\end{array}$ & Hase & $A \beta$-Fasern & $1: 2000$ & Sigma \\
\hline Periferin & Maus (IgG1) & A $\delta$ - und C-Fasern & $1: 800$ & Chemicon \\
\hline $\begin{array}{l}\text { IB4- Alexa Fluor } \\
\text { gelabelt (AF488) }\end{array}$ & $\begin{array}{l}\text { Griffonia } \\
\text { Simplicifolia }\end{array}$ & $\begin{array}{l}\text { Nicht peptiderge } \\
\text { Neurone }\end{array}$ & $1: 300$ & $\begin{array}{l}\text { Invitrogen/Molecular } \\
\text { Probes }\end{array}$ \\
\hline$\beta$-Galactosidase & Huhn & $\begin{array}{l}\text { CNP- sowie NPR2 } \\
\text { exprimierende Zellen }\end{array}$ & $1: 5000$ & abcam \\
\hline CGRP & Maus (IgG1) & Peptiderge Neurone & 1:1000 & Sigma \\
\hline Substanz P & $\begin{array}{l}\text { Ratte } \\
\text { (IgG2a) }\end{array}$ & Peptiderge Neurone & $1: 200$ & $B D$ \\
\hline STMN2 & Hase & Pan-Neurone & $1: 1000$ & ProteinTech \\
\hline
\end{tabular}




\subsubsection{6 x-Gal-Färbung}

Für die Lokalisierung der CNP- und NPR2-Experssion wurde die x-Gal-Färbung verwendet. Hierbei handelt es sich um eine histochemische Methode, die die Detektion einer ReporterGenexpression ermöglicht. ${ }^{144}$ Sie basiert auf die Insertion einer LacZ-Expressionskassette in ein Allel des zu untersuchenden Gens (Npr2 bzw. Nppc). Bei LacZ handelt es sich um ein aus Bakterien stammendes Gen, welches das Enzym $\beta$-Galactosidase ( $\beta$-gal) codiert. Dieses ist in der Lage das Substrat 5-Brom-4-chlor-3-indolyl- $\beta$-D-galactopyranisid (x-Gal) zu Galactose und 5-Brom-4-chlor3-hydroxyindol zu hydrolysieren. Durch Sauerstoffoxidation wird 5-Brom-4-chlor-3-hydroxyindol in den dunkelblauen Farbstoff 5,5'-Dibrom-4,4'-dichlor-indigo umgewandelt, welcher für den Nachweis der Reporter-Genexpression Lichtmikroskopisch erfasst wird. ${ }^{145}$

Für die x-Gal Färbung wurden $14 \mu \mathrm{m}$ dicke Gefrierschnitte von Npr2 ${ }^{+/ L a c z}$ - sowie von $\mathrm{CNP}^{+/ L a c Z}$-Mäusen angefertigt. Dabei wurde Gewebe von DRG-Neuronen und Rückenmark angefärbt. x-Gal-Färbungen an Rückenmarksgewebeschnitten von $\mathrm{Npr}^{+/ \text {LacZ }}$-Mäusen wurden von Oliver Drees (Universität Witten/Herdecke) bereitgestellt. Vor der eigentlichen Farbreaktion wurden die Schnitte für zehn Minuten bei RT in Färbepuffer gewaschen (s. Tabelle 3-8). Für die Färbung wurde der Färbepuffer mit $1 \mathrm{mg} / \mathrm{ml}$ x-Gal (Sigma Aldrich) und $5 \mathrm{mM}$ Kaliumferricyanid $\left(\mathrm{K}_{3}\left[\mathrm{Fe}(\mathrm{CN})_{6}\right]\right)$ (Sigma Aldrich) sowie $5 \mathrm{mM}$ Kaliumferrocyanid $\left(\mathrm{K}_{4}\left[\mathrm{Fe}(\mathrm{CN})_{6}\right]\right)$ (Sigma Aldrich) versetzt. Zur Entwicklung der Farbreaktion wurden die Schnitte über Nacht bei $37^{\circ} \mathrm{C}$ inkubiert. Anschließend wurden sie dreimal in 1xPBS gewaschen und unter Verwendung von Fluoromount-G eingedeckelt. Die Aufnahmen erfolgten mit einer Farbkamera.

\subsubsection{Software, graphische Auswertung und Statistik}

Die Aufnahmen mit dem Nikon-Mikroskop wurden über die Nikon-Software NIS-Elements erfasst. Die graphische Bearbeitung und Quantifizierung erfolgte über Adobe Photoshop CS und ImageJ. Für die Aufnahme der Gelelektrophoresen der Genotypisierung wurde die Software Image Lab von BioRad ${ }^{\circledR}$ verwendet. Die Ergebnisse der qPCR wurden mit dem CFX-Manager ${ }^{T M}$ ausgewertet und konvertiert. Die anschließende Datenanalyse wurde nachfolgend mit Microsoft ${ }^{\circledR}(M S)$ Excel $^{\circledR}$ 
2016 durchgeführt. Quantifizierungs- sowie Verhaltensexperimente wurde mit den Programmen MS ${ }^{\circledR}$ Exce $^{\circledR} 2016$ sowie SPSS Statistik 26 für Windows und GraphPad Prism analysiert.

Zur Auswertung der Verhaltenstests wurde die Normalverteilung der Daten mithilfe des Kolmogorov-Smirnov-Tests überprüft. Für die Bestimmung einer statistischen Signifikanz wurde je nach Methode der Student's t-test oder im Falle einer Zeitabhängigkeit die einfaktorielle Varianzanalyse (ANOVA) mit anschließendem adjustiertem Bonferroni-Post-Hoc Test durchgeführt. Bei einer asymptotischen Signifikanz im Kolmogorov-Smirnov-Test wurde der Mann-Whitney-U-Test durchgeführt. Daten mit Messwiederholungen wurden mit einer Repeated-Measurement-ANOVA auf statistische Signifikanz geprüft.

Zur Analyse der Daten des Rota-Rod Tests wurde der Mann-Whitney-U-Test genutzt. Die Daten sind als Median mit Interquartilsabstand dargestellt. Die jeweiligen Signifikanzen wurden mit dem p-Wert angegeben

Tabelle 3-17: p-Werte

\begin{tabular}{lll}
\hline $\mathbf{p}$-Wert & Kennzeichnung & Signifikanzniveau \\
\hline $\mathrm{p}<0,05$ & $*$ & Leicht signifikant \\
$\mathrm{p}<0,01$ & $* *$ & Signifikant \\
$\mathrm{p}<0,001$ & $* * *$ & Hoch signifikant \\
\hline
\end{tabular}




\section{$4 \quad$ ERGEBNISSE}

\subsection{Expressionsanalysen von CNP und NPR2}

Ziel der vorliegenden Arbeit war es, die Funktion von NPR2 und CNP in der Schmerzverarbeitung zu untersuchen und mögliche Downstream-Targets zu charakterisieren. Daher wurden anfangs die Expressionsmuster von CNP, NPR2, cGKI und CRP4 in den schmerzrelevanten Geweben, Rückenmark und DRGs, analysiert.

\subsubsection{Verteilung von CNP in Spinalganglien und Rückenmark}

Die Expression von CNP in Spinalganglien und Rückenmark wurde zunächst mithilfe von x-Gal-Färbungen an Gewebeschnitten von CNP+/Lacz-Mäusen untersucht. Diese zeigten, dass CNP nicht in DRGs, dafür jedoch in der grauen Substanz des Rückenmarks mit Anreicherung im Dorsalhorn gebildet wird (s. Abbildung 7 Ai und Aii).

Um die Daten zu verifizieren wurden zusätzlich In-situ-Hybridisierungen mit spezifischen CNP-Sonden angefertigt. Hierfür wurden DRG- und Rückenmarksschnitte von C57/BL6-Mäusen (im weiteren Verlauf als WT bezeichnet) verwendet. Sie wiesen ein ähnliches Expressionsmuster auf wie die Analyse der x-Gal-Färbung und konnten somit die Ergebnisse bestätigen (s. Abbildung 7 Bi und Bii). 
Ai)

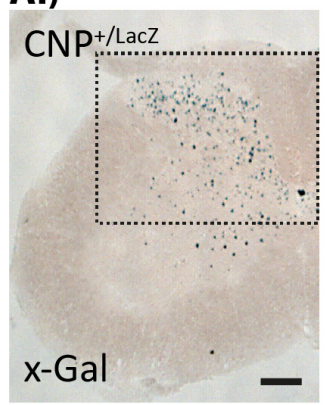

Bi)

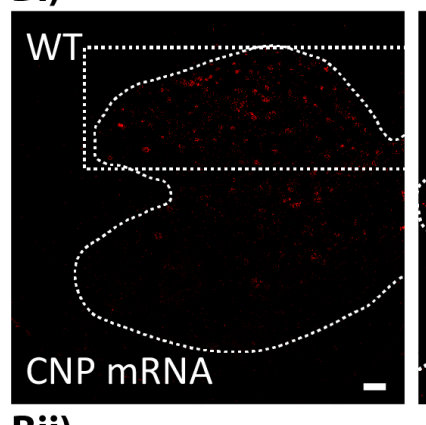

\section{Bii)}

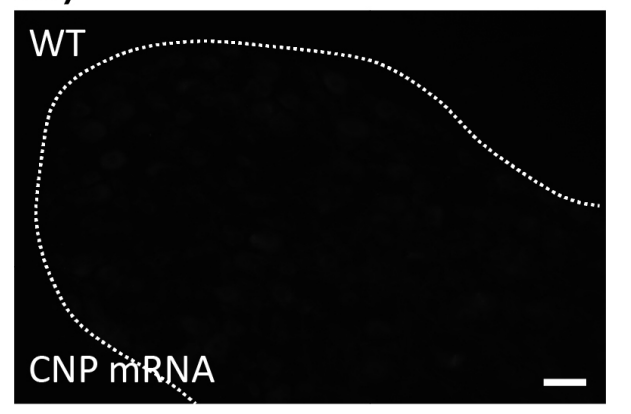

Aii)

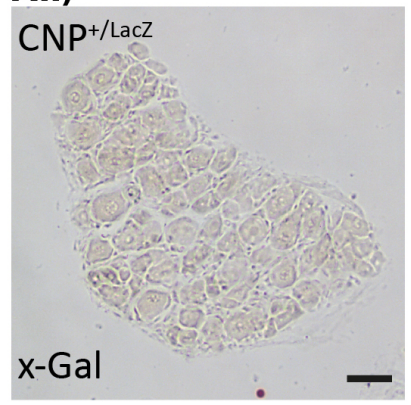

X-Gal
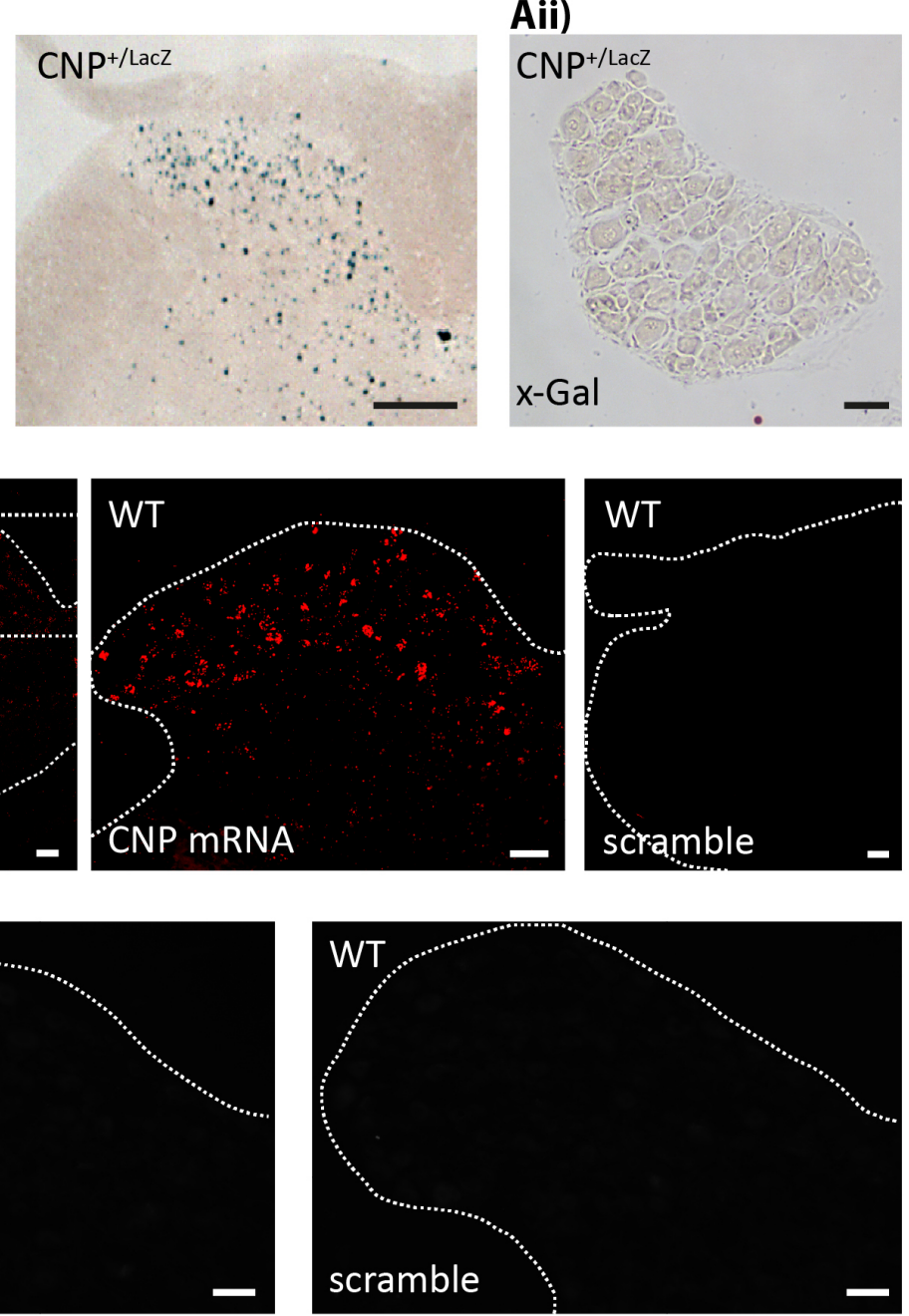

Abbildung 7: Expressionsanalysen für CNP A) x-Gal Färbung für CNP (blau) auf Gewebe von Ai) Rückenmark und Aii) DRGs B) In-situ-Hybridisierung für CNP (rot) auf Bi) Rückenmarksgewebe und Bi) DRGs mit entsprechenden scrambleKontrollen; Maßstab $50 \mu \mathrm{m}$. 
Zur Überprüfung, ob CNP im Rückenmark neuronal oder über das Gefäßendothel gebildet wird, wurde eine Immunfluoreszenzfärbung an $\mathrm{CNP}^{+/ L a c z}$-Gewebe mit Antikörpern gegen $\beta$-Gal (zur Detektion der CNP-Expression) und dem pan-neuronalen Marker NeuN durchgeführt. Hierbei zeigte sich, dass ein Großteil der Neurone CNP exprimierten (s. Abbildung 8).
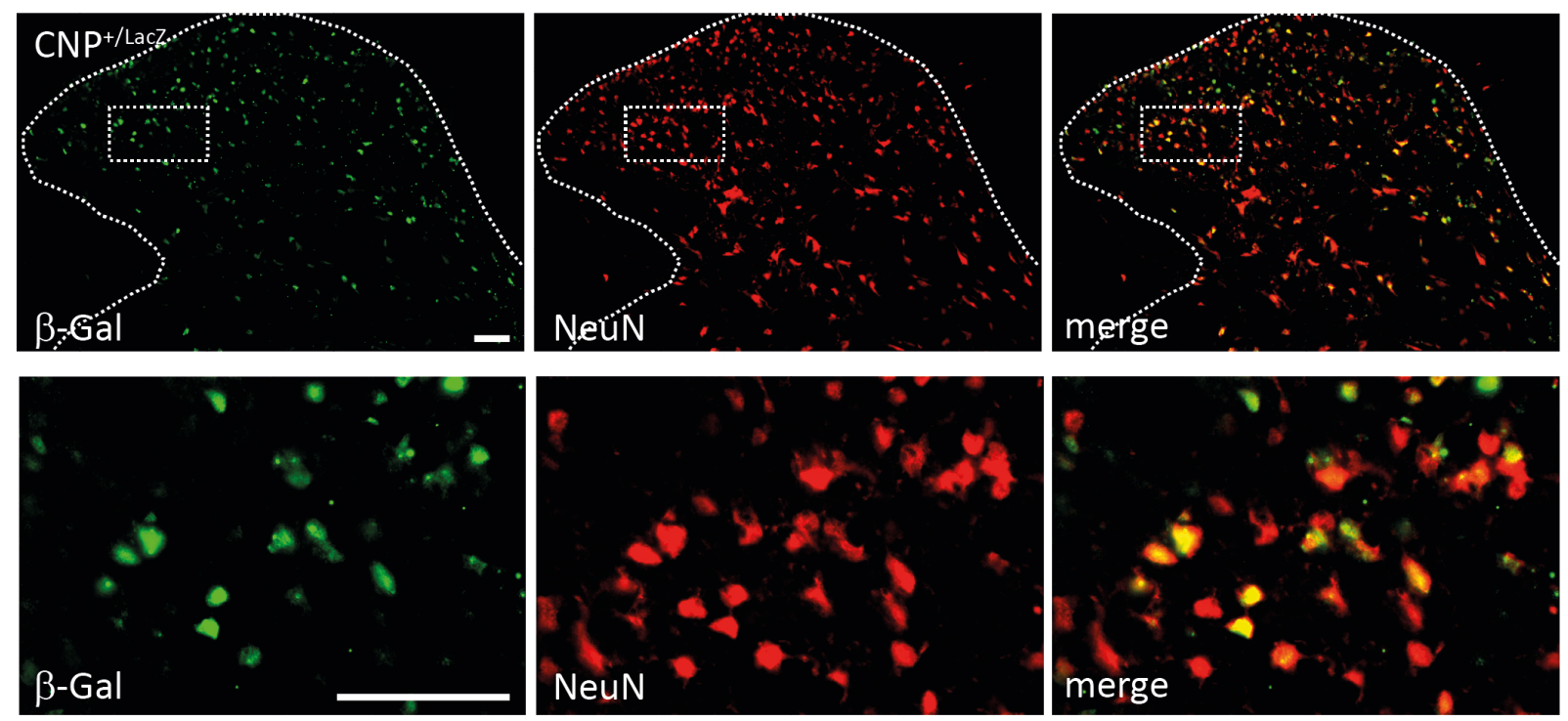

Abbildung 8: Expressionsanalysen für CNP mit Immunfluoreszenzfärbungen für $\beta$-Gal (grün) und NeuN (rot) auf Rückenmarksgewebe von CNP ${ }^{+/ L a c Z}$-Mäusen; Maßstab $50 \mu \mathrm{m}$.

Um festzustellen in welchem neuronalen Subtypen CNP vermehrt gebildet wird, wurde im Anschluss eine kombinierte In-situ-Hybridisierung an Rückenmarksschnitten von C57/BL6-Mäusen durchgeführt. Hierfür wurden Sonden für VGAT, als Marker für inhibitorische Neuronen sowie VGLUT2, als Marker für exzitatorische Neuronen, verwendet. Wie in Abbildung 9 zu erkennen ist, wird CNP sowohl in VGAT-positiven als auch VGLUT2-positiven Neuronen exprimiert (s. Abbildung 9 A und B). Die quantitative Analyse ergab, dass CNP in $24 \%$ aller VGAT sowie in $20 \%$ aller VGLUT2 positiven Neurone vorliegt (s. Abbildung 9 C). Somit wird CNP sowohl von inhibitorischen als auch exzitatorischen Neuronen exprimiert. 

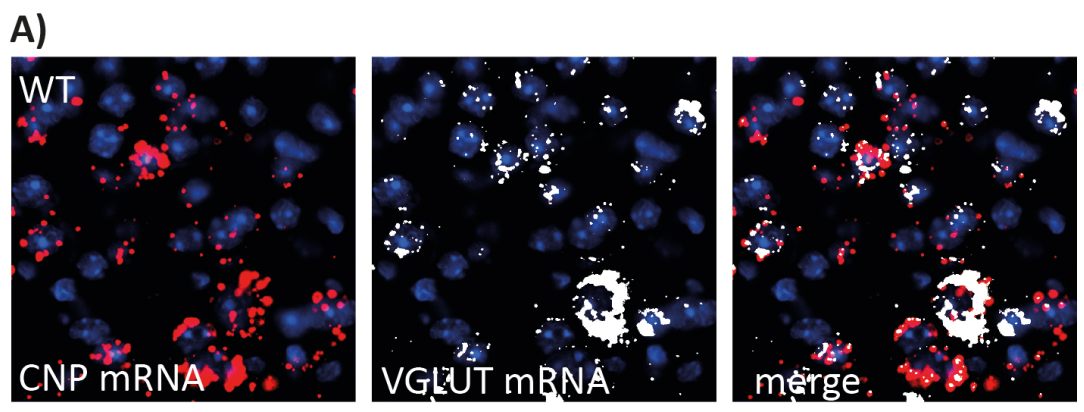

B)
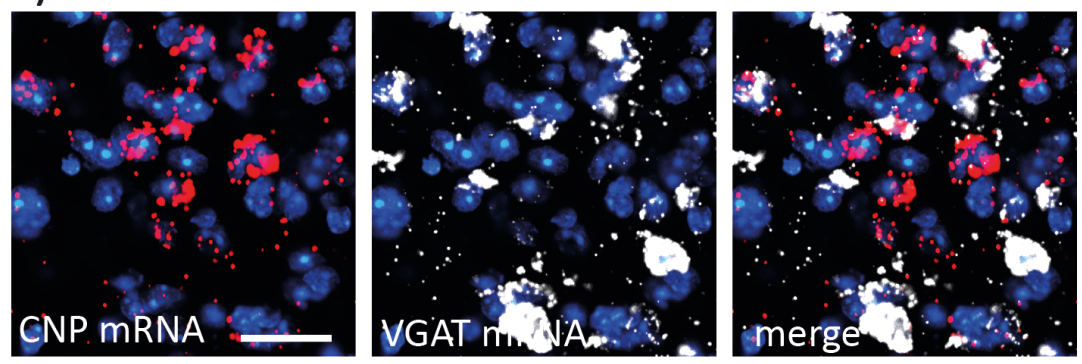

C)

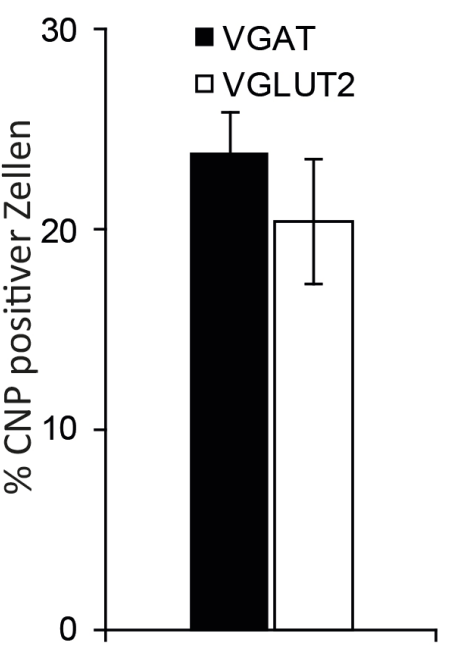

Abbildung 9: Coexpression im Rückenmark von: A) CNP (rot) und VGLUT (weiß) und B) CNP (rot) und VGAT (weiß); mit DAPI (blau) als Kernfärbung; Maßstab $50 \mu \mathrm{m}$. C) Verteilungshistogramm für CNP positive Zellen, die ebenfalls positiv für VGAT beziehungsweise VGLUT2 waren; mit $n=4$ Tieren und 4.836 Zellen für VGAT bzw. 2.912 Zellen für VGLUT2; dargestellt ist der Mittelwert \pm SEM.

\subsubsection{Verteilung von NPR1 und NPR2 in Spinalganglien und Rückenmark}

Zur Untersuchung des Expressionsprofils von NPR2, wurden zunächst x-Gal Färbungen an Gewebeschnitten von Npr2+/LacZ-Mäusen durchgeführt. Diese zeigten eine schwache NPR2Expression in den äußeren Laminae des Dorsalhorns sowie in einigen wenigen DRG-Neuronen (circa $8 \%$, s. Abbildung $10 \mathrm{~A}$ und $\mathrm{Bi}$ ). Um die Ergebnisse zu verifizieren wurde zusätzlich eine In-Situ-Hybridisierung für NPR2 in DRG-Gewebe adulter C57/BL6-Tiere (Alter circa zwei Monate) durchgeführt. Hier konnte ein starkes Signal für NPR2 detektiert werden, dessen neuronale Expression durch die Cofärbung mit dem Pan-neuronalen Marker Stathmin-like 2 bestätigt wurde (s. Abbildung 10 Bii) Diese Ergebnisse stehen im Widerspruch zu den zuvor gemachten Beobachtungen der x-Gal-Färbung.

In-situ-Hybridisierungen, die für NPR1 in DRG-Gewebe durchgeführt wurden, zeigten keine Färbung (s. Abbildung 10 C). Somit scheint NPR1 nicht in Spinalganglien exprimiert zu werden. 
A)

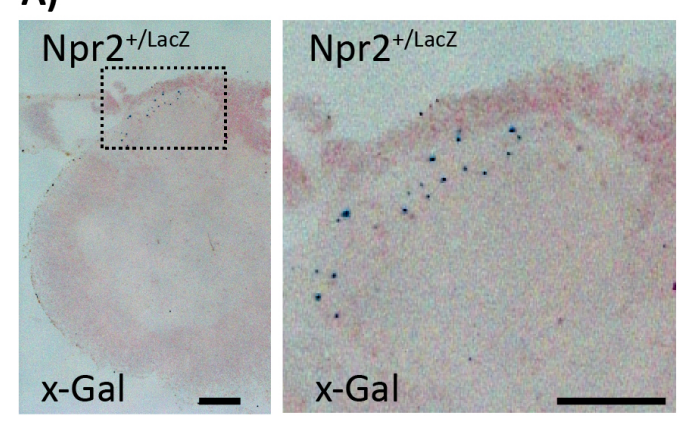

C)

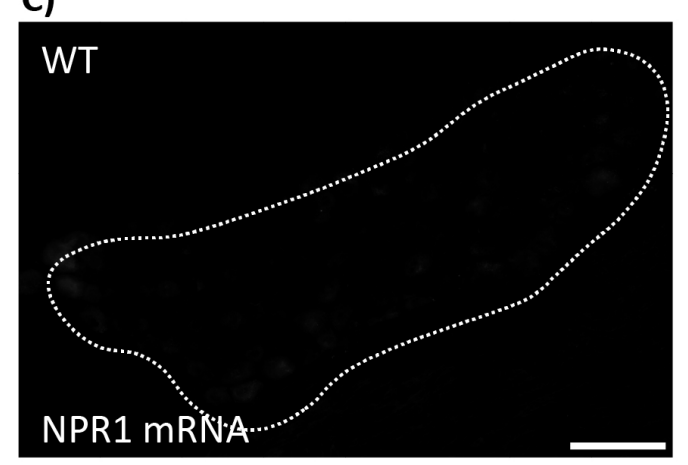

Bi)

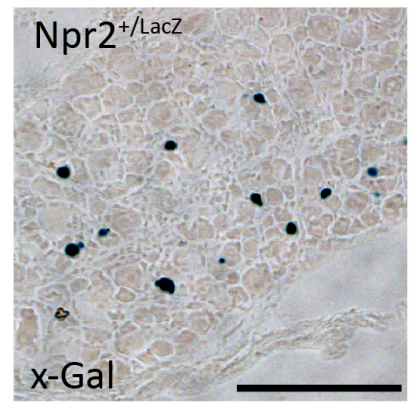

Di)

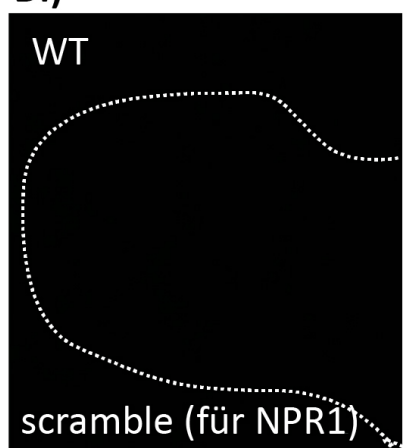

Bii)

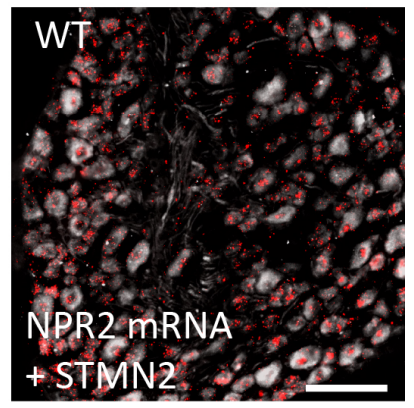

Dii)

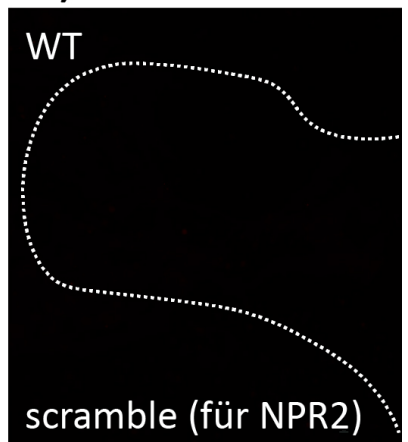

Abbildung 10: A) x-Gal-Färbung für NPR2 (blau) im Rückenmark und Bi) in DRGs sowie Bii) In-situ-Hybridisierung für NPR2 (rot) und dem Marker STMN2 (weiß) in DRGs; C) In-Situ-Hybridisierung für NPR1 in DRGs; D) entsprechende scramble-Kontrollen mit Di) für NPR1 und Dii) für NPR2. Maßstab $100 \mu \mathrm{m}$.

In Kontrollexperimenten wurde die Spezifität der eingesetzten NPR2-Sonde (NPR2-Sonde I, hybridisierter Bereich: 1.521-2.451 bp) durch Einsatz einer weiteren Sonde (NPR2-Sonde II) überprüft. Letztere wurde so entworfen, dass sie in einem nicht-überlappenden Bereich (hybridisierter Bereich: bp 627-1.061 bp, Exon 1-2) binden konnte. Hierfür wurden DRG-Schnitte verwendet, die nach der In-situ-Hybridisierung mit dem pan-neuronalen Marker STMN2 angefärbt wurden (s. Abbildung $11 \mathrm{~A}$ und B). Im Anschluss wurde das neuronale NPR2-Signal quantifiziert. Dabei wurde für beide Sonden eine ähnliche Signalintensität und -menge festgestellt. Mit beiden Sonden konnte NPR2 in nahezu $80 \%$ aller DRG-Neurone detektiert werden (s. Abbildung $11 \mathrm{C}$ ). 


\section{A)}

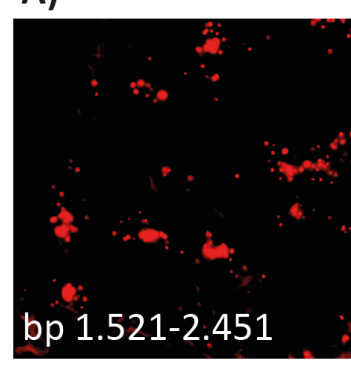

B)

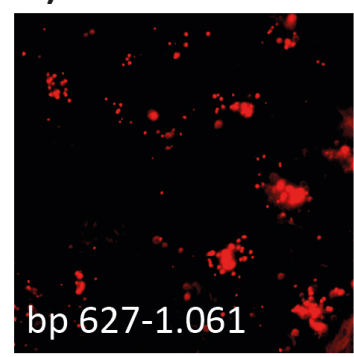

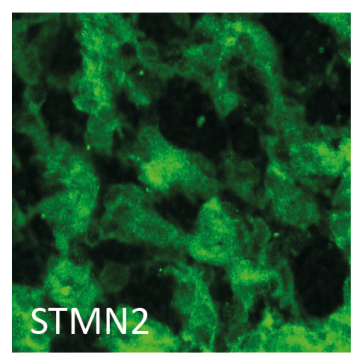
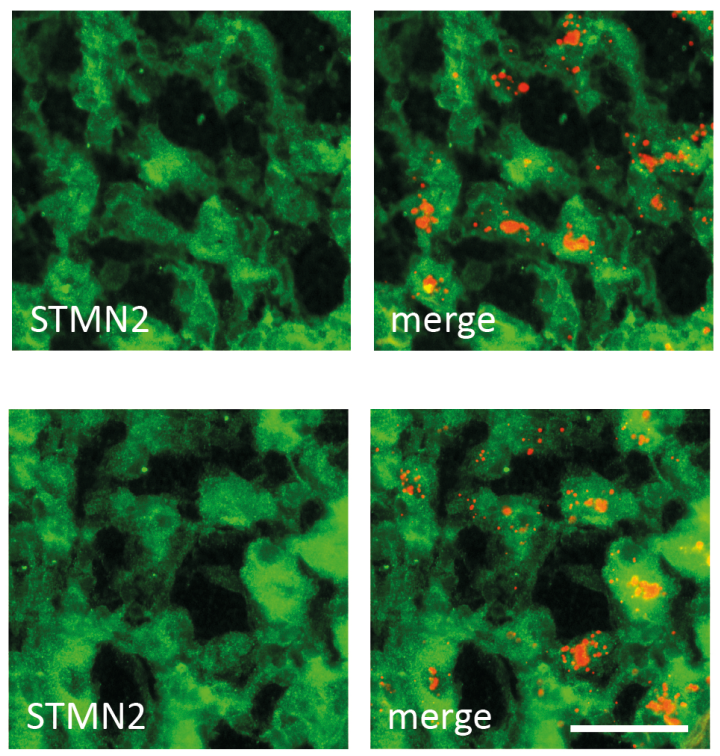

C)

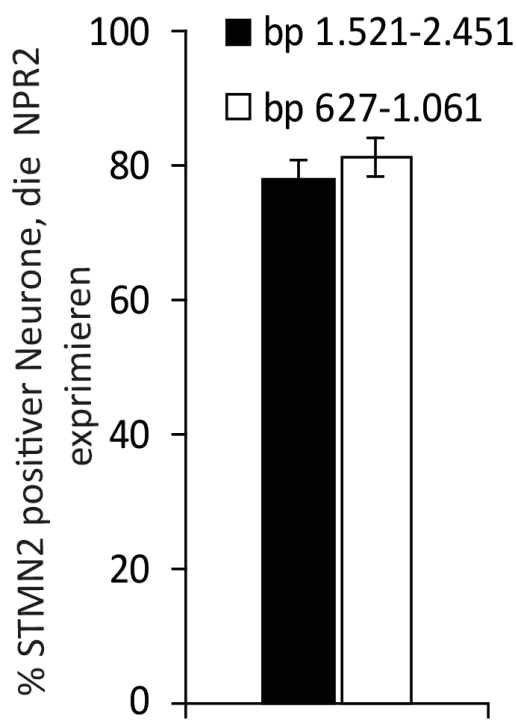

Abbildung 11: Colokalisation von STMN2 (grün) mit Signal der In-situ-Hybridisierung für A) NPR2-Sonde I (rot,

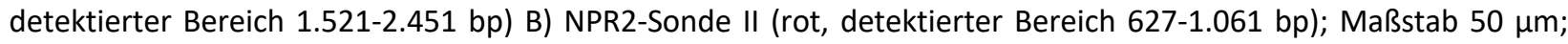
C) Quantifizierung NPR2-Sonde I gegen NPR2-Sonde II); mit $n=4$ Tieren und 2.312 Zellen für NPR2-Sonde I sowie 2.071 Zellen für NPR2-Sonde II; $p=0,417$; dargestellt ist der Mittelwert \pm SEM, verwendete Statistik: T-Test.

Für die genaue Subgruppenanalyse wurden zusätzlich Färbungen mit Antikörpern gegen das Neurofilament 200 (NF200), einem Marker für myelinisierte Fasern sowie Peripherin, einem Marker für nicht-myelinisierte Fasern angefertigt (s. Abbildung $12 \mathrm{~A}$ und B). Es konnte gezeigt werden, dass fast $40 \%$ aller NPR2-positiven Zellen ein Signal für NF200 und nahezu $60 \%$ für Peripherin aufwiesen (s. Abbildung $12 \mathrm{C}$ ). Diese Daten zeigen, dass NPR2 in myelinisierten und nicht-myelinisierten DRG-Neuronen exprimiert wird. 

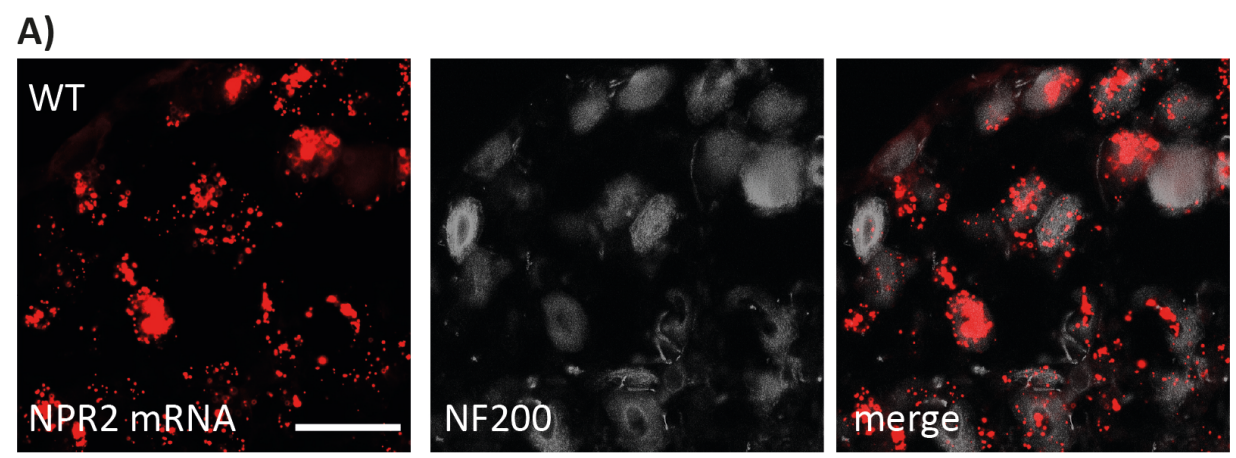

B)
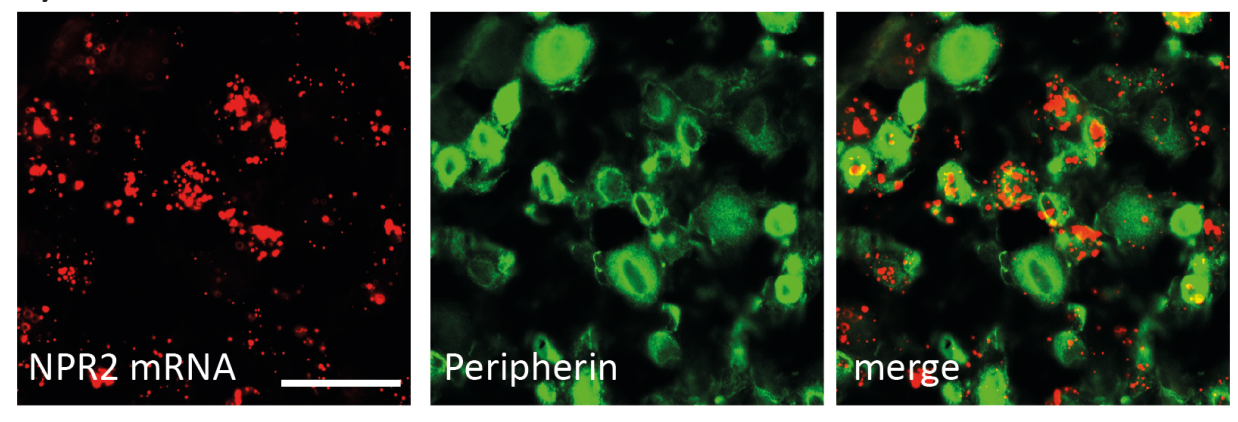

C)

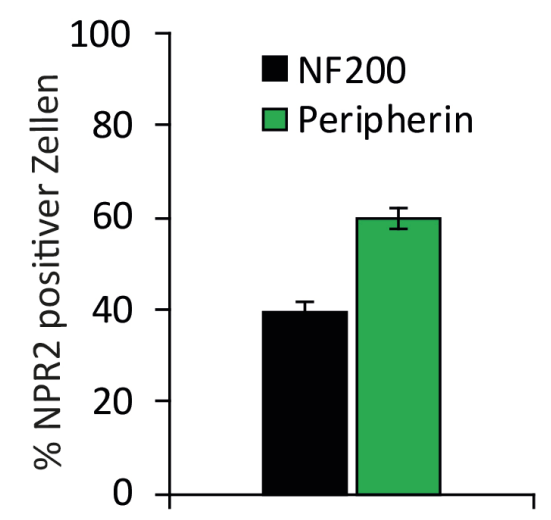

Abbildung 12: Kombinierte In-situ-Hybridisierung für NPR2 (rot) mit Immunfluoreszenzfärbungen in DRGs. A) Colokalisation von NPR2 (rot) mit einem gegen NF200 gerichteten Antikörper (weiß) zur Detektion myelinisierter Fasern. B) Colokalisation von NPR2 (rot) mit einem gegen Peripherin gerichteten Antikörper (grün) zur Detektion nicht-myelinisierter Fasern; Maßstab $50 \mu \mathrm{m}$; C) Quantitative Auswertung der NPR2-exprimierenden Zellpopulationen; mit $n=6$ Tieren und 2.287 Zellen für Peripherin und NF200; dargestellt ist der Mittelwert \pm SEM. 
Da publizierte Daten von Npr2+/Lacz-Mäusen mittels $x$-Gal-Färbungen eine altersbedingte Runterregulation von NPR2 in DRG-Neuronen zeigten, ${ }^{95}$ wurde als zusätzliches Kontrollexperiment eine quantitative Echtzeit-PCR durchgeführt und die relative NPR2 mRNA-Expression in Geweben von C57/BL6-Mäusen unterschiedlichen Alters bestimmt (ein Monat, zwei Monate, ein Jahr). Zusätzlich zu DRGs wurde als Kontrollgewebe Rückenmark und Cerebellum eingesetzt. Es konnte keine signifikante altersabhängige Expressionsänderung für NPR2 nachgewiesen werden (s.Abbildung 13).

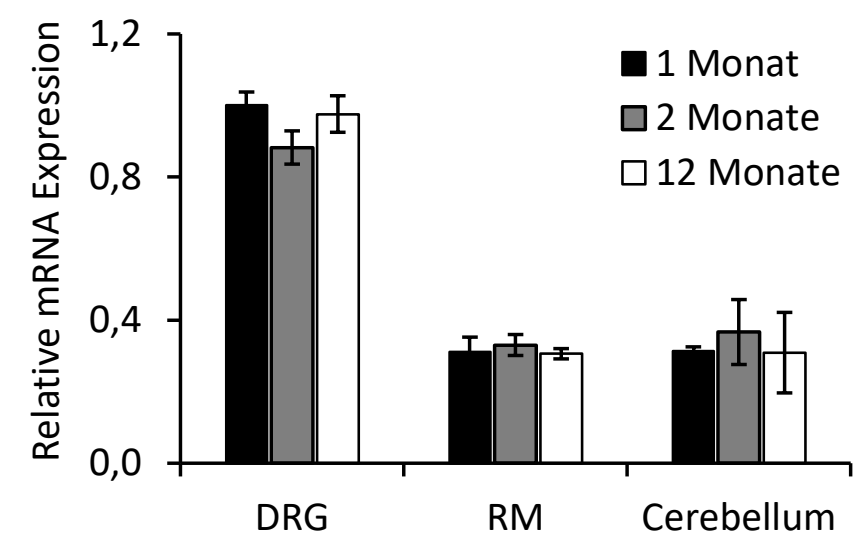

Abbildung 13: Relative NPR2 mRNA-Expression in C57/BL6-Mäusen. Untersucht wurde die mRNA-Expression in DRGs, Rückenmark und Cerebellum; mit $n=4$ Tieren pro Gruppe und $\mathrm{p}(\mathrm{DRGs})=0,465, \mathrm{p}(\mathrm{RM})=0,836$ sowie $\mathrm{p}$ (Cerebellum) $=0,247)$; dargestellt ist der Mittelwert \pm SEM; verwendete Statistik: One-Way-ANOVA.

\subsubsection{Colokalisation mit möglichen Downstream-Targets}

In vorherigen Studien wurde belegt, dass cGKI $\alpha$ als wichtiges Zielprotein der Guanylatzkylasen fungiert. Es wird vermutet, dass sie in DRG-Neuronen von pGCs aktiviert wird. ${ }^{118}$ Um diese Hypothese zu bestätigen, wurden In-situ-Hybridisierungen für NPR2 zusätzlich mit einem spezifischen cGKI-(PKGI)Antikörper angefärbt. Diese Färbungen zeigten, dass cGKI $\alpha$ in nahezu $100 \%$ aller DRG-Neurone vorliegt und somit mit NPR2 colokalisiert ist (s. Abbildung 14 A). Die Auswertung der Quantifizierung ergab, dass $100 \%$ aller NPR2 positiven Neurone ebenfalls positiv für cGKI waren, wohingegen in rund $70 \%$ aller cGKI positiven Zellen ein Signal für NPR2 detektiert wurde (s. Abbildung 14 B). 
A)

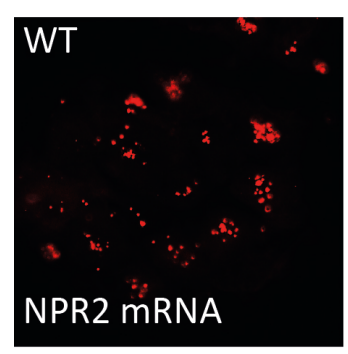

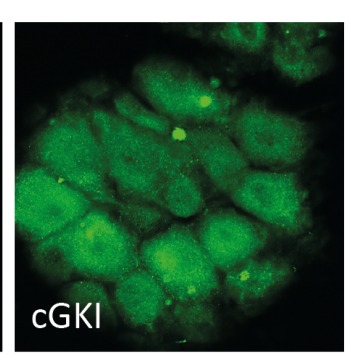

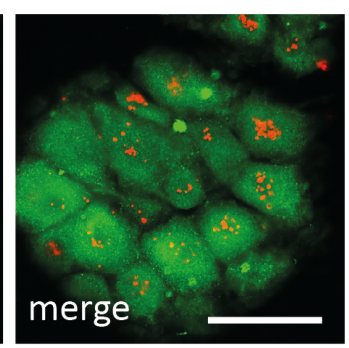

B)

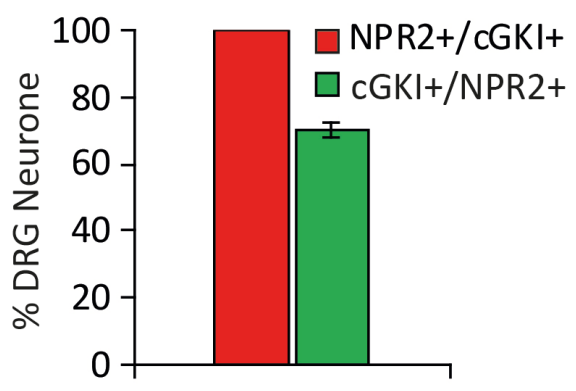

Abbildung 14: A) Cofärbung an In-situ-Hybridisierungsschnitten für NPR2 (rot) mit einem spezifischen Antikörper gegen cGKI (grün); Maßstab $50 \mu \mathrm{m}$; B) Quantifizierung für cGKI positive Zellen, die auch positiv für NPR2 sind und NPR2 positive Zellen, welche ebenfalls positiv für cGKI sind; mit $n=6$ Tieren und 2.816 Zellen; dargestellt ist der Mittelwert \pm SEM.

Als mögliches Zielprotein der cGKla und somit potentielles Downstream-Target von NPR2 wurde in einer vorangehenden Untersuchung das Cystein-reiche Protein 4 (CRP4) nachgewiesen. ${ }^{110}$ In-situ-Hybridisierungen für CRP4, die im Anschluss mit STMN2 angefärbt wurden, zeigen, dass CRP4 in vielen DRG-Neuronen exprimiert wird (s. Abbildung 15 A).

Um Hinweise einer möglichen NPR2/cGMP/cGKl $\alpha$ abhängigen CRP4-Aktivierung zu finden, wurde an DRG-Gewebeschnitten eine kombinierte In-situ-Hybridisierung mit NPR2- und CRP4-Sonden sowie cGKI- und CRP4-Sonden durchgeführt. Diese zeigten, dass CRP4 sowohl mit NPR2 als auch mit cGKI in DRG-Neuronen colokalisiert ist (s. Abbildung 15 B und C).

Die quantitative Analyse der Cofärbungen von NPR2 und CRP4 ergab, dass circa $88 \%$ aller NPR2-exprimierenden Zellen ein Signal für CRP4 zeigten. Der Anteil an CRP4 positiven Zellen, die ebenfalls positiv für NPR2 waren, betrug nahezu $87 \%$ (s. Abbildung 15 D). 

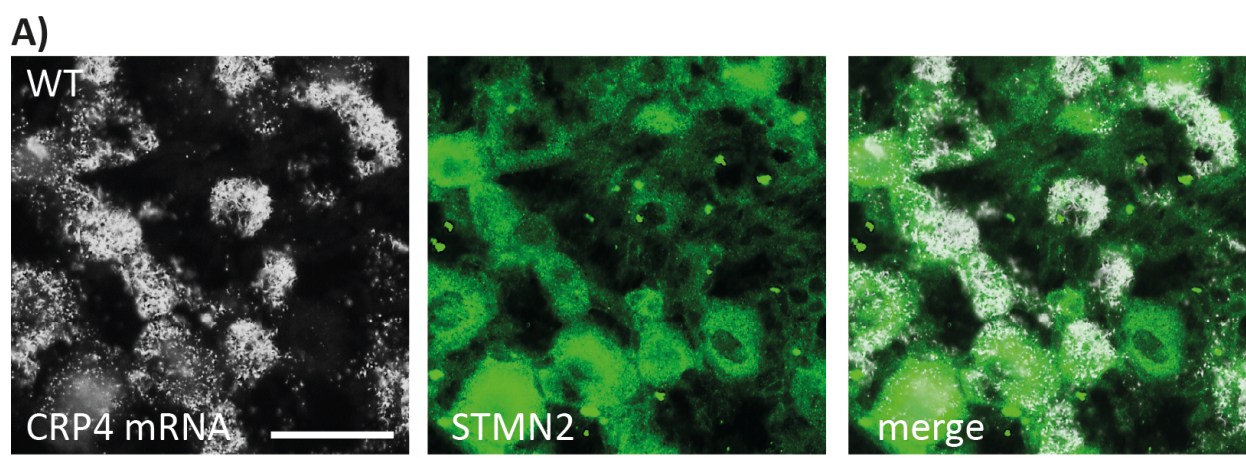

B)
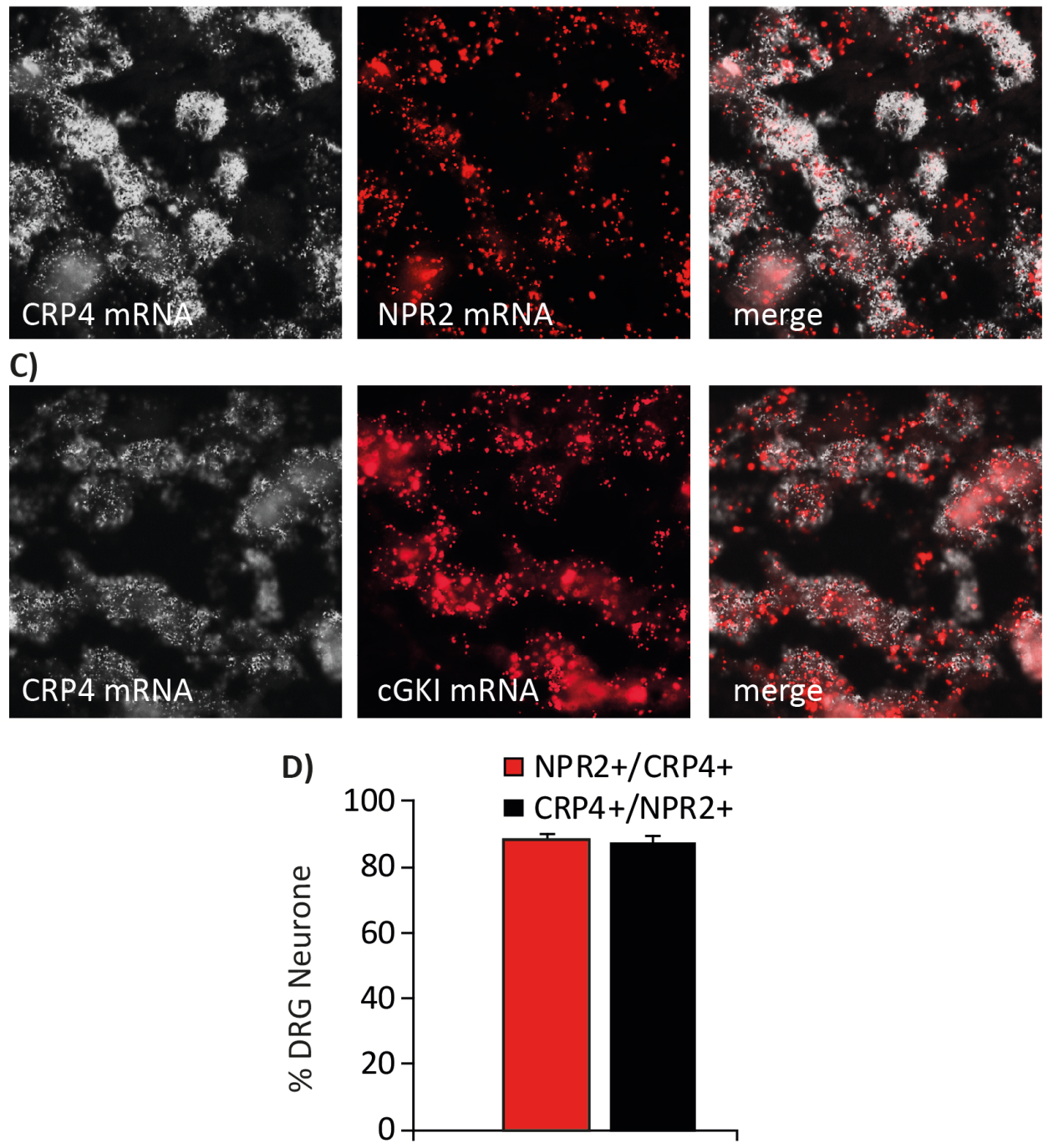

Abbildung 15: In-situ-Hybridisierungen in DRG-Neuronen A) Colokalisation von CRP4 (weiß) und STMN2 (grün); B) Coexpression von CRP4 (weiß) und NPR2 (rot); C) Coexpression von CRP4 (weiß) und cGKI (rot); D) Quantifizierungsergebnisse für CRP4 positive Zellen, die auch positiv für NPR2 sind, sowie NPR2 positive Zellen, die auch positiv für CRP4 sind; $n=4$ Tiere und 2.461 Zellen; dargestellt ist der Mittelwert \pm SEM. 
Generierung und Verifizierung eines konditionellen Npr2-Knockouts

\subsection{1} Zucht und Grundcharakterisierung der Adv-Npr2-Linie

Nachdem NPR2 in DRG-Neuronen detektiert wurde, wurden Mäuse gezüchtet, die in diesem Gewebe einen vollständigen konditionellen Npr2-Knockout aufweisen sollten. Durch Verpaarung

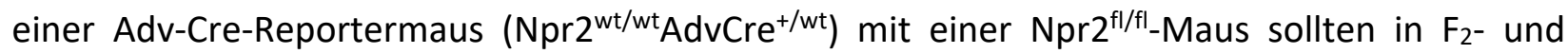
höheren Generationen konditionelle Adv-Npr2 $\left.{ }^{-/-M a ̈ u s e ~(~} \mathrm{Npr}^{\mathrm{fl} / \mathrm{fl}} \mathrm{AdvCr} \mathrm{C}^{+/ \mathrm{wt}}\right)$ und zugehörige wildtypische Wurfgeschwister ( $\left.\mathrm{Npr}^{\mathrm{fl} / \mathrm{fl}} \mathrm{Adv} \mathrm{Cre}^{\mathrm{wt} / \mathrm{wt}}\right)$ generiert werden. Es fiel jedoch bereits in der $\mathrm{F}_{2}$-Generation auf, dass nur etwa $6 \%$ (Daten nicht gezeigt) und in der F3-Generation $25 \%$ der Gesamtzucht den gewünschten Genotypen (Npr2 ${ }^{\mathrm{fl} / \mathrm{fl}} \mathrm{AdvCre}^{+/ \mathrm{wt}}$ ) trugen (s. Abbildung 16).

Auch schien die Fertilität der Mäuse eingeschränkt zu sein. Aus diesem Grund wurde die Zucht eingestellt.

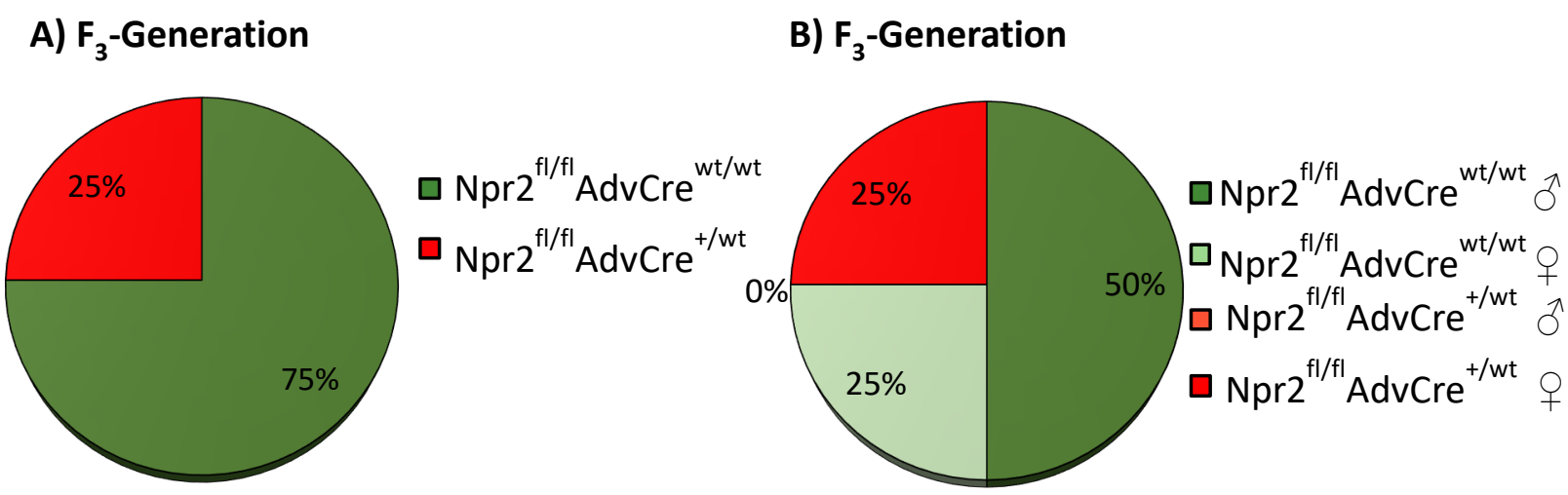

Abbildung 16: Verteilungsrate der möglichen Genotypen in der $F_{3}$-Generation A) Geschlechtsunspezifisch und B) Geschlechtsspezifisch; mit $n\left(F_{3}\right)=4$ Tieren; dargestellt als prozentualer Anteil.

\subsubsection{Zucht und Grundcharakterisierung der SNS-Npr2-Line}

Für die nachfolgenden Untersuchungen wurden konditionelle Knockout-Mäuse mit einer spezifischen Deletion in Nav1.8 exprimierenden DRG-Neuronen generiert (SNS-Npr2-Linie). Hierfür wurde in der $\mathrm{F}_{0}-$ Generation eine SNS-Cre-Reportermaus (Npr2 ${ }^{\mathrm{wt} / \mathrm{wt}} \mathrm{SNSCr}^{+/ \mathrm{wt}}$ ) mit einer homozygoten Maus der Npr2-flox-Linie $\left(\mathrm{Npr} 2^{f \mid f l}\right.$ ) gekreuzt (s. Kapitel 3.2.1.1). Anschließend 
wurden für weitere Experimente aus der $\mathrm{F}_{2}$ - und höheren Generationen homozygot gefloxte Npr2-Mäuse, welche heterozygot die Cre-Rekombinase exprimierten ( $\left.\mathrm{Npr}^{\mathrm{fl} / \mathrm{fl}} \mathrm{SNSCre} \mathrm{Ct}^{+/ \mathrm{wt}}\right) \mathrm{mit}$ homozygot gefloxten Npr2-Mäusen, welche kein Träger der Cre-Rekombinase waren

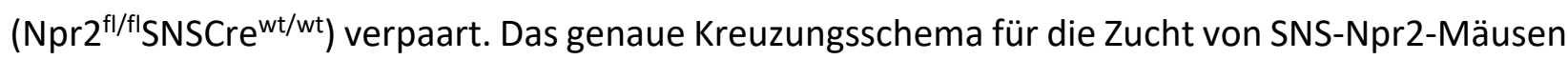
ist Abbildung $17 \mathrm{~A}$ zu entnehmen.

A)

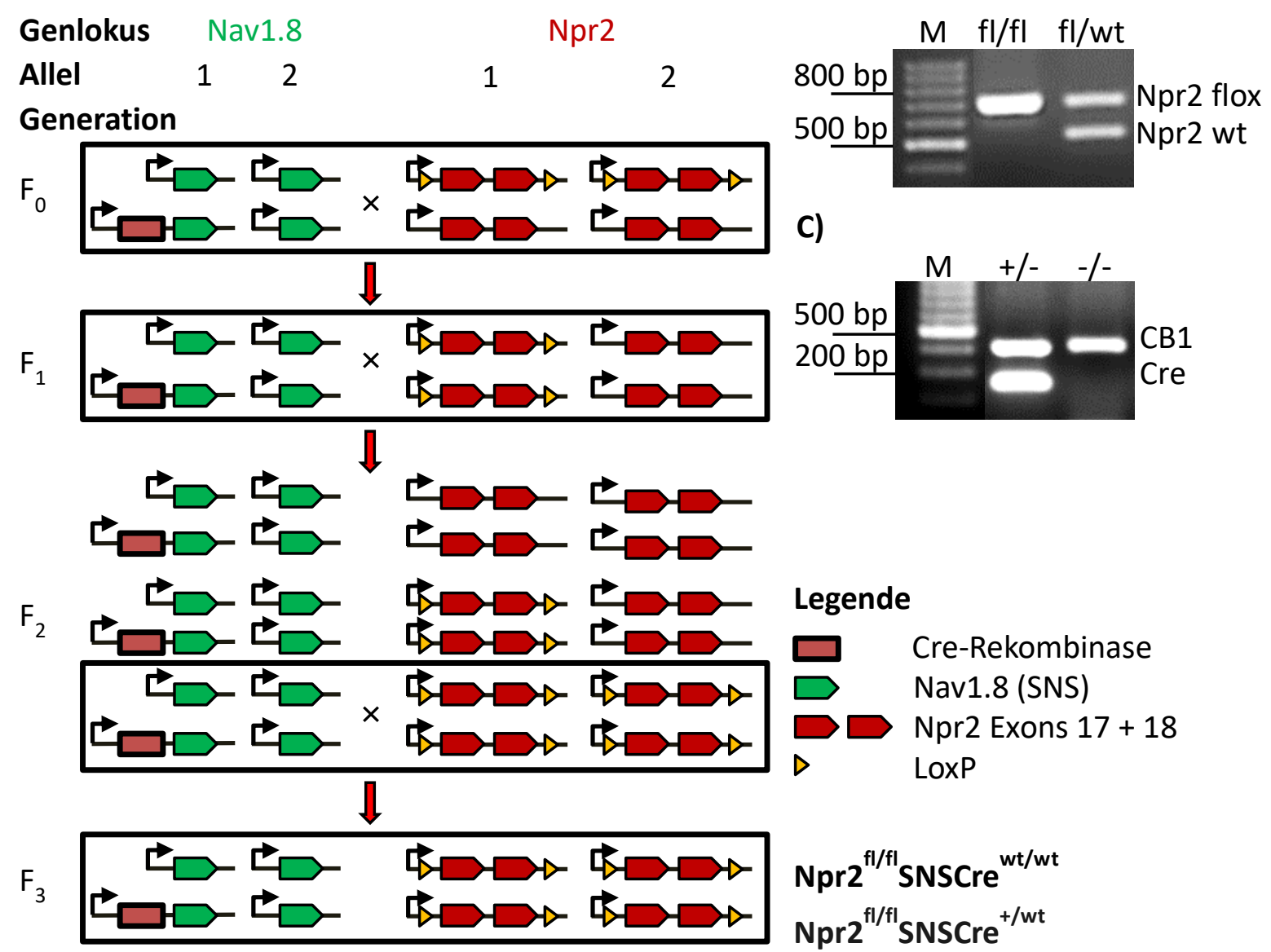

Abbildung 17: A) Vererbungsschema zur Generierung von konditionellen SNS-Npr2 ${ }^{-{ }_{-}-}\left(\mathrm{Npr}^{\mathrm{flox} / \mathrm{flox}} \mathrm{SNSCre}^{+/ \mathrm{wt}}\right)$ und

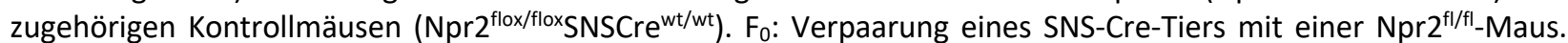
$F_{1}$ : Verpaarung mit heterozygot gefloxten Tieren der $F_{1}$-Generation, wobei eines Träger der SNS-Cre-

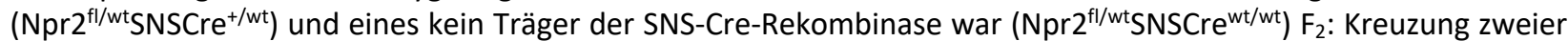
homozygot gefloxter Tiere ( $\left.\mathrm{Npr}^{\mathrm{fl} / f \mid} \mathrm{SNSCre}{ }^{+/ w t} \times \mathrm{Npr}^{\mathrm{fl} / \mathrm{fl}} \mathrm{SNSCre}{ }^{\mathrm{wt} / \mathrm{wt}}\right)$ um eine höhere Zuchteffizienz zu erhalten $\mathrm{F}_{3}$ : In dieser Generation wurden nur Kontrolltiere (Npr2 ${ }^{\mathrm{fl} / \mathrm{fl}} \mathrm{SNSCr} \mathrm{C}^{\mathrm{wt} / \mathrm{wt}}$ ) und konditionelle Knokout-Tiere (Npr2 ${ }^{\mathrm{fl} / \mathrm{fl}} \mathrm{SNSCre}{ }^{+/ \mathrm{wt}}$ ) geboren. B) und C) zeigen die PCR-Ergebnisse zur Bestimmung des Genotyps, mit Abbildung B) für die loxP-Sequenz. Homozygote Tiere weisen nur eine Bande bei 684 bp auf, während heterozygote Tiere auch das WT-Allel bei einer Laufhöhe 506 bp aufzeigen. C) PCR zur Detektion der Cre-Rekombinase (bei 250 bp) mit CB1 als Kontrollgen (bei 500 bp). 
Die Identifizierung des Genotyps erfolgte mithilfe einer PCR. Das gefloxte Allel für NPR2 wies eine Laufbande von 684 bp auf, während das Wildtyp-Allel bei 506 bp lag (s. Abbildung 17 B). Der Nachweis der Cre-Rekombinase erfolgte bei einer Laufhöhe von 250 bp, wohingegen Cre-negative Tiere keine Bande aufzeigten. Daher wurde zur Überprüfung der PCR das Housekeeping Cannabinoid Receptor Typ 1-Gen (CB1-Gen) nachgewiesen, welches bei allen Tieren bei 500 bp amplifiziert wurde (s. Abbildung $17 \mathrm{C}$ ).

Im Anschluss wurde die Geburtenrate hinsichtlich der Genotypen-Vererbung untersucht. Dabei wurde das genetische Verteilungsmuster auf eine eventuelle Geschlechtsspezifität überprüft. Die Analyse ergab, dass der Anteil der möglichen Genotypen-Ausprägungen in etwa gleich war und somit den Mendel'schen Regeln entsprach (s. Abbildung 18).

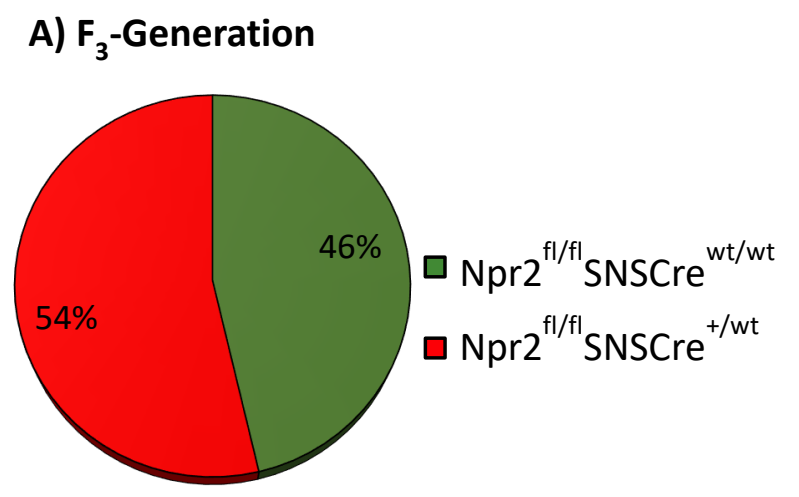

B) $F_{3}$-Generation

Abbildung 18: Verteilungsrate der möglichen Genotypen in der $F_{3}$-Generation A) Geschlechtsunspezifisch und B) Geschlechtsspezifisch mit $n\left(F_{3}\right)=41$ Tieren; dargestellt als prozentualer Anteil.

Da die Literatur für globale Npr2\%-Mäuse in einem Zeitraum von drei bis sechs Wochen nach Geburt eine erhöhte Letalität beschreibt, ${ }^{77,95,146-149}$ wurde über zwei Monate das Überleben der SNS-Npr2-Linie erfasst (mit $n\left(\right.$ Kontrolle) $=25$ und $n\left(\right.$ SNS-Npr $2^{-1-}$ ) $=27$ Tieren). Alle untersuchten Tiere erreichten das Alter von zwei Monaten. Daher scheinen weder Kontrolltiere $\left(\mathrm{Npr}^{\mathrm{fl} / \mathrm{fl} \mathrm{SNSCre}}{ }^{\mathrm{wt} / \mathrm{wt}}\right)$ noch SNS-Npr2/--Mäuse $\left(\mathrm{Npr}^{\mathrm{fl} / \mathrm{fl}} \mathrm{SNSCr} \mathrm{C}^{+/ \mathrm{wt}}\right)$ in diesem Zeitraum eine eingeschränkte Lebenserwartung aufzuweisen. Auch das Körpergewicht (s. Abbildung 19 A) und die Naso-anale Länge waren in beiden Kohorten ähnlich (s. Abbildung 19 B und C). Somit konnte gezeigt werden, dass Mäuse der SNS-Npr2-Linie lebens- und vermehrungsfähig sind und eine normale Körpergröße besitzen. 
A)

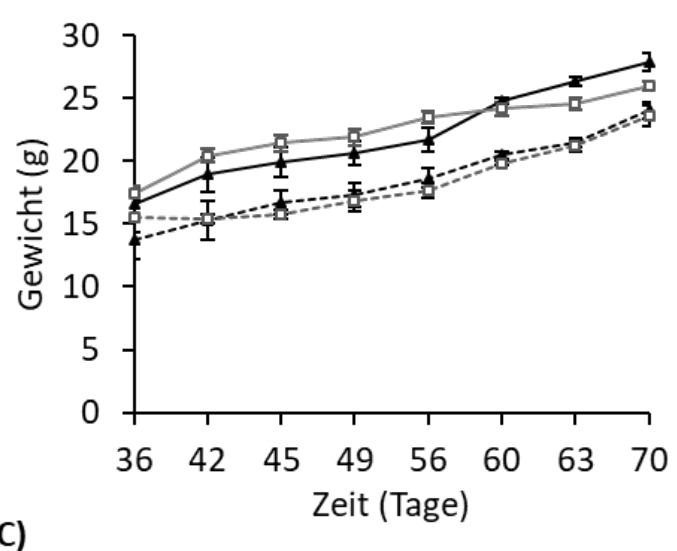

C)
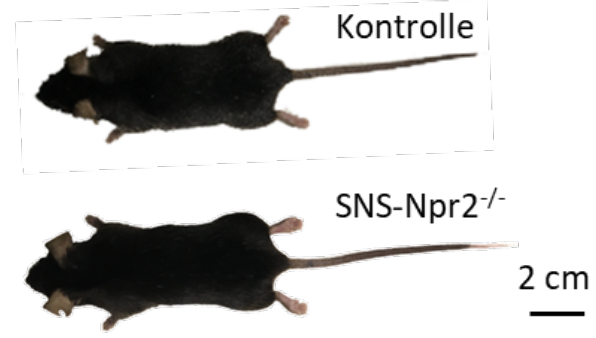

B)

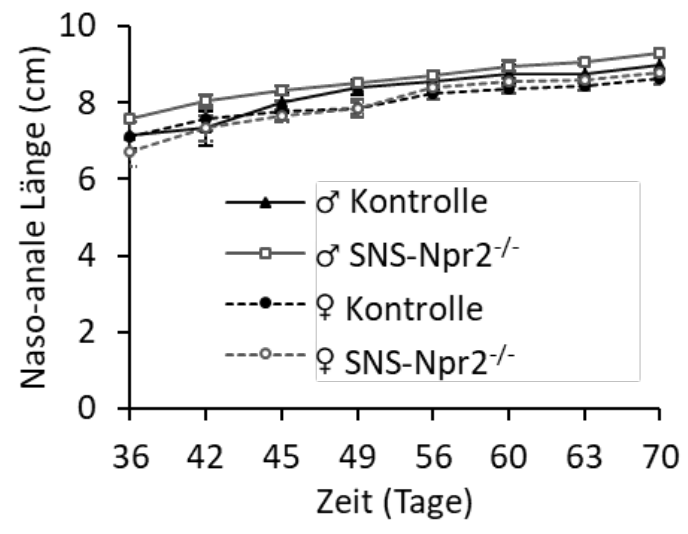

Abbildung 19: A) Körpergewicht $(p$ (männlich) $=0,658$ und $p$ (weiblich $)=0,953)$; B) Naso-anale Länge von SNS-Npr2 ${ }^{-}$-Mäusen und zugehörigen Kontrolltieren; $n=4-5$ Tiere pro Gruppe und Geschlecht mit $p($ männlich $)=$ 0,403 und $p$ (weiblich) $=0,802$; dargestellt ist der Mittelwert \pm SEM; verwendete Statistik: Repeated-MeasurementANOVA. C) Typische Körpergröße einer SNS-Npr2 $\%$-Maus im Vergleich zu einem Kontrolltier.

\subsubsection{Verifizierung des Knockouts und mögliche kompensatorische Regulation von NPR1 und NPR3}

Um den konditionellen Knockout von NPR2 in Nav1.8 positiven DRG-Neuronen nachzuweisen, wurde eine quantitative Echtzeit-PCR (qPCR) mit Knockout-spezifischen Primern durchgeführt. Hierfür wurde Gewebe von DRGs, Rückenmark und Cerebellum eingesetzt. Wie in Abbildung $20 \mathrm{~A}$ dargestellt, zeigten SNS-Npr2--Mäuse im Vergleich zu Kontrolltieren eine signifikante Runterregulation der NPR2 mRNA in DRG-Gewebe auf. Gewebe von Rückenmark und Cerebellum, die als Kontrollen eingesetzt wurden, wiesen hingegen keine Expressionsänderungen auf. 
Zudem wurden qPCR-Analysen für NPR1 und NPR3 durchgeführt. Diese dienten zur Überprüfung einer möglichen kompensatorischen Regulation. Es wurden jedoch weder für NPR1 (s. Abbildung 20 B) noch NPR3 (s. Abbildung 20 C) Expressionsunterschiede in den einzelnen Geweben festgestellt.

A)

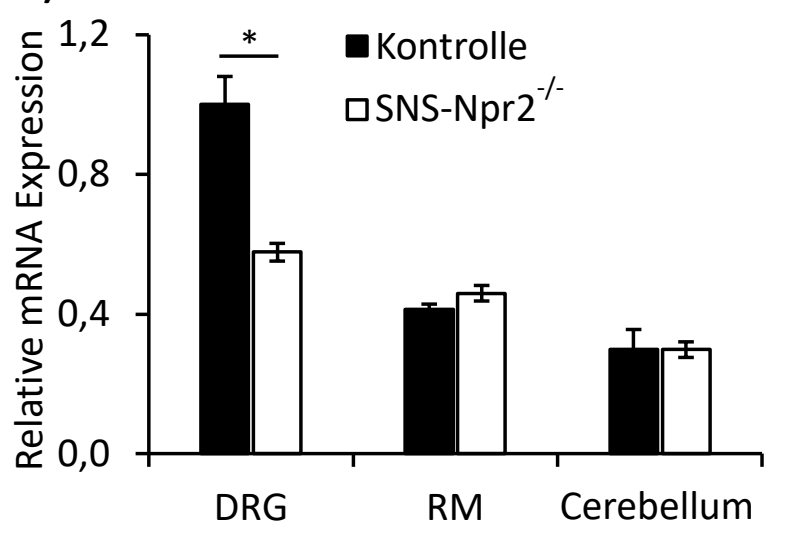

C)

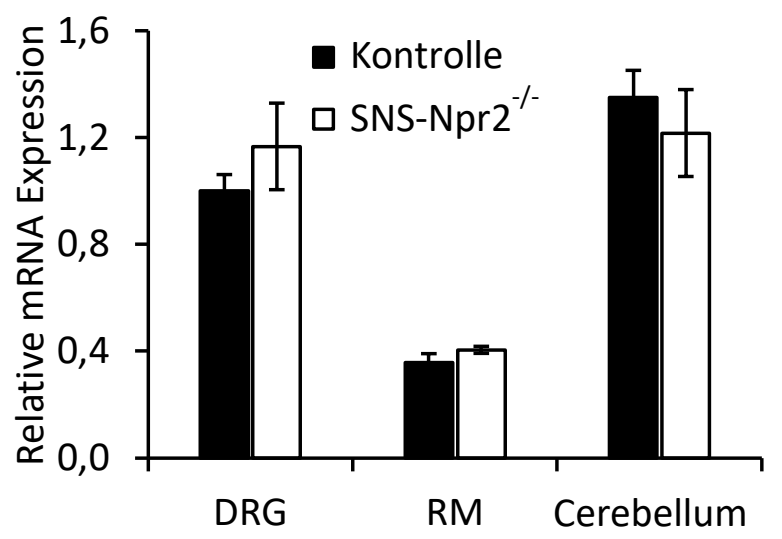

B)

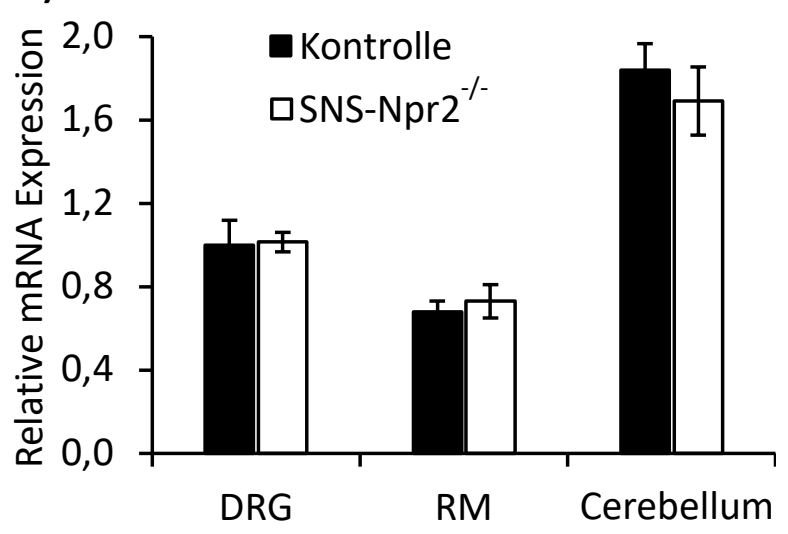

Abbildung 20: Relative mRNA Expressionslevel in SNS-Npr2 ${ }^{-/-}$-Mäusen und zugehörigen Kontrolltieren für A) Expression von NPR2 in DRGs $(p=0,0002), \operatorname{RM}(p=0,61)$ und Cerebellum $(p=0,49)$; B) Expression von NPR1 in DRGs $(p=0,92)$, RM $(p=0,21)$ und Cerebellum $(p=0,50)$; C) Expression von NPR3 in DRGs $(p=0,36), \operatorname{RM}(p=0,21)$ und Cerebellum $(p=0,50) ; n=4$ Tieren pro Gruppe; dargestellt ist der Mittelwert \pm SEM; verwendete Statistik: T-Test. Abkürzung: RM, Rückenmark. 


\subsubsection{Morphologie der Spinalganglien und des Rückenmarks}

Um Hinweise auf mögliche Bifurkationsstörungen in der T-Verzweigung der Dornfortsätze abzuschätzen, wurde die anatomische Struktur des Rückenmarks erfasst. Hierfür wurde die Größe und Breite von Rückenmarksschnitten (LO-L3) gemessen. Es konnten keine signifikanten Veränderungen zwischen SNS-Npr2\%-Mäusen und Kontrolltieren festgestellt werden (s.Abbildung $21 \mathrm{~A}$ und C).

Zudem wurden Immunfluoreszenzfärbungen mit den Markern Substanz P und IB4 angefertigt, um mögliche Modifikationen schmerzrelevanter Laminae auszuschließen. Auch hier waren keine Unterschiede erkennbar (s. Abbildung 21 B).

Neben Untersuchungen des Rückenmarks wurde die Verteilung einzelner neuronaler Subpopulationen in Spinalganglien analysiert. Hierzu wurden die Marker NF200, IB4 und CGRP eingesetzt (s. Abbildung $22 \mathrm{Ai}$ und Aii). Zusätzlich wurde die Expression von TRPV1-positiven Neuronen untersucht (s. Abbildung $22 \mathrm{Bi}$ und Bii). Dabei wiesen Kontroll- und SNS-Npr2\%--Mäuse ein ähnliches Verteilungsmuster auf (NF200(Kontrolle) $=38,39 \pm$ SEM = 0,75 \% und NF200(SNS$\mathrm{Npr}^{-{ }^{--}}$) $=40,49 \pm \mathrm{SEM}=0,89 \%$; IB4(Kontrolle) $=41,74 \pm \mathrm{SEM}=1,40 \%$ und IB4(SNS-Npr2 ${ }^{-1}$ ) $=$ $36,20 \pm \mathrm{SEM}=2,62 \% ; \mathrm{CGRP}($ Kontrolle $)=16,58 \pm \mathrm{SEM}=2,18 \%$ und CGRP(SNS-Npr2 ${ }^{--}$) $=17,83 \pm$ SEM $=0,73 \%$ sowie TRPV1 (Kontrolle) $=21,33 \pm$ SEM $=4,11 \%$ und TRPV1 $\left(\right.$ SNS-Npr2 $\left.{ }^{-/}\right)=21,64 \pm$ $\mathrm{SEM}=1,43 \%)($ s. Abbildung $22 \mathrm{C}$ ). 
Ai)

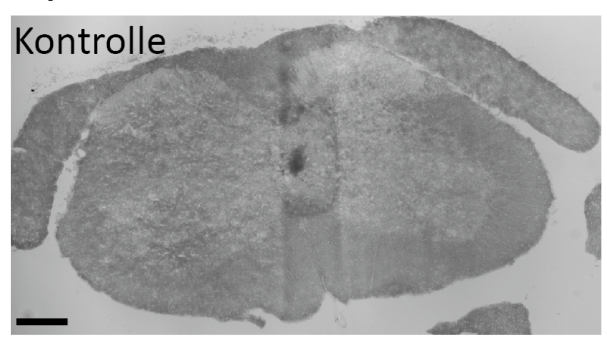

Aii)

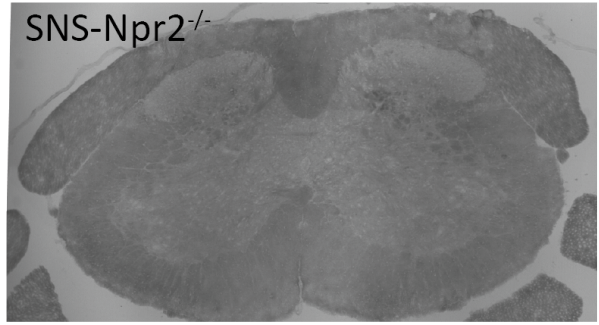

Bi)
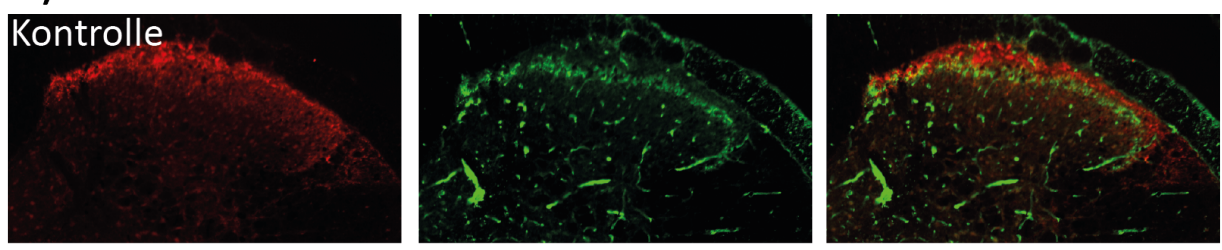

Bii)
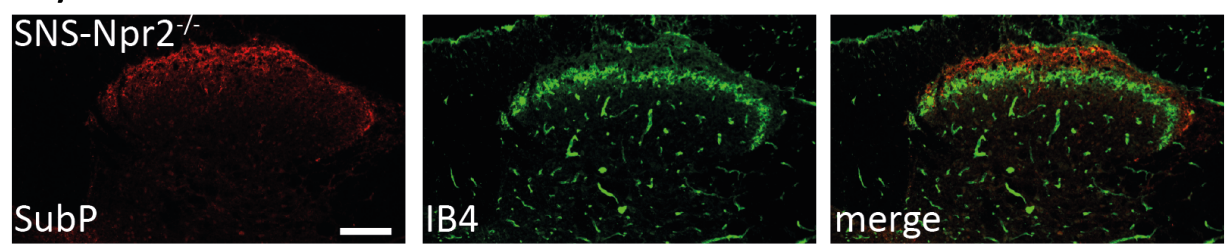

C)

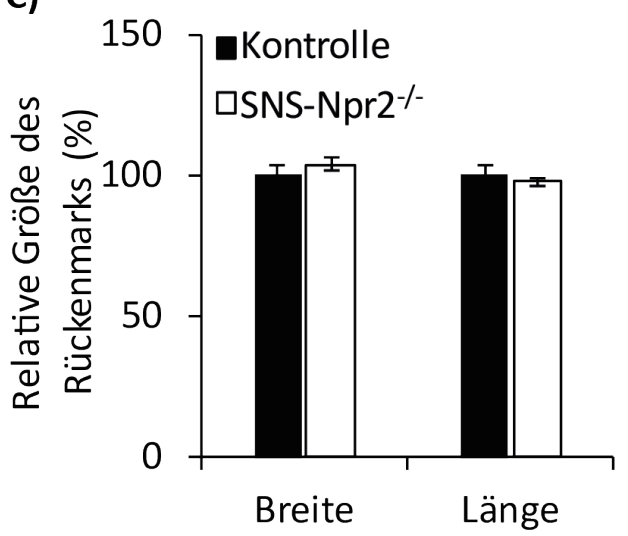

Abbildung 21: Anatomische Struktur des Rückenmarks von Ai) Kontrolltieren und Aii) SNS-Npr2 ${ }^{--M a ̈ u s e n ; ~ M a ß s t a b ~}$ $200 \mu \mathrm{m}$. B) Morphologie des Dorsalhorns von Bi) Kontrolltieren und Bii) SNS-Npr2 ${ }^{-1}-$ Mäusen. Färbungen des Rückenmarks mit den Markern Substanz P (rot) und IB4 (grün); Maßstab $100 \mu \mathrm{m}$. C) Darstellung der relativen Länge $(p=0,35)$ und Breite $(p=0,53)$ des Rückenmarks; mit $n=3$ Tieren pro Gruppe, ausgezählte Schnitte: Kontrolltiere $=11$ und SNS-Npr2 ${ }^{-}-$Mäusen $=16$; verwendete Statistik: T-Test. 
Ai)
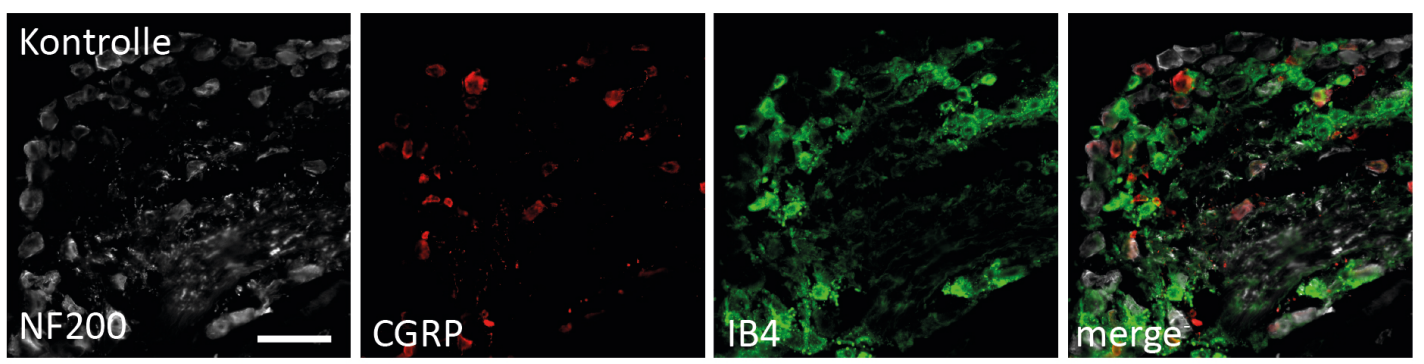

Aii)
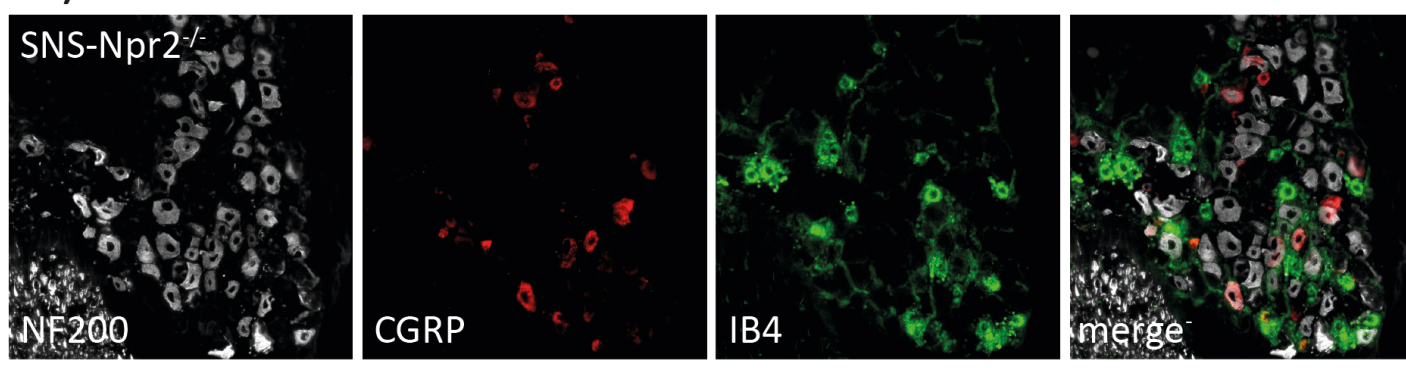

$\mathrm{Bi)}$
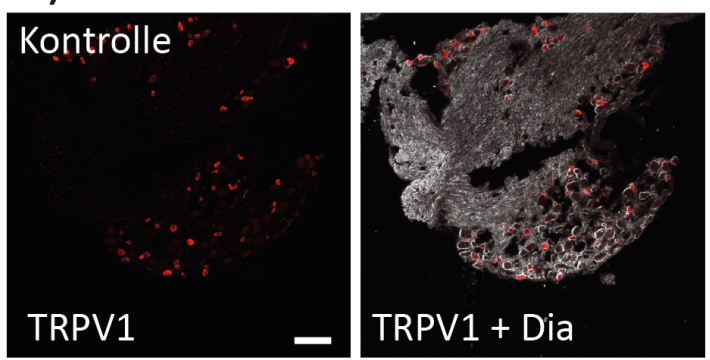

C)

Bii)
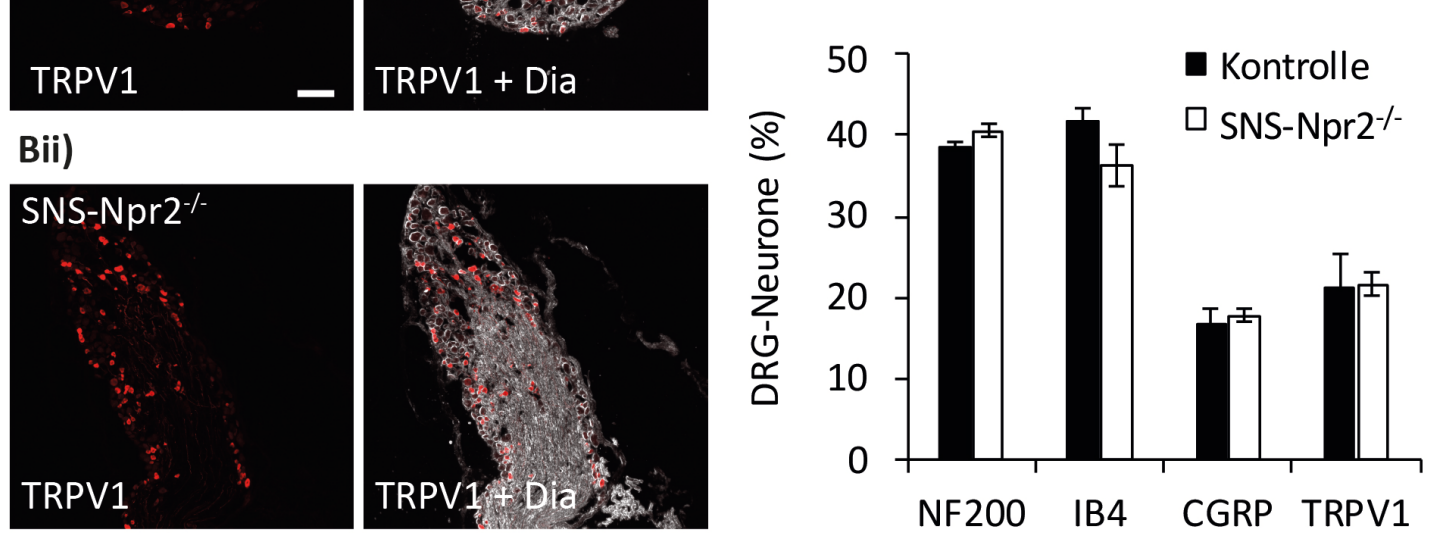

Abbildung 22: Immunfluoreszenzfärbungen an DRG-Gewebeschnitten von Kontrolltieren und SNS-Npr2 ${ }^{-1}$-Mäusen mit A) NF200 (weiß), CGRP (rot) und IB4 (grün) sowie B) TRPV1 (rot) und durchlichtmikroskopischer Aufnahme (Dia) zur Erfassung der Gesamtzellzahl C) Verteilungshistogramm einzelner neuronaler Subpopulationen von Kontrolltieren gegenüber SNS-Npr2 ${ }^{--}$-Mäusen; mit 4-5 Tieren pro Gruppe und $\mathrm{n}\left(\mathrm{SNS}-\mathrm{Npr}^{-{ }^{-}}\right)=6.557$ Zellen bzw. $\mathrm{n}($ Kontrolle $)=6.892$ Zellen für NF200; mit $n\left(\right.$ SNS-Npr2 $\left.^{-1}\right)=8.411$ Zellen und $\mathrm{n}$ (Kontrolle) $=6.258$ Zellen für IB4; mit $\mathrm{n}\left(\mathrm{SNS}-\mathrm{Npr}^{--}\right)=7.148$ Zellen und $\mathrm{n}$ (Kontrolle) $=6.189$ Zellen für CGRP, mit $\mathrm{n}\left(\mathrm{SNS}-\mathrm{Npr}^{-{ }^{-}}\right)=8.273$ Zellen und $\mathrm{n}($ Kontrolle $)=7.171$ Zellen für TRPV1; dargestellt ist der Mittelwert \pm SEM; verwendete Statistik: T-Test. 


\subsection{4 Überprüfung der motorischen Koordination}

Um zu gewährleisten, dass die motorische Koordinationsfähigkeit der SNS-Npr2-Linie nicht beeinträchtigt ist, wurde der Rotarod-Test durchgeführt. Da nahezu alle Mäuse die Cut-off-Zeit von 120 Sekunden erreichten, konnte sicher gestellt werden, dass Tiere der SNS-Npr2-Linie eine normale Motorik besitzen (s Abbildung 23).

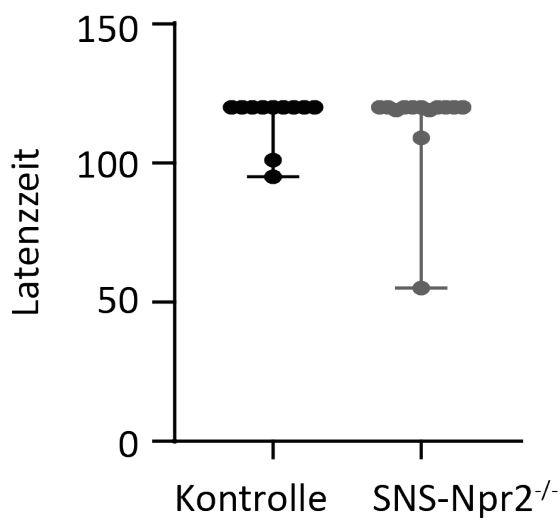

Abbildung 23: Rotarod-Test der SNS-Npr2-Linie mit $n=12-13$ Tieren pro Gruppe und $p=0,513$. Dargestellt ist der Median der Latenzzeit mit Interquartilabstand. Die Cut-off-Zeit betrug $120 \mathrm{~s}$; verwendete Statistik: Mann-Whitney-U-Test.

\subsubsection{Nozizeptives Verhalten der SNS-Npr2-Linie}

\subsubsection{Modelle des akuten Schmerzes}

Für die Charakterisierung des akuten Schmerzverhaltens der SNS-Npr2-Linie wurden verschiedene Modelle durchgeführt. Zur Erfassung möglicher Änderungen in der mechanischen Nozizeption wurde der Dynamic Plantar Test eingesetzt. Kontroll- und SNS-Npr2 ${ }^{--}$-Tiere wiesen ähnliche Reaktionszeiten auf ( $p=0,14)$ (s.Abbildung 24 A).

Das akute thermische Schmerzverhalten wurde mit Hilfe des Hargreaves und Tail-Flick Test bestimmt. Im Hargreaves Test konnte kein Reaktionsunterschied zwischen SNS-Npr2\%--Mäusen und entsprechenden Wildtypen festgestellt werden $(p=0,99)$ (s Abbildung 24 B). 
Im Tail-Flick Test wurde bei einer Intensität von IR 30 bei SNS-Npr2\%-Tieren tendenziell eine erhöhte Latenzzeit gegenüber Kontrolltieren gemessen, die jedoch nicht signifikant war $(p=0,099)$ (s. Abbildung 24 C). Somit konnten für Mäuse der SNS-Npr2-Linie weder im Dynamic Plantar noch im Hargreaves beziehungsweise Tail-Flick Test signifikante Unterschiede bestimmt werden.
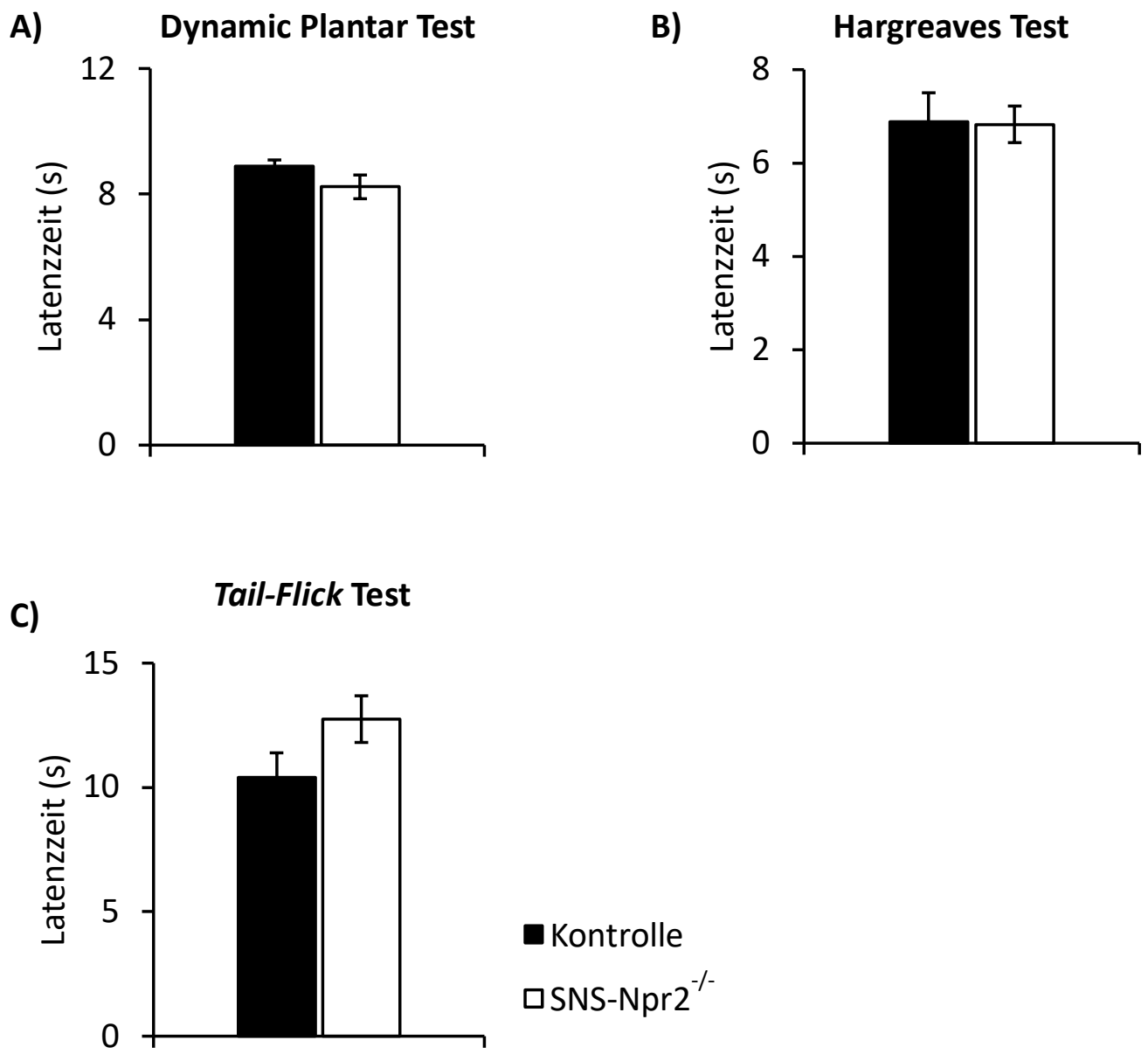

Abbildung 24: Akutes nozizeptives Verhalten der SNS-Npr2-Linie A) Dynamic Plantar Test zur Detektion der mechanischen Schmerzschwelle; mit $n=12$ Tieren pro Gruppe und $p=0,14$; B) Thermisches Schmerzverhalten im Hargreaves Plantar Test; mit $n=8$ Tieren pro Gruppe und $p=0,99$ und C) Thermisches Schmerzverhalten im Tail-Flick Test mit $n=12-13$ Tieren pro Gruppe und $p=0,099$; dargestellt ist der Mittelwert \pm SEM; verwendete Statistik: T-Test.

Als weiterer Akuttest wurde der Hot-Plate Test bei Temperaturen von $50{ }^{\circ} \mathrm{C}, 52{ }^{\circ} \mathrm{C}$ und $54^{\circ} \mathrm{C}$ durchgeführt. Es ließ sich feststellen, dass SNS-Npr2\%--Mäuse im Vergleich zu Kontrolltieren eine höhere Latenzzeit aufwiesen. Da in vorherigen Studien eine altersbedingte Runterregulation von NPR2 beschrieben wurde, ${ }^{95}$ wurde dieser Versuch an zwei Kohorten unterschiedlichen Alters 
durchgeführt. Die Kohorte junger Mäuse umfasste Tiere im Alter von 10 Wochen bis 4 Monaten, während die zweite Kohorte Tiere zwischen 7,5 bis 10 Monate einschloss. In beiden Gruppen zeigten SNS-Npr2\%-Mäuse eine höhere Hitzeschmerzschwelle im Vergleich zu Kontrolltieren. Allerdings war die phänotypische Charakteristik dieser Kohorten bei den einzelnen Temperaturen unterschiedlich ausgeprägt. So zeigten SNS-Npr2 ${ }^{-/}-$Mäuse der jungen Kohorte bereits bei $50{ }^{\circ} \mathrm{C}$ und $52{ }^{\circ} \mathrm{C}$ einen signifikant erniedrigten Hitzeschmerz (s Abbildung $25 \mathrm{~A}$ ) während dieser bei der alten Kohorte erst bei $52{ }^{\circ} \mathrm{C}$ und $54^{\circ} \mathrm{C}$ signifikant erniedrigt war (s. Abbildung $25 \mathrm{~B}$ ).

Demnach zeigten sowohl junge als auch alte SNS-Npr2/--Mäuse im Vergleich zu Kontrolltieren eine signifikant reduzierte Hitzeschmerzschwelle.
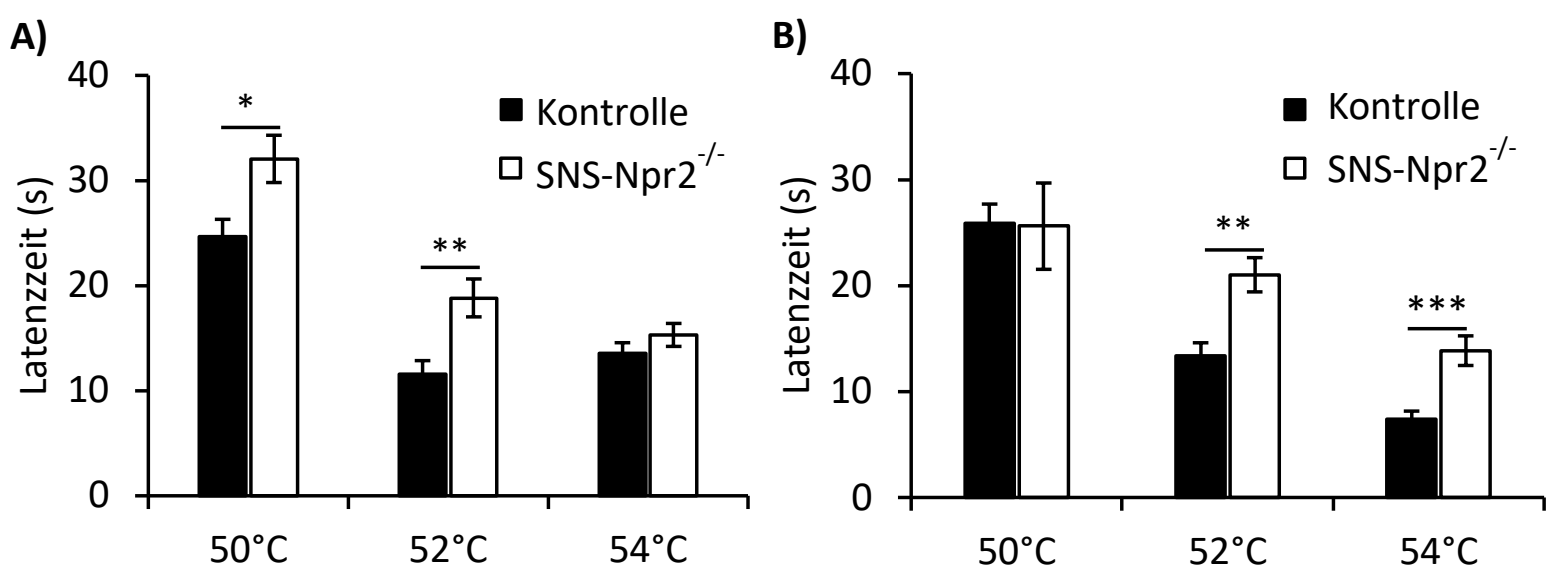

Abbildung 25: Hot-Plate Daten für A) junge Mauskohorte: 1-4 Monate alt; mit $\mathrm{n}=12-13$ Tieren pro Gruppe und $p=0,013$ bei $50{ }^{\circ} \mathrm{C}, p=0,003$ bei $52^{\circ} \mathrm{C}$ und $p=0,252$ bei $54{ }^{\circ} \mathrm{C}$ ); B) alte Mauskohorte: 8 - 10 Monate alt; mit $n=11-12$ Tieren pro Gruppe und $p=0,949$ bei $50^{\circ} \mathrm{C}, \mathrm{p}=0,0011$ bei $52{ }^{\circ} \mathrm{C}$ und $\mathrm{p}=0,0005$ bei $54{ }^{\circ} \mathrm{C}$; dargestellt ist der Mittelwert \pm SEM; verwendete Statistik: T-Test.

\subsubsection{Modelle der schnellen Schmerzsensibilisierung}

Als Modelle der schnellen Schmerzsensibilisierung wurden der Capsaicin- und Formalin-Test angewendet. Diese dienen der gezielten Aktivierung verschiedener Rezeptoren und damit einhergehender Mechanismen. Im Capsaicin-Test werden spezifisch TRPV1-Kanäle stimuliert (s. Abbildung 26 Ai und Aii). Allerdings konnten hier keine signifikanten Unterschiede zwischen den beiden Kohorten festgestellt werden $(p=0,263)$. 
Der Formalin-Test bewirkt eine gezielte Aktivierung der TRPA1-Kanäle (s. Abbildung 26 Bi und Bii). Er lässt sich in zwei Phasen untergliedern. Phase I, die durch eine direkte Stimulation der Nozizeptoren ausgelöst wird (0-10 Minuten), wies keine Gruppenunterschiede auf ( $p=0,607)$. Allerdings war in Phase II (15-35 Minuten) bei SNS-Npr2\%-Mäusen das Leckverhalten signifikant reduziert $(p=0,034)$. Dies deutet auf eine Beteiligung von NPR2 hin. Phase II ist hierbei durch inflammatorische Prozesse in der Peripherie und zentrale Veränderungen im Rückenmark gekennzeichnet. $^{138,139}$

Ai)

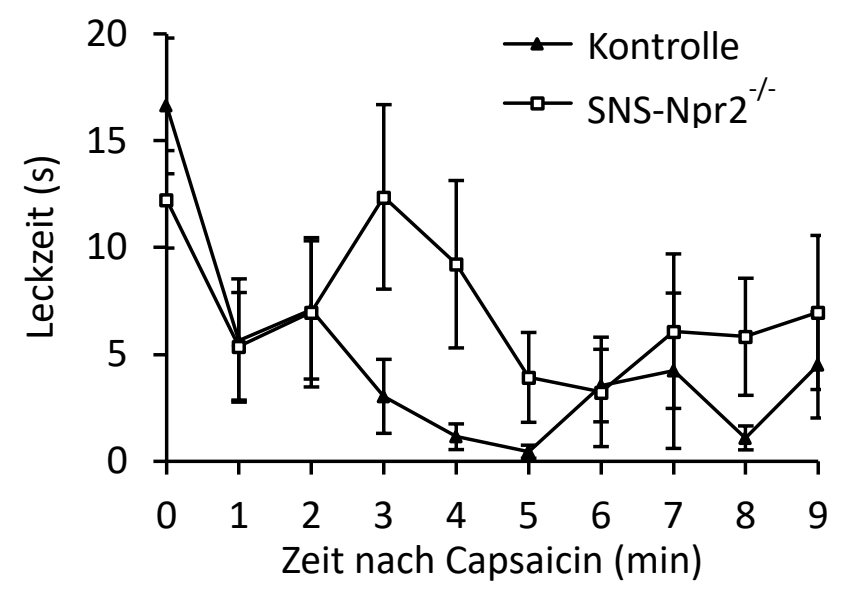

Bi)

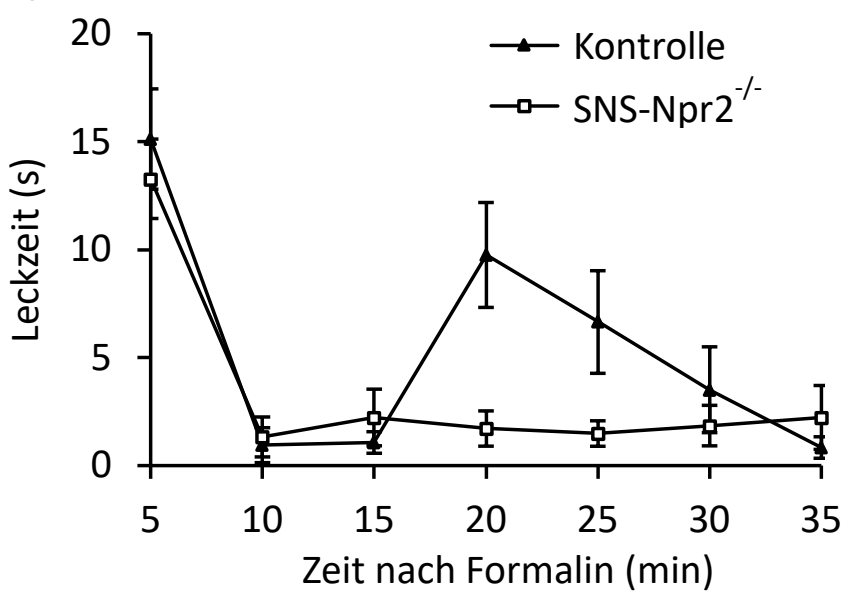

Aii)

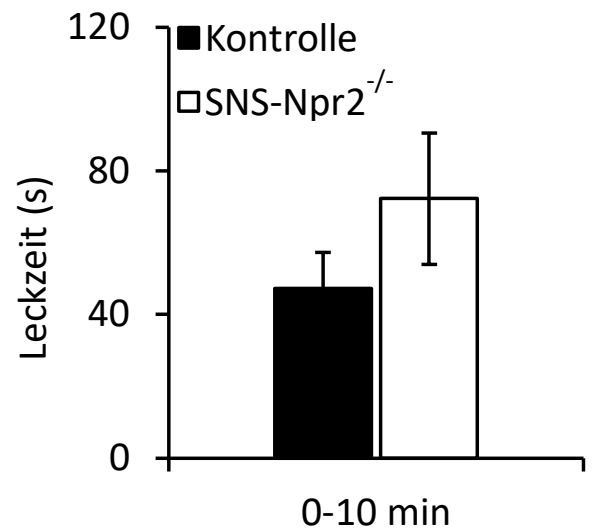

Bii)

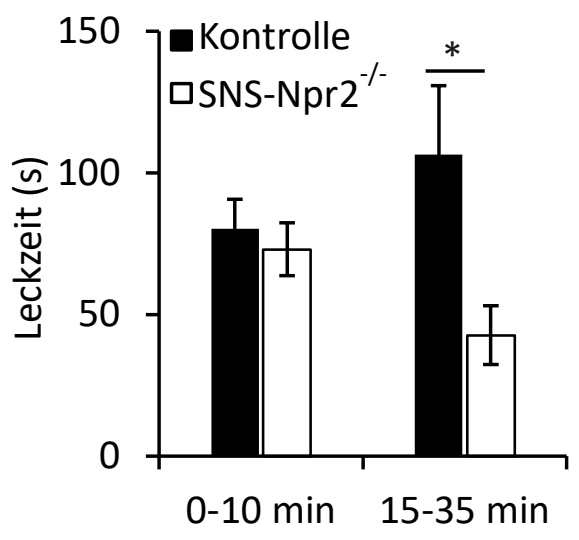

Abbildung 26: Leckverhalten von SNS-Npr2\%- und Kontrollmäusen in Modellen der schnellen Schmerzsensibilisierung. A) Capsaicin-Test. Der Zeitverlauf des Pfotenleckens ist in Ai) und die Summe der Leckzeit über 10 min in Aii) dargestellt. $n=9-10$ Tiere pro Gruppe mit $p=0,263$. B) Formalin-Test. Der Zeitverlauf des Pfotenleckens ist in $\mathrm{Bi}$ ) und die Summe in Phase I (0-10 min) und Phase II (15-35 min) ist in Bii) dargestellt. $n=10$ Tiere pro Gruppe und $p=0,607$ (Phase I) sowie $p=0,034$ (Phase II); die Daten sind dargestellt als Mittelwerte \pm SEM; verwendete Statistik: Repeated-measurement ANOVA und T-Test. 


\subsubsection{Mechanische Hyperalgesie im Modell der Zymosan induzierten Pfotenentzündung}

Um die Bedeutung von NPR2 für persistierende inflammatorische Schmerzen zu untersuchen, wurde das Zymosanmodell verwendet. Das Schmerzverhalten wurde im Zeitverlauf durch mechanische Stimulation mit dem Dynamic Plantar Aesthesiometer analysiert. Kontroll- und SNS-Npr2 $\%$-Mäuse entwickelten gleichermaßen eine mechanische Hyperalgesie $(p=0,74)$, welche zwischen vier bis sieben Stunden ihren Höhepunkt erzielte (s. Abbildung 27 A).
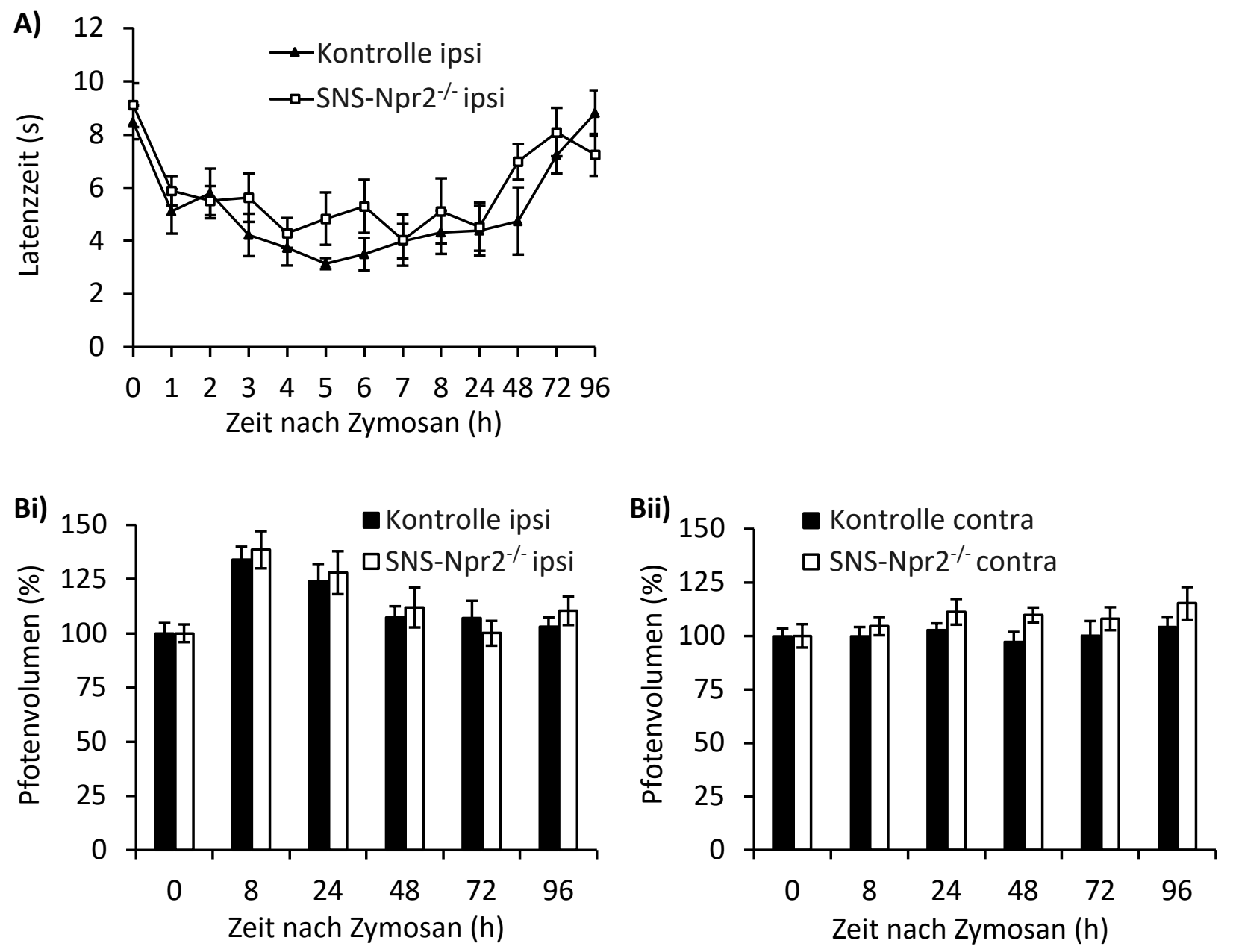

Abbildung 27: Verhalten von SNS-Npr2 ${ }^{--}$und Kontrollmäusen im Modell der Zymosan-induzierten Pfotenentzündung. A) Mechanischen Hyperalgesie nach einseitiger intraplantarer Zymosan A Injektion mit $n=8$ Tieren pro Gruppe und $p=0,515$; B) Pfotenödem Bi) ipslateral im Vergleich zur Bii) kontralateralen unbehandelten Seite; dargestellt ist der Mittelwert \pm SEM; verwendete Statistik: Repeated-Measurement-ANOVA. 
Zudem wurde das sich entwickelnde Pfotenödem untersucht, um eventuelle Unterschiede im Entzündungsgrad festzustellen. Dabei wurde die Schwellung mithilfe eines Plethysmometers bestimmt. Die Messungen erfolgten jeweils an Zeitpunkt Null sowie acht, 24, 48, 72 und 96 Stunden nach Versuchsbeginn. Es konnte gezeigt werden, dass die hervorgerufene Pfotenschwellung nach acht Stunden am stärksten ausgeprägt war (s. Abbildung $27 \mathrm{Bi}$ ). Die kontralaterale Pfote wies hingegen keine Veränderung auf (s. Abbildung 27 Bii). Somit wurde bestätigt, dass eine Entzündungsreaktion durch Zymosan A hervorgerufen wurde, die jedoch in beiden Kohorten gleichermaßen stark entwickelt war.

\subsubsection{Mechanische und thermische Hyperalgesie im Crush Injury Modell}

Zur Untersuchung neuropathischer Schmerzen wurde eine Crush Injury am N. ischiadicus durchgeführt. Um altersbedingte Änderungen auszuschließen, wurde diese sowohl an jungen als auch alten Tieren ausgeführt. Hierbei sollte festgestellt werden, inwieweit NPR2 einen Einfluss auf die Ausbildung chronischer Schmerzen hat. Zur Messung der sich entwickelnden mechanischen Hyperalgesie wurde die Latenzzeit im Dynamic Plantar Aesthesiometer untersucht. In der Kohorte der jungen Tiere bildeten Kontroll- und SNS-Npr2---Mäuse eine vergleichbare mechanische Hyperalgesie aus, die sich nach 3 Tagen manifestierte und während der Degenerationsphase (Tag 0-14) andauerte $(p=0,445)$. Auch konnten keine signifikanten Unterschiede während der Regenerationsphase (Tag 21-35) festgestellt werden (s. Abbildung 28 A). Gleiche Ergebnisse ließen sich für Mäuse der alten Kohorte feststellen ( $p=0,307)$. Hier fiel auf, dass die Streuung innerhalb der Gruppe größer war als bei jungen Mäusen (s. Abbildung $28 \mathrm{~B}$ ). 
A)

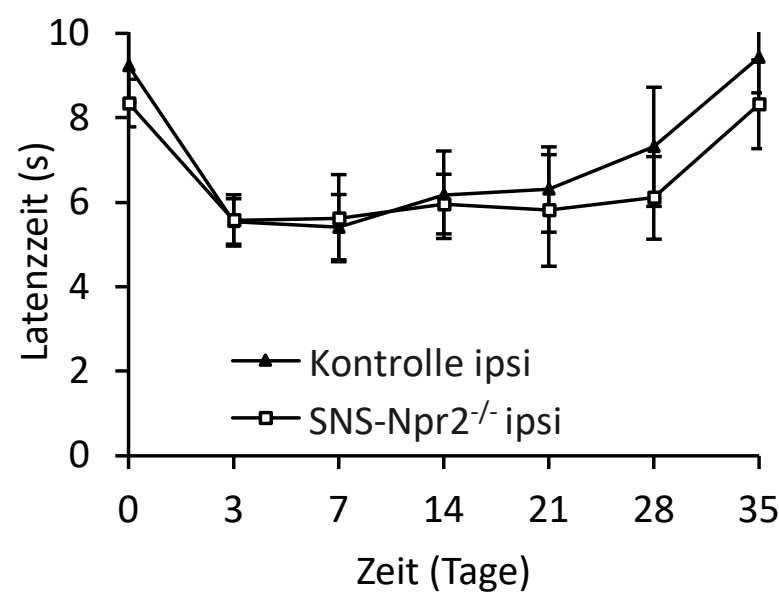

B)

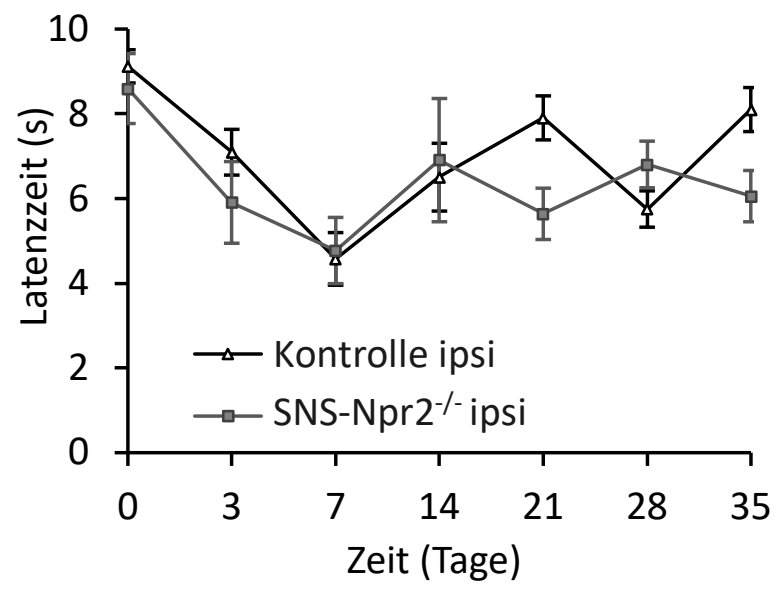

Abbildung 28: Mechanische Hyperalgesie von SNS-Npr2 ${ }^{-}$- und Kontrollmäusen nach Crush Injury. A) Junge Mäuse: 1-4 Monate alt; mit $n=7-8$ Tieren pro Gruppe und $p=0,445$. B) Alte Mäuse: $8-10$ Monate alt; mit $n=5-6$ Tieren pro Gruppe und $p=0,307$; dargestellt ist der Mittelwert \pm SEM; verwendete Statistik: Repeated-Measurement-ANOVA.

Um die thermische Hyperalgesie der Tiere zu untersuchen, wurde zusätzlich der Hargreaves Test durchgeführt. Es konnte gezeigt werden, dass junge SNS-Npr2\%--Mäuse während der Degenerationsphase an Tag 3 eine signifikant erhöhte Latenzzeit gegenüber Kontrolltieren aufwiesen. Diese lag über der basalen Reizreaktion. Im weiteren Messverlauf konnten hingegen keine Gruppenunterschiede festgestellt werden (s. Abbildung 29 A). Messungen an alten Tieren wiesen keine signifikanten Verhaltensänderungen zwischen den Kohorten auf (s. Abbildung 29 ).

A)

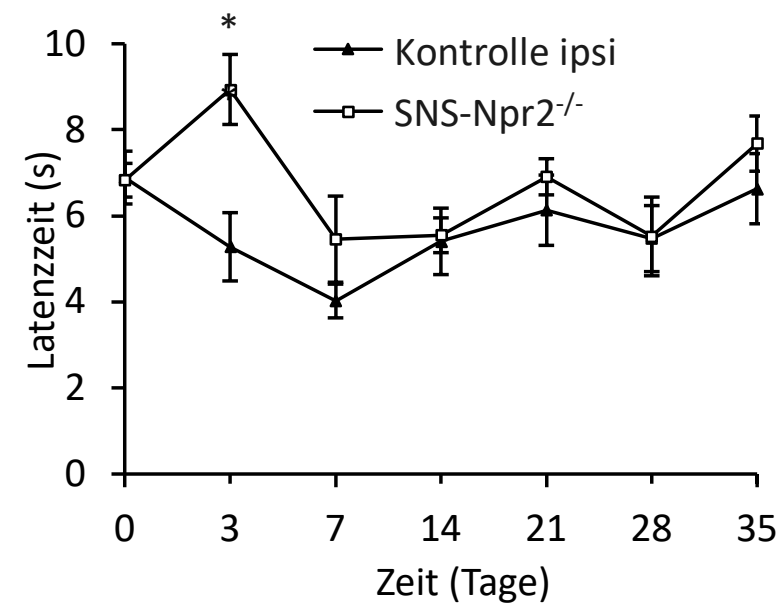

B)

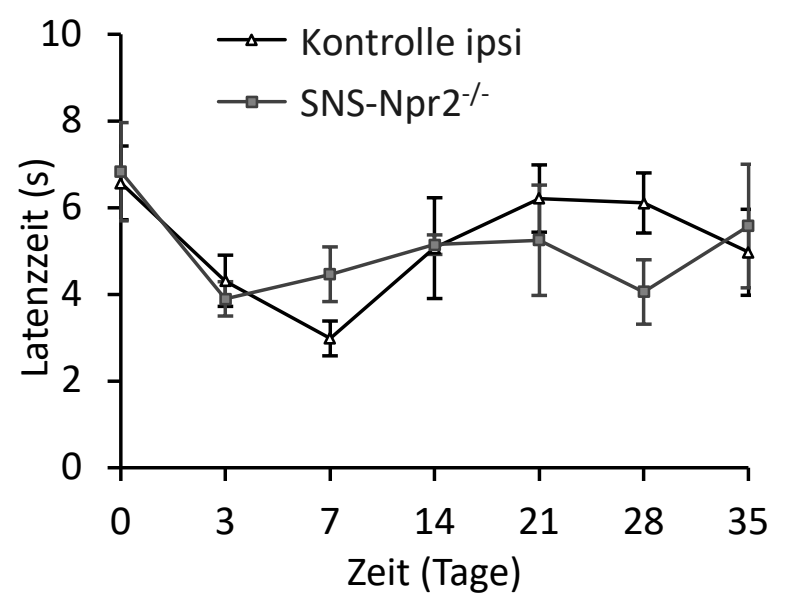

Abbildung 29: Thermischen Hyperalgesie nach Crush Injury A) Junge Mäuse: 1-4 Monate alt; mit $n=7-8$ Tieren pro Gruppe und $p=0,006$. B) Alte Mäuse: 8-10 Monate alt; mit $n=5-6$ Tieren pro Gruppe und $p=0,566$; Dargestellt ist der Mittelwert \pm SEM; verwendete Statistik: Repeated-Measurement-ANOVA. 


\subsection{Generierung und Verifizierung eines konditionellen CNP-Knockouts 4.3.1 Zucht und Grundcharakterisierung der Lbx1-Nppc-Linie}

Neben Mäusen der SNS-Npr2-Linie sollten Tiere mit einem spezifischen Knockout für CNP untersucht werden. Nachdem die Expressionsanalyse für CNP ergab, dass dieses nicht in DRGs, sondern hauptsächlich im Dorsalhorn des Rückenmarks gebildet wurde, sollten Rückenmarksspezifische konditionelle Lbx1-Nppc-Knockoutmäuse generiert werden.

Hierfür wurde vorab mit Hilfe einer kombinierten In-situ-Hybridisierung untersucht, ob CNP von Lbx1 exprimierenden Zellen gebildet wird (s. Abbildung 30). Die Analyse ergab, dass $48,62 \%$ der CNP-positiven Zellen ein Signal für Lbx1 aufwiesen ( $n=4$ Tiere; 1.998 gezählte Zellen). Somit schien Lbx1 als Promotorgen der Cre-Rekombinase für eine konditionelle Rückenmarksspezifische Lbx1-Nppc-Linie geeignet zu sein.
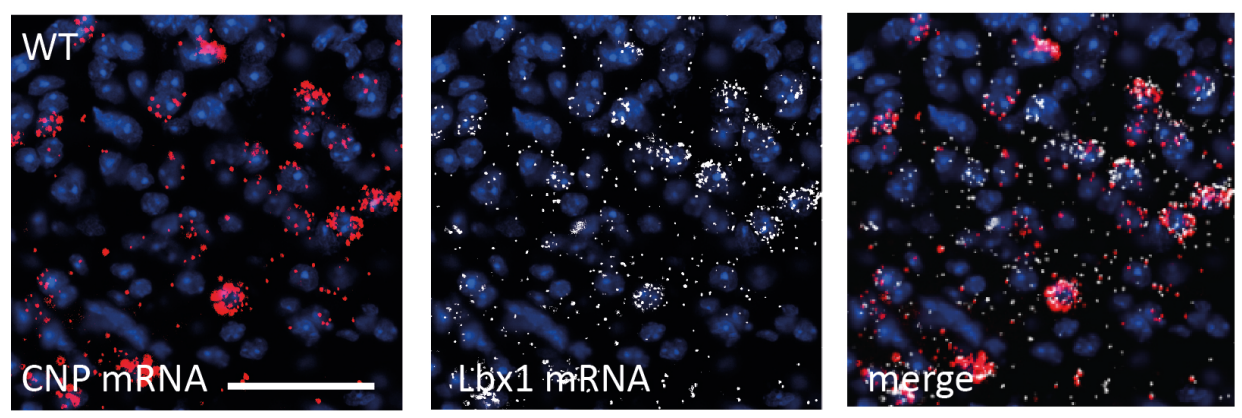

Abbildung 30: In-situ-Hybridisierung zur Untersuchung der Coexpression von CNP (rot) und Lbx1 (weiß); Maßstab $50 \mu \mathrm{m}$.

Für die Genotypisierung wurden neben der bereits beschriebenen Cre-PCR auch eine PCR für die Detektion der loxP-Sequenz im Nppc-Gen durchgeführt. Dabei betrugen die zu erwartenden Banden eine Laufhöhe von 266 bp (WT-Bande) und 300 bp (loxP-Bande). Im Verlauf dieser Arbeit wurde das Problem bekannt, dass weibliche Träger einer Lbx1Cre-Rekombinase für die Zucht konditioneller Knockoutmäuse ungeeignet sind. Ursache ist, dass weibliche Mäuse im geringen Maß dieses Enzym bereits in Oozyten exprimieren. ${ }^{150}$ Somit kann nicht gewährleistet werden, dass nicht schon in der Keimbahn die loxP-Sequenzen erkannt und entfernt werden. Dadurch 
kann eine Runterregulation des flankierten Gens auch in anderen Geweben stattfinden. Ist dies der Fall, resultieren aus dieser Kreuzung globale Knockouttiere (s. Abbildung 31).
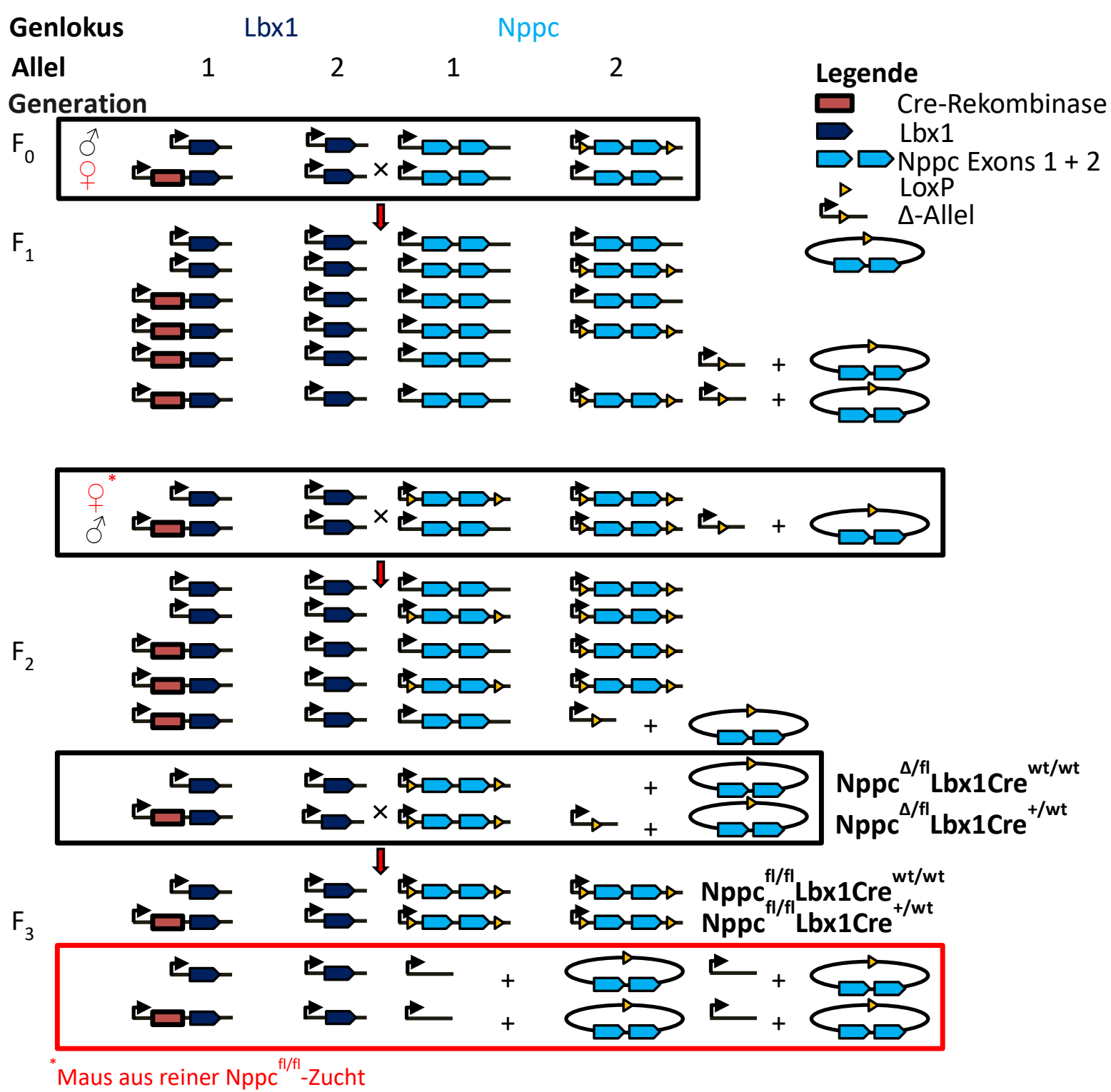

Abbildung 31: Zuchtstrategie der Lbx1-Nppc-Linie; $F_{0}$ : Verpaarung eines weiblichen Lbx1-Cre-Tieres mit einer männlichen Nppc ${ }^{\mathrm{fl} / \mathrm{wt}}$-Maus. $\mathrm{F}_{1}$ : Mögliche Genotypen. Aufgrund transienter Cre-Rekombinaseexpression wird die loxP-Sequenz teilweise in der Keimbahn entfernt. Es entstehen Tiere mit einem $\Delta$-Allel. Die loxP-Sequenz wird nur in einem Teil des Gewebes erkannt, sodass das WT- und das fl-Allel nachgewiesen werden können. $F_{2}$ : Durch Kreuzung

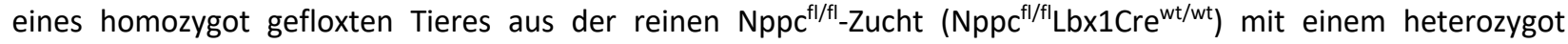

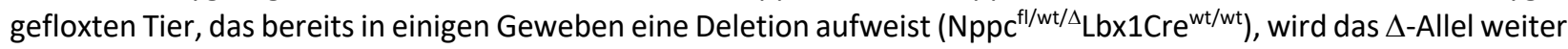

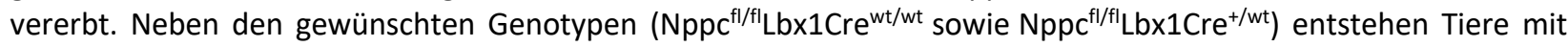
einem vollständigen Verlust des fl-Allels ( $\mathrm{Nppc}^{\mathrm{fl} / \Delta} \mathrm{Lbx}_{1 \mathrm{Cre}^{\mathrm{w} / \mathrm{wt}}}$ und $\mathrm{Nppc}^{\mathrm{fl} / \Delta} \mathrm{Lbx}_{1} \mathrm{Cre}^{+/ \mathrm{wt}}$ ) $\mathrm{F}_{3}$ : Es kommt zum Verlust des Nppc-Gens (Nppc ${ }^{\Delta / \Delta}$ Lbx $1 C r e^{\text {wt } / w t}$ und $\mathrm{Nppc}^{\Delta / \Delta} \mathrm{Lbx}_{1 \mathrm{Cre}}{ }^{+/ \mathrm{wt}}$ ). 
Aus diesem Grund wurde neben der normalen Nppc-flox- eine Triple-PCR durchgeführt, die einen Nachweis der Deletionsbande ( $\Delta$-Bande bei 333 bp) ermöglicht und globale Knockouttiere erkennt (s. Abbildung 32).

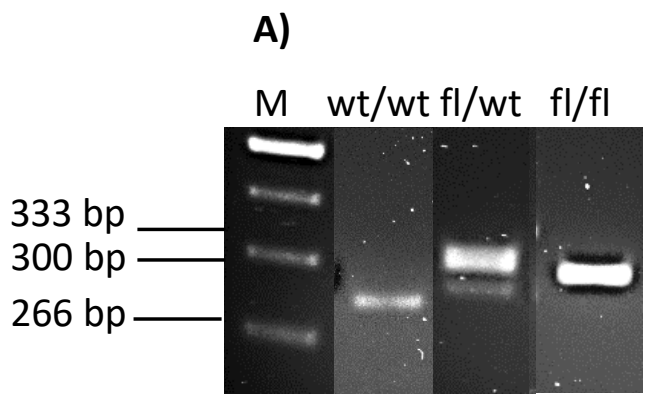

B)

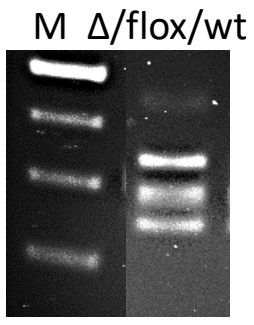

Ci)

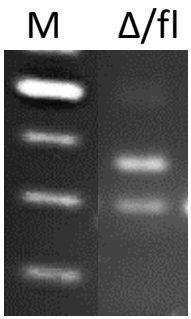

Cii)

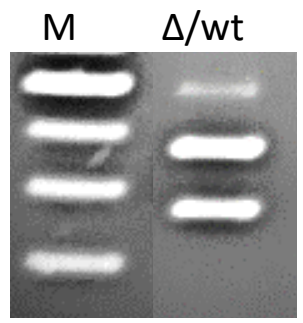

Abbildung 32: Nppc-Triple-PCR zur Detektion des $\Delta$-Allels und der möglichen Genotypen. A) Mögliche Genotypen für $\mathrm{Nppc}$ der $\mathrm{F}_{0}-$ Genertation ( $\mathrm{Nppc}^{\mathrm{wt} / \mathrm{wt}}$; $\mathrm{Nppc}^{\mathrm{fl} / \mathrm{wt}} ; \mathrm{Nppc}^{\mathrm{fl} / \mathrm{fl}}$ ); B) In der $\mathrm{F}_{1}$-Generation findet bereits teilweise eine transiente Cre-Rekombinaseexpression statt. Diese Tiere weisen neben der WT- und Flox-Bande bereits das $\Delta$-Allel auf $\left.\left(\mathrm{Nppc}^{\Delta / f 1 / w t}\right) \mathrm{C}\right)$ In der $\mathrm{F}_{2}$-Generation wurde aufgrund transienter Cre-Rekombinaseexpression eines der gefloxten Allele vollständig entfernt. Diese Tiere weisen nur noch ein gefloxtes Allel $\mathrm{Nppc}^{\Delta / f l} \mathrm{Ci}$ ) bzW. ein WT-Allel Nppc ${ }^{\Delta / \mathrm{wt}} \mathrm{Cii}^{\mathrm{i}}$ sowie die $\Delta$-Bande auf.

Mithilfe dieser PCR wurde bereits in der $\mathrm{F}_{1}$-Generation bei $75 \%$ der Tiere der Lbx1-Nppc-Linie die $\Delta$-Bande identifiziert. Diese Tiere werden im weiteren Verlauf unter der Nomenklatur $\Delta$ Lbx1-Nppc geführt.

Daher wurden in dieser Arbeit hauptsächlich heterozygote globale $\Delta$ Lbx1-Nppc ${ }^{-/}$-Tiere mit entsprechenden $\Delta$ Kontrolltieren verglichen. Die Ergebnisse der Verhaltenstests können somit nicht eindeutig auf die Runterregulation von CNP im Rückenmark zurückgeführt werden.

Parallel zur Analyse der SNS-Npr2-Linie wurde auch hier die Geburtenrate auf das genetische Verteilungsmuster untersucht. Die Analyse ergab, dass in der $\mathrm{F}_{4}$-Generation $73 \%$ aller Tiere die $\Delta$-Bande aufwiesen, wobei 55 \% zusätzlich Cre-Rekombinase-Träger waren. Nur $18 \%$ aller Tiere waren tatsächlich konditionelle Knockouttiere und $9 \%$ zugehörige Kontrolltiere. Die genetische Vererbung schien dabei geschlechtsunabhängig zu sein und entsprach somit den Mendel'schen Regeln (s. Abbildung 33). 


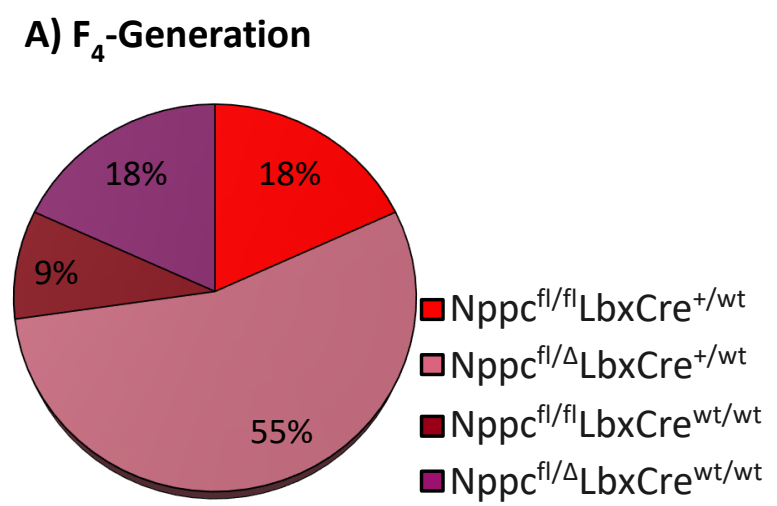

B) $F_{4}$-Generation

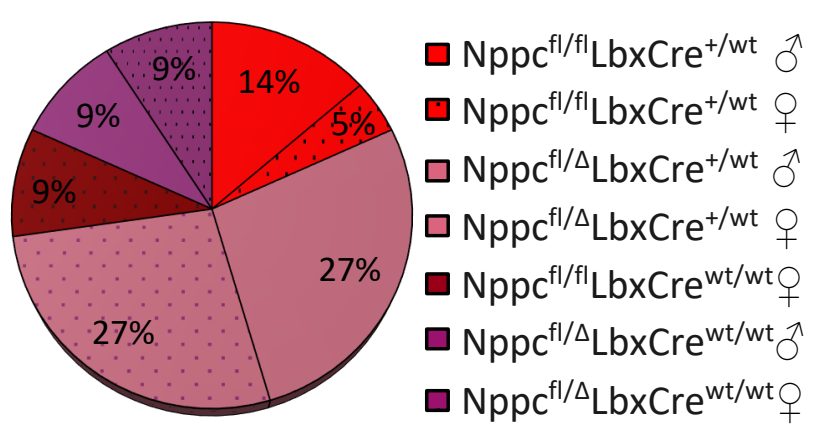

Abbildung 33: Verteilungsrate der möglichen Genotypen in der $F_{3}$-Generation A) Geschlechtsunspezifisch und B) Geschlechtsspezifisch mit $n\left(F_{3}\right)=41$; dargestellt als prozentualer Anteil.

Da auch für globale Nppc-Knockoutlinien die Literatur eine erhöhte Sterblichkeitsrate beschreibt, ${ }^{149}$ wurde das Überleben der $\Delta$ Lbx1-Nppc-Linie über zwei Monate erfasst. Es konnte festgestellt werden, dass Mäuse dieser Linie keine erhöhte Letalität aufwiesen. Auch wurden keine Gruppenunterschiede bezüglich des Körpergewichts (s. Abbildung 34 A) oder der Naso-analen Länge festgestellt (s. Abbildung 34 B und C). 
A)

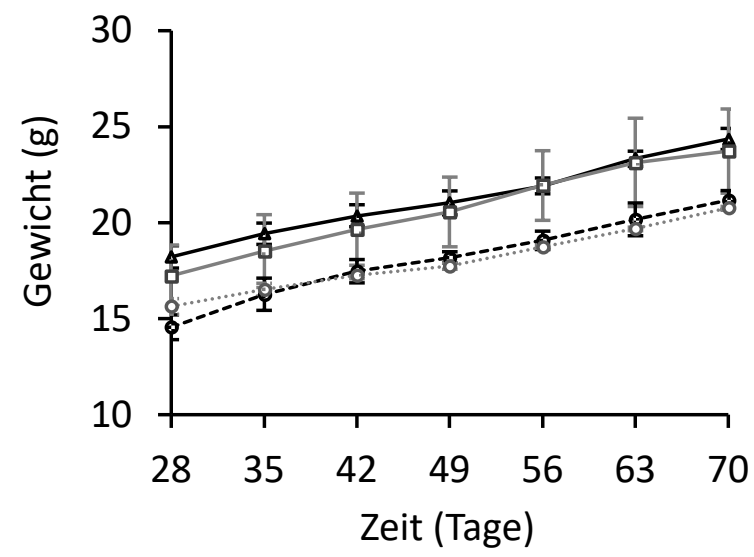

C)

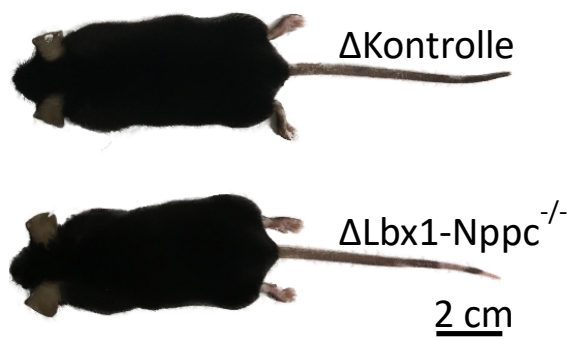

B)

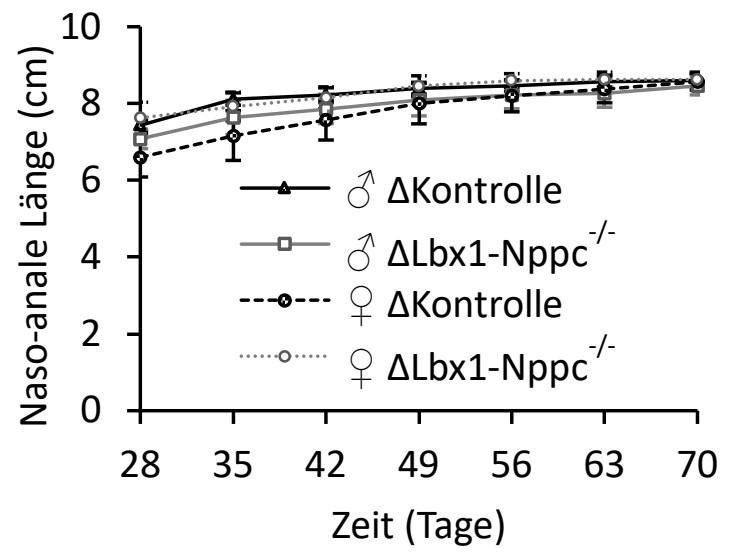

Abbildung 34: A) Körpergewicht ( $p$ (männlich) $=0,764$ und $p$ (weiblich) $=0,930)$ und B) Naso-anale Länge $\left(\mathrm{p}\right.$ (männlich) $=0,385$ und $\mathrm{p}$ (weiblich) $=0,343$ ) von $\Delta$ Lbx1-Nppc ${ }^{-1-}$-Mäusen und zugehörigen $\Delta$ Kontrolltieren; $n=4-5$ Tiere pro Gruppe und Geschlecht C) Repräsentative Darstellung der Körpergröße von $\Delta$ Lbx1-Nppc ${ }^{-/}$-Mäusen und zugehörigen $\Delta$ Kontrolltieren im ausgewachsenen Stadium; die Daten sind dargestellt als Mittelwerte \pm SEM; verwendete Statistik: Repeated-Measurement-ANOVA.

Nachdem bekannt wurde, dass Mäuse dieser Linie teilweise als Träger der $\Delta$-Bande heterozygote globale Knockouttiere waren, wurden im Anschluss Tiere aus der reinen Nppc-flox-Zucht

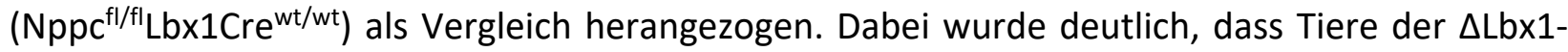
Nppc-Linie verkürzte Extremitäten und somit eine gestörte chondrale Ossifikation aufwiesen (s. Abbildung 35), die auch bei globalen CNP /--Mäusen auftritt. ${ }^{149,151}$ 


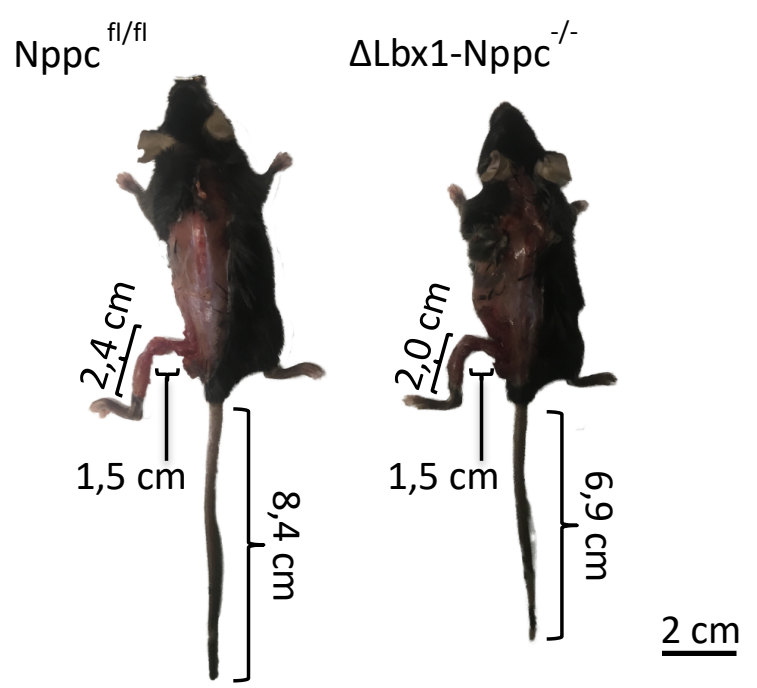

Abbildung 35: Darstellung der chondralen Ossifikation in globalen $\Delta$ Lbx1-Nppc ${ }^{-/}-$Mäusen im Vergleich zu Kontrolltieren der reinen Nppc-flox-Zucht; Alter der Tiere: 4 Monate.

\subsection{2 Überprüfung der motorischen Koordination}

Bevor die Linie in schmerzrelevanten Verhaltenstests untersucht wurde, wurde sie im Rotarod-Test auf eine eingeschränkte Motorik getestet. Dieser Test ergab, dass nicht alle Tiere die Cut-off-Zeit von 120 Sekunden erreichten. Hiervon waren jedoch nur Kontrolltiere betroffen (s. Abbildung 36). Die statistische Auswertung nach dem Mann-Whitney-U-Test ergab keinen signifikanten Gruppenunterschied.

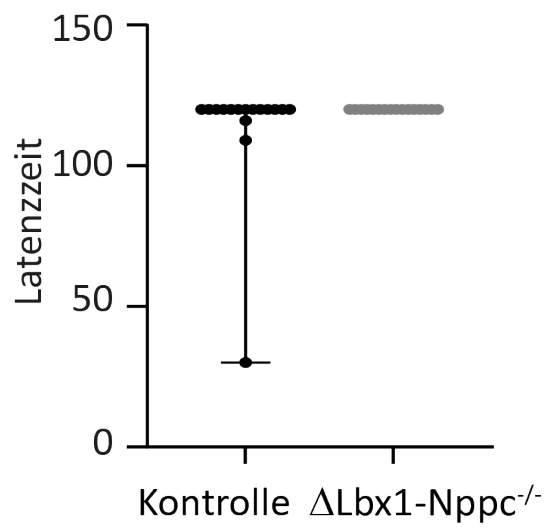

Abbildung 36: Rotarod-Test der $\Delta$ Lbx1-Nppc-Linie; dargestellt ist der Median der Latenzzeit mit Interquartilsabstand. Die Cut-off-Zeit betrug $120 \mathrm{~s}$; mit $\mathrm{n}=16$ Tieren pro Gruppe und $\mathrm{p}=0,074$; verwendete Statistik: Mann-Whitney-U-Test. 


\subsubsection{Modelle des akuten nozizeptiven Schmerzes}

Wie bereits in Kapitel 4.2.5 für die Linie SNS-Npr2 beschrieben, wurde auch bei der Linie $\Delta$ Lbx1-Nppc die mechanische und thermische Nozizeption im Dynamic Plantar (s. Abbildung 37 A), Hargreaves (s. Abbildung 37 B), sowie im Tail-Flick Test (s. Abbildung 37 C) untersucht. Allerdings ließen sich für keinen der Versuche signifikante Änderungen zwischen den beiden Kohorten feststellen.

A) Dynamic Plantar Test

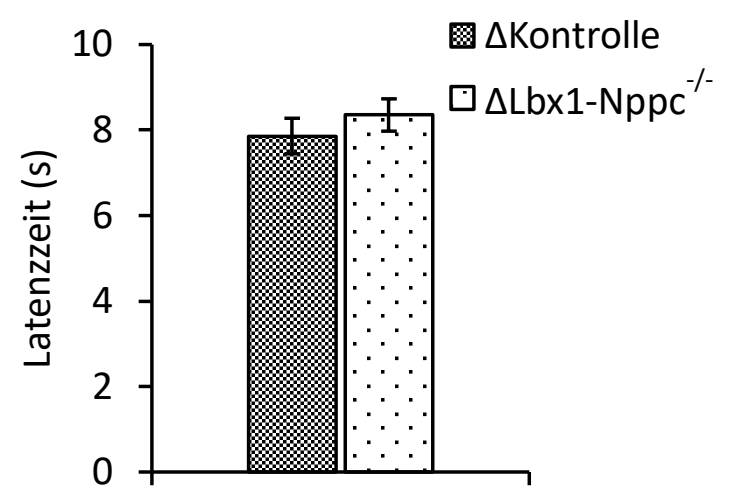

C)

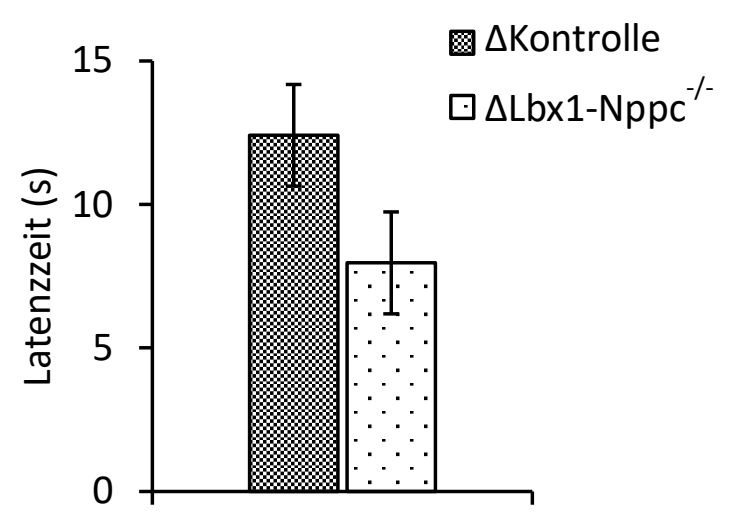

B) Hargreaves Test

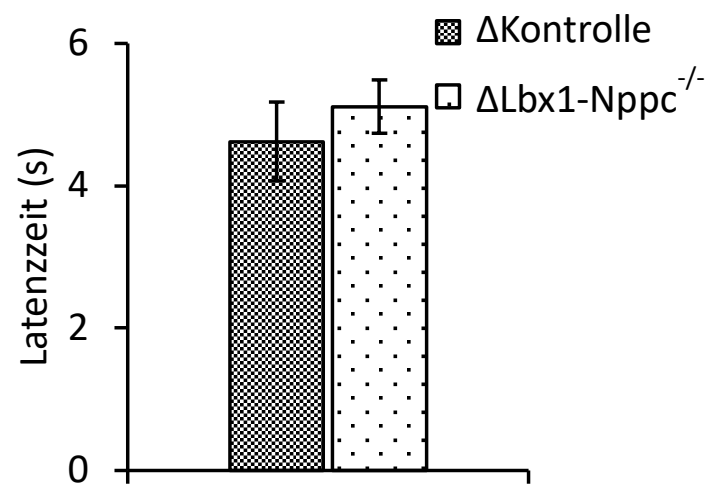

Abbildung 37: Akutes nozizeptives Verhalten der $\Delta$ Lbx1-Nppc ${ }^{-/-M a ̈ u s e ~ u n d ~} \Delta$ Kontrolltieren. A) Latenzzeit nach mechanischer Stimulation im Dynamic Plantar Test; mit $n=6-7$ Tieren pro Gruppe und $p=0,397$; B) Latenzzeit nach thermischer Stimulation im Hargreaves Plantar Test; mit $n=6$ pro Tieren Gruppe und $p=0,486$. C) Latenzzeit nach thermischer Stimulation im Hargreaves Tail-Flick Test; mit $n=6$ Tieren pro Gruppe und $p=0,106$; dargestellt ist der Mittelwert \pm SEM; verwendete Statistik: T-Test. 
Neben den zuvor aufgeführten Versuchen wurde der Hot-Plate-Test durchgeführt. Dieser ergab, dass $\Delta$ Lbx1-Nppc ${ }^{-/}-$Mäuse im Vergleich zu $\Delta$ Kontrolltieren bei $52{ }^{\circ} \mathrm{C}$ und $54{ }^{\circ} \mathrm{C}$ eine signifikant reduzierte Hitzeempfindlichkeit aufwiesen (s.Abbildung $38 \mathrm{~A}$ ).

Die Analyse von Lbx1-Nppc ${ }^{-/-}$-Mäusen und entsprechenden Kontrolltieren, die nicht über die $\Delta$-Bande verfügten, schienen bei $52{ }^{\circ} \mathrm{C}$ ähnliche Tendenzen zu zeigen (s. Abbildung $38 \mathrm{~B}$ ). Da die vorhandene n-Zahl jedoch zu gering war, wurde hier auf eine statistische Auswertung verzichtet.

A)

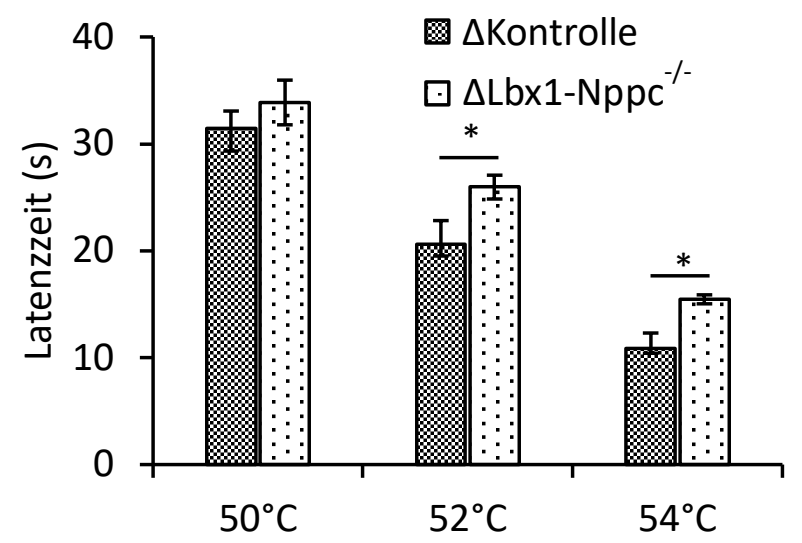

B)

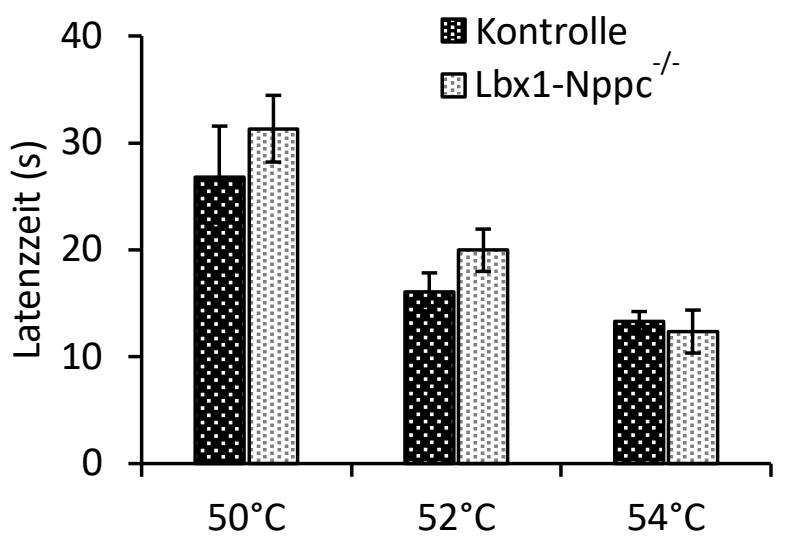

Abbildung 38: Hot-Plate Test A) $\Delta$ Lbx1-Nppc ${ }^{-/}-$Mäuse und entsprechende Kontrolltiere; mit $\mathrm{n}=8$ - 11 Tieren pro Gruppe und $p=0,449$ bei $50{ }^{\circ} \mathrm{C}$ und $p=0,050$ bei $52{ }^{\circ} \mathrm{C}$ und $p=0,029$ bei $54{ }^{\circ} \mathrm{C}$. B) Lbx1-Nppc ${ }^{-/}$-Mäuse und entsprechende Kontrolltiere; mit $n=3-6$ Tiere pro Gruppe; dargestellt ist der Mittelwert \pm SEM; verwendete Statistik: T-Test. 


\subsection{Verhaltenstest an CRP4-Mäusen}

In vorherigen Studien wurde CRP4 als mögliches Target im NPR2-vermittelten Schmerzmechanismus identifiziert. Daher wurden neben Mäusen der Linien SNS-Npr2 und $\Delta$ Lbx1-Nppc auch globale Knockoutmäuse der CRP4-Linie in ausgewählten Verhaltenstests untersucht. CRP4-Mäuse sind lebensfähig und fertil. Sie weisen eine normale Körpergröße auf und zeigen keine schwerwiegenden körperliche oder verhaltenstechnische Beeinträchtigungen. ${ }^{110}$

\subsubsection{Der Hot-Plate Test als akutes nozizeptives Schmerzmodell}

Aufgrund der Beobachtung, dass SNS-Npr2\%- sowie $\Delta$ Lbx1-Nppc ${ }^{-/-M a ̈ u s e ~ e i n e ~ e r h o ̈ h t e ~}$ Hitzeschmerztoleranz gegenüber entsprechenden Kontrolltieren aufzeigten, wurde der Hot-Plate-Test auch bei Tieren der CRP4-Linie durchgeführt. Obwohl für CRP4\%-Mäuse bei einer Temperatur von $52^{\circ} \mathrm{C}$ die Tendenz zu einer erhöhten Hitzeempfindlichkeit $(p=0,071)$ verzeichnet wurde, ließen sich für keine der eingesetzten Temperaturen $\left(50^{\circ} \mathrm{C}, 52^{\circ} \mathrm{C}, 54^{\circ} \mathrm{C}\right)$ signifikante Unterschiede zwischen den beiden Gruppen feststellen (s. Abbildung 39).

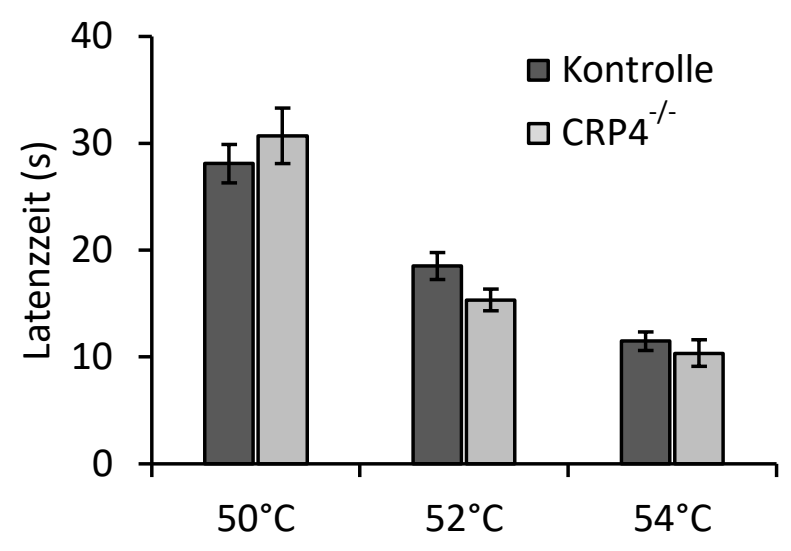

Abbildung 39: Daten des Hot-Plate-Test für globale CRP4 $\%$-Mäuse mit $n=10-12$ Tieren pro Gruppe 10 und $p=0,407$ bei $50{ }^{\circ} \mathrm{C}$ und $p=0,0714$ bei $52{ }^{\circ} \mathrm{C}$ und $p=0,463$ bei $54{ }^{\circ} \mathrm{C}$; dargestellt ist der Mittelwert \pm SEM; verwendete Statistik: T-Test. 


\section{$5 \quad$ DISKUSSION}

In vorherigen Studien konnte gezeigt werden, dass cGMP eine wichtige Funktion in der Schmerzverarbeitung hat. Über die Aktivierung der cGMP-abhängigen Proteinkinase cGKIa erfolgt die Phosphorylierung verschiedener Downstream-Targets, die den Reiz zur weiteren Verarbeitung an das Gehirn leiten. Während der Einfluss der cGMP-produzierenden NO-GCs bereits intensiv erforscht wurde, ist die Funktion der partikulären Guanylatzyklasen im nozizeptiven System weitgehend unklar. Einige Studienergebnisse liefern jedoch Hinweise, dass cGKIa in DRGs mit partikulären Guanylatzyklasen colokalisiert und nach Stimulation mit natriuretischen Peptiden aktiviert wird. ${ }^{118}$ Daher sollte im Rahmen der vorliegenden Arbeit die Rolle dieser Enzymklasse auf die Schmerzverarbeitung mithilfe von Expressionsanalysen und tierexperimentellen Tests genauer untersucht werden.

\subsection{Expressionsanalysen von CNP und NPR2 und möglichen Downstream- Targets}

Um Hinweise für die Bedeutung partikulärer Guanylatzyklasen in der Schmerzverarbeitung zu erlangen, wurde zunächst der Bildungsort von CNP, NPR1 und NPR2 im schmerzrelevanten Gewebe untersucht. Hierfür wurden In-situ-Hybridisierungen, Immunfluoreszenz- und x-GalFärbungen angefertigt (s. Kapitel 4.1).

Expressionsanalysen für NPR1 und NPR2 im Gewebe adulter Mäuse zeigten, dass NPR1 nicht in Spinalganglien exprimiert wird (s. Kapitel 4.1.2). NPR2 hingegen wurde in nahezu $80-90 \%$ aller DRG-Neurone nachgewiesen, wobei circa $60 \%$ von A $\delta$ - und C-Fasern gebildet werden. Das Ergebnis steht im Widerspruch zu Daten der $\mathrm{x}$-Gal-Färbung sowie Publikationen anderer Arbeitsgruppen. ${ }^{95}$ Diese dokumentierten anhand von $\mathrm{Npr}^{+/ \text {LacZ }}$-Mäusen, dass NPR2 im Embryonalzustand stark exprimiert wird, postnatal jedoch auf $10 \%$ absinkt. ${ }^{95}$ Daher wurden verschiedene Kontrollexperimente durchgeführt. Weder Daten der qPCR noch der Einsatz einer zweiten In-situ-Hybridisierungssonde bestätigten eine altersbedingte Abnahme des relativen mRNA-Levels (s. Kapitel 4.1.2). Unterstützt werden Ergebnisse der vorliegenden Arbeit auch von zwei verschiedenen Transkriptomanalysen. ${ }^{16,17}$ Beide Arbeiten belegten eine starke NPR2- 
Expression in sensorischen Neuronen adulter Mäuse (Alter: sechs bis acht Wochen). Zudem bestätigten sie die Ergebnisse der Expressionsanalyse zu NPR1: Auch hier konnte NPR1 nicht in DRG-Neuronen detektiert werden. ${ }^{16,17}$

Aktiviert wird NPR2 durch den Peptidliganden CNP. Es konnte festgestellt werden, dass weder Ergebnisse der In-situ-Hybridisierung noch $x$-Gal-Färbungen eine Expression für CNP in DRG-Neuronen zeigten. Allerdings scheint CNP verstärkt in Neuronen des Dorsalhorns gebildet zu werden. Gleiche Resultate erzielten die Trankskriptomanalysen der genannten Studien. ${ }^{16,17,152}$ Dabei scheint CNP vor allem in GABAergen inhibitorischen Neuronen der Laminae II-VI sowie in glutamatergen exzitatorischen Neuronen der Laminae II-V des Rückenmarks exprimiert zu werden. ${ }^{16}$ Diese Ergebnisse decken sich mit der quantitativen Auswertung der kombinierten In-situ-Hybridisierung für CNP mit VGAT und VGLUT2. Hier konnte gezeigt werden, dass CNP zu gleichen Anteilen in exzitatorischen sowie inhibitorischen Neuronen vorliegt (s. Kapitel 4.1.1). Aufgrund der Tatsache, dass nicht alle Signale für CNP neuronal zugeordnet werden konnten, wird vermutet, dass CNP auch im Gefäßendothel exprimiert werden könnte, wie es in anderen Studien beschrieben wurde. ${ }^{153}$ Dies deutet darauf hin, dass CNP vom Rückenmark freigesetzt und retrograd die Aktivierung von NPR2 in DRG-Neuronen bewirken könnte.

Ein wichtiges Schlüsselprotein in der Reizweiterleitung von Schmerzen ist die cGMP-abhängige Proteinkinase $1 \alpha$ (cGKl $\alpha)$. Viele Studien zeigten, dass cGKl $\alpha$ in der Mehrzahl primär afferenter Neurone exprimiert wird $^{7,108,110,112,154}$ und mit NPR2 colokalisiert ist ${ }^{96,116-118}$.

Ergebnisse der vorliegenden Arbeit konnte diese Annahmen bestätigen. So konnte gezeigt werden, dass CGKI $\alpha$ in allen NPR2-positiven Zellen gebildet wird, was mit den Expressionsanalysen von Zeisel übereinstimmt. ${ }^{16}$ Diese Beobachtungen stützen die Vermutung, dass eine schmerzassoziierte cGMP-Produktion in DRG-Neuronen durch NPR2 reguliert ist. Weitere Hinweise, die den Einfluss von NPR2 im nozizeptiven System untermauern, ergibt die nachgewiesene Colokalisierung von NPR2 und cGKI a mit CRP4 in DRG-Neuronen (s. Kapitel 4.1.3). CRP4 wurde in der Literatur bereits als wichtiger Mediator in der Reizweiterleitung von Schmerzen beschrieben. ${ }^{110}$ So liefern tierexperimentelle Verhaltenstests mit CRP4\%--Mäusen 
Hinweise, dass dieses Protein eine antiinflammatorische Funktion einnimmt. ${ }^{110}$ Aktiviert wird CRP4 durch Phosphorylierung. Indem NPR2 über rückenmarksstämmigen CNP in DRG-Neuronen aktiviert wird, könnte über die dadurch ausgelöste cGMP-Produktion cGKla aktiviert werden. Diese könnte im nächsten Schritt eine Phosphorylierung von CRP4 ermöglichen. CRP4, nun in seiner aktiven Form, kann das Signal weiter prozessiert (s Abbildung 40).

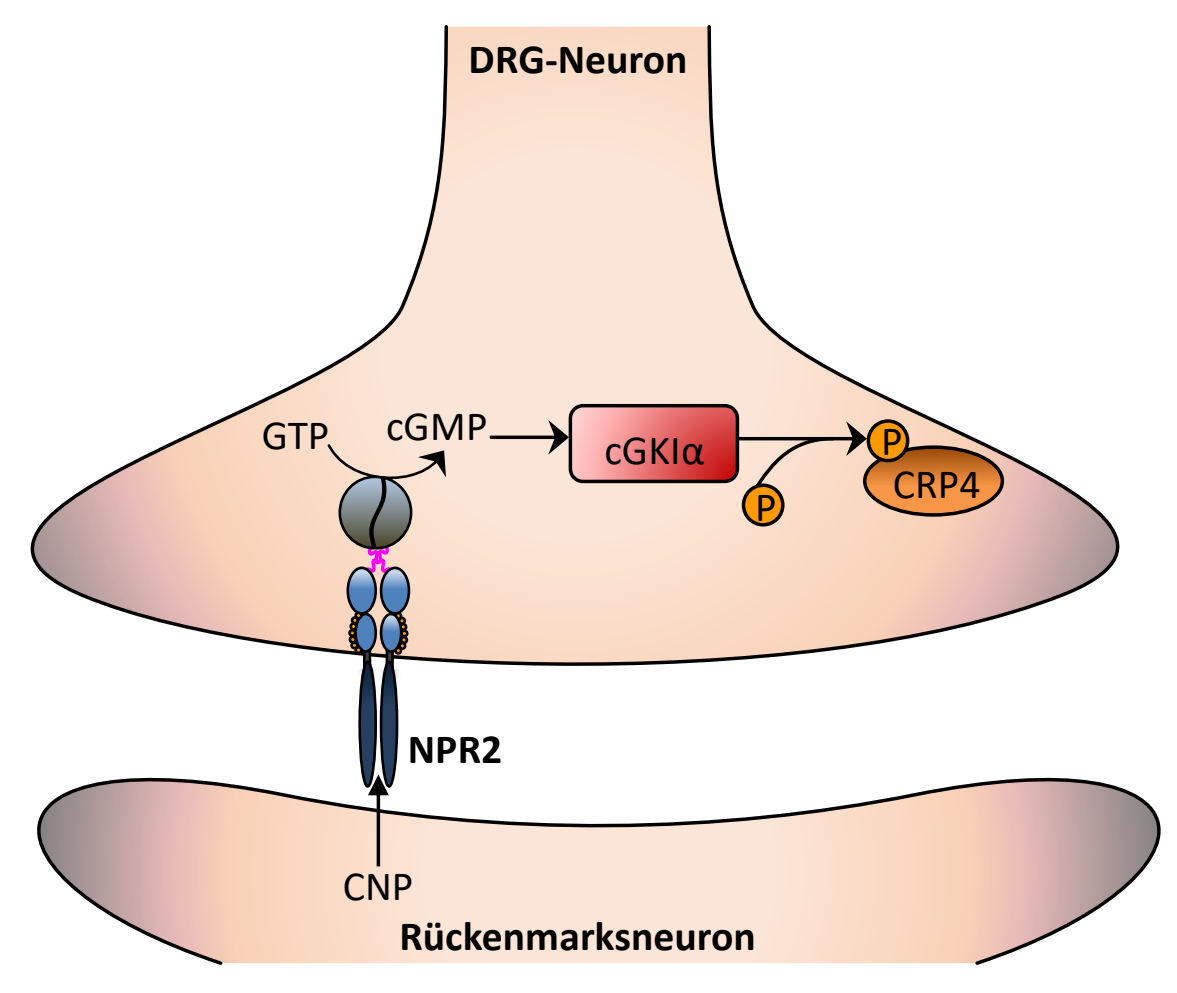

Abbildung 40: Möglicher Signalweg von NPR2 und CRP4. Über einen retrograden Transport aus dem Rückenmark kann CNP an NPR2 binden. Die Bildung von cGMP ermöglicht die Aktivierung von cGKl $\alpha$, welche im Anschluss CRP4 phosphoryliert. Dadurch wird das Signal weiter prozessiert.

\subsection{Grundcharakterisierung und Zuchtprobleme der verschiedenen Mauslinien}

Nachdem CNP und NPR2 im nozizeptiven System lokalisiert wurden, sollte anhand gewebsspezifischer Knockoutmäuse untersucht werden, welchen Einfluss sie auf die Verarbeitung von Schmerzen haben. Hierfür wurden konditionelle Adv-Npr2 ${ }^{-{ }_{-}}$, SNS-Npr2 ${ }^{--}$ sowie Lbx1-Nppc ${ }^{--}$- Mäuse generiert. Aus früheren Studien ist bekannt, dass ein Fehlen von CNP und NPR2 mit verschiedenen Defekten assoziiert ist. Es konnte festgestellt werden, dass ein 
globaler Knockout von CNP und NPR2 zu Kleinwuchs führt. Zudem weisen Tiere einer solchen Linie eine erhöhte Letalität auf. ${ }^{74,77,82,95,146,148,149}$ Neben einer verringerten Naso-analen Länge zeichnen sich diese Mäuse durch eine Verkürzung der mittleren und distalen Extremitäten sowie der Schwanzlängen aus. ${ }^{149}$ Im Gegensatz hierzu konnten bei konditionellen SNS-Npr2 ${ }^{-/-M a ̈ u s e n ~}$ weder Auffälligkeiten bezüglich ihres Wachstums noch Einschränkungen in ihrer Lebenserwartung verzeichnet werden. Anders verhielt es sich bei Tieren der Lbx1-Nppc-Linie. Diese zeigten zwar keine verkürzte Lebenserwartung oder signifikante Unterschiede in ihrer Naso-analen Länge. Allerdings wurden sowohl in der Kontroll- als auch in der Knockoutkohorte vermehrt Kümmerlinge geboren, die durch eine Verkürzung der hinteren Extremitäten und des Schwanzes auffielen. Damit einhergehend zeigten Ergebnisse des Rotarodtests, dass einige Mäuse dieser Linie die Cut-off-Zeit von 120 s nicht erreichten. Auffällig war, dass dies vor allem Tiere der Kontrollgruppe betraf.

Mögliche Ursache hierfür könnte die nicht erfolgreiche Anwendung des Cre-Lox-Systems sein, welches für die Zucht eingesetzt wurde. Die Cre-Rekombinase ist in der Regel auf Gene ausgerichtet, die in einer begrenzten Zellzahl adulter Mäuse exprimiert werden. Durch Kreuzung einer Cre-Mauslinie mit einer Linie, welche die Cre-Rekombinase-Erkennungssequenz loxP trägt kann jedoch eine unerwartete transiente Expression der Cre-Rekombinase in der Keimbahn oder während der frühen Entwicklung ausgelöst werden. Dabei ist schon eine schwache Expression dieses Enzyms ausreichend, um die loxP-Sequenz zu erkennen und unerwünschte Rekombinationsereignisse zu erzeugen. Da Lbx1 in geringem Maße in Oozyten weiblicher Mäuse exprimiert wird, ${ }^{150}$ kann im Falle einer Verpaarung mit weiblichen Lbx1-Cre ${ }^{+/ w t}$-Trägern die Cre-Rekombinase schon in der Keimbahn aktiv sein. Auch das Gen Nppc wird wegen seiner Rolle in der Bifurkation sowie des Knochenwachstums während der Embryonalentwicklung früh exprimiert. ${ }^{127,155}$ Da bereits für die erste Kreuzung weibliche Lbx1-Cre ${ }^{+/ w t}-M a ̈ u s e ~ e i n g e s e t z t$ wurden, fand offenbar schon in der $\mathrm{F}_{1}$-Generation eine Rekombination des gefloxten Nppc-Allels

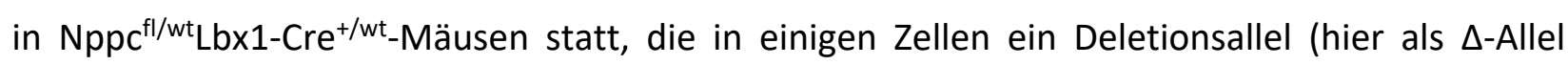
bezeichnet) erzeugten. ${ }^{156,157}$ Dieses wurde durch erneute Verpaarung unabhängig vom Lbx1-Cre+-Allel weitervererbt. Somit wurden neben konditionellen Lbx1-Nppc- hauptsächlich heterozygote globale $\Delta$ Lbx1-Nppc-Mäuse generiert, die sich phänotypisch durch ein verkürztes 
longitudinales Knochenwachstums manifestierten. Verhaltenstests mit diesen Tieren müssen daher kritisch betrachtet werden und können lediglich als Hinweis für einen möglichen Einfluss von CNP auf das nozizeptive System dienen.

Eine transiente Expression der Adv-Cre-Rekombinase ist möglicherweise auch Ursache für die Zuchtproblematik der Adv-Npr2-Linie, die eine sehr geringe Anzahl von Mäusen des gewünschten Genotyps Npr2 $2^{\mathrm{fl} / \mathrm{fl} /} / \mathrm{Adv}-\mathrm{Cr} \mathrm{e}^{+/ \mathrm{wt}}$ hervorbrachte. Auch hier wurden für die Verpaarung weibliche $\mathrm{Adv}^{-C r e}{ }^{+/ w t}-M a ̈ u s e ~ e i n g e s e t z t$. Für Adv-Cre wird in der Literatur ebenfalls eine geringe Rekombinase-Expression in Oozyten beschrieben. ${ }^{150,158}$ Für diese Vermutung spricht, dass in der $F_{1}$-Generation teilweise Tiere auftraten, die negativ für loxP waren und nur das WT-Allel trugen. Da für diese Zucht bereits in der Fo-Generation homozygote Npr2 ${ }^{\mathrm{fl} / \mathrm{fl}}-\mathrm{Tiere}$ mit Adv-Cre ${ }^{+/ \mathrm{wt}_{-}}$-Tieren verpaart wurden, müsste im Falle einer gerichteten Rekombination in der $\mathrm{F}_{1}$-Generation ausschließlich heterozygot gefloxte Mäuse geboren werden. Dies deutet darauf hin, dass bereits in der Keimbahn eine Deletion des gefloxten Allels stattfand.

Neben ihrer Bedeutung in der chondralen Ossifikation sind NPR2 und CNP gemeinsam mit cGKI als führende Faktoren identifiziert worden, die die T-Verzweigung der Zentralaxone entlang des Rückenmarks regulieren. ${ }^{94,95,127,159,160}$ Fehlen diese Faktoren, treten Anomalien der Rückenmarksmorphologie auf, ${ }^{95,161}$ was gegebenenfalls das nozizeptive Verhalten der Versuchstiere beeinflussen könnte. ${ }^{162}$

Für SNS-Npr2\%-Mäuse konnten weder Anomalien in der Rückenmarksmorphologie noch in der Zusammensetzung verschiedener schmerzrelevanter neuronaler Subpopulationen in DRGs nachgewiesen werden (s Kapitel 4.2.3.1). Auch zeigten SNS-Npr2\%-Mäuse keine Defekte in ihrer motorischen Koordination. Daher konnte sichergestellt werden, dass die Ergebnisse der weiteren Tests auf die Rolle von NPR2 in nozizeptiven Prozessen zurückzuführen sind. 


\subsection{Auswertung der Verhaltenstests mit Mäusen der Linien SNS-Npr2 und Lbx1-Nppc}

Um weitere Hinweise über ein mögliches Zusammenspiel von CNP, NPR2, cGMP, cGKI $\alpha$ und CRP4 und ihrer Bedeutung im nozizizeptiven System zu erlangen, wurden im Anschluss die zuvor beschriebenen Mauslinien in verschiedenen tierexperimentellen Analysen genauer untersucht.

Zunächst wurden Verhaltenstests durchgeführt, die die mechanische Reizbarkeit unter

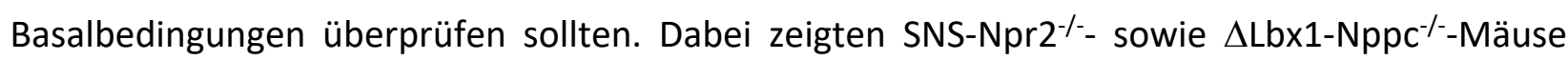
eine normale Reaktion auf. Gleiches ließ sich aus früheren Studien mit CRP4\%--Mäusen feststellen. ${ }^{110}$ Diese Ergebnisse lassen darauf schließen, dass NPR2, CNP sowie CRP4 nicht an molekularen Mechanismen beteiligt sind, die für die Weiterleitung nichtschädigender Reize verantwortlich sind.

Allerdings schienen SNS-Npr2/--Mäuse im Hot-Plate Test eine signifikant erhöhte Hitzeschmerzschwelle zu haben, die sowohl bei jungen als auch alten Tieren ausgeprägt war. Dies deutet darauf hin, dass NPR2 an hitzerelevanten Signalwegen beteiligt ist. Gleiche Ergebnisse erzielte Tröster et al. mit Npr2 ${ }^{\mathrm{fl} / \mathrm{fl}} ; \mathrm{Wnt}^{\mathrm{Cre}}-$ Mäusen. ${ }^{95} \mathrm{Npr} 2^{\mathrm{fl} / \mathrm{fl}} ; \mathrm{Wnt} 1^{\mathrm{Cre}}-$ Mäuse wiesen jedoch Bifurkationsstörungen auf. Daher konnte nicht eindeutig sichergestellt werden, dass der beobachtete Phänotyp auf diese Tatsache zurück zu führen ist. Vorliegende Ergebnisse mit SNS-Npr2 ${ }^{--}$-Mäusen stützen jedoch die Vermutung, dass die gemessene Reaktion auf einer reduzierten, beziehungsweise fehlenden NPR2-Expression in DRG-Neuronen beruht. Untermauert wurden die Beobachtungen durch Untersuchungen mit $\Delta$ Lbx1-Nppc ${ }^{-/-}$-Mäusen (s. Kapitel 4.3.3), die ebenfalls reduziert auf Hitze reagierten. Eine Wiederholung des Versuchs mit Lbx1-Nppc ${ }^{-/-}$-Tieren zeigte, dass sie bei $52^{\circ} \mathrm{C}$ eine ähnliche Tendenz aufwiesen. Diese Beobachtungen deckten sich auch mit den aus der Literatur beschriebenen Ergebnissen von Versuchen mit SNS-PKGI-/-Mäusen, welche im Hot-Plate Test eine erhöhte Latenzzeit bei $52{ }^{\circ} \mathrm{C}$ aufwiesen. ${ }^{163}$ Somit scheint eine CNP abhängige NPR2-Aktivierung und eine damit einhergehende cGKla-Ansteuerung in DRG-Neuronen maßgeblich an der Hitzeschmerzempfindung beteiligt zu sein. 
Hervorzuheben ist, dass CRP4 ${ }^{-/-}$-Mäuse einen gegenläufigen Effekt zu zeigen schienen. Auch wenn keine signifikanten Unterschiede zwischen Kontroll- und CRP4 ${ }^{--}$-Tieren feststellbar waren, ließ sich für letztere bei $52{ }^{\circ} \mathrm{C}$ eine reduzierte Latenzzeit beobachten $(p=0,07)$.

\subsubsection{Tail-Flick und Plantar Test}

Um weitere Veränderungen im thermischen Schmerzverhalten zu untersuchen, wurde mit SNS-Npr2\%- sowie mit $\Delta$ Lbx1-Nppc ${ }^{-/}$-Mäusen zusätzlich der Plantar und Tail-Flick Test durchgeführt. Anders als erwartet, zeichneten sich jedoch für keines der beiden Experimente phänotypische Unterschiede ab (s. Abbildung 24 und Abbildung 37).

Ähnliche Ergebnisse ließen sich für SNS-PKG ${ }^{-}-$Mäuse beobachten. Auch sie zeigten weder im Hargreaves noch im Tail-Flick Test eine veränderte Erregbarkeit gegenüber Kontrolltieren. ${ }^{119,163}$ Eine mögliche Begründung für diese Ergebnisse kann in der erhöhten Messfehleranfälligkeit der Methode liegen. So werden schon kleinste Bewegungen als Reaktion gewertet. Zudem ist ein gleicher Abstand zwischen Messobjekt und Hitzequelle nicht immer gewährleistet. Daher wurde der Schwanz aufgrund seiner kegelförmigen Morphologie nicht immer an seinem tiefsten Punkt stimuliert. Der Plantar Test wurde zusätzlich dadurch erschwert, dass teilweise die zu messende Pfote nicht gut einsehbar war. Aus diesem Grund konnte nicht immer sichergestellt werden, dass die Pfote planar auf der Messebene lag und die Wärmequelle die Pfote tatsächlich erfasste. Auch konnte die Temperatur der Hitzequelle nicht genau definiert werden. Daher sind Ergebnisse dieses Versuches im Vergleich zum Hot-Plate Test weniger aussagekräftig.

\subsubsection{Untersuchung möglicher Interaktionspartner}

Zwei der wichtigsten Thermorezeptoren sind der Vallinoidrezeptor 1 (TRPV1) sowie der Transient Receptor Potential Ankyrin 1 Rezeptor (TRPA1). ${ }^{164-166}$ Daher wurde in Versuchen der schnellen Schmerzsensibilisierung ein möglicher Zusammenhang zwischen TRPV1 und NPR2 sowie TRPA1 und NPR2 genauer charakterisiert (s. Kapitel 4.2.5.2). Im Capsaicin-Modell, welches gezielt die TRPV1 Kanäle ansteuert, wurden keine signifikanten Unterschiede zwischen SNS-Npr2 ${ }^{-/-M a ̈ u s e n ~}$ sowie Kontrolltieren festgestellt. Somit scheint TRPV1 nicht am NPR2 vermittelten HitzeSignalweg beteiligt zu sein. 
Um eine Beziehung zwischen NPR2 und TRPA1 herzustellen, wurde der Formalin-Test durchgeführt. Dieser lässt sic in zwei Phasen untergliedern. Phase-I zeichnet sich durch eine direkte Aktivierung der Nozizeptoren aus, während in Phase-Il Entzündungsprozesse in der Peripherie eingeleitet werden, die mit einer zentralen Sensibilisierung im Rückenmark einher gehen. ${ }^{167}$ Diese wird durch die neuronale Aktivität der Nozizeptoren in Phase I induziert. ${ }^{168}$ Eine bedeutende Rolle spielt dabei die Aktivierung von TRPA1-Kanälen, welche vermehrt in C-Fasern von DRG-Neuronen exprimiert werden. ${ }^{169}$ In Phase-I verhielten sich beide Kohorten ähnlich. Allerdings konnte bei SNS-Npr2\%-Mäusen in Phase-II eine signifikante Reduktion des Leckverhaltens registriert werden. Beobachtungen dieser Arbeit deckten sich mit den Ergebnissen des Formalin-Tests mit $\mathrm{Npr} 2^{\mathrm{fl} / \mathrm{fl}} ; \mathrm{Wnt}^{\mathrm{Cre}}-\mathrm{Mäusen}$, die ebenfalls eine reduzierte Reaktionszeit in Phase-II aufzeigten. ${ }^{95}$ Dies deutet darauf hin, dass TRPA1 und nicht TRPV1 am NPR2 vermittelten Hitzeempfinden beteiligt ist.

Weitere Hinweise, die einen Zusammenhang zwischen TRPA1 und dem NPR2 vermittelten Signalweg vermuten lassen, belegen Untersuchungen an SNS-PKGI ${ }^{--} 119$ sowie globalen PKG-1\%Mäusen. ${ }^{109}$ Auch hier konnte festgestellt werden, dass diese Tiere eine signifikant verringerte Reizantwort im Formalin-Test aufwiesen. Bei globalen $\mathrm{PKGl}^{-/-}$-Mäusen waren dabei sowohl Phase-I als auch Phase-Il betroffen.

In einer vorherigen Studie wurde festgestellt, dass CRP4 ${ }^{-/-}$-Mäuse, im Gegensatz zu den anderen beschriebenen Mauslinien, eine erhöhte Reaktion in Phase-II des Formalin-Tests aufzeigten. ${ }^{110}$ Damit einhergehend schienen CRP4\%--Mäuse einen signifikant erhöhten Entzündungsschmerz im Zymosan-Modell zu besitzen. Globale $\mathrm{PKGl}^{-/-}$-Mäuse wiesen hingegen den gegenläufigen Effekt auf. ${ }^{109}$ Auch zeigten SNS-PKG1\%-Mäuse in dem Freund's Complete Adjuvant-(CFA-)Test, einem weiteren Entzündungsmodell, eine reduzierte mechanische und thermische Erregbarkeit. ${ }^{119}$ Diese Ergebnisse ließen vermuten, dass NPR2 auch an inflammatorischen Prozessen beteiligt ist. Tatsächlich wurde jedoch für SNS-Npr2\%-Mäuse im Zymosan-Modell kein verändertes Schmerzverhalten dokumentiert (s. Kapitel 4.2.5.3). 
Die vorliegenden Daten sowie Ergebnisse aus der Literatur liefern Hinweise, dass NPR2 am TRPA1vermittelten Hitzeschmerz beteiligt ist. Hierbei scheint eine Aktivierung von NPR2 pronozizeptiv zu wirken. Da SNS-Npr2/--Mäuse im Fomalinmodell nur in Phase-Il einen Phänotyp zeigten, scheint NPR2 vor allem an Prozessen der zentralen Sensibilisierung mitzuwirken. Zudem wird die Vermutung der vorangestellten Expressionsanalysen unterstützt, dass eine NPR2-Aktivierung in sensorischen Neuronen durch rückenmarkstämmiges CNP erfolgen könnte. Hierfür sprechen auch Transkriptomuntersuchungen von Zeisel et al., welche eine Expression von TRPA1 und NPR2 in peptidergen DRG-Neuronen nachwiesen. Eine Colokalisierung zwischen CNP und TRPA1 konnte hingegen nicht festgestellt werden. ${ }^{16}$

Das durch NPR2 gebildete cGMP scheint anschließend in den DRG-Neuronen die Aktivierung von cGKla auszulösen und den pronozizeptiven Effekt hervorzurufen. Eine Phosphorylierung von CRP4 ausgehend von cGKla über NPR2 scheint hingegen antinozizeptiv zu sein. Daher wird angenommen, dass CRP4 als Tranksriptionsfaktor die Expression weiterer schmerzrelevanter Gene beeinflusst oder als Adaptorprotein die Bildung von Multiproteinkomplexen ermöglicht, die eine antinozizeptive Wirkung ausüben. Hierfür spricht, dass für CRP4 in anderen Geweben eine Adaptorfunktion nachgewiesen wurde. ${ }^{170}$

Zudem besteht die Möglichkeit, dass dephosphoryliert vorliegendes CRP4 in Abwesenheit schmerzhafter Stimuli pronozizeptive Signalwege unterdrückt. Durch einen noxischen Hitzereiz oder bei Prozessen der zentralen Sensibilisierung könnte CRP4 phosphoryliert und dieser Effekt aufgehoben werden. Hierfür spricht, dass eine Deletion von NPR2 und cGKIa zu einem verminderten Schmerzempfinden führt, da eine Phosphorylierung von CRP4 verhindert wird. ${ }^{110}$

\subsubsection{Mögliche Signalwege für NPR2 und TRPA1}

Unklar ist, ob der beschriebene Signalweg aktivierend oder modulierend auf die TRPA1-vermittelte Reizantwort wirkt. Es ist bekannt, dass TRPA1-Kanäle vermehrt in den terminalen Endigungen der C-Fasern lokalisiert und mit TRPV1 coexprimiert sind. ${ }^{169,171-175}$ Hier fungieren sie als polymodale Sensoren, die thermische und chemische Reize erkennen und diese in elektrische Signale überführen. ${ }^{176,177}$ Lange Zeit wurde TRPA1 hauptsächlich als 
Thermorezeptor für die Detektion von Kälteschmerz diskutiert. ${ }^{175}$ Während er schon länger bei Drosophila oder Klapperschlangen als wichtiger Sensor für schädliche Hitze bekannt ist ${ }^{178}$ wurde erst kürzlich berichtet, dass humanes TRPA1 nach Redox-Modifikation und Exposition mit einigen Liganden ebenfalls durch hohe Temperaturen aktiviert werden kann. ${ }^{38,179}$ Darüber hinaus zeigte eine Studie, dass akute schädliche Wärmereize bei Mäusen über die drei TRP-Kanäle TRPA1, TRPM3 und TRPV1 erfasst werden. ${ }^{32}$ Dies deutet darauf hin, dass TRPA1 sowohl durch Kälte als auch Hitze stimuliert wird. ${ }^{38}$ Zudem kann die Funktion von TRPA1 durch mehrere Faktoren moduliert werden. Hierzu zählen neben einigen endogen wirkenden Substanzen auch verschiedene exogene Wirkstoffe (s. Kapitel 1.1.2). ${ }^{39} \mathrm{Zu}$ letzterem gehört unter anderem das Formalin. Es wird angenommen, dass TRPA1 nach Formalin-Injektion über eine kovalente Modifizierung von Cystein- und Lysinresten am N-Terminus aktiviert wird. ${ }^{169}$ Im Anschluss kommt es zu einem vermehrten $\mathrm{Ca}^{2+}-$ und $\mathrm{Na}^{+}$-Einstrom in die Zelle, was eine Depolarisation der Zellmembran hervorruft. Dies führt zur Erzeugung von Aktionspotentialen, die eine Neurotransmitterfreisetzung sowohl an peripheren als auch an zentralen neuralen Projektionen bewirken. ${ }^{180}$

\subsubsection{Endogene Aktivierung und Modulierung von TRPA1}

Der Mechanismus, der zu einer endogenen Modulierung beziehungsweise Aktivierung von TRPA1 führt, ist bisher nicht genau geklärt. Es wird angenommen, dass TRPA1 durch Bradykinin angeregt wird. ${ }^{181}$ Dabei steht die Hypothese im Raum, dass Bradykinin zunächst eine Aktivierung von TRPV1 auslöst. Es kommt zu einem vermehrten $\mathrm{Ca}^{2+}$-Influx. ${ }^{182-184}$ Der erhöhte intrazelluläre $\mathrm{Ca}^{2+}$-Spiegel verstärkt die Aktivierung von TRPA1. ${ }^{182,185}$ Zudem wird vermutet, dass eine Aktivierung von TRPA1 über eine Neurotransmitter- oder Wachstumsfaktorrezeptoren vermittelte Phospholipase C (PLC) Stimulation erfolgt. ${ }^{186}$ Auch hier wird die Rolle von Bradykinin diskutiert, welches an Bradykinin-Rezeptoren (BK-Rezeptoren) auf sensorischen Neuronen bindet. ${ }^{45,185,187}$ Hierbei handelt es sich um die G-Protein gekoppelte Rezeptoren (GPCR) $B_{1}$ und $\mathrm{B}_{2} \cdot{ }^{179}$ Werden diese durch Bradykinin stimuliert, wird über einen Gq-vermittelten Signalweg die PLC angeregt. Anschließend kann 1,2-Diacylglicerin (DAG) aus dem Abbau von Phosphatidylinositol-4,5-bisphosphat $\left(\mathrm{PIP}_{2}\right)$ in Inositoltriphosphat $\left(\mathrm{IP}_{3}\right)$ gebildet werden. Dies 
bewirkt eine verstärkte $\mathrm{Ca}^{2+}{ }^{2+}$ Freisetzung aus dem Endoplasmatischem Retikulum (ER). Die erhöhte intrazelluläre $\mathrm{Ca}^{2+}-$ Konzentration scheint direkt aktivierend auf TRPA1 zu wirken. Gleichzeitig wird eine Aktivierung der Proteinkinase C (PKC) hervorgerufen. ${ }^{181,188,189}$ Zudem wird vermutet, dass Bradykinin die Produktion von cAMP durch Stimulierung der Adenylatzyklase (AC) initiiert. Im Anschluss erfolgt eine Aktivierung der Proteinkinase A (PKA). Durch die Ansteuerung von PKA und PKC wird eine Phosphorylierung von TRPA1 induziert, welche signifikant die Aktivierungsschwelle von TRPA1 erhöht und somit eine Sensibilisierung der Nozizeptoren herbeiführt. ${ }^{189-192}$ Ein weiterer Mechanismus, der in der Literatur beschrieben wird, ist, dass zunächst eine Aktivierung von TRPV1 stattfindet (s. Abbildung 41). Diese kann sowohl über Hitze, Capsaicin oder Bradykinin ausgelöst werden. Als Folge kommt es zu einem vermehrten $\mathrm{Ca}^{2+}$ Influx. ${ }^{182-184}$ Der erhöhte intrazelluläre $\mathrm{Ca}^{2+}$-Spiegel verstärkt die Aktivierung von TRPA1 (s. Abbildung 41). ${ }^{182,185}$

Es ist jedoch unwahrscheinlich, dass NPR2 bei den beschriebenen Signalwegen beteiligt ist. Der Ursprung der Annahme liegt darin begründet, dass SNS-Npr2/--Mäuse im Capsaicin-Modell keine Auffälligkeiten aufwiesen und somit eine Beteiligung von TRPV1 fragwürdig ist. Zudem wird Bradykinin als Gewebshormon während Entzündungsprozessen freigesetzt. Hier löst es durch direkte Erregung von Nozizeptoren akute Schmerzen aus, denen eine länger anhaltende Sensibilisierung für thermische und mechanische Reize folgt. ${ }^{193}$ Da SNS-Npr2 ${ }^{-/-M a ̈ u s e ~ j e d o c h ~}$ keinen Phänotyp im inflammatorischen Zymosan-Modell zeigten, deuten diese Ergebnisse auf einen anderen Mechanismus hin. 


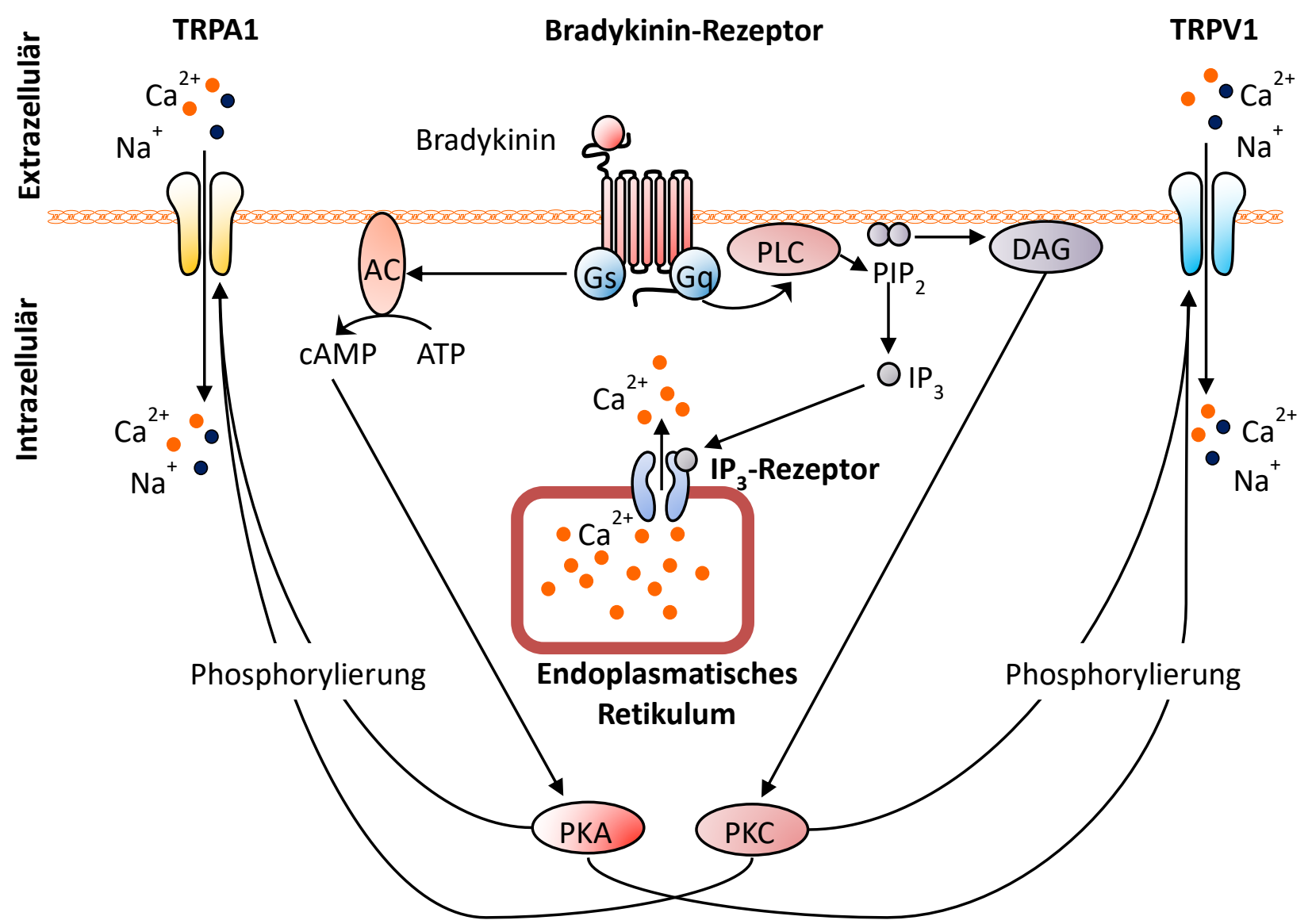

Abbildung 41: Darstellung möglicher zusammenhängender Signalwege, die eine Sensibilisierung von TRPA1 auslösen. Durch Bindung von Bradykinin an den Bradykinin-Rezeptor 2 (BK2) wird über ein Gq-Protein die Phospholipase C (PLC) aktiviert. Diese spaltet im nächsten Schritt Phosphatidylinositol-4,5-Bisphosphat ( $\mathrm{PIP}_{2}$ ) in Diacylglycerin (DAG) und Inositoltriphosphat $\left(\mathrm{IP}_{3}\right)$. $\quad \mathrm{IP}_{3}$ bindet an den Inositoltriphosphat-Rezeptor $\left(\mathrm{IP}_{3} \mathrm{R}\right)$ und induziert eine $\mathrm{Ca}^{2+}$-Freisetzung aus dem endoplasmatischen Retikulum (ER). Gleichzeitig wird über DAG die Aktivierung der Proteinkinase C (PKC) eingeleitet. Diese löst im Anschluss eine Phosphorylierung von TRPV1 sowie TRPA1 aus und erhöht so die Aktivierungsschwelle der beiden Kanäle. Wird TRPV1 stimuliert, strömt vermehrt Ca ${ }^{2+}$ in die Zelle, was ebenfalls modulierend auf TRPA1 wirkt. Auch kann über BK2 ein Gs-Protein stimuliert werden, welches durch eine Aktivierung der Adenylatzyklase $(A C)$ die Synthese von cAMP herbeiführt. Das gebildete cAMP aktiviert die Proteinkinase A, welche wiederum über Phosphorylierung die Sensibilisierung von TRPA1 und TRPV1 einleitet. ${ }^{179}$

Eine weitere Hypothese, die in der Literatur diskutiert wird, ist die Idee, dass cGKl $\alpha$ eine Phosphorylierung von IP $\mathrm{I}_{3}$-Rezeptoren auslöst und diese positiv moduliert. Dadurch kann nach Aktivierung der PLC vermehrt $\mathrm{Ca}^{2+}$ aus dem ER freigesetzt werden und so stimulierend auf TRPA1 wirken (s. Abbildung 42). ${ }^{119}$ Hintergrund für diese Theorie ist, dass Patch-Clamp Untersuchungen an DRG-Neuronen von SNS-PKG ${ }^{-1-M a ̈ u s e n ~ n a c h ~ I n k u b a t i o n ~ m i t ~ P L C-L i g a n d e n ~ e i n e n ~ s i g n i f i k a n t ~}$ verringerten $\mathrm{Ca}^{2+}$-Einstrom nachwiesen. ${ }^{119}$ 


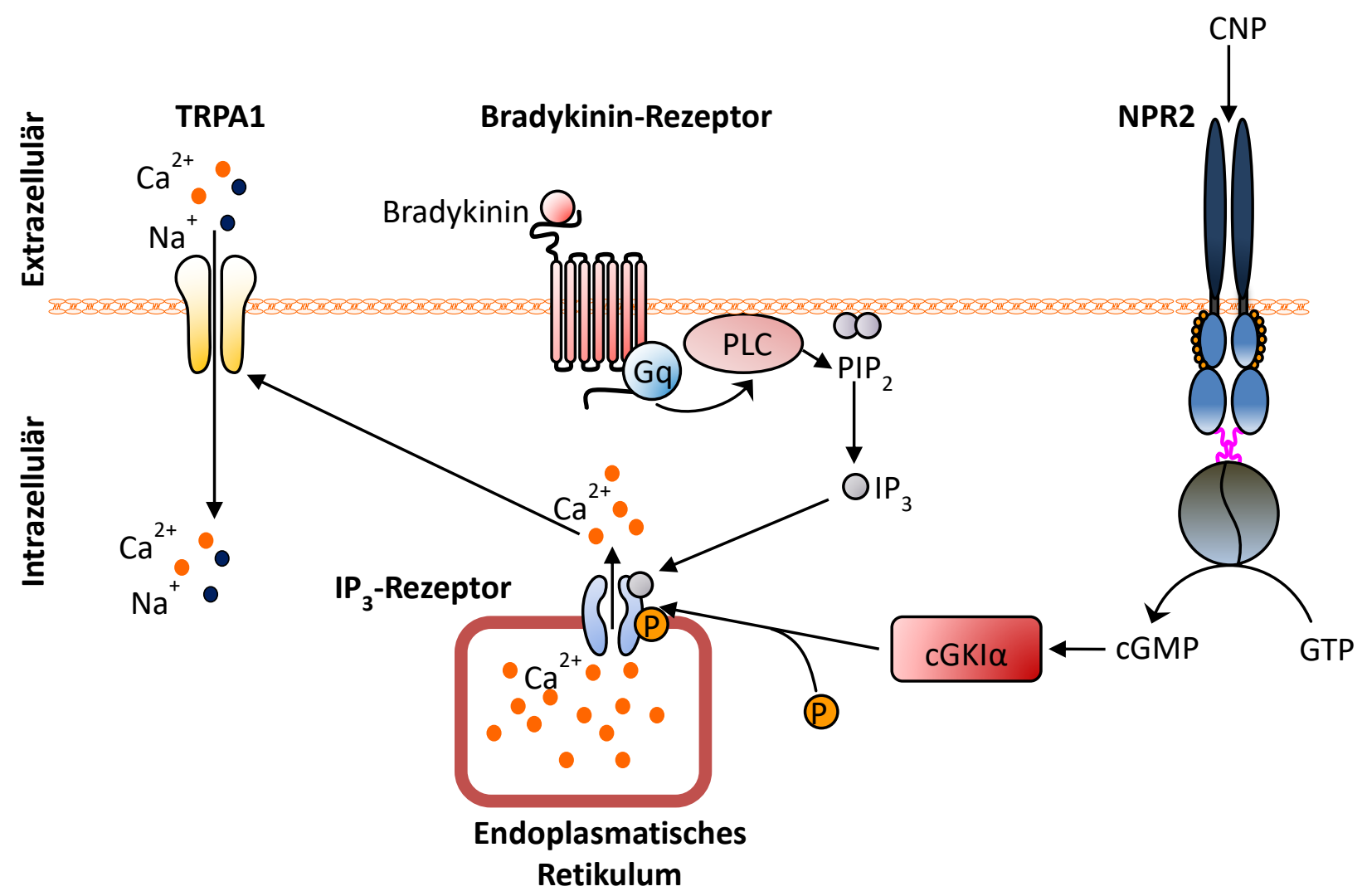

Abbildung 42: Hypothetischer Signalweg, der eine Sensibilisierung von TRPA1 unter cGKI $\alpha$-Aktivierung bewirkt. Durch Bindung von Bradykinin an den Bradykinin-Rezeptor $2\left(\mathrm{BK}_{2}\right)$ wird über ein Gq-Protein die PLC aktiviert. Diese spaltet im nächsten Schritt PIP 2 in DAG und IP. Gleichzeitig wird über eine Aktivierung von NPR2 cGKI $\alpha$ stimuliert und phosphoryliert im Anschluss IP ${ }_{3} R$. Dadurch kann $\mathrm{IP}_{3}$ leichter binden und es wird vermehrt $\mathrm{Ca}^{2+}$ aus dem ER freigesetzt. Der erhöhte intrazelluläre $\mathrm{Ca}^{2+}$-Spiegel wirkt positiv modulierend auf TRPA1. ${ }^{119}$

Eine mögliche Theorie, die den beobachteten Phänotypen erklären könnte, ist die Annahme, dass im Falle eines Hitzereizes TRPA1 über cGKI $\alpha$ direkt phosphoryliert wird und so eine verstärkte Schmerzantwort auslöst (s. Abbildung 43). Für diese Hypothese spricht, dass das Fehlen von NPR2 sowie cGKI zu einem verringerten Hitzeempfinden führt, welches auch in $\Delta \mathrm{Lbx1-Nppc}{ }^{-1-M a ̈ u s e n}$ beobachtet wurde. Somit würde eine durch NPR2 ausgelöste cGKl $\alpha$-Aktivierung direkt modulierend auf TRPA1-Kanäle wirken. Dies könnte auch den oben beschriebenen verringerten $\mathrm{Ca}^{2+}$-Einstrom bei DRGs von SNS-PKG1 ${ }^{-1-}$-Mäusen erklären. Da TRPA1 durch die Abwesenheit von cGKl $\alpha$ weniger stark phosphoryliert vorliegt, bewirkt eine Stimulation durch Bradykinin eine geringere Aktivierung des TRPA1-Kanals, welcher somit weniger stark für $\mathrm{Ca}^{2+}$ durchlässig ist. 


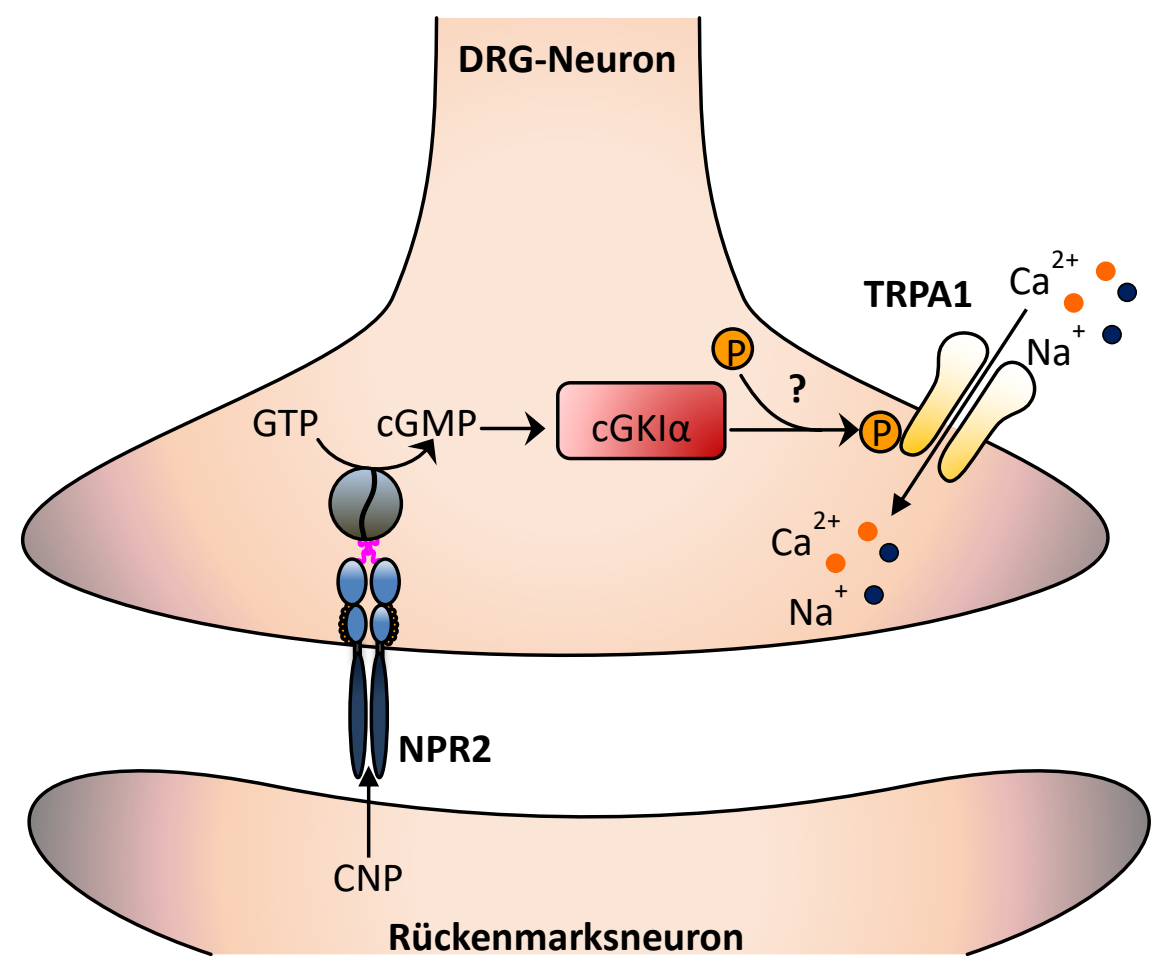

Abbildung 43: Möglicher Signalweg von NPR2 und TRPA1. Durch Bindung des Peptidliganden CNP wird NPR2 aktiviert und cGMP gebildet. Dies führt zu einer Aktivierung von cGKl $\alpha$, welche eine Phosphorylierung von TRPA1 ermöglicht. Im phosphorylierten Zustand ist die Aktivierungsschwelle von TRPA1 erhöht und es strömt vermehrt Ca ${ }^{2+}$ in die Zelle.

Eine weitere Erklärung könnte eine TRPA1-vermittelte Aktivierung von $\mathrm{Ca}^{2+}$-abhängigen Kinasen sein. Durch die Kanalöffnung von TRPA1 gelangt vermehrt $\mathrm{Ca}^{2+}$ in die Zelle. Dadurch können $\mathrm{Ca}^{2+}$-abhängige Kinasen angesteuert werden. Diese könnten im nächsten Schritt eine Phosphorylierung der Kinase Homologie Domäne (KHD) von NPR2 bewirken. Als Phosphatquelle dient ATP. Gleichzeitig fungiert ATP als positiver allosterischer Regulator für NPR2, indem es an seine katalytische Domäne bindet. ${ }^{147}$ Damit das CNP-Aktivierungssignal an diese übertragen werden kann, muss sie an einer Kombination von fünf Serin- und zwei Threoninresten phosphoryliert vorliegen. ${ }^{194-197}$ Erst dann findet nach extrazellulärer Ligandenbindung die Signalübertragung an die katalytische Domäne des Enzyms statt. Im Gegensatz zu vielen Wachstumsfaktorrezeptoren wird die NPR2-Phosphorylierung jedoch bei der Bindung von CNP nicht erhöht, sondern nimmt ab. ${ }^{195,198}$ Darüber hinaus korrelierte der zeitliche Verlauf der Dephosphorylierung mit dem zeitlichen Verlauf der CNP-abhängigen Desensibilisierung der Guanylatzyklase-Aktivität. ${ }^{194}$ Dies deutet darauf hin, dass die katalytische Aktivität von NPR2 mit 
seinem Phosphorylierungszustand zusammenhängt. Daher gibt es mindestens zwei separate Mechanismen, welche die Guanylatzyklase-Aktivität von NPR2 erhöhen oder verringern. Diese beruhen auf einer Änderung der CNP-Konzentration oder des Phosphorylierungsgrades des Rezeptors. Welche Enzyme die Phosphorylierung der KHD bewirken, ist jedoch nicht geklärt. Eine der bekanntesten neuronalen $\mathrm{Ca}^{2+}$-abhängigen Proteinkinasen ist die Calmodulin-abhängige Proteinkinase (CaM-Kinase). Dabei wird vor allem die CaM-Kinase II vermehrt in Neuronen gebildet. In einer aktuellen Studie wird eine TRPA1-abhängige Aktivierung der CaM-Kinase II (CaM-K-II) beschrieben. ${ }^{199}$ Zudem zeigen Transkriptomanalysen von Usoskin et al. und Zeisel et al. eine hohe Coexpression von TRPA1, NPR2, cGKI $\alpha$, CRP4 und der CAM-Kinase II in einigen peptidergen sowie nicht-peptidergen DRG-Neuronen. ${ }^{16,17}$ Somit könnte ein thermischer Reiz die Öffnung von TRPA1-Kanälen bewirken, wodurch der intrazelluläre $\mathrm{Ca}^{2+}$-Spiegel erhöht wird. Dieser führt zu einer Aktivierung von $\mathrm{Ca}^{2+}$-abhängigen Proteinkinasen (z. B. der CaM-K-II), welche im Anschluss ausgehend von ATP eine Phosphorylierung der Serin- und Theroninreste der KHD von NPR2 hervorrufen. Dadurch kommt es zu einer Sensibilisierung von NPR2, welches nun verstärkt CNP binden und seine Guanylatzyklaseaktivität entfalten kann. Im nächsten Schritt werden durch eine Aktivierung von cGKI $\alpha$ die Signale weiter prozessiert (s. Abbildung 44). Diese Erklärung ist jedoch spekulativer Natur und konnte bisher nicht ausreichend nachgewiesen werden.

Es muss berücksichtig werden, dass auch die $\Delta$ Lbx1-Nppc ${ }^{-/-}$-Mäuse ein signifikant verringertes Schmerzverhalten im Hot-Plate Test zeigten. Diese ließ sich ebenfalls für Lbx1-Nppc/--Mäuse abzeichnen. Auch wird in der Literatur eine thermische Hyperalgesie beschrieben, die durch eine intraplantare CNP-Injektion ausgelöst wird. ${ }^{200}$ Zudem berichtet eine humanen Phase-II Studie, welche die subkutane Applikation des CNP-Analogons "Vosoritid“ für die Behandlung von Achondroplasie untersuchte, von einem auftretenden Hitzeschmerz der von einem Teil der Probanden nach Verabreichung beschrieben wurde. ${ }^{201}$

Diese Ergebnisse lassen darauf schließen, dass auch die Konzentration von CNP einen Einfluss auf das thermische Schmerzverhalten haben könnte. 


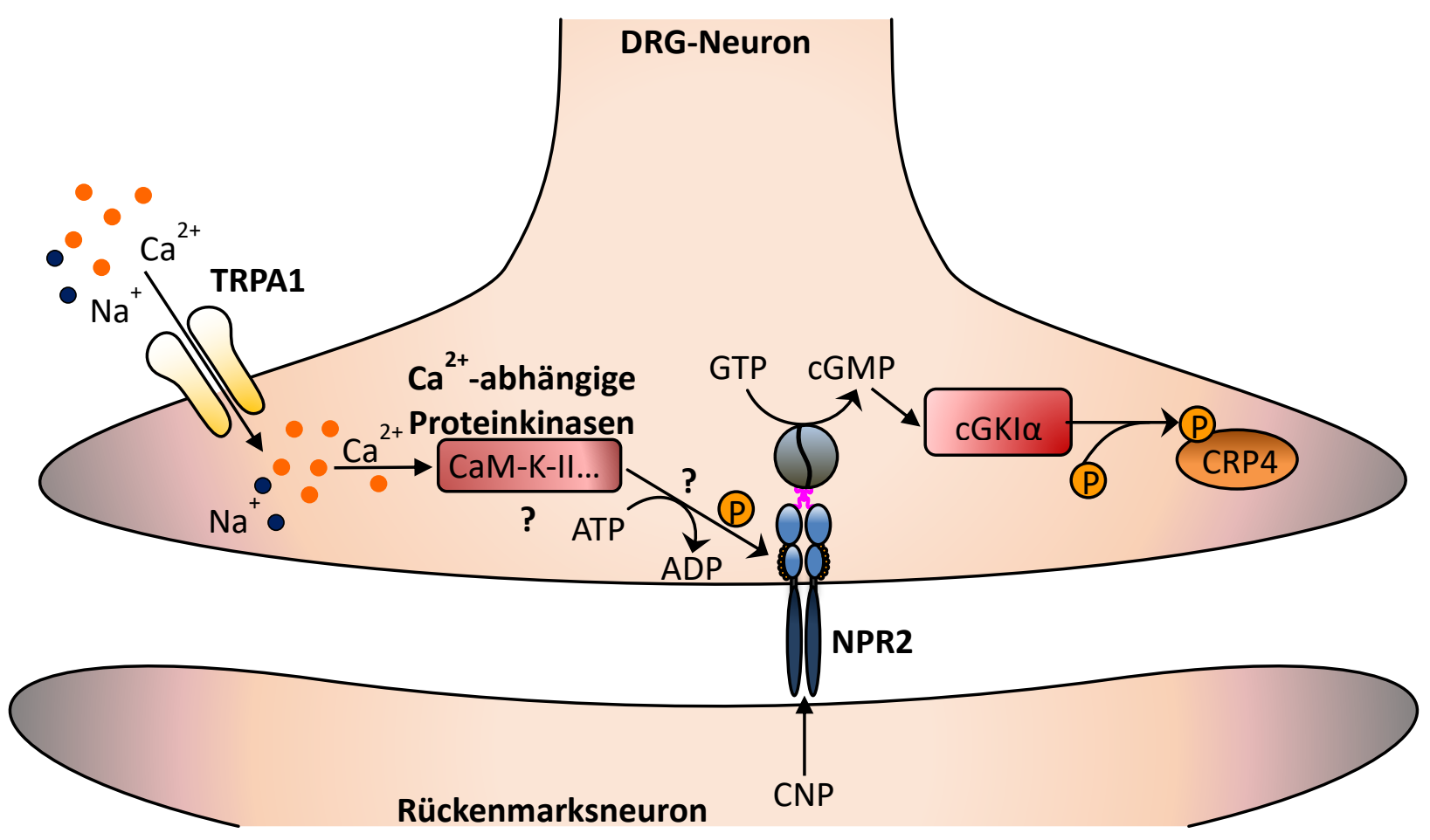

Abbildung 44: Theoretischer Signalweg, der eine Sensibilisierung von NPR2 auslöst. Noxische Hitzestimuli lösen eine Aktivierung von TRPA1 aus. Dadurch tritt vermehrt $\mathrm{Ca}^{2+}$ in die Zelle ein. Die erhöhte intrazelluläre $\mathrm{Ca}^{2+}-K_{0}$ zonzentration bewirkt eine Aktivierung $\mathrm{Ca}^{2+}$-abhängiger Proteinkinasen (z. B. CaM-K-II). Durch ATP-Hydrolyse wird im nächsten Schritt die Kinase Homologie Domäne (KHD) von NPR2 phosphoryliert. Dies führt zu einer Sensibilisierung von NPR2, wodurch nach Bindung von CNP vermehrt cGMP gebildet wird. Im Anschluss werden über eine cGKI $\alpha$-Aktivierung weitere Proteine (u.a. CRP4) aktiviert und das Signal weiter prozessiert.

Neben der Hypothese, dass TRPA1 eine Rolle bei der Detektion von Hitzeschmerz zugesprochen wird, beschreiben verschiedene Veröffentlichungen, dass dieser Kanal auch eine Funktion beim Erfassen von noxischer Kälte hat. Wird der Körper einer niedrigen Temperatur ausgesetzt, reagiert er mit einer kälteinduzierten Vasokonstriktion und einer darauffolgenden Vasodilatation. Diese physiologische Reaktion ist entscheidend um das Gewebe vor Kälteverletzung zu schützen. Die anfängliche schnell einsetzende Vasokonstriktion verhindert einen starken Wärmeverlust. Darauf folgt eine Vasodilatation, die für den Schutz vor lokalen kälteinduzierten Verletzungen wesentlich ist. ${ }^{202}$ Der genaue Mechanismus, der die Veränderung des lokalen Gefäßtonus auslöst, ist bisher unzureichend geklärt. Allerdings konnte eine murine Studie belegen, dass TRPA1 als vaskulärer Sensor fungiert, der sowohl die initiale Vasokonstriktion anstößt als auch an vasodilatorischen Prozessen beteiligt ist, ${ }^{203,204}$ indem es die Freisetzung der Neuropeptide CGRP und Substanz $\mathrm{P}$ sowie von NO fördert ${ }^{202}$. Auch für Hitzereize beschreibt die Literatur eine 
Vasodilatation, die aufgrund der genannten vasoaktiven Peptide von C-Fasern über einen AxonReflex-Mechanismus freigesetzt werden. ${ }^{205,206}$ Zudem wird CNP durch die Aktivierung von NPR2 ebenfalls eine vasorelaxierende Bedeutung zugesprochen. ${ }^{207,208}$ Hierbei geht man bisher jedoch von einer Freisetzung aus dem Gefäßendothel aus. ${ }^{208}$ In-situ-Hybridisierungen sowie $\beta$-Gal Färbungen, die im Rahmen dieser Arbeit an Gewebeschnitten der Pfote durchgeführt wurden (Daten nicht gezeigt), konnten jedoch keine CNP-Expression im Gefäßendothel nachweisen. Daher liegt die Vermutung nahe, dass ein Zusammenhang zwischen einer TRPA1-Aktivierung, einer CNP-Freisetzung aus dem Rückenmark und einer Aktivierung von neuronalem NPR2 besteht, der ebenfalls den Gefäßtonus nach einem noxischen thermischen Stimulus beeinflussen könnte. Um diese Vermutung $z u$ bestätigen müsste der Einfluss von NPR2 in Kälteschmerzmodellen genauer untersucht werden.

\subsection{Einfluss von NPR2 auf neuropathische Schmerzen}

Um den Einfluss von NPR2 auf neuropathische Schmerzen zu untersuchen, wurde das Modell der Crush Injury angewendet. Durch Quetschung des Ischiasnerven können in diesem Modell Desowie Regenerationsprozesse des Axons dargestellt werden (s. Kapitel 3.2.1.11). Um auch hier altersbedingte Regulationsmechanismen auszuschließen wurde dieser Versuch sowohl an jungen als auch alten Tieren durchgeführt (Alter junge Kohorte: 10 Wochen bis 4 Monaten; Alter alte Kohorte: 7,5 bis 10 Monate). Untersuchungen zur mechanischen Reizbarkeit lieferten keine Hinweise für eine Beteiligung von NPR2 (s. Abbildung 28). Allerdings war die Sensitivität gegenüber thermischen Stimuli an Tag drei der Degenerationsphase für junge SNS-Npr2 ${ }^{-/}$-Tiere signifikant verringert (s. Abbildung 29). Dabei lag die dort gemessene Latenzzeit über den Ausgangswerten. Möglicherweise liegt hier eine Desensibilisierung gegenüber Hitzereizen vor. Dieser Effekt ließ sich in alten Tieren jedoch nicht feststellen. Ein stärkerer und länger anhaltender Verlust der Wärmeempfindlichkeit nach Crush Injury, wie für die junge Kohorte beobachtet, wurde auch für SNS-PKG1\%-Mäuse dokumentiert. ${ }^{163}$ Diese Daten untermauern die Vermutung, dass TRPA1 am Signalweg von CNP/NPR2/cGKl $\alpha$ beteiligt ist.

Neben cGMP kann cGKI $\alpha$ auch über reaktive Sauerstoffspezies (ROS) aktiviert werden und zur Entwicklung einer Hyperalgesie beitragen. ${ }^{209}$ So zeigten cGKI $\alpha$ Knock-In-Mäuse, deren cGKl $\alpha$ nicht 
über oxidative Signale aktiviert wird, ein reduziertes Schmerzverhalten in chronischen Schmerzmodellen. ${ }^{209}$ Hervorzuheben ist, dass zwischen cGKla Knock-In-Mäusen und ihren wildtypischen Wurfgeschwistern keine signifikanten Unterschiede in den verschiedenen Akutmodellen (u.a. Hot-Plate und Hargreaves) beobachtet wurden. ${ }^{209}$ Auch wiesen sie weder im Formalin- noch im Zymosan-Modell ein verändertes Schmerzverhalten auf. Somit scheint eine ROS- induzierte cGKl $\alpha$-Aktivierung vor allem an der Ausbildung neuropathischer Schmerzen beteiligt zu sein, ${ }^{209}$ während eine cGKl $\alpha$-Aktivierung über NPR2 primär für die Entstehung von Akutschmerz verantwortlich ist. Hierbei scheint NPR2 vor allem eine pronozizeptive Rolle bei der thermischen Reizweiterleitung zu spielen. Studien zu löslichen Guanylatzyklasen zeigten, dass diese hingegen besonders bei der Entwicklung inflammatorischer und neuropathischer Schmerzen beteiligt sind. ${ }^{67}$ So konnte Petersen et al. in seiner Publikation nachweisen, dass Mäuse mit einem NO-GC1-Defizit weniger Reaktionen in neuropathischen Schmerzmodellen zeigten, während ein Knockout von NO-GC2 zu einem signifikant erhöhten Entzündungsschmerz im Zymosan- und CFA-Modell führte. ${ }^{67}$ Auch konnten diese Beobachtungen an konditionellen Rückenmarksspezifischen Knockoutmäusen bestätigt werden. ${ }^{67}$ Dies deutet darauf hin, dass Iösliche und partikuläre Guanylatzyklasen unterschiedliche Funktionen im nozizeptiven System erfüllen. Zudem scheint die Art der cGKl $\alpha$-Aktivierung entscheidend für die Schmerzempfindung zu sein. 


\section{$6 \quad$ AUSBLICK}

Die vorliegende Arbeit liefert Hinweise, dass NPR2 an der Entstehung von Hitzeschmerz beteiligt ist. Als möglicher Interaktionspartner wurde TRPA1 identifiziert. In der Literatur wird TRPA1 als wichtiger Mediator für die Empfindung thermischer und inflammatorischer Reize diskutiert. Trotz kontroverser Diskussionen wird ihm sowohl eine Funktion zur Detektion von Hitze- als auch Kälteempfindung zugesprochen. Um gezieltere Aussagen für seine Bedeutung am CNP/NPR2/cGKl $\alpha$-vermittelten Signalweg zu treffen, sollten weitere Verhaltenstests mit Knockout-Mauslinien durchgeführt werden. So sollten die in dieser Arbeit durchgeführten Versuche mit Mäusen der Lbx1-Nppc-Linie wiederholt werden, die die Deletionsbande nicht aufweisen. Zudem sollten die hier ausgeübten Verhaltensmodelle mit Mäusen der CRP4-Linie durchgeführt werden.

Da TRPA1 auch eine Bedeutung zur Erfassung von Kälte zugesprochen wird, sollten zudem die hier aufgeführten Knockoutlinien in spezifischen Kälteschmerzmodellen getestet werden. Darunter fällt neben dem klassischen Cold-Plate Test auch der Cold-Plantar Test, bei dem die Pfote der Mäuse einer extrem niedrigen Temperatur, ausgelöst durch Trockeneis, ausgesetzt wird. $^{210}$

Auch könnte der Thermal-Preference Test ${ }^{211}$ weitere Rückschlüsse über die Funktion des CNP/NPR2/cGKI $\alpha$-vermittelten Signalwegs zur Erfassung von thermischen Reizen ergeben. In diesem Test werden die Mäuse auf eine Platte gesetzt, bei der die einzelnen Areale verschiedene Temperaturen besitzen. ${ }^{211}$ Anschließend wird die Bewegung der Mäuse beobachtet.

Um ein verändertes Thermoempfinden in inflammatorischen Modellen zu testen, wäre eine Möglichkeit diese Linien nach Zymosaninjektion im Hargreaves Test zu untersuchen.

Diese Tests liefern jedoch lediglich Hinweise für eine mögliche Beteiligung von TRPA1. Wie bereits zu Beginn der Arbeit beschrieben, wird ein Wechselspiel verschiedener Kanäle diskutiert, die die Temperaturempfindung auslösen. Daher sollten zusätzlich molekularbiologische und 
elektrophysiologische Untersuchungen erfolgen. So muss eine Colokalisation von TRPA1 mit NPR2 über spezifische In-situ-Hybridisierungssonden oder Antikörper nachgewiesen werden. Über $\mathrm{Ca}^{2+}$-Imaging an DRG-Neuronen der beschriebenen Mauslinien sollte eine spezifische Aktivierung von TRPA1 und weiteren Kanälen (TRPV1, TRPM3, TRPM8) untersucht werden. Hierfür sollten exogene Substanzen wie Allylthiocyanat, Capsaicin, Menthol sowie CNP eingesetzt werden. 


\section{$7 \quad$ ZUSAMMENFASSUNG}

Viele Studien konnten nachweisen, dass die Produktion von cGMP eine entscheidende Funktion im nozizeptiven System einnimmt. Hierbei wurde vor allem die cGMP-Produktion über lösliche Guanylatzyklasen untersucht. Welche Rolle die partikulären Guanlyatzyklasen bei der Entstehung von Schmerzen haben ist weitgehend ungeklärt. Die vorliegende Arbeit zeigte, dass die partikuläre Guanylatzyklase NPR2 stark in DRG-Neuronen exprimiert wird und dort mit cGKI $\alpha$ sowie CRP4 colokalisiert ist. Aktiviert wird NPR2 über den Peptidliganden CNP. Hervorzuheben ist, dass CNP nicht in primär afferenten Neuronen, dafür jedoch vermehrt im Dorsalhorn des Rückenmarks gebildet wird. Tierexperimentelle Untersuchungen zeigten, dass SNS-Npr2\%--Mäuse ein verringertes Schmerzverhalten bei thermischer Stimulation aufwiesen. Während sie im Capsaicin-Test keinen Phänotyp zeigten, wiesen sie in Phase II des Formalin-Modells ein signifikant reduziertes Leckverhalten auf. Diese Ergebnisse liefern Hinweise für eine Beteiligung des CNP/NPR2/cGKI-Signalwegs an der Detektion von Hitzeschmerz und an der TRPA1vermittelten Schmerzantwort. Dabei scheint NPR2 eine pronozizeptive Funktion zu besitzen. CRP4 als Zielprotein scheint hingegen eine antinozizeptive Wirkung zu haben. Zudem kann die Hypothese aufgestellt werden, dass CNP über einen retrograden Transport aus dem Rückenmark die Aktivierung von NPR2 auslösen könnte.

Zusammengefasst zeigen die Daten dieser Arbeit, dass eine cGMP-abhängige Aktivierung durch NPR2 primär für die Detektion thermischer Reize zuständig ist, während die Literatur Hinweise darauf gibt, dass lösliche Guanylatzyklasen vor allem an inflammatorischen und neuropathischen Prozessen beteiligt sind. ${ }^{67}$ Daher scheinen partikuläre und lösliche Guanylatzyklasen unterschiedliche Eigenschaften im nozizeptiven System zu besitzen. 
8 ABKÜRZUNGSVERZEICHNIS

\begin{tabular}{|c|c|c|}
\hline Anfangsbuchstabe & Abkürzung & Erläuterung \\
\hline \multicolumn{3}{|l|}{ A } \\
\hline & A & Absorption \\
\hline & A. dest & Auqua destillata \\
\hline & Abb. & Abbildung \\
\hline & $A C$ & Adenylatzyklase \\
\hline & ADP & Adenosindiphosphat \\
\hline & Adv & Advillin \\
\hline & AF & Alexa-Fluor \\
\hline & AMPA & $\alpha$-Amino-3-hydroxy-5-methyl-4-isoxazol-Propionsäure \\
\hline & ANO1 & Kanal Anoctamin-1 \\
\hline & ANOVA & einfaktorielle Varianzanalyse \\
\hline & ANP & atriales natriuretisches Peptid \\
\hline & AS & Aminosäure \\
\hline & Atf3 & aktivierende Trankskriptionsfaktor 3 \\
\hline & ATP & Adenosintriphosphat \\
\hline \multicolumn{3}{|l|}{ B } \\
\hline & BAM8-22 & adrenales Medulla Peptid 8-22 \\
\hline & BK-Rezeptoren & Bradykinin-Rezeptoren \\
\hline & $\mathrm{BK}_{\mathrm{Ca}}$ & Calcium-aktivierte Kaliumkanäle mit großer Leitfähigkeit \\
\hline & BNP & Brain natriuretisches Peptid/ B Typ natriuretisches Peptid \\
\hline & Bp & Basenpaare \\
\hline & BSA & Bovines Serumalbumin \\
\hline \multicolumn{3}{|l|}{ C } \\
\hline & C-ANF & ANP Analogon \\
\hline & $\mathrm{Ca}^{2+}$ & Calcium-lon \\
\hline & CaM-Kinase (II) & Calmodulin-abhängige Proteinkinase (II) \\
\hline & CAMP & zyklisches Adenosinmonophosphat \\
\hline & cDNA & komplementäre DNA \\
\hline & CFA & Freund's Complete Adjuvant \\
\hline
\end{tabular}


C

$\begin{array}{ll}\text { cGK } & \text { cGMP-abhängige Proteinkinase } \\ \text { CGKI / PKGI } & \text { cGMP-abhängige Proteinkinase I } \\ \text { CGKII } & \text { cGMP-abhängige Proteinkinase II } \\ \text { GGMP } & \text { zyklisches Guanosinmonophosphat } \\ \text { CGRP } & \text { Calcitonin gene related peptides } \\ \mathrm{Cl}^{-} & \text {Chlorid-lon } \\ \text { CMH } & \text { C-Faser mit Mechano- und Hitzesensibilität } \\ \text { CNG } & \text { zyklische Nukleotid-aktivierter-lonenkanal } \\ \text { CNP } & \text { C-natriuretisches Peptid } \\ \text { CO } & \text { Kohlenstoffmonoxid } \\ \text { CO } 2 & \text { Kohlenstoffdioxid } \\ \text { Cox-2 } & \text { Cyclooxygenase 2 } \\ \text { Cre } & \text { Cyclization recombination } \\ \text { CRP4/CRP2 } & \text { Cystein-reiches LIM-Protein 4 } \\ \text { CT } & \text { Cycle threshold } \\ \text { Cy3 } & \text { Cyanin 3 } \\ \text { Cy5 } & \text { Cyanin 5 } \\ \text { C-Jun } & \text { Jun Proto-Onkogen } \\ \end{array}$

D

\begin{tabular}{lll}
\hline DAG & 1,2-Diacylglicerin \\
DAPI & 4',6-Diamidin-2-phenylindol \\
DEPC & Diethyldicarbonat \\
DMSO & Dimethylsulfoxid \\
DNA & Desoxyribonukleinsäure \\
dNTPs & Desoxyribonukleotidtriphosphate \\
DPA & Dynamic Plantar Aesthesiometers \\
& \\
\hline E & Effizienz \\
EPSPs & exzitatorische postsynaptische Potentiale \\
ER & Endoplasmatisches Retikulum \\
ERK & extracellular-signal regulated Kinase
\end{tabular}


$\mathbf{F}$

Fwd Forward

G

g

g

GABA

Gal

GAPDH

GC

GC-D

GC-F/ Ret2-GC Guanylatzyklase F

GC-G

Guanylatzyklase G

GC-C/ StaR

GC-E/ Ret1-GC

GCAPs

GFAP

GPCR

GS

GTP

\section{Gramm}

Galactosidase

Guanylatzyklase

Guanylatzyklase D

Guanylatzyklase C

Guanylatzyklase E

Proteine

Glutaminsynthase
Erdbeschleunigung

$\gamma$-Aminobuttersäure

Glycerinaldehydphosphat-Dehydrogenase

zytosolische Calcium-bindende Guanylatzyklase-aktivierende

Glial fibrillary acidic protein

G-Protein gekoppelte Rezeptoren

Guanosindiphosphat

H

h

$\mathrm{H} 1 / \mathrm{H} 4$

$\mathrm{H}_{2} \mathrm{O}$

$\mathrm{HCl}$

$\mathrm{HCN}$

$\mathrm{HCO}_{3}{ }^{2-}-$

HTM
Stunde/n

Histaminrezeptoren

Wasser

Salzsäure

hyperpolarization activated and cyclic nucleotide gated

Hydrogencarbonat

high-threshold mechanical nociceptors

I

IASP

IB4

$\mathrm{IP}_{3}$
International Association for the Study of Pain

Isolectin B4

Inositoltriphosphat 
I

\begin{tabular}{|c|c|c|}
\hline & $\mathrm{IP} \mathrm{P}_{3} \mathrm{R} 1$ & Inositol 1,4,5-Triphosphat Rezeptor 1 \\
\hline & IPSP & inhibitorisches postsynaptisches Potential \\
\hline & IR & Infrarot \\
\hline & ISH & In-situ-Hybridisierung \\
\hline J & & \\
\hline & JNK & C-Jun N-terminale Kinase \\
\hline K & & \\
\hline & KCC2 & $\mathrm{K}^{+} / \mathrm{Cl}^{-}$-Cotransporter \\
\hline & $\mathrm{KCl}$ & Kaliumchlorid \\
\hline & $\mathrm{kg}$ & Kilogramm \\
\hline & KHD & Kinase Homologie Domäne \\
\hline & KIf6 & Krueppel-like Factor 6 \\
\hline & KO & Knockout \\
\hline $\mathbf{L}$ & & \\
\hline & 1 & Liter \\
\hline & L & Lumbal \\
\hline & Lbx1 & Ladybird Homeobox 1 \\
\hline & loxP & locus of crossing over of bacteriophage PI \\
\hline & LTMRs & low-threshold-Mechanorezeptoren \\
\hline & LTPs & Synaptische Langzeitpotenzierung \\
\hline M & & \\
\hline & $\mathrm{M}$ & Mol pro Liter \\
\hline & MAPK & mitogen-activated protein Kinase \\
\hline & $\mathrm{mg}$ & Milligramm \\
\hline & $\mathrm{Mg}^{2+}$ & Magnesium-lon \\
\hline & $\min$ & Minute \\
\hline & $\mathrm{ml}$ & Milliliter \\
\hline & MLC & Myosin-leichte-Ketten-Kinase \\
\hline & $\mathrm{mM}$ & Millimolar \\
\hline & $\mathrm{mm}$ & Millimeter \\
\hline & Mrgpr & Mas-related G Protein gekoppelter Rezeptor \\
\hline
\end{tabular}


M

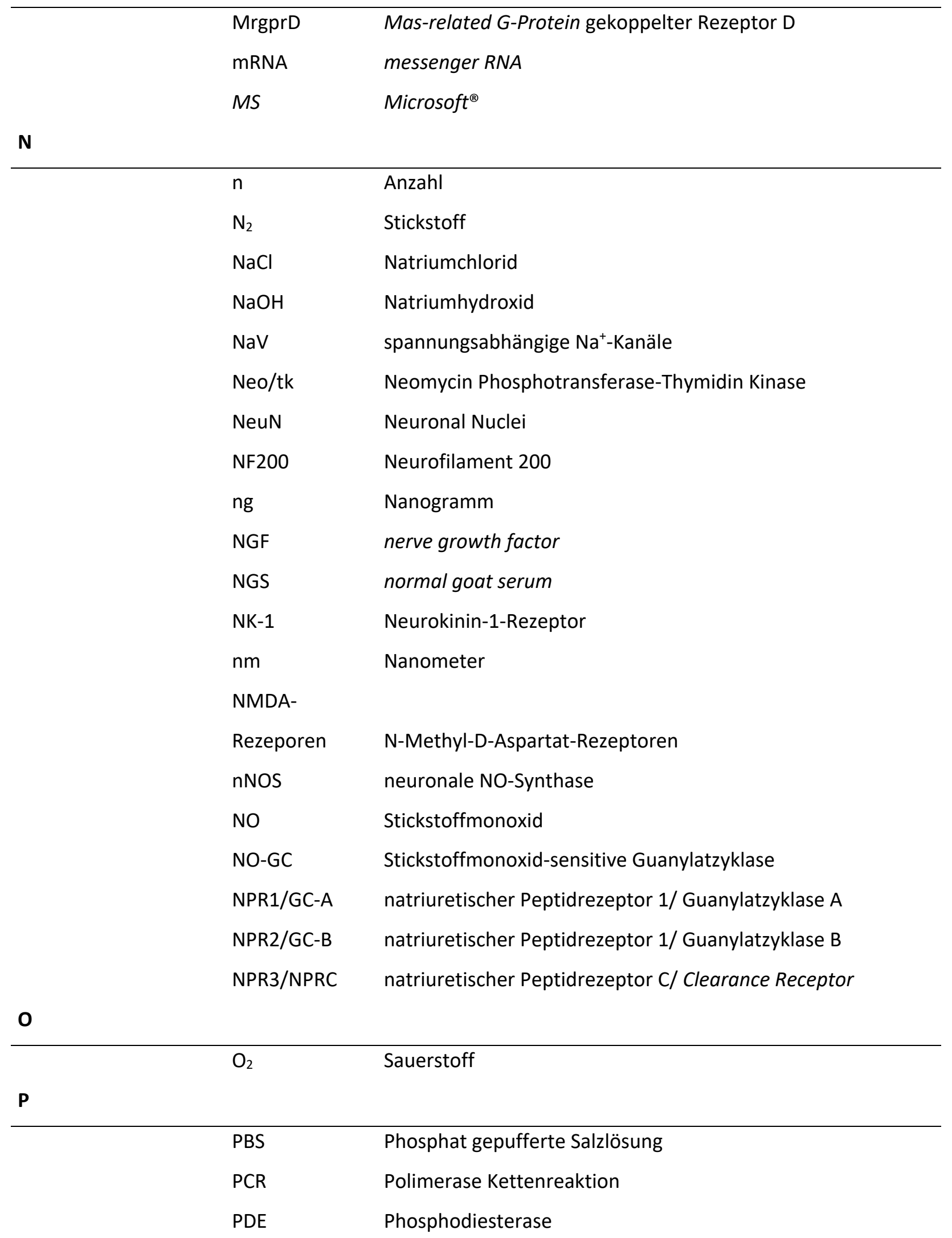


$\mathbf{P}$

$\begin{array}{ll}\text { PFA } & \text { Paraformaldehyd } \\ \text { pGC } & \text { partikuläre Guanylatzyklasen } \\ \text { PGE }_{2} & \text { Glycinrezeptors } \alpha 3 \\ \text { PI3K } & \text { Phosphoinositid-3-Kinase } \\ \text { PIP }_{2} & \text { Phosphatidylinositol-4,5-bisphosphat } \\ \text { PKA } & \text { cAMP-abhängige Proteinkinase A } \\ \text { PKC } & \text { Protein Kinase C } \\ \text { PLC } & \text { Phospholipase C }\end{array}$

Q

$\begin{array}{ll}\text { QLR } & \text { Qizaol-Reagenz } \\ \text { qPCR } & \text { quantitative Echtzeit-PCR }\end{array}$

$\mathbf{R}$

$\begin{array}{ll}\text { RA } & \text { rapidly adapting } \\ \text { RAGs } & \text { Regenerations-assoziierten Gene } \\ \text { Rev } & \text { reverse } \\ \text { RM } & \text { Rückenmark } \\ \text { RNA } & \text { Ribonukleinsäure } \\ \text { ROS } & \text { reaktive Sauerstoffspezies } \\ \text { rpm } & \text { Umdrehungen pro Minute } \\ \text { RT } & \text { Raumtemperatur } \\ \text { RT } & \text { reverse Transkriptase }\end{array}$

S

$\mathrm{s}$

SA

SEM

sGC

SNS-Cre

SPSS

STABW

STMN2

SubP
Sekunde

slow adapting

Standard error of the mean

lösliche Guanylatzyklasen

transgene insertion 1

Statistical Product and Service Solution

Standardabweichung

Stathmin-like 2

Substanz P 
T

\begin{tabular}{|c|c|c|}
\hline & $\mathrm{t}$ & Zeit \\
\hline & TBE & TRIS-Borat-EDTA \\
\hline & $\mathrm{TH}$ & Tyrosinhydroxylase \\
\hline & TrkA & Tropomyosin Rezeptor-Kinase-A \\
\hline & TrkB & Tropomyosin-Rezeptor-Kinase-B \\
\hline & TRP & transient receptor potential \\
\hline & TRPA & Ankyrin-Unterfamilie \\
\hline & TRPC & kanonische Unterfamilie \\
\hline & TRPM & Melastatin-Unterfamilie \\
\hline & TRPML & Mucolipin-Unterfamilie \\
\hline & TRPP & Polycystin-Unterfamilie \\
\hline & TRPV & Vanilloid-Rezeptor-Unterfamilie \\
\hline \multicolumn{3}{|c|}{$\mathbf{U}$} \\
\hline & u.a. & und andere \\
\hline & UV & Ultraviolett \\
\hline \multicolumn{3}{|c|}{$\mathbf{v}$} \\
\hline & V & Volt \\
\hline & VASP & Vasodilatator-stimulierte Phosphoprotein \\
\hline & VGAT & vesikulärer GABA-Transporter \\
\hline & VGLUT & vesikulärer Glutamat-Transporter \\
\hline & VIS & visuelles Spektrum \\
\hline \multicolumn{3}{|c|}{$\mathbf{w}$} \\
\hline & Wnt1 & Wingless-Type MMTV Integration Site Family Member 1 \\
\hline & WT & Wildtyp \\
\hline \multicolumn{3}{|c|}{$x$} \\
\hline & x-Gal & 5-Bromo-4-chloro-3-indolyl- $\beta$-D-galactopyranosid \\
\hline Z & & \\
\hline & ZNS & Zentrales Nervensystem \\
\hline
\end{tabular}


Symbole

$\begin{array}{ll}{ }^{\circ} \mathrm{C} & \text { Grad Celsius } \\ \alpha & \text { alpha } \\ \beta & \text { beta } \\ \delta & \text { delta } \\ \Delta & \text { Delta } \\ \mu \mathrm{l} & \text { Mikroliter } \\ \mu \mathrm{m} & \text { Mikrometer } \\ \% & \text { Prozent }\end{array}$

Außerdem wurden SI-Präfixe und die üblichen Abkürzungen für Aminosäuren und SI-Einheiten verwendet. 


\section{$9 \quad$ LITERATUR}

1. Julius, D. \& Basbaum, A. I. Molecular mechanisms of nociception. Nature 413, 203-210 (2001).

2. Latremoliere, A. \& Woolf, C. J. Central sensitization: a generator of pain hypersensitivity by central neural plasticity. J. Pain 10, 895-926 (2009).

3. Woolf, C. J. Pain: Moving from Symptom Control toward Mechanism-Specific Pharmacologic Management. Ann. Intern. Med. 140, 441-451 (2004).

4. Basbaum, A. I. et al. Cellular and Molecular Mechanisms of Pain. Cell 139, 267-284 (2009).

5. Rexed, B. The cytoarchitectonic organization of the spinal cord in the cat. J. Comp. Neurol. 96, 415-495 (1952).

6. D'Mello, R. G. \& Dickenson, A. H. Spinal cord mechanisms of pain. Br. J. Anaesth. 101, 8-16 (2008).

7. Schmidtko, A. et al. No NO, no pain? The role of nitric oxide and cGMP in spinal pain processing. Trends Neurosci. 32, 339-346 (2009).

8. Peirs, C. \& Seal, R. P. Neural circuits for pain: Recent advances and current views. Science (80-. ). 354, 578-584 (2016).

9. Wang, X. et al. Excitatory superficial dorsal horn interneurons are functionally heterogeneous and required for the full behavioral expression of Pain and Itch. Neuron 78, 312-324 (2013).

10. Meyer, R. A. \& Ringkamp, M. A role for uninjured afferents in neuropathic pain. Sheng $L i$ Xue Bao 60, 605-609 (2008).

11. Giordano, J. The neurobiology of nociceptive and anti-nociceptive systems. Pain Physician 8, 277-290 (2005).

12. Perl, E. R. Ideas about pain, a historical view. Nat. Rev. Neurosci. 8, 71-80 (2007).

13. Wooten, M. et al. Three functionally distinct classes of C-fibre nociceptors in primates. Nat. Commun. 5, (2014).

14. Olausson, H. W. et al. Unmyelinated tactile afferents have opposite effects on insular and somatosensory cortical processing. Neurosci. Lett. 436, 128-132 (2008).

15. Zimmerman, A. et al. The gentle touch receptors of Mammalian Skin. Science (80-. ). 346, 950-954 (2014).

16. Zeisel, A. et al. Molecular architecture of the mouse nervous system. Cell 174, 999-1014 (2018).

17. Usoskin, D. et al. Unbiased classification of sensory neuron types by large-scale single-cell RNA sequencing. Nat. Neurosci. 18, 145-153 (2015).

18. Moore, C. et al. Regulation of Pain and Itch by TRP Channels. Neurosci. Bull. 34, 120-142 (2018). 
19. Tan, C.-H. \& McNaughton, P. A. The TRPM2 ion channel is required for sensitivity to warmth. Nature 536, 460-463 (2016).

20. Cesare, P. \& Mcnaughton, P. A novel heat-activated current in nociceptive neurons and its sensitization by bradykinin. Proc. Natl. Acad. Sci. U. S. A. 93, 15435-15439 (1996).

21. Caterina, M. J. et al. The capsaicin receptor: A heat-activated ion channel in the pain pathway. Nature 389, 816-824 (1997).

22. Jordt, S.-E. et al. Lessons from peppers and peppermint: The molecular logic of thermosensation. Curr. Opin. Neurobiol. 13, 487-492 (2003).

23. Vriens, J. et al. TRPM3 Is a Nociceptor Channel Involved in the Detection of Noxious Heat. Neuron 70, 482-494 (2011).

24. Cho, H. et al. The calcium-activated chloride channel anoctamin 1 acts as a heat sensor in nociceptive neurons. Nat. Neurosci. 15, 1015-1021 (2012).

25. Vriens, J. et al. Peripheral thermosensation in mammals. Nat. Rev. Neurosci. 15, 573-589 (2014).

26. Moparthi, L. et al. Human TRPA1 is intrinsically cold-and chemosensitive with and without its N-terminal ankyrin repeat domain. Proc. Natl. Acad. Sci. 111, 16901-16906 (2014).

27. McKemy, D. D. et al. Identification of a cold receptor reveals a general role for TRP channels in thermosensation. Nature 416, 52-58 (2002).

28. Chen, J. et al. Species differences and molecular determinant of TRPA1 cold sensitivity. Nat. Commun. 4, 1-7 (2013).

29. McKemy, D. D. How cold is it? TRPM8 and TRPA1 in the molecular logic of cold sensation. Mol. Pain 1, 1744-8069 (2005).

30. Chung, M. K. et al. Warm temperatures activate TRPV4 in mouse 308 keratinocytes. J. Biol. Chem. 278, 32037-32046 (2003).

31. Peier, A. M. et al. A heat-sensitive TRP channel expressed in keratinocytes. Science (80-. ). 296, 2046-2049 (2002).

32. Vandewauw, l. et al. A TRP channel trio mediates acute noxious heat sensing. Nature 555, 662-666 (2018).

33. Leffler, A. et al. high-threshold heat-activated channel in cultured rat dorsal root ganglion neurons resembles TRPV2 and is blocked by gadolinium. Eur. J. Neurosci. 26, 12-22 (2007).

34. Vriens, J. \& Voets, T. Sensing the heat with TRPM3. Pflugers Arch. Eur. J. Physiol. 470, 799807 (2018).

35. Kanazawa, T. \& Matsumoto, S. Expression of transient receptor potential vanilloid 1 and anoctamin 1 in rat trigeminal ganglion neurons innervating the tongue. Brain Res. Bull. 106, 17-20 (2014).

36. Vandewauw, I. \& Voets, T. Heat is absolute, cold is relative. Nat. Neurosci. 19, 1188-1189 (2016). 
37. Koivisto, A. et al. TRPA1 antagonists for pain relief. Pharmaceuticals 11, 117 (2018).

38. Moparthi, L. et al. Human TRPA1 is a heat sensor displaying intrinsic U-shaped thermosensitivity. Sci. Rep. 6, 1-10 (2016).

39. Talavera, K. et al. Mammalian transient receptor potential TRPA1 channels: from structure to disease. Physiol. Rev. 100, 725-803 (2020).

40. Woolf, C. J. Dissecting out mechanisms responsible for peripheral neuropathic pain: Implications for diagnosis and therapy. Life Sci. 74, 2605-2610 (2004).

41. Finnerup, N. B. et al. Pharmacotherapy for neuropathic pain in adults: A systematic review and meta-analysis. Lancet Neurol. 14, 162-173 (2015).

42. Kosek, E. et al. Do we need a third mechanistic descriptor for chronic pain states? Pain 157, 1382-1386 (2016).

43. Trouvin, A.-P. \& Perrot, S. New concepts of pain. Best Pract. Res. Clin. Rheumatol. 33, 101415 (2019).

44. Freynhagen, R. et al. Current understanding of the mixed pain concept: a brief narrative review. Curr. Med. Res. Opin. 35, 1011-1018 (2019).

45. McMahon, S. B. Inflammatory mediators and modulators of pain. Wall Melzack's Textb. Pain 49-72 (2005).

46. Woolf, C. J. \& Ma, Q. Nociceptors-Noxious Stimulus Detectors. Neuron 55, 353-364 (2007).

47. Reichling, D. B. et al. The fundamental unit of pain is the cell. Pain 154, S2-S9 (2013).

48. Ma, T. C. \& Willis, D. E. What makes a RAG regeneration associated? Front. Mol. Neurosci. 8, 1-13 (2015).

49. Doron-Mandel, E. et al. Growth control mechanisms in neuronal regeneration. FEBS Lett. 589, 1669-1677 (2015).

50. Jenkins, R. \& Hunt, S. P. Long-term increase in the levels of c-jun mRNA and jun proteinlike immunoreactivity in motor and sensory neurons following axon damage. Neurosci. Lett. 129, 107-110 (1991).

51. Renthal, W. et al. Transcriptional reprogramming of distinct peripheral sensory neuron subtypes after axonal injury. Neuron 108, 1-17 (2020).

52. Scholz, J. \& Woolf, C. J. Can we conquer pain? Nat. Neurosci. 5, 1062-1067 (2002).

53. Kim, Y. H. et al. TRPV1 in GABAergic Interneurons Mediates Neuropathic Mechanical Allodynia and Disinhibition of the Nociceptive Circuitry in the Spinal Cord. Neuron 74, 640647 (2012).

54. Zeilhofer, H. U. Cellular and Molecular Life Sciences The glycinergic control of spinal pain processing. Cell. Mol. Life Sci. 62, 2027-2035 (2005).

55. Watkins, L. R. et al. Glial activation: A driving force for pathological pain. Trends Neurosci. 24, 450-455 (2001). 
56. Mika, J. et al. Importance of glial activation in neuropathic pain. Eur. J. Pharmacol. 716, 106-119 (2013).

57. Milligan, E. D. et al. Evidence that exogenous and endogenous fractalkine can induce spinal nociceptive facilitation in rats. Eur. J. Neurosci. 20, 2294-2302 (2004).

58. Tsuda, M. et al. P2X 4 receptors induced in spinal microglia gate tactile allodynia after nerve injury. Nature 424, 778-783 (2003).

59. Woolf, C. J. et al. Peripheral nerve injury triggers central sprouting of myelinated afferents. Nature 355, 75-78 (1992).

60. Foroutan, A. et al. Chloroquine-induced scratching is mediated by NO/cGMP pathway in mice. Pharmacol. Biochem. Behav. 134, 79-84 (2015).

61. Haddadi, A.-S. et al. Peripheral NMDA receptor/NO system blockage inhibits itch responses induced by chloroquine in mice. Acta Derm. Venereol. 97, 571-577 (2017).

62. Friebe, A. et al. cGMP: a unique 2 nd messenger molecule-recent developments in cGMP research and development. (2020).

63. Dumoulin, A. et al. Sensory Neurons: The Formation of T-Shaped Branches Is Dependent on a cGMP-Dependent Signaling Cascade. Neuroscientist 27, 47-57 (2021).

64. Sotolongo, A. et al. Epigenetic regulation of soluble guanylate cyclase (sGC) $\beta 1$ in breast cancer cells. FASEB J. 30, 3171-3180 (2016).

65. Derbyshire, E. R. \& Marletta, M. A. Structure and regulation of soluble guanylate cyclase. Annu. Rev. Biochem. 81, 533-559 (2012).

66. Mohammadoo-Khorasani, M. et al. Soluble guanylate cyclase isoenzymes: The expression of $\alpha 1, \alpha 2, \beta 1$, and $\beta 2$ subunits in the benign and malignant breast tumors. J. Cell. Physiol. 235, 1358-1365 (2020).

67. Petersen, J. et al. Distinct functions of soluble guanylyl cyclase isoforms NO-GC1 and NOGC2 in inflammatory and neuropathic pain processing. Pain 160, 607-618 (2019).

68. Schmidtko, A. Nitric oxide-mediated pain processing in the spinal cord. in Pain Control 103117 (Springer, 2015).

69. Zhang, X. et al. Nitric oxide synthase-like immunoreactivity in lumbar dorsal root ganglia and spinal cord of rat and monkey and effect of peripheral axotomy. J. Comp. Neurol. 335, 563-575 (1993).

70. Luo, Z. D. et al. Neuronal nitric oxide synthase mRNA upregulation in rat sensory neurons after spinal nerve ligation: Lack of a role in allodynia development. J. Neurosci. 19, 92019208 (1999).

71. Guan, Y. et al. Genetic knockout and pharmacologic inhibition of neuronal nitric oxide synthase attenuate nerve injury-induced mechanical hypersensitivity in mice. Mol. Pain 3, 1-10 (2007).

72. Martucci, C. et al. The purinergic antagonist PPADS reduces pain related behaviours and interleukin-1 $\beta$, interleukin-6, iNOS and nNOS overproduction in central and peripheral 
nervous system after peripheral neuropathy in mice. $P A I N^{\circledR} 137,81-95$ (2008).

73. Saha, S. et al. The linker region in receptor guanylyl cyclases is a key regulatory module. Mutational analysis of guanylyl cyclase C. J. Biol. Chem. 284, 27135-27145 (2009).

74. Potter, L. R. Guanylyl cyclase structure, function and regulation. Cell. Signal. 23, 1921-1926 (2011).

75. Palczewski, K. et al. Guanylate cyclase-activating proteins: Structure, function, and diversity. Biochem. Biophys. Res. Commun. 322, 1123-1130 (2004).

76. Ramamurthy, V. et al. Interactions within the Coiled-coil Domain of RetGC-1 Guanylyl Cyclase are Optimized for Regulation Rather than for High Affinity. J. Biol. Chem. 276, 26218-26229 (2001).

77. Kuhn, M. Molecular physiology of membrane guanylyl cyclase receptors. Physiol. Rev. 96, 751-804 (2016).

78. Fülle, H.-J. et al. A receptor guanylyl cyclase expressed specifically in olfactory sensory neurons. Proc. Natl. Acad. Sci. 92, 3571-3575 (1995).

79. Schulz, S. et al. The cloning and expression of a new guanylyl cyclase orphan receptor. J. Biol. Chem. 273, 1032-1037 (1998).

80. Lumsden, N. G. et al. C-type Natriuretic Peptide (CNP): Cardiovascular Roles and Potential as a Therapeutic Target. Curr. Pharm. Des. 16, 4080-4088 (2011).

81. Bryan, P. M. et al. A sensitive method for determining the phosphorylation status of natriuretic peptide receptors: cGK-la does not regulate NPR-A. Biochemistry 45, 12951303 (2006).

82. Potter, L. R. et al. Natriuretic peptides, their receptors, and cyclic guanosine monophosphate-dependent signaling functions. Endocr. Rev. 27, 47-72 (2006).

83. Akiyama, T. \& Carstens, E. Neural processing of itch. Neuroscience 250, 697-714 (2013).

84. Wu, C. et al. Furin-mediated processing of pro-C-type natriuretic peptide. J. Biol. Chem. 278, 25847-25852 (2003).

85. Schulz, S. et al. The primary structure of a plasma membrane guanylate cyclase demonstrates diversity within this new receptor family. Cell 58, 1155-1162 (1989).

86. Chrisman, T. D. et al. Seminal plasma factors that cause large elevations in cellular cyclic GMP are C-type natriuretic peptides. J. Biol. Chem. 268, 3698-3703 (1993).

87. Nagase, M. et al. Tissue distribution and localization of natriuretic peptide receptor subtypes in stroke-prone spontaneously hypertensive rats. J. Hypertens. 15, 1235-1243 (1997).

88. Stingo, A. J. et al. Cardiovascular and renal actions of C-type natriuretic peptide. Am. J. Physiol. Circ. Physiol. 262, H308-H312 (1992).

89. Canaan-Kühl, S. Identification of ' $B$ ' receptor for natriuretic peptide in human kidney. Endocrinology 130, 550-552 (1992). 
90. Mattingly, M. T. et al. Erratum: Presence of C-type natriuretic peptide in human kidney and urine (Kidney International 46 (1994)(744-747)). Kidney Int. 50, 1442 (1996).

91. Peake, N. J. et al. Role of C-type natriuretic peptide signalling in maintaining cartilage and bone function. Osteoarthr. Cartil. 22, 1800-1807 (2014).

92. Wang, W. et al. Acromesomelic dysplasia, type maroteaux caused by novel loss-of-function mutations of the NPR2 gene: Three case reports. Am. J. Med. Genet. Part A 170, 426-434 (2016).

93. Zhang, M. et al. Granulosa Cell Ligand NPPC and Its Receptor NPR2 Maintain Meiotic Arrest in Mouse Oocytes. Science (80-. ). 330, 366-369 (2010).

94. Schmidt, H. et al. The receptor guanylyl cyclase Npr2 is essential for sensory axon bifurcation within the spinal cord. J. Cell Biol. 179, 331-340 (2007).

95. Tröster, P. et al. The absence of sensory axon bifurcation affects nociception and termination fields of afferents in the spinal cord. Front. Mol. Neurosci. 11, 1-18 (2018).

96. Kishimoto, I. et al. C-Type Natriuretic Peptide is a Schwann Cell-Derived Factor For Development and Function of Sensory Neurones. J. Neuroendocrinol. 20, 1213-1223 (2008).

97. Kone, B. C. Molecular biology of natriuretic peptides and nitric oxide synthases. Cardiovasc. Res. 51, 429-441 (2001).

98. Murthy, K. S. et al. Gi-1/Gi-2-dependent signaling by single-transmembrane natriuretic peptide clearance receptor. Am. J. Physiol. Liver Physiol. 278, G974-G980 (2000).

99. Maack, T. Receptors of atrial natriuretic factor. Annu. Rev. Physiol. 54, 11-27 (1992).

100. Kallenborn-Gerhardt, W. et al. Phosphodiesterase $2 \mathrm{~A}$ localized in the spinal cord contributes to inflammatory pain processing. Anesthesiology 121, 372-382 (2014).

101. Heine, S. et al. CNGA3: A target of spinal nitric oxide/cGMP signaling and modulator of inflammatory pain hypersensitivity. J. Neurosci. 31, 11184-11192 (2011).

102. de Vente, J. et al. The role of phosphodiesterase isoforms 2, 5, and 9 in the regulation of NO-dependent and NO-independent cGMP production in the rat cervical spinal cord. $J$. Chem. Neuroanat. 31, 275-303 (2006).

103. Bao, F. et al. A selective phosphodiesterase-4 inhibitor reduces leukocyte infiltration, oxidative processes, and tissue damage after spinal cord injury. J. Neurotrauma 28, 10351049 (2011).

104. Whitaker, C. M. et al. Rolipram attenuates acute oligodendrocyte death in the adult rat ventrolateral funiculus following contusive cervical spinal cord injury. Neurosci. Lett. 438, 200-204 (2008).

105. Kruse, L. S. et al. Phosphodiesterase 3 and 5 and cyclic nucleotide-gated ion channel expression in rat trigeminovascular system. Neurosci. Lett. 404, 202-207 (2006).

106. Pollock, J. et al. A comparison between the distinct inward currents activated in rat cultured dorsal root ganglion neurones by intracellular flash photolysis of two forms of caged cyclic 
guanosine monophosphate. Neurosci. Lett. 338, 143-146 (2003).

107. Casteel, D. E. et al. A crystal structure of the cyclic GMP-dependent protein kinase I $\beta$ dimerization/docking domain reveals molecular details of isoform-specific anchoring. $J$. Biol. Chem. 285, 32684-32688 (2010).

108. Tao, Y.-X. \& Johns, R. A. Activation of cGMP-dependent protein kinase la is required for Nmethyl-D-aspartate-or nitric oxide-produced spinal thermal hyperalgesia. Eur. J. Pharmacol. 392, 141-145 (2000).

109. Tegeder, I. et al. Reduced inflammantory hyperalgesia with preservation of acute thermal nociception in mice lacking cGMP-dependent protein kinase I. Proc. Natl. Acad. Sci. U. S. A. 101, 3253-3257 (2003).

110. Schmidtko, A. et al. Cysteine-rich protein 2, a novel downstream effector of cGMP/cGMPdependent protein kinase I-mediated persistent inflammatory pain. J. Neurosci. 28, 1320-1330 (2008).

111. Song, X. J. et al. CAMP and cGMP contribute to sensory neuron hyperexcitability and hyperalgesia in rats with dorsal root ganglia compression. J. Neurophysiol. 95, 479-492 (2006).

112. Sung, $Y$. et al. Activation and retrograde transport of protein kinase $G$ in rat nociceptive neurons after nerve injury and inflammation. Neuroscience 141, 697-709 (2006).

113. Sung, Y. et al. A neuronal isoform of protein kinase $G$ couples mitogen-activated protein kinase nuclear import to axotomy-induced long-term hyperexcitability in Aplysia sensory neurons. J. Neurosci. 24, 7583-7595 (2004).

114. Schmidtko, A. et al. Inhibition of cyclic guanosine $5^{\prime}$-monophosphate-dependent protein kinase I (PKG-I) in lumbar spinal cord reduces formalin-induced hyperalgesia and PKG upregulation. Nitric Oxide 8, 89-94 (2003).

115. Tegeder, I. et al. Dual effects of spinally delivered 8-bromo-cyclic guanosine monophosphate (8-bromo-cGMP) in formalin-induced nociception in rats. Neurosci. Lett. 332, 146-150 (2002).

116. Schmidtko, A. et al. cGMP produced by NO-sensitive guanylyl cyclase essentially contributes to inflammatory and neuropathic pain by using targets different from cGMPdependent protein kinase I. J. Neurosci. 28, 8568-8576 (2008).

117. Kallenborn-Gerhardt, W. \& Schmidtko, A. A novel signaling pathway that modulates inflammatory pain. J. Neurosci. 31, 798-800 (2011).

118. Zhang, F.-X. et al. Inhibition of inflammatory pain by activating B-type natriuretic peptide signal pathway in nociceptive sensory neurons. J. Neurosci. 30, 10927-10938 (2010).

119. Luo, C. et al. Presynaptically localized cyclic GMP-dependent protein kinase 1 is a key determinant of spinal synaptic potentiation and pain hypersensitivity. PLoS Biol 10, e1001283 (2012). 
120. Lu, R. et al. BKCa channels expressed in sensory neurons modulate inflammatory pain in mice. $P A I N^{\circledR} 155,556-565$ (2014).

121. Louis, H. A. et al. Comparison of three members of the cysteine-rich protein family reveals functional conservation and divergent patterns of gene expression. J. Biol. Chem. 272, 27484-27491 (1997).

122. Chang, D. F. et al. LIM-only protein, CRP2, switched on smooth muscle gene activity in adult cardiac myocytes. Proc. Natl. Acad. Sci. U. S. A. 104, 157-162 (2007).

123. Schmidt, H. et al. A genetic strategy for the analysis of individual axon morphologies in cGMP signalling mutant mice. in Guanylate Cyclase and Cyclic GMP 193-204 (Springer, 2013).

124. Zurborg, S. et al. Generation and characterization of an Advillin-Cre driver mouse line. Mol. Pain 7, 1-10 (2011).

125. Agarwal, N. et al. Conditional Gene Deletion in Primary Nociceptive Neurons of Trigeminal Ganglia and Dorsal Root Ganglia. Genesis 38, 122-129 (2004).

126. Sieber, M. A. et al. Lbx1 acts as a selector gene in the fate determination of somatosensory and viscerosensory relay neurons in the hindbrain. J. Neurosci. 27, 4902-9 (2007).

127. Schmidt, H. et al. C-type natriuretic peptide (CNP) is a bifurcation factor for sensory neurons. Proc. Natl. Acad. Sci. U. S. A. 106, 16847-16852 (2009).

128. Ter-Avetisyan, G. et al. Bifurcation of axons from cranial sensory neurons is disabled in the absence of Npr2-Induced cGMP signaling. J. Neurosci. 34, 737-747 (2014).

129. Lu, R. et al. Slack channels expressed in sensory neurons control neuropathic pain in mice. J. Neurosci. 35, 1125-1135 (2015).

130. Hargreaves, K. M. et al. A new and sensitive method for measuring thermal nociception in cutaneous hyperalgesia. Pain 32, 77-88 (1988).

131. Eddy, N. B. \& Leimbach, D. Synthetic analgesics. II. Dithienylbutenyl-and dithienylbutylamines. J. Pharmacol. Exp. Ther. 107, 385-393 (1953).

132. Mogil, J. S. et al. Heritability of nociception I: responses of 11 inbred mouse strains on 12 measures of nociception. Pain 80, 67-82 (1999).

133. Willis, W. D. The role of TRPV1 receptors in pain evoked by noxious thermal and chemical stimuli. Exp. Brain Res. 196, 5-11 (2009).

134. O'Neill, J. et al. Unravelling the mystery of capsaicin: a tool to understand and treat pain. Pharmacol. Rev. 64, 939-971 (2012).

135. Sakurada, T. et al. The capsaicin test in mice for evaluating tachykinin antagonists in the spinal cord. Neuropharmacology 31, 1279-1285 (1992).

136. Dubuisson, D. \& Dennis, S. G. The formalin test: a quantitative study of the analgesic effects of morphine, meperidine, and brain stem stimulation in rats and cats. Pain 4, 161-174 (1977). 
137. Hunskaar, S. et al. Formalin test in mice, a useful technique for evaluating mild analgesics. J. Neurosci. Methods 14, 69-76 (1985).

138. Coderre, T. J. et al. Central nervous system plasticity in the tonic pain response to subcutaneous formalin injection. Brain Res. 535, 155-158 (1990).

139. Tjølsen, A. et al. The formalin test: an evaluation of the method. Pain 51, 5-17 (1992).

140. Meller, S. T. \& Gebhart, G. F. Intraplantar zymosan as a reliable, quantifiable model of thermal and mechanical hyperalgesia in the rat. Eur. J. Pain 1, 43-52 (1997).

141. Chomczynski, P. A reagent for the single-step simultaneous isolation of RNA, DNA and proteins from cell and tissue samples. Biotechniques 15, 532-534 (1993).

142. Giulietti, A. et al. An overview of real-time quantitative PCR: applications to quantify cytokine gene expression. Methods 25, 386-401 (2001).

143. Schnell, S. A. et al. Reduction of lipofuscin-like autofluorescence in fluorescently labeled tissue. J. Histochem. Cytochem. 47, 719-730 (1999).

144. Horwitz, J. P. et al. Substrates for cytochemical demonstration of enzyme activity. I. Some substituted 3-indolyl- $\beta$-D-glycopyranosides1a. J. Med. Chem. 7, 574-575 (1964).

145. Levitsky, K. L. et al. Direct confocal acquisition of fluorescence from X-gal staining on thick tissue sections. Sci. Rep. 3, 1-6 (2013).

146. Bartels, C. F. et al. Mutations in the transmembrane natriuretic peptide receptor NPR-B impair skeletal growth and cause acromesomelic dysplasia, type Maroteaux. Am. J. Hum. Genet. 75, 27-34 (2004).

147. Potter, L. R. Natriuretic peptide metabolism, clearance and degradation. FEBS J. 278, 18081817 (2011).

148. Dickey, D. M. et al. Catalytically active guanylyl cyclase B requires endoplasmic reticulummediated glycosylation, and mutations that inhibit this process cause dwarfism. J. Biol. Chem. 291, 11385-11393 (2016).

149. Chusho, H. et al. Dwarfism and early death in mice lacking C-type natriuretic peptide. Proc. Natl. Acad. Sci. U. S. A. 98, 4016-4021 (2001).

150. Yue, F. et al. A comparative encyclopedia of DNA elements in the mouse genome. Nature 515, 355-364 (2014).

151. Komatsu, Y. et al. Significance of C-type natriuretic peptide (CNP) in endochondral ossification: analysis of CNP knockout mice. J. Bone Miner. Metab. 20, 331-336 (2002).

152. Häring, M. et al. Neuronal atlas of the dorsal horn defines its architecture and links sensory input to transcriptional cell types. Nat. Neurosci. 21, 869-880 (2018).

153. Nakao, K. et al. Endothelium-Derived C-Type Natriuretic Peptide Contributes to Blood Pressure Regulation by Maintaining Endothelial Integrity. Hypertension 69, 286-296 (2017).

154. Qian, Y. et al. cGMP-dependent protein kinase in dorsal root ganglion: relationship with 
nitric oxide synthase and nociceptive neurons. J. Neurosci. 16, 3130-3138 (1996).

155. Tassano, E. et al. Genotype-Phenotype Correlation of 2q37 Deletions Including NPPC Gene Associated with Skeletal Malformations. PLoS One 8, (2013).

156. Spinelli, V. et al. Screening strategy to generate cell specific recombination: a case report with the RIP-Cre mice. Transgenic Res. 24, 803-812 (2015).

157. Song, A. J. \& Palmiter, R. D. Detecting and avoiding problems when using the Cre-lox system. Trends Genet. 34, 333-340 (2018).

158. Guo, T. et al. Optical clearing reveals TNBS-induced morphological changes of VGLUT2positive nerve fibers in mouse colorectum. Am. J. Physiol. Liver Physiol. (2021).

159. Schmidt, H. et al. cGMP-mediated signaling via cGKla is required for the guidance and connectivity of sensory axons. J. Cell Biol. 159, 489-498 (2002).

160. Schmidt, H. \& Fritzsch, B. Npr2 null mutants show initial overshooting followed by reduction of spiral ganglion axon projections combined with near-normal cochleotopic projection. Cell Tissue Res. 378, 15-32 (2019).

161. Wolter, S. et al. GC-B deficient mice with axon bifurcation loss exhibit compromised auditory processing. Front. Neural Circuits 12, 65 (2018).

162. Dumoulin, A. et al. Molecular analysis of sensory axon branching unraveled a cGMPdependent signaling cascade. Int. J. Mol. Sci. 19, (2018).

163. Valek, L. et al. Redox-guided axonal regrowth requires cyclic GMP dependent protein kinase 1: Implication for neuropathic pain. Redox Biol. 11, 176-191 (2017).

164. Yao, J., Liu, B. \& Qin, F. Modular thermal sensors in temperature-gated transient receptor potential (TRP) channels. Proc. Natl. Acad. Sci. 108, 11109-11114 (2011).

165. Nozadze, I. et al. Role of thermo TRPA1 and TRPV1 channels in heat, cold, and mechanical nociception of rats. Behav. Pharmacol. 27, 29-36 (2016).

166. Tominaga, M. \& Caterina, M. J. Thermosensation and pain. J. Neurobiol. 61, 3-12 (2004).

167. Hunskaar, S. et al. Dissociation between antinociceptive and anti-inflammatory effects of acetylsalicylic acid and indomethacin in the formalin test. Pain 25, 125-132 (1986).

168. Coderre, T. J. \& Melzack, R. Cutaneous hyperalgesia: contributions of the peripheral and central nervous systems to the increase in pain sensitivity after injury. Brain Res. 404, 95106 (1987).

169. McNamara, C. R. et al. TRPA1 mediates formalin-induced pain. Proc. Natl. Acad. Sci. 104, 13525-13530 (2007).

170. Straubinger, J. et al. Amplified pathogenic actions of angiotensin II in cysteine-rich LIM-only protein 4-negative mouse hearts. FASEB J. 31, 1620-1638 (2017).

171. Nagata, K. et al. Nociceptor and hair cell transducer properties of TRPA1, a channel for pain and hearing. J. Neurosci. 25, 4052-4061 (2005).

172. Kobayashi, K. et al. Distinct Expr. TRPM8, TRPA1, TRPV1 mRNAs rat Prim. Affer. neurons 
with adelta/c-fibers Coloca. with trk Recept. J Comp Neurol 493, 596-606 (2005).

173. Bautista, D. M. et al. Pungent Prod. from garlic Act. Sens. ion channel TRPA1. Proc Natl Acad Sci USA 102, 12248-12252 (2005).

174. Laursen, W. J. et al. Species-specific temperature sensitivity of TRPA1. Temperature 2, 214226 (2015).

175. Story, G. M. et al. ANKTM1, a TRP-like channel expressed in nociceptive neurons, is activated by cold temperatures. Cell 112, 819-829 (2003).

176. Sinica, V. et al. Human and mouse TRPA1 are heat and cold sensors differentially tuned by voltage. Cells 9, 57 (2020).

177. Hung, C.-Y. \& Tan, C.-H. TRP channels in nociception and pathological pain. in Advances in Pain Research: Mechanisms and Modulation of Chronic Pain 13-27 (Springer, 2018).

178. Cordero-Morales, J. F. et al. Cytoplasmic ankyrin repeats of transient receptor potential A1 (TRPA1) dictate sensitivity to thermal and chemical stimuli. Proc. Natl. Acad. Sci. 108, E1184-E1191 (2011).

179. Kádková, A. et al. Molecular basis of TRPA1 regulation in nociceptive neurons. A review. Physiol. Res. 66, (2017).

180. Nilius, B. \& Flockerzi, V. Mammalian transient receptor potential (TRP) cation channels. in Handbook of Experimental Pharmacology 2, 583-630 (Springer-Verlag Berlin Heidelberg, 2014).

181. Bandell, M. et al. Noxious cold ion channel TRPA1 is activated by pungent compounds and bradykinin. Neuron 41, 849-857 (2004).

182. Chuang, H. et al. Bradykinin and nerve growth factor release the capsaicin receptor from Ptdlns $(4,5)$ P 2-mediated inhibition. Nature 411, 957-962 (2001).

183. Liang, Y.-F. et al. Sustained sensitization and recruitment of rat cutaneous nociceptors by bradykinin and a novel theory of its excitatory action. J. Physiol. 532, 229 (2001).

184. Premkumar, L. S. \& Ahern, G. P. Induction of vanilloid receptor channel activity by protein kinase C. Nature 408, 985-990 (2000).

185. Bautista, D. M. et al. TRPA1 mediates the inflammatory actions of environmental irritants and proalgesic agents. Cell 124, 1269-1282 (2006).

186. Montell, C. et al. The TRP channels, a remarkably functional family. Cell 108, 595-598 (2002).

187. McMahon, S. B. \& Wood, J. N. Increasingly irritable and close to tears: TRPA1 in inflammatory pain. Cell 124, 1123-1125 (2006).

188. Mizumura, K. et al. Excitation and sensitization of nociceptors by bradykinin: what do we know? Exp. brain Res. 196, 53-65 (2009).

189. Andrade, E. L. et al. TRPA1 antagonists as potential analgesic drugs. Pharmacol. Ther. 133, 189-204 (2012). 
190. Dai, Y. et al. Sensitization of TRPA1 by PAR2 contributes to the sensation of inflammatory pain. J. Clin. Invest. 117, 1979-1987 (2007).

191. Pethö, G. \& Reeh, P. W. Sensory and signaling mechanisms of bradykinin, eicosanoids, platelet-activating factor, and nitric oxide in peripheral nociceptors. Physiol. Rev. (2012).

192. Wang, S. et al. Phospholipase $C$ and protein kinase $A$ mediate bradykinin sensitization of TRPA1: a molecular mechanism of inflammatory pain. Brain 131, 1241-1251 (2008).

193. Dray, A. \& Perkins, M. Bradykinin and inflammatory pain. Trends Neurosci. 16, 99-104 (1993).

194. Potter, L. R. \& Hunter, T. Identification and characterization of the major phosphorylation sites of the B-type natriuretic peptide receptor. J. Biol. Chem. 273, 15533-15539 (1998).

195. Potter, L. R. Phosphorylation-dependent regulation of the guanylyl cyclase-linked natriuretic peptide receptor B: dephosphorylation is a mechanism of desensitization. Biochemistry 37, 2422-2429 (1998).

196. Yoder, A. R. et al. Mass spectrometric identification of phosphorylation sites in guanylyl cyclase A and B. Biochemistry 49, 10137-10145 (2010).

197. Yoder, A. R. et al. A functional screen provides evidence for a conserved, regulatory, juxtamembrane phosphorylation site in guanylyl cyclase A and B. PLoS One 7, e36747 (2012).

198. Schulz, S. C-type natriuretic peptide and guanylyl cyclase B receptor. Peptides 26, 10241034 (2005).

199. Wang, Z. et al. TRPA1 inhibition ameliorates pressure overload-induced cardiac hypertrophy and fibrosis in mice. EBioMedicine 36, 54-62 (2018).

200. Loo, L. et al. The C-type natriuretic peptide induces thermal hyperalgesia through a noncanonical G $\beta \gamma$-dependent modulation of TRPV1 channel. J. Neurosci. 32, 11942-11955 (2012).

201. Savarirayan, R. et al. C-type natriuretic peptide analogue therapy in children with achondroplasia. N. Engl. J. Med. 381, 25-35 (2019).

202. Aubdool, A. A. et al. TRPA1 is essential for the vascular response to environmental cold exposure. Nat. Commun. 5, 1-13 (2014).

203. Graepel, R. et al. 4-oxo-2-nonenal (4-ONE): evidence of transient receptor potential ankyrin 1-dependent and-independent nociceptive and vasoactive responses in vivo. J. Pharmacol. Exp. Ther. 337, 117-124 (2011).

204. Grant, A. D. et al. An examination of neurogenic mechanisms involved in mustard oilinduced inflammation in the mouse. Eur. J. Pharmacol. 507, 273-280 (2005).

205. Carter, S. J. \& Hodges, G. J. Sensory and sympathetic nerve contributions to the cutaneous vasodilator response from a noxious heat stimulus. Exp. Physiol. 96, 1208-1217 (2011).

206. Magerl, W. \& Treede, R.-D. Heat-evoked vasodilatation in human hairy skin: axon reflexes due to low-level activity of nociceptive afferents. J. Physiol. 497, 837-848 (1996). 
207. Drewett, J. G. et al. Natriuretic peptide receptor-B (guanylyl cyclase-B) mediates C-type natriuretic peptide relaxation of precontracted rat aorta. J. Biol. Chem. 270, 4668-4674 (1995).

208. Hodes, A. \& Lichtstein, D. Natriuretic hormones in brain function. Front. Endocrinol. (Lausanne). 5, 201 (2014).

209. Lorenz, J. E. et al. Oxidant-Induced Activation of cGMP-Dependent Protein Kinase la Mediates Neuropathic Pain after Peripheral Nerve Injury. Antioxidants Redox Signal. 21, 1504-1515 (2014).

210. Brenner, D. S. et al. A simple and inexpensive method for determining cold sensitivity and adaptation in mice. JoVE (Journal Vis. Exp. e52640 (2015).

211. Noël, J. et al. The mechano-activated K+ channels TRAAK and TREK-1 control both warm and cold perception. EMBO J. 28, 1308-1318 (2009). 


\section{0}

\section{KOOPERATIONSPARTNER}

Soweit nicht anders vermerkt, wurde diese Arbeit von mir und unter Anweisung meines Betreuers während meiner Zeit als Doktorandin am Institut für Pharmakologie und Klinische Pharmazie angefertigt. Jeder Beitrag, der nicht von mir durchgeführt wurde, wurde explizit in dieser Arbeit gekennzeichnet. Im nachfolgenden sind die wesentlichen Kooperationspartner und das erhaltene Material aufgelistet:

Tabelle 10-1: Aufgelistet sind die wesentlichen Kooperationspartner dieser Doktorarbeit.

\begin{tabular}{|c|c|c|}
\hline Kooperationspartner & & Material \\
\hline PD Dr. Hannes Schmidt & $\begin{array}{l}\text { Interfakultäres Institut für Biochemie; } \\
\text { Eberhard Karls Universität Tübingen }\end{array}$ & 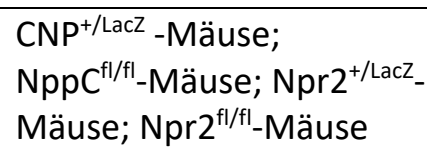 \\
\hline $\begin{array}{l}\text { Prof. Dr. Peter Ruth und } \\
\text { Prof. Dr. Robert Lukowski }\end{array}$ & $\begin{array}{l}\text { Institut für Pharmazie; } \\
\text { Eberhard Karls Universität Tübingen }\end{array}$ & CRP4 ${ }^{-1-}$-Mäuse \\
\hline DFG FOR 2060 & & Finanzielle Unterstützung. \\
\hline
\end{tabular}




\section{$11 \quad$ ANHANG}

\subsection{Veröffentlichungen und Tagungsbeiträge}

\subsubsection{Veröffentlichungen}

Wiebke Kallenborn-Gerhardt, Katharina Metzner, Ruirui Lu, Jonas Petersen, Miriam S. Kuth, Sandra Heine, Oliver Drees, Mandy Paul, Elvir Becirovic, Lea Kennel, Cathrin Flauaus, Tilman Groß, Gesine Wack, Stephan W. Hohmann, Dina Nemirovski, Domenico Del Turco, Martin Biel, Gerd Geisslinger, Stylianos Michalakis, Achim Schmidtko. Neuropathic and cAMP-induced pain behavior is ameliorated in mice lacking CNGB1. 2020; Neuropharmacology, 108087.

Jonas Petersen, Evanthia Mergia, Lea Kennel, Oliver Drees, Rebecca Dorothee Steubing, Catherine Isabell Real, Wiebke Kallenborn-Gerhardt, Ruirui Lu, Andreas Friebe, Doris Koesling, Achim Schmidtko. Distinct functions of soluble guanylyl cyclase isoforms NO-GC1 and NO-GC2 in inflammatory and neuropathic pain processing. 2019; Pain,160(3), 607-618.

Stefanie Peters, Michael Paolillo, Evanthia Mergia, Doris Koesling, Lea Kennel, Achim Schmidtko, Michael Russwurm, Robert Feil. cGMP Imaging in Brain Slices Reveals Brain Region-Specific Activity of NO-Sensitive Guanylyl Cyclases (NO-GCs) and NO-GC Stimulators. 2018; Int. J. Mol. Sci., 19(8), 2313.

Ruirui Lu, Cathrin Flauaus, Lea Kennel, Jonas Petersen, Oliver Drees, Wiebke Kallenborn-Gerhardt, Peter Ruth, Robert Lukowski, Achim Schmidtko. $\mathrm{K}_{\mathrm{Ca}} 3.1$ channels modulate the processing of noxious chemical stimuli in mice. 2017; Neuropharmacology, 125, 386-395.

Wiebke Kallenborn-Gerhardt, Christine Möser, Jana Lorenz, Mircoc Steger; Julianac Heidler, Reynirb Scheving, Jonas Petersen, Lea Kennel, Cathrin Flauaus, Ruirui Lu, Aimee L. Edinger, Irmgard Tegeder, Gerd Geisslinger, Heinrich Heide, Ilka Wittig, Achim Schmidtko. Rab7-a novel redox target that modulates inflammatory pain processing. 2017; Pain, 158(7), 1354-1365. 


\subsubsection{Tagungsbeiträge}

Lea Kennel, Jonas Petersen, Cathrin Flauaus, Oliver Drees, Hannes Schmidt, Peter Ruth, Robert Lukowski, Achim Schmidtko. Mechanisms of Cystein-rich protein 4 activation in pain processing. 8th International Conference on cGMP. Bamberg. 23.-25.06.2017

Lea Kennel, Jonas Petersen, Cathrin Flauaus, Oliver Drees, Hannes Schmidt, Peter Ruth, Robert Lukowski, Achim Schmidtko. Mechanisms of Cystein-rich protein 4 activation in pain processing. Poster Präsentation. 3rd German Pharm-Tox Summit. Göttingen. 26.02.-01.03.2018

Lea Kennel, Jonas Petersen, Cathrin Flauaus, Ruirui Lu, Oliver Drees, Hannes Schmidt, Peter Ruth, Robert Lukoswki, Achim Schmidtko. Mechanisms of Cystein-rich protein 4 activation in pain processing. Poster Präsentation. 4th Biennal Meeting of Rhine-Main Neuroscience Network. Oberwesel.13.-15.06.2018

Lea Kennel, Jonas Petersen, Tilman Groß, Cathrin Flauaus, Ruirui Lu, Oliver Drees, Hannes Schmidt, Peter Ruth, Robert Lukoswki, Achim Schmidtko. Mechanisms of Cystein-rich protein 4 activation in pain processing. Poster Präsentation. FOR 2060 Conference. Tübingen. 08.-10.10.2018

Lea Kennel, Jörg Isensee, Jonas Petersen, Tilman Groß, Cathrin Flauaus, Ruirui Lu, Julia Straubinger, Hannes Schmidt, Peter Ruth, Tim Hucho, Robert Lukoswki, Achim Schmidtko. Mechanisms of Cystein-rich protein 4 activation in pain processing. Poster Präsentation. The Challenge of Chronic Pain. Hinxton, UK. 04.-06.03.2019

Lea Kennel, Jörg Isensee, Jonas Petersen, Tilman Groß, Cathrin Flauaus, Ruirui Lu, Julia Straubinger, Hannes Schmidt, Peter Ruth, Tim Hucho, Robert Lukoswki, Achim Schmidtko. Mechanisms of Cystein-rich protein 4 activation in pain processing. Poster Präsentation. European Federation for Pharmaceutical Sciences (EUFEPS). Frankfurt am Main. 06.-08.03.2019

Lea Kennel, Jörg Isensee, Jonas Petersen, Tilman Groß, Cathrin Flauaus, Ruirui Lu, Julia Straubinger, Hannes Schmidt, Peter Ruth, Tim Hucho, Robert Lukoswki, Achim Schmidtko. Function of natriuretic peptides in pain processing. Poster Präsentation. 9th International Conference on cGMP. Mainz. 14.-16.06.2019 